

\title{
MANIFESTING CIVIC-NESS
}

\author{
by \\ Heather Breeze \\ Bachelor of Architectural Science (Honours), Ryerson University \\ 2014 \\ A thesis \\ presented to Ryerson University \\ in partial fulfillment of the \\ requirements for the degree of \\ Master of Architecture \\ in the Program of \\ Architecture \\ Toronto, Ontario, Canada, 2019 \\ (c) (Heather Breeze) 2019
}





\section{Author's Declaration}

I hereby declare that I am the sole author of this thesis. This is a true copy of the thesis, including any required final revisions, as accepted by my examiners.

I authorize Ryerson University to lend this thesis to other institutions or individuals for the purpose of scholarly research.

I further authorize Ryerson University to reproduce this thesis by photocopying or by other means, in total or in part, at the request of other institutions or individuals for the purpose of scholarly research.

I understand that my thesis may be made electronically available to the public. 


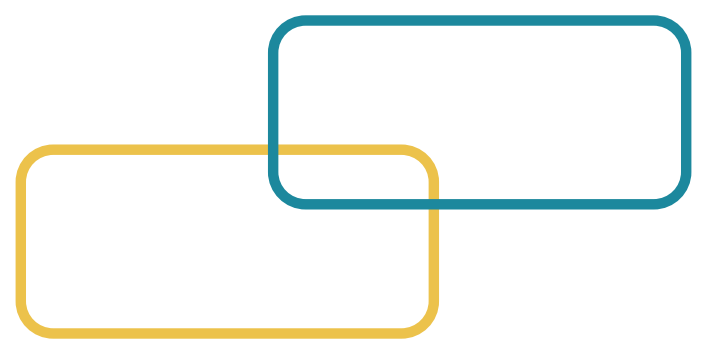




\section{Abstract}

Urban centres have seen decreasing public notions of civic-ness, as citizens' understanding and implementation of civic engagement have shifted into the individualistic and private physical realm. The characteristics of a citizen in the contemporary age are scattered and ill-defined, leading to a dilemma of citizenship, and where and how civic engagement takes place. Analyzing this quandary from an architectural perspective begins to question how a space can become civic, and addresses the necessity of physical space for increased civic engagement. This thesis aims to define and suggest a bridge for the current gap in civic architecture that is citizen-oriented, combining programmatic and spatial functions as an architectural alternative to highly institutional governmental spaces. The alternative provides a platform of tangible, non-privatized spaces that have the potential to make room for a more balanced approach to participation that encourages the engagement of a substantive citizenry. 



\section{Acknowledgements}

Dr. Leila Farah, whose endless encouragement, discussions, and time fueled this thesis and inspired me every day to try more, do more, and be more. I have learned so much from you and I thank you for giving me your all.

Jenn McArthur, whose meticulous notes and feedback were invaluable in shaping this project. Thank you for the practical steering.

Jurij Leshchyshyn, whose thoughtful conversations and shared passions helped shape my perspective on architecture's place in the world. Thank you for the coffeehouse meetings that turned into conversations and debates.

Pursuing the opportunity to present my work at the Interstices Under Construction Symposium in Auckland in July 2019 was a dream come true. I thank Dr. Miljana Horvat, John Cirka, ICRSF, YSGS and the RSU for the support that made it possible, and Leila for finding such a unique event.

My friends, family, and cohort; our solidarity and your confidence kept me going for a year. Thank you for being a part of it. 

To I.M.,

for your persistent and enduring ability to inspire. 



\section{Table of Contents}

Author's Declaration iii

Abstract $\quad$ V

Acknowledgement vii

$\begin{array}{ll}\text { Dedication } & \text { ix }\end{array}$

Table of Contents $\quad$ xi

List of Figures $\quad$ xii

$\begin{array}{ll}\text { Preface } & \text { xix }\end{array}$

Introduction $\quad 1$

1.0 Civics 3

1.1 Civil Society and Citizenship

1.2 Civic Space

1.3 Cities and Urbanism

2.0 Influences

2.1 Social Movements

2.2 Designing \& Building Civic Space

2.2.1 Corporatocracy

2.2.2 Community

2.3 Toronto's Programmatic Civic Context

3.0 Theories

3.1 Contemporary Approaches

3.2 Programmatic Explorations

3.3 Spatial Explorations

4.0 Manifestations

4.1 Programmatic Precedents

4.2 Programmatic Principles

4.3 Spatial Precedents

4.4 Spatial Principles

4.5 Toronto's Spatial Civic Context

5.0 Constructions

5.1 The Local Democratic Zone

5.2 Sites

Conclusion

5.3 Program and Space

Appendices

141

Works Cited \& Considered 


\section{List of Figures}

0.0 Figure 0.1: Preface (Source: Heather Breeze)

Figure 0.2: Introduction (Source: Heather Breeze)

1.0 Civics Figure 1.01: Civic Engagement Month, Wen-Min, 2017. (Source: https://www greatervalleyglencouncil.org/category/department-of-neighborhood-empowerment/). Accessed July 4, 2019.

Figure 1.02: Citizen/economic interaction. (Source: Heather Breeze)

Figure 1.03: Author's intrepretation of James Holston's formal vs substantial citizenship. (Source: Heather Breeze)

Figure 1.04: Glade Spring Town Square, Elyse Gerstenecker, 2011. (Source: https:// preservationinpink.wordpress.com/2011/12/09/ruminations-on-a-small-town/). Accessed July 6, 2019.

Figure 1.05: Dense urban centre. (Source: Heather Breeze)

Figure 1.06: Civic realm (Source: Heather Breeze)

Figure 1.07: Greek agora, Priscila Melo, n.d. (Source: https://www.estudokids.com.br/ademocracia-em-atenas/). Accessed October 1, 2018.

Figure 1.08: Greek pnyx, J. Bruhlman, n.d. (Source: http://www.ancientgreecefacts.com/ greek-athenians/the-agorain-ancient-athens/) Accessed October 1, 2018.

Figure 1.09: Civic vs. public. (Source: Heather Breeze)

Figures 1.10a,b: Civic action. (Source: Heather Breeze)

Figure 1.11: Black Lives Matter, Mark Blinch, July 2016. (Source: https://www.thestar.com/ news/gta/2017/06/02/black-lives-matter-not-registered-for-this-years-pride-parade. html). Accessed December 9, 2018.

Figure 1.12: Formal status in a city. (Source: Heather Breeze)

Figure 1.13: Urban archipelago of civic-ness. (Source: Heather Breeze)

Figure 1.14: Notions in this chapter. (Source: Heather Breeze)

Figure 2.01: New Urban Activism, Erin Johnson \& Paisaje Transversal, 2016. (Source: https://www.paisajetransversal.org/2016/03/new-urban-activism-in-madrid-socialmovement-emerges.html?m=1) Accessed July 27, 2019).

Figure 2.02: Orcasitas, Madrid, E. Cachfeiros, 1981. (Source: Castells, M. [1983]. The city and the grassroots: A cross-cultural theory of urban social movements, pp. 245. Berkeley, CA: University of California Press).

Figure 2.03: Lavapies, Madrid, M. Alvarez-Bullia, 1981. (Source: Castells, M. [1983]. The city and the grassroots: A cross-cultural theory of urban social movements, pp. 249. Berkeley, CA: University of California Press).

Figure 2.04: Madrid neighbourhoods. (Source: Heather Breeze)

Figure 2.05: Tahrir Square 1, Egyptian Streets, 2015. (Source: https://egyptianstreets.com/ 
wp-content/uploads/2015/01/Screen-Shot-2015-01-31-at-12.57.13-pm.png). Accessed April 7, 2019

Figure 2.06: Tahrir Square 2, Andre Pain, November 2012. (Source: http://archive.boston. com/bigpicture/2012/11/protests_return_to_tahrir_squa.html). Accessed December 9, 2018.

Figure 2.07: Tahrir Square activity (Source: Heather Breeze)

Figure 2.08: Zuccotti Park 2, Noel Y. C., 2011. http://2.bp.blogspot.com/-7rsET625HYg/ TqS7WT-9Rwl/AAAAAAAAMyM/Reln-jRuuFY/s1600/DSC_0333.JPG Accessed April 7, 2019.

Figure 2.09: Zuccotti Park, Seth Wenig, 2011. (Source: https://www.csmonitor.com/USA/ Politics/2011/1115/Fight-for-Zuccotti-Park-Court-set-to-have-its-say-on-Occupy-ousterVIDEO) Accessed July 27, 2019).

Figure 2.10: Zuccotti Park activity. (Source: Heather Breeze)

Figure 2.11: Social movements as democratic practices. (Source: Heather Breeze)

Figure 2.12: Maple Leaf Square, Condo Realty, n.d. https://www.condoroyalty.com/media/ k2/galleries/264/1.jpg Accessed April 7, 2019.

Figure 2.13: Quayside Common Space, Sidewalk Toronto, 2019. (Source: https:// sidewalktoronto.ca/wp-content/uploads/2019/02/FEB14-SWTO-Business-Case-Overview. pdf). Accessed April 7, 2019.

Figure 2.14: Possum and Wallaby Dreaming, Yurry Prokopenko, 2017. https://www. tripsavvy.com/canberra-attractions-4135946. Accessed April 7, 2019.

Figure 2.15: Protestors at Canberra, Dylan Wood, 2016. http://theconversation.com/howcan-we-meaningfully-recognise-cities-as-indigenous-places-65561. Accessed April 7, 2019

Figure 2.16: Toronto's Wards, City of Toronto, 2018. (Source: https://www.toronto.ca/ city-government/data-research-maps/neighbourhoods-communities/ward-profiles-2/47ward-model/. Accessed December 10, 2019.

Figure 2.17: Toronto Ward 10, City of Toronto, 2018. https://www.toronto.ca/citygovernment/data-research-maps/neighbourhoods-communities/ward-profiles-2/25ward-model/. Accessed December 10, 2019.

3.0 Theories Figures 3.01a,b,c,d: Defining civic space. (Source: Heather Breeze)

Figure 3.02: Public space and power. (Source: Heather Breeze)

Figure 3.03: Self-organized urban archipelago. (Source: Heather Breeze)

Figures 3.04a,b: Visibility. (Source: Heather Breeze)

Figure 3.05: Accessibility. (Source: Heather Breeze)

Figure 3.06: Social hierarchies. (Source: Heather Breeze)

Figure 3.07: Decentralization. (Source: Heather Breeze) 
Figure 3.08: Self-organization. (Source: Heather Breeze)

Figure 3.09: Infrastructure space. (Source: Heather Breeze)

Figure 3.10: Participation. (Source: Heather Breeze)

Figure 3.11: Public-private gradient. (Source: Heather Breeze)

Figure 3.12: Collectivism and individualism. (Source: Heather Breeze)

Figure 3.13: Physical and visual access and barriers. (Source: Heather Breeze)

Figure 3.14: Porosity. (Source: Heather Breeze)

Figure 3.15: Enclosure. (Source: Heather Breeze)

Figures 3.16a,b: Studies in porosity. (Source: Heather Breeze)

Figures 3.17a,b: Studies in enclosure. (Source: Heather Breeze)

Figure 3.18: Transparency. (Source: Heather Breeze)

Figure 3.19: Opacity. (Source: Heather Breeze)

Figures 3.20a,b: Studies in transparency. (Source: Heather Breeze)

Figures 3.21a,b: Studies in opacity. (Source: Heather Breeze)

Figures 3.22a,b,c: Possible spatial moments. (Source: Heather Breeze)

\subsection{Manifestations Figure 4.01: Working group. (Source: Heather Breeze)}

Figure 4.02: PNLT Flyer, Parkdale Neighbourhood Land Trust, 2019. http://www.pnlt.ca/. Accessed April 8, 2019.

Figure 4.03: Parkdale Rooming House, Parkdale Neighbourhood Land Trust, 2019. http:// www.pnlt.ca/. Accessed July 4, 2019.

Figure 4.04: Limite Limite Tower, City Mine(d), 2004. http://beta.citymined.org/tower-limitelimite/. Accessed April 8, 2019

Figure 4.05: Limite Limite Meeting, City Mine(d), 2002. http://beta.citymined.org/limitelimite/. Accessed April 8, 2019.

Figure 4.06: Centrum Nieuw West Amsterdam, Bieke Van Hees, 2018. (Source: https:// biekevanhees.com/2018/04/16/centrum-nieuw-west-amsterdam/). Accessed July 27, 2019.

Figure 4.07: Het Street Art Museum Amsterdam, Jan hart, 2014. (Source: https:// geheugenvanwest.amsterdam/page/21320/nieuw-west-onwaarschijnlijke-toeristischetrekpleister). Accessed July 27, 2019.

Figure 4.08: Structured partnership. (Heather Breeze)

Figure 4.09: Hoogvliet WIMBY, Maarten Laupman, 2007. http://www.spatialagency.net/ database/crimson.architectural.historians. Accessed April 8, 2019.

Figure 4.10: WIMBY, Crimson Architectural Historians, 2009. https://www.crimsonweb.org/ spip.php?article29. Accessed July 4, 2019.

Figure 4.11: Civic Engagement Month, Wen-Min, 2017. https://www. greatervalleyglencouncil.org/category/department-of-neighborhood-empowerment/. 
Accessed July 4, 2019.

Figure 4.12: Neighbourhood Councils Empower LA, Department of Neighbourhood Empowerment, n.d. http://empowerla.org/department/. Accessed July 4, 2019.

Figure 4.13: Orestad Park, Orestad.dk, 2005. https://bornibyen.dk/koebenhavn/ places/1126-byparken-oerestad-city. Accessed April 8, 2019

Figure 4.14: MUTOPIA City Park Orestad Copenhagen, MUTOPIA, 2011. (Source: https:// aplust.net/blog/mutopia_city_park_orestad_city_copenhagen/. Accessed July 27, 2019.

Figure 4.15: Programmatic civic engagement. (Source: Heather Breeze)

Figure 4.16: Accessibility. (Source: Heather Breeze)

Figure 4.17: Decentralization. (Source: Heather Breeze)

Figure 4.18: Self-Organization. (Source: Heather Breeze)

Figure 4.19: Urbanity. (Source: Heather Breeze)

Figure 4.20a: Quasi-civic spatial precedent one. (Source: Heather Breeze)

Figure 4.20b: Quasi-civic spatial precedent two. (Source: Heather Breeze)

Figure 4.20c: Quasi-civic spatial precedent three. (Source: Heather Breeze)

Figures 4.21a-e: Parliaments Around the World, XML, 2017. (Source: https://archinect.com/ features/article/150007828/parliaments-around-the-world-what-can-architecture-teachus-about-democracy) Accessed June 23, 2019.

Figure 4.22a: Voxman Music Building, Tim Griffith, 2017. https://www.archdaily. com/886640/voxman-music-building-Imn-architects/5a4f303bf197cc8fba00019d-

voxman-music-building-Imn-architects-photo. Accessed April 8, 2019

Figure 4.22b: The Commons, Department of Architecture, 2016. (Source: https:// departmentofarchitecture.co.th/portfolio/the-commons/) Accessed June 23, 2019.

Figure 4.22c: LocHal Tilburg, Stijn Bollaert, 2019. (Source: https://www.civicarchitects.eu/ projects/lochal-tilburg) June 23, 2019.

Figure 4.22d: Munkegaard School, Adam Mork, 2019. (Source: https://www.archdaily. com/919433/the-munkegaard-school-dorte-mandrup) Accessed June 23, 2019.

Figure 4.22e: Brooklyn Botanic Garden Visitor Center. Photo: Weiss/Manfredi, 2012. http:// www.weissmanfredi.com/project/brooklyn-botanic-garden-visitor-center Accessed March 25, 2019 .

Figure 4.23a: The Soho Commons, Rafael Arthur, 2017. (Source: http://www.the-Isa. org/2017/01/12/first-looksecond-year-design-projects/) Accessed October 2, 2018

Figure 4.23b: Hangar at Kenmore Town Square, Andrew Pogue, 2018. (Source: https://www. archdaily.com/900413/the-hangar-at-kenmore-town-square-graham-baba-architects?ad_ medium=gallery) Accessed June 23, 2019.

Figure 4.23c: San Vicente Ferrer Community Centre, Alejandra Arango, 2016. (Source: https://www.archdaily.com/784640/parque-educativo-san-vicente-ferrer-plan-barquitectos?ad_medium=gallery) Accessed June 23, 2019. 
Figure 4.23d: Place Montrealaises, Lateral Office, 2017. http://lateraloffice.com/filter/Work/ PLACE-MONTREALAISES-2017. Accessed April 8, 2019.

Figure 4.23e: New Market in Celje, Miran Kambic, 2010. (Source: https://www.archdaily. com/60657/new-market-in-celje-arhitektura-krusec?ad_medium=gallery) Accessed June 23, 2019.

Figures 4.24a-f: Spatial principles. (Source: Heather Breeze)

Figure 4.26: A walkthrough of the East York Civic Centre. (Source: Heather Breeze)

Figure 4.27: Toronto Reference Library, first abstraction. (Source: Heather Breeze)

Figure 4.28: Toronto Reference Library, second abstraction. (Source: Heather Breeze)

Figure 4.29: Toronto Reference Library, third abstraction. (Source: Heather Breeze)

Figure 4.30: Nathan Phillips Square, first abstraction. (Source: Heather Breeze)

Figure 4.31: Nathan Phillips Square, second abstraction. (Source: Heather Breeze)

Figure 4.32: Nathan Phillips Square, third abstraction. (Source: Heather Breeze)

5.0 Constructions Figure 5.01: General functions. (Source: Heather Breeze)

Figure 5.02: Module and liminal elements. (Source: Heather Breeze)

Figures 5.03a: Site context map 1. (Source: Heather Breeze)

Figures 5.03b: Site context map 2. (Source: Heather Breeze)

Figures 5.03c: Site map. (Source: Google Maps)

Figure 5.04: Site plan. (Source: Heather Breeze)

Figure 5.05: Approach to site. (Source: Heather Breeze)

Figure 5.06: Project diagram showing the closing of the gap between program and space. (Source: Heather Breeze)

Figure 5.07: Pavilion roof plan. (Source: Heather Breeze)

Figure 5.08: Entry into pavilion 1. (Source: Heather Breeze)

Figure 5.09: Pavilion 1 plan. (Source: Heather Breeze)

Figure 5.10: Administration area in pavilion 2. (Source: Heather Breeze)

Figure 5.11: Pavilion 2 plan. (Source: Heather Breeze)

Figure 5.12: Multi-purpose space being used for children's activities. (Source: Heather Breeze)

Figure 5.13: Pavilion 3 plan. (Source: Heather Breeze)

Figure 5.14: Members planning civic activity. (Source: Heather Breeze)

Figure 5.15: Pavilion 4 plan. (Source: Heather Breeze)

Figure 5.16: Site section. (Source: Heather Breeze)

Figure 5.17: Plan of absent centre. (Source: Heather Breeze)

Figures 5.18: Citizens using the absent centre to relax. (Source: Heather Breeze)

Figure 5.19: Citizens using the absent centre to display. (Source: Heather Breeze)

Figure 5.20: Citizens using the absent centre to present. (Source: Heather Breeze) 
Figure 5.21: Citizens using the absent centre to demonstrate. (Source: Heather Breeze)

Figure 5.22: Wall \& canopy section. (Source: Heather Breeze)

Figure 5.23: Roof \& wall detail. (Source: Heather Breeze)

Figure 5.24: Canopy connection detail. (Source: Heather Breeze)

Figures 5.25a: Ward 2 context map 1. (Source: Heather Breeze)

Figures 5.25b: Ward 2 context map 2. (Source: Heather Breeze)

Figures 5.25c: Ward 2 site. (Source: Google Maps)

Figure 5.26a: Ward 2 local democratic zone general functions. (Source: Heather Breeze)

Figure 5.26b: Ward 2 local democratic zone general functions. (Source: Heather Breeze)

Figures 5.27a: Ward 23 context map 1. (Source: Heather Breeze)

Figures 5.27b: Ward 23 context map 2. (Source: Heather Breeze)

Figures 5.27c: Ward 23 site. (Source: Google Maps)

Figure 5.28a: Ward 23 local democratic zone general functions. (Source: Heather Breeze)

Figure 5.28b: Ward 23 local democratic zone general functions. (Source: Heather Breeze

Figures 5.29: Local democratic zones forming a network across Toronto. (Source: Heather Breeze) 


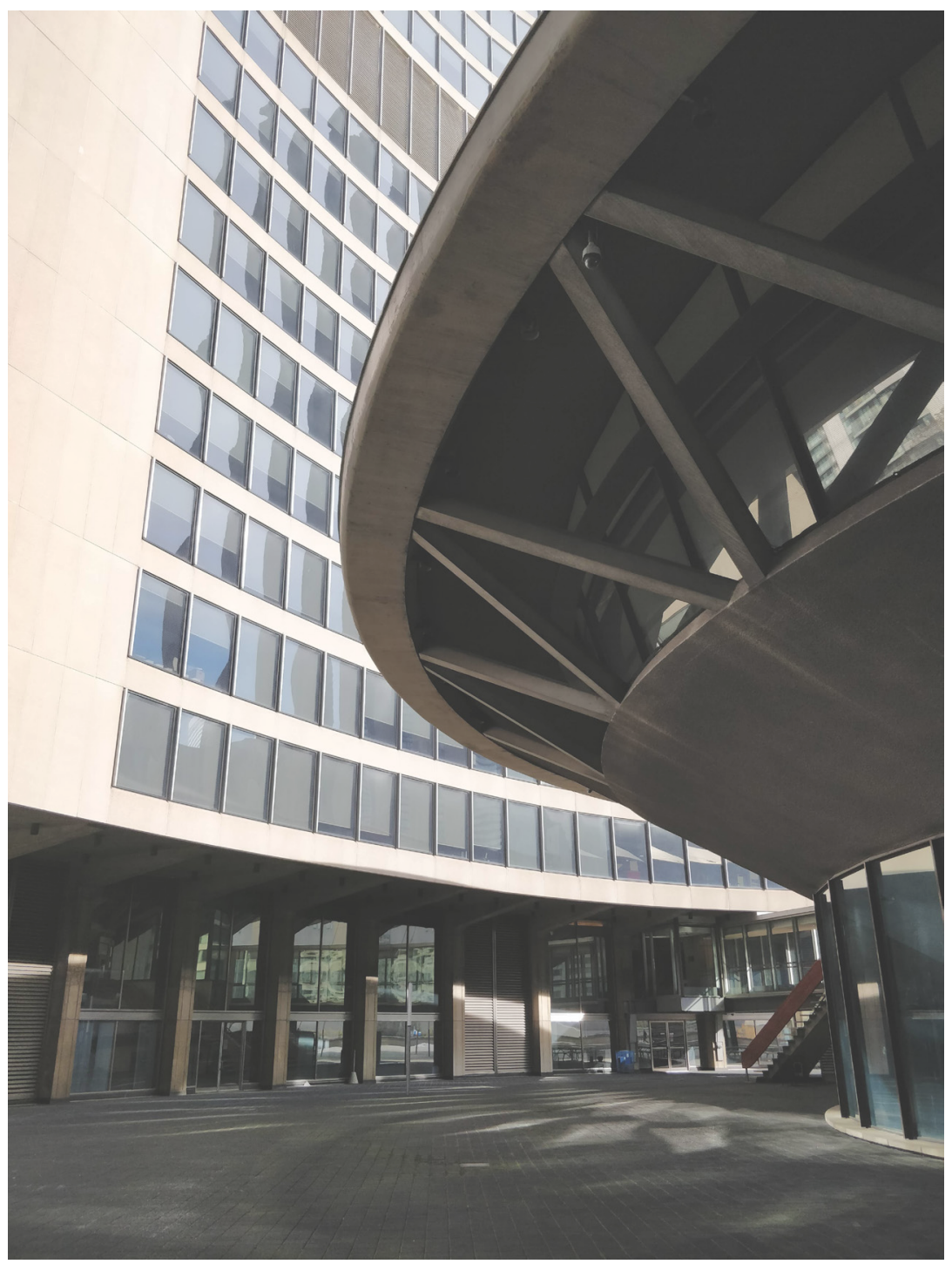




\section{Preface}

(Opposite) Figure 0.1

At the very beginning of this thesis, when I was conducting my early and preliminary research, I read a book by architect and author Keller Easterling titled Extrastatecraft: The Power of Infrastructure Space. It had a profound impact on me, as the author perfectly encapsulated many of my own thoughts about the profession and discipline of architecture, thoughts I had been struggling to make coherent throughout the first five years of my architectural education. I am continually preoccupied with the sheer broadness of territory that architecture is expected to cover in terms of problem-solving, and how projects and the profession at large are extremely vulnerable to external influences. Perhaps much more subtly than other disciplines, but just as important, is the intertwining of policy and politics with architecture, and the resultant restrictions on the profession.

Easterling writes, "Spatial variables, it was hoped, would shape a universal language. Nevertheless, while infrastructure space may be the operating system for zones as well as other generic spatial products...architects have usually not devised the rules" (Easterling, 2014, pp. 189). This quote illustrates a very real conundrum for many architects and designers, as it calls into question our ability to effect change in a system that has very rigid requirements and expectations of the discipline of architecture. Western design typically follows a linear path that embodies and adheres to a political status quo, making it difficult and risky for the architect to go against the grain. However, the huge potential for and the readymade role of the architect as a political actor is ever-present in my mind when viewing the built environment in which I place myself every day.

In their essay Democracy and Public Policy, Dale Krane and Gary S. Marshall point out two important purposes of democracy. The first is that "democratic government is designed to constrain the emergence of a permanent ruling class and encourage widespread civic participation", (Krane \& Marshall, 2005, pp. 81) and the second is the pursuit of the continual positive development of the individual (Krane \& Marshall, 2005, pp. 82).

These two aspects come together to form the basis for participatory democracy, which we can consider here to be a system of governance that at once requires and encourages the epitome of individual virtue that can contribute to collective societal goals and civil sustainability. In both politics and architecture, the responsibility of the individual to both intangibly and tangibly contribute to the well-being of collective society should be an ever-present goal.

My hope for this thesis is the overall expansion of the perspective of the architect and my own architectural orientations, to include a deeper understanding of the intangible forces of the world and how those shape our own tangible work. 


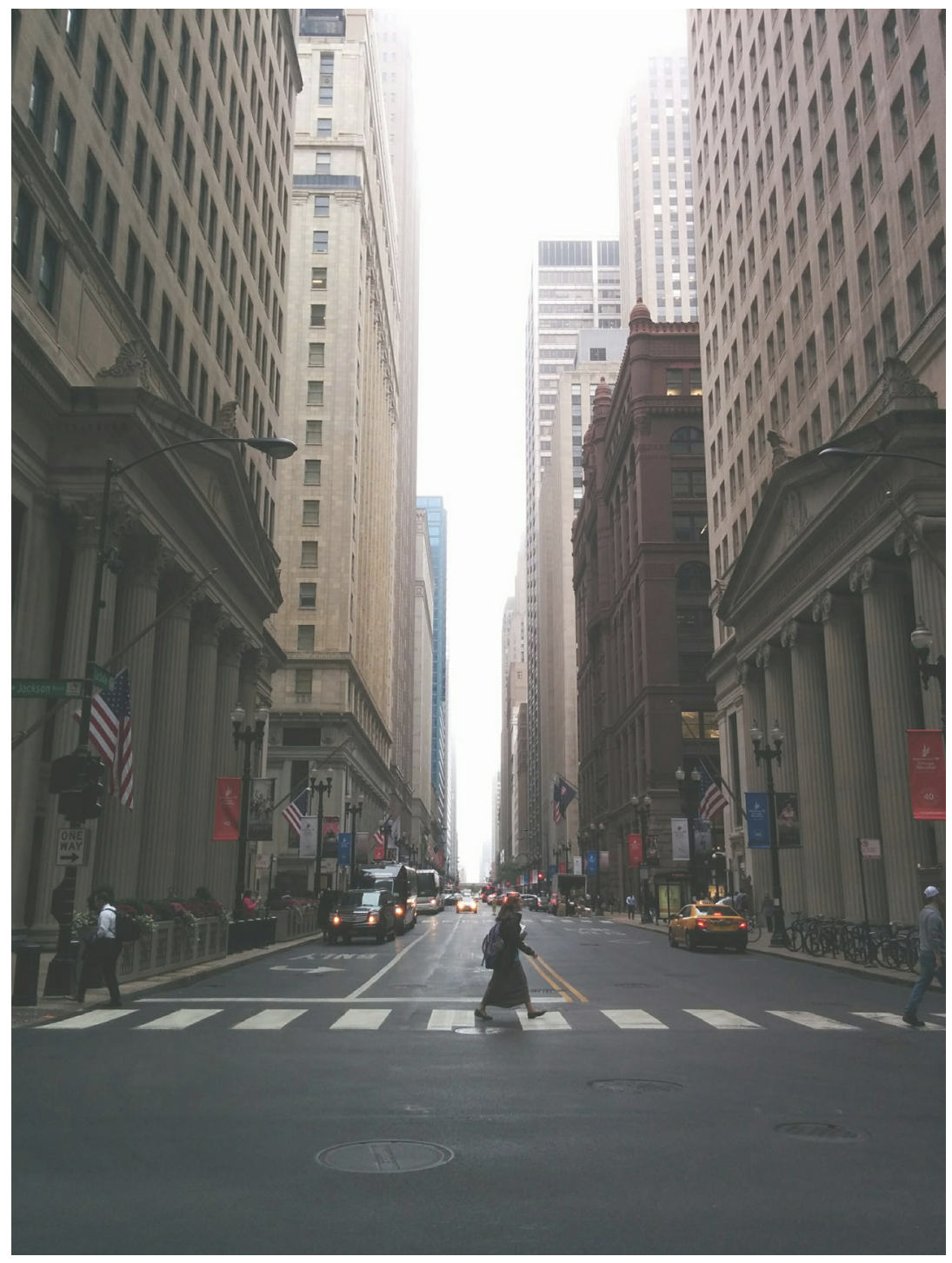




\section{Introduction}

(Opposite) Figure 0.2

Dense urban centres in the Western world have recently been experiencing an extremely rapid mash-up of bureaucracy and politicking with entertainment and pop culture. This has led to a society that is becoming ever more fraught with polarization, false information, and contention. The yearning of citizens to be more intimately intertwined with their structures of democracy should be celebrated, but this effect of accelerated pseudo-punditry now shines a very bright light on the fragility and weaknesses in our systems of governance.

The more attention that is diverted to such distractions, the more likely it is for the actual systems of bureaucratic governance to not only go unnoticed, but to begin to break down from neglect, forming new gaps and challenges. The disconnect between the conception of how government functions, and its actual impacts on the daily lives of citizens is disturbingly large. This dilemma will become more and more persistent if little beyond a surface-level understanding of municipal processes is available to the citizenry.

There is an opportunity in which to investigate contemporary notions of society's civic culture and how this contributes to governance. This thesis researches the intersection of architecture and local democracy in urban centres, and asks the question, how can alternative interventions of civic space encourage more civic engagement that leads to an increase in participatory democracy?

The ability to involve oneself in the real issues of governance should be more accessible for the average citizen. This acknowledgement of the relationship of the individual to their collective community has the potential to carry significant action. We learned from the ancient Greeks to celebrate the polis, the idea that it is the responsibility and the privilege of all those urban dwellers to fully recognize their capacity and exercise their ability to contribute to the political society.

A city requires a neutral platform for citizens and groups of all kinds to gather, to discuss with those who may have different political or ideological affiliations, without looming government backdrop or symbolism. The space should be one in which all citizens feel comfortable inhabiting, in order to learn and then act on the governmental processes and systems that affect our real lives, far more tangibly than the highest-ranking news headlines about tweets or misappropriated language.

Citizens should be able to take governmental issues into their own hands without waiting for permission, as a way of peacefully, effectively, and collectively responding to undesirable top-down impositions. This is only possible when the collective has room to shed tendency towards outrage and quick judgement, and can instead work towards change from a variety of perspectives. A bridge between the community and the existing government structure could form that takes advantage of architecture as a continual arbitrator to create a physical manifestation of civic-ness. 


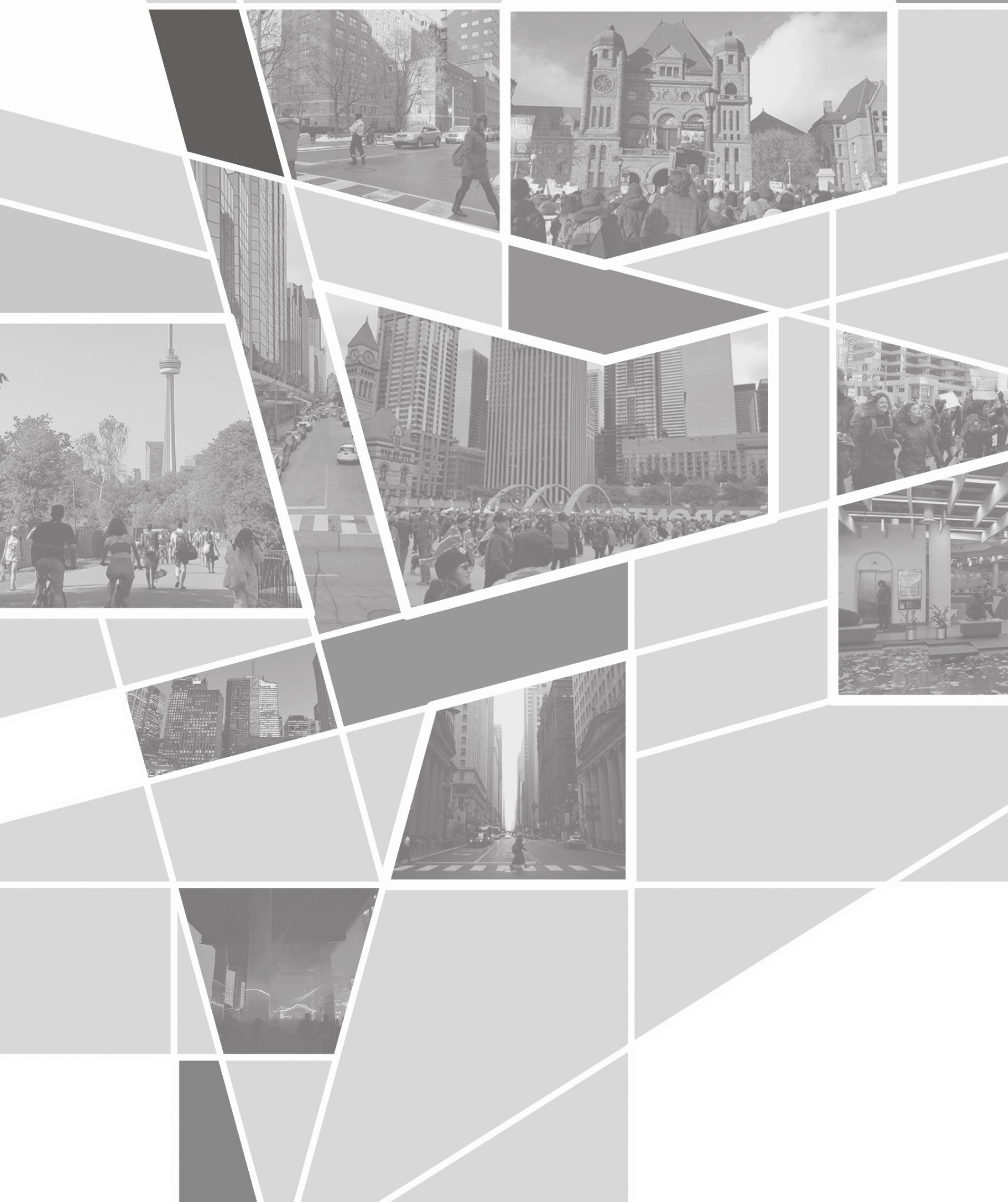




\subsection{Civil Society and Citizenship}

It is necessary to begin this thesis with a discussion of the idea of civil society. Despite its continual evasion of a hard definition, within most of the Western world there is a base understanding of what a civil society entails. Socrates conjured the phrase societas civilis, in contrast to barbaric society, after much discussion and thought experimentation with his peers (Setianto, 2007) of which the main principle was the conscious weighing of individual needs, opinions, and general idiosyncratic tendencies against societal "norms". Benny Setianto elaborates on this idea: "Concurrently, in Rome, the individual who participated in the public realm was viewed as participating toward civitas (city-state).

The fulfillment of civic duties determined the civic virtue of individuals. It could be concluded that some societies existed outside civitas and others inside civitas. Those inside civitas might be called civitas societies, in which each individual is bound by civic duties as civic virtue" (Setianto, 2007). Aristotle further contributed to what became the foundational and continuing principles of Western democracy and civil society with two key characterizations: "the opportunity for the individual to participate in making public policy, and the individual's freedom, protected by constitutional law, from intervention by the State" (Setianto, 2007).

During Aristotle's time in ancient Greece, this participation in civitas was considered quite differently than its modern manifestation. To simply be a member of the polis was to practice civitas: "In this sense, membership of the polis is contrasted, not with abstaining from specifically political activity, but with living a solitary life, isolated from any shared social activity, or with life in another type of social unit, such as the ethnos, the nation" (Mulgan, 1990, pp. 196). The level of virtue to which a man could reach was altered by his more conventional involvement in the political processes, but simply existing in and contributing to the city-state was to be a political being, and thus a citizen.

The formation of the independent country of America and its founding virtues established a kind of civil society that was quite different from those of Europe. Diverging from similarly established European nations, the American project eschewed strict collective behavioural culture and instead promoted more individual freedom. Inhabitants of this country were not bound specifically by class 
or religion or the fear of punishment; although all of these things continued to play a role, they were no longer the main drivers of societal arrangements. Relationships between Americans were based off of trust, commonalities, and neighbourliness, which Robert Putnam was the first to phrase as "social capital" (Murray, 2012, pp. 236).

The sociologist Charles Murray has spent most of his career attempting to categorize exactly what sort of virtues served for the founding basis of the American project that championed equality of opportunity, and how the crumbling of these virtues has in turn paved the way for growing inequality. In his latest book he names four: religion, marriage, industriousness, and honesty. It is the way in which a citizen practices these four virtues that we can measure their level of social capital, an essential concept for understanding the contemporary civic sphere in both an individual and a collective context. Murray's overall thesis is that the changing state of his four named virtues is leading to a massive decline in social capital, and this change can be seen in Canada as well as America.

In his seminal work Bowling Alone, Putnam was the first to highlight the importance of social capital, and Murray takes the concept further to use it as quantifiable link of civically-oriented connection between citizens. These connections are indicative of what Murray prioritized: "The second unparalleled aspect of American community life [is the] vibrant civic engagement in solving local problems" (Murray, 2012, pp. 238). It can be established that one of the key components of citizenship is both the ability and the tendency to engage in these behaviours; not because of coercion or additional incentive, but because of the opportunity to govern oneself in a true sense of freedom.

The identification and presence of social capital is essential to a functional civil society. Michael Watts further defines the concept as "the social norms and institutionalized relationships that underwrite developmental resources - here invoke the networks of civil society as a precondition for trust, duty, and accountability within the domains of welfare on the economy" (Watts, 1999, pp. 68-9). He refers back to Jurgen Habermas' idea of modern society being hinged on the formation of institutions that allow for collective problem-solving. 
Figure 1.01: Council meetings are great examples of collective problem-solving.

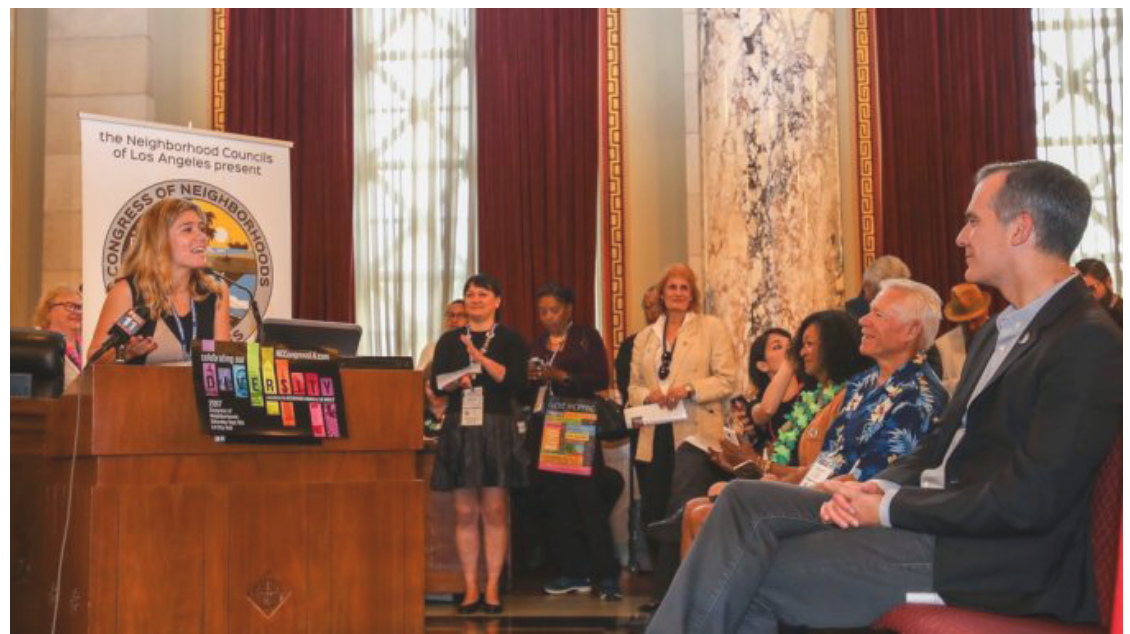

What does the situation look like now in a contemporary age where social change is occurring at an exponentially increasing rate? As Murray and Watts both recognize, the rapid disintegration of traditional non-political or government-run institutions is poised to pose a significant problem in terms of the ability of citizens to engage in action meant to effect societal change.

Murray sums up this problem quite succinctly: "consider two indexes of decline in social capital: social disengagement, meaning that people no longer belong to sports clubs, hobby clubs, fraternal organizations, nationality groups, or veterans groups; and civic disengagement, meaning that people no longer belong to service groups, youth groups, school service groups, or local political organizations" (Murray, 2012, pp. 243). Increasing civic disengagement signals a call for a pivotal shift in how we think about the opportunities citizens have in which to engage, and what challenges there are for those who wish to practice civic-ness in new ways.

Etienne Balibar explicitly identifies this shift into the contemporary: "the citizen of antiquity, inscribed a network of community affiliations that constitute the very structure of the city, characterized by his objective personal status, be it hereditary or quasi-hereditary. Modern citizenship, found on both subjective and universalist principles... must nevertheless be inaugurated by a positive institution" (Balibar, 1999, pp.198). He points out the key distinction: whereas the ancient citizen was as such due to class, sovereignty, and an inarguable system of exclusion, modern citizenship can potentially be claimed by anyone who recognizes and participates in the society of shared goods and services. This distinction, with its roots in Aristotelian thinking, is another argument in support of a citizenship increasingly reflective of a collective attitude that hinges less and less on geography, and more on the participation and acknowledgement of the oikonomike, or the economic state.

As urban spheres become ever more dense and its citizens are leaning more and more towards individualistic practises, this realm of oikonomike, as termed by Aristotle to mean the sphere of private household affairs, becomes the one in which the citizen is increasingly or sometimes solely operating. "Unlike politics, the principle of economy acts not in the public interest but in its own interest; furthermore, it cannot be questioned because its sphere is not the public sphere of the polis, but the private space of the house" (Aureli, 2011, pp. 3). This shift from the innate understanding of political responsibility as a collective community, into one 


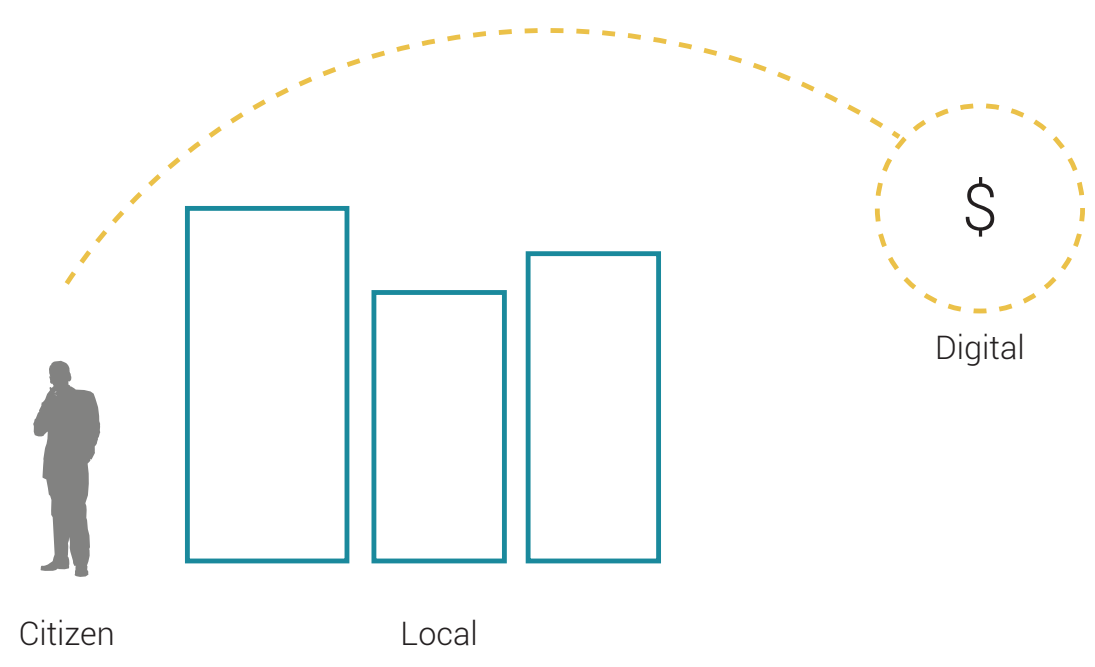

focused on the private domain, has had a major impact on how a citizen views his or her responsibility for and involvement in the civic and especially governmental processes.

Balibar further outlines his concept of citizenship with the inclusion of the caveat that both those who govern and those who are governed must be actively engaged with one another to truly qualify as civically engaging; the governing party acts and the governed party moves to (potentially) hold them in check. Balibar calls this democratic citizenship: "it is not so much the type of citizenship that slides the state in the name of the hypothetically autonomous civil society, as it is the type that manifests itself in the constitution of strong counterpowers" (Balibar, 1999, pp. 207). This definition provides a uniquely poignant encapsulation of not just the direction in which contemporary citizenship is leaning, but an active method against which to examine levels of civic engagement.

If civic engagement is increasingly reflective of a collective attitude that hinges less and less on geography, and more on the participation and acknowledgement of the economic state, there is room for further re-constructing of how to achieve and acknowledge citizenship. James Holston, who has written extensively on contemporary citizenship and how civic engagement will affect the future of civilized societies, defines two types of citizenship: "Formal citizenship refers to membership in a political community - in modern history, pre-eminently the nation state. Substantive citizenship concerns civil, political, and social rights available to people" (Holston, 1999, pp. 168). If substantive citizenship continues to grow in recognition then perhaps it signifies a return to multiple and overlapping citizenships, as existed before nationalism superseded local management in the twentieth century and cemented the state-centric notion of citizenship.

The quandary with such a loose definition is that it removes a sense of duty from the citizen. It is easy to become passive and uninterested in one's civic state when membership requires nothing more than declaration of such. Balibar points out a simple rule that can aid in outlining a contemporary citizenship: "at the very least, citizenship implies a distinction between those who govern and those who are governed, and a separation of public service and civic society" (Balibar, 1999, pp. 204). Validating this foundational implication allows for the focus to be placed
Figure 1.02: Citizens are increasingly engaging with the economic sphere outside of locational boundaries. 


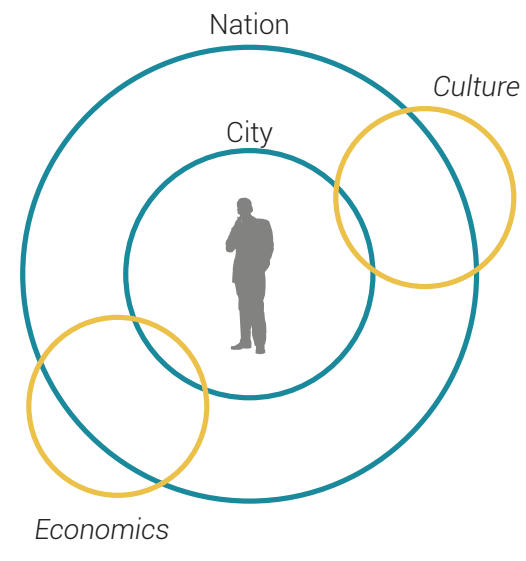

Formal Citizenship

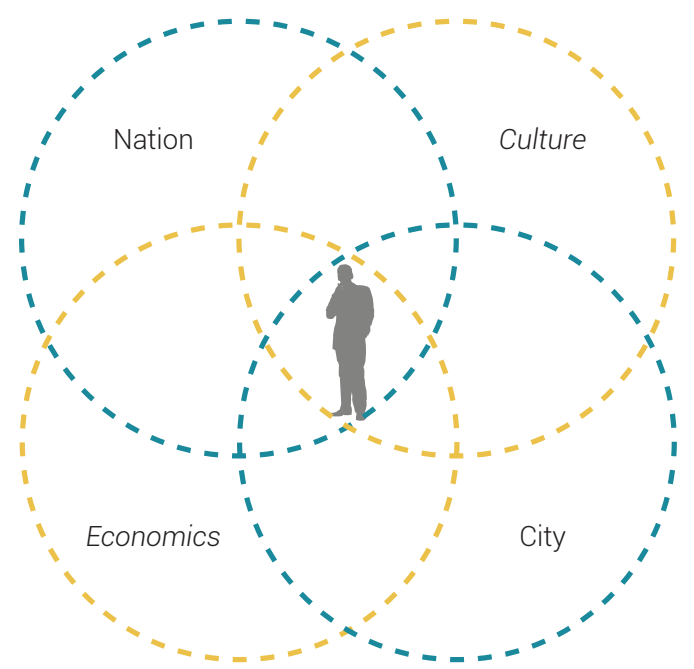

Substantive Citizenship
Figure 1.03: Author's interpretion of James Holston's formal vs. substantive citizenship. upon one segment or the other; in this case, how do those who are governed interact with those who are governing?

Arjun Appadurai and James Holston begin to address this question with their own observation of the future of citizenship: "the project of national citizenship depends less on the idea of the nation as a neutral framework for competing interests than on that of the nation as a community of shared purposes and commensurable citizens" (Appadurai \& Holston, 1999, pp. 6). As discussed before, the societal shift from the traditional ancient polis to the contemporary oikonomike has resulted in citizenship or civic engagement being unintentionally synonymous with the consumer. No longer just based around shared virtues and shared purpose, Western social relationships can now be quantified in terms of the value of services and goods. Classic markers of kinship with one's local community have begun to erode with the explosion of a capitalism that is extremely neoliberal:

"...the core of the liberal compact of citizenship: it requires that people perceive through a kind of leap of faith, that they are sufficiently similar to form common purpose. This perception is sustained in the long run through performances of citizenship. These determine, first, that there are meaningful common goods; second, that active participation rather than mere reception or inheritance establishes the fundamental claim to goods; and, third, that those who participate have equal - or at least fairly adjusted - rights regardless of other differences. This liberal compact is now under tremendous strain" (Appadurai \& Holston, 1999, pp. $6)$. 
The worry of thinkers such as Charles Murray and Etienne Balibar is that the noted "leap of faith" is becoming increasingly rare in contemporary social culture. Citizens typically rely on active participation in an economic realm rather than a political one in which to prove their accepted societal status. However, the lack of formal locational connection to possible claims of citizenship has created an opportunity which can be taken advantage of by those wishing to finalize new approaches to citizenship. This new citizenship can be harnessed with the production of contemporary civic spaces.

Starting with Aristotle and moving up to the present day, the coming together of these thinkers and their own theories has created the bedrock of this thesis. The symbiotic relationship between politics and space is passionately discussed within a faction of the architectural world. This thesis continues to synthesize these ideas, analyze precedents with the resulting perspective, and explores a design proposal that incorporates them. 


\subsection{Civic Space}

While the initial rise of digital communication platforms provided huge breakthroughs to connect people over long distances, the twenty first century has seen a massive upwards swing of those platforms being used to access or create communities based on shared interests, by those who otherwise are having difficulty finding like-minded people. Citizens are using digital media to connect on levels that transcend location, showcasing an example of tangible infrastructure facilitating intangible interactions.

Still, providing physical spaces in which some of these intangible interactions may manifest remains a key part of civic life. As compared to a small town or rural community, a city contains multitudes of choices and variety in spatial typologies, simply based on sheer volume. But it may in fact be this volume of choice that acts as a detriment to the civic underpinnings of the community; in the absence of a

(Left) Figure 1.04: Small town centre.

(Right) Figure 1.05: Dense urban centre. town-square-like gathering place, citizens are less tuned into the subconscious thread of civic life, instead relying on small enclaves of niche purpose. This trend will continue as cities fill with more and more people, of more and more diverse backgrounds, interests, and goals.
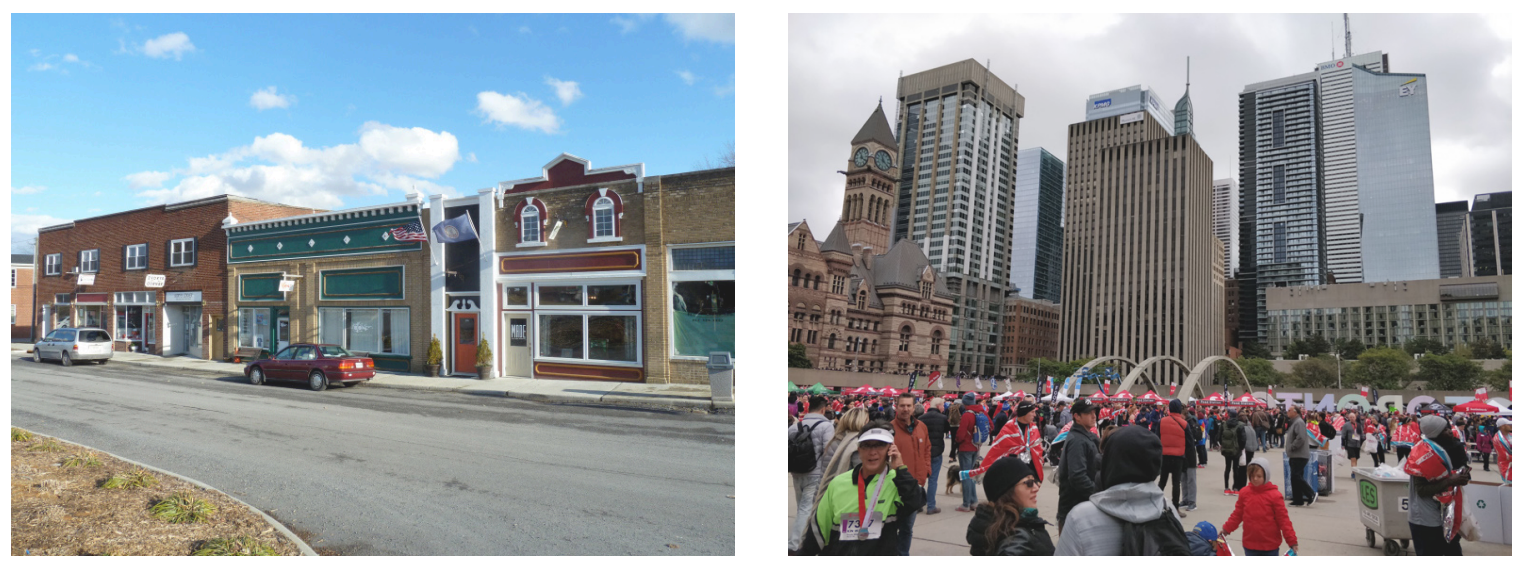

Further to Iveson's discussion of opportunities for various types of public address in a city, he quotes from authors Shelley and Urry: "any hope for public citizenship and democracy then will depend on the capacity to navigate these new material, mobile worlds that are neither public nor private" (Iveson, 2007, pp. 10). Here Iveson has highlighted the two-issue difficulty with attempting to provide a contemporary definition of civic space: how to properly identify and create something that is specifically civic within the larger realm of public space, and how to incorporate digital or non-physically focused space into the public realm. 
Rather than focusing on a return to outdated physical modes of civic participation and gathering spaces, there is instead the opportunity to re-articulate what is meant by civic action, and common space. Ever since even Aristotle, it has been difficult to collectively agree upon what is meant by phrases such as civic duty or civic virtue, and which activities do or not fall under this label simply for taking place in the city's public domain. Can we only categorize loud protestations in a plaza as civic participation, or can we also say the man riding the public subway is taking a civic action? When thinking of the public domain, it is counter-productive to attempt to draw a line between what is proper civic engagement and what is not. The time is ripe for a shift in thinking about the civic sphere.

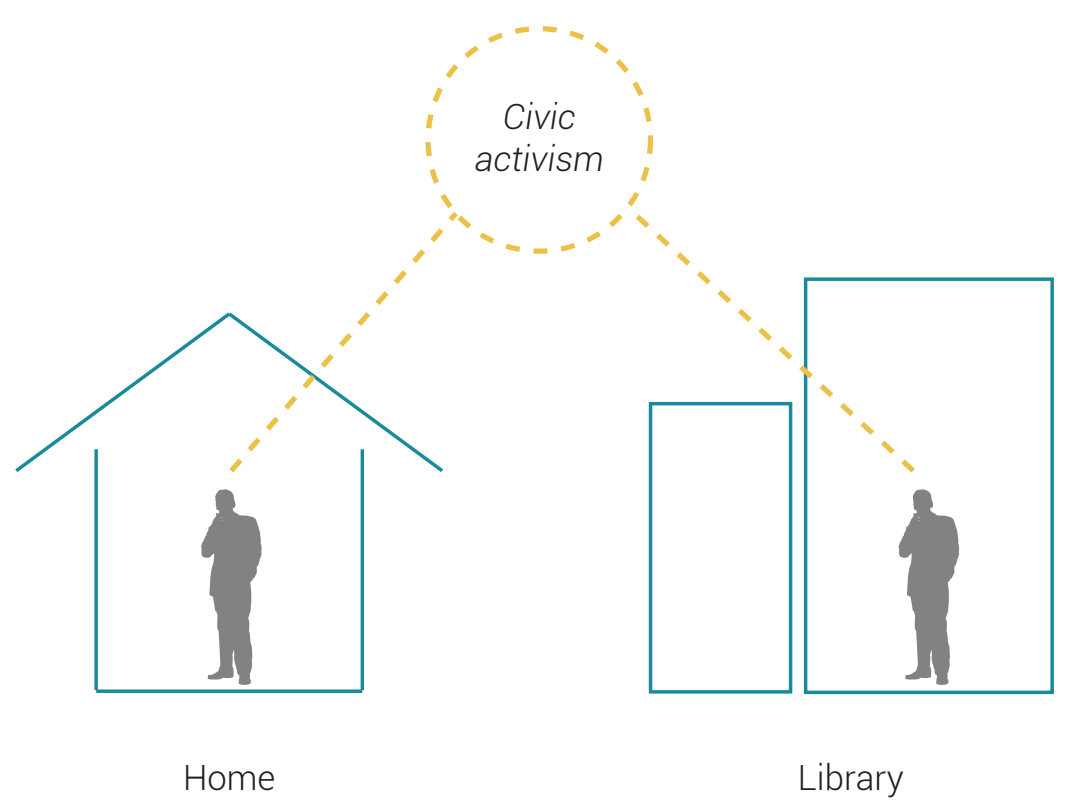

Figure 1.06: What exactly constitutes the civic realm?

Historically there were two tangible types of designated civic space. The first was the pnyx, which functioned like an amphitheatre, and the second was the agora, an open outdoor space (Democratic, 2016). The physical difference between these two are extremely important for how they influence action and gathering. The first was intentionally geared towards spectacle. The audience members were positioned towards the front of the space, which may have had a podium-like structure intended to elevate one person at a time who required the attention of the community. It was meant as a performance space, one in which a citizen could 
conduct civic action in a very structured and formal environment. The agora, on the other hand, was purposely less structured, with two key formal components to define the activities taking place. The intended functions of both of these spaces have a place in contemporary society, but the formal arrangements are no longer nearly as clearly delineated.
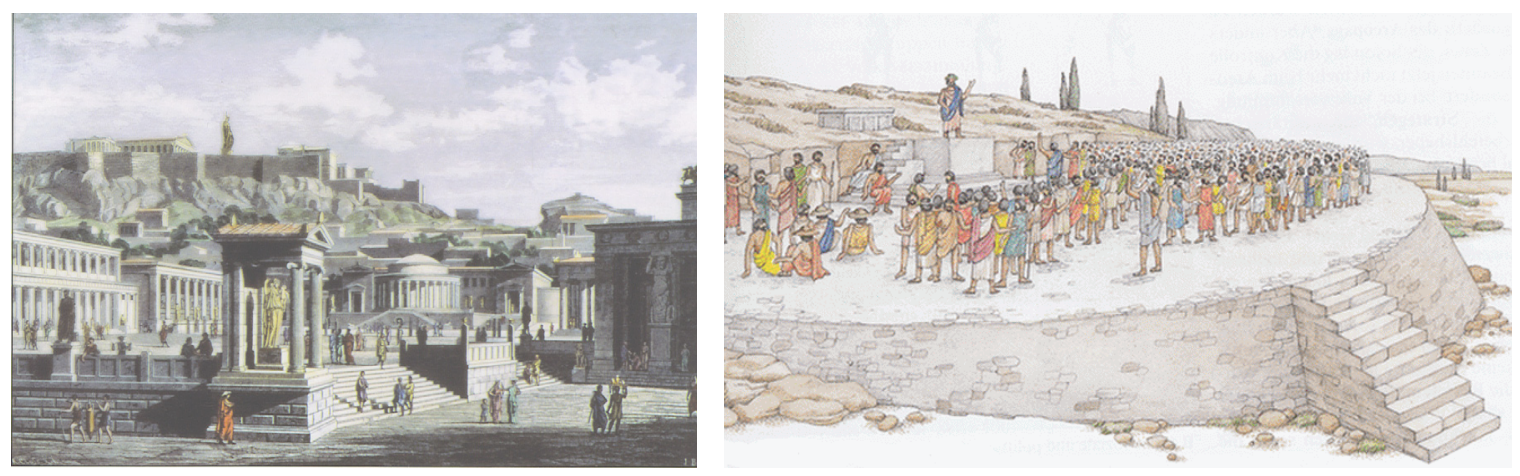

(Left) Figure 1.07: Greek agora (Right) Figure 1.08: Greek pnyx
Fran Tonkiss discusses the contradictions around the interpretations and uses of public and common space within a city: "one of the primary rights to the city is the claim to common public space. A division between public and private has been a key device used by social theorists in analyzing social relations, but it is not always clear how this dualism relates to actual public places in the city" (Tonkiss, 2005, pp. 5). The reduction in physical public life as a result of the migration of collectives to their individual private realms has had the unfortunate side effect of a reduction in the perceived importance of the physical public realm. As discussed previously, as citizens increasingly take part in society with an economic priority rather than a political one, traditional channels of communication among a collective begin to fall apart from disuse.

This is especially alarming when it comes to civic space. Civic space is defined for this thesis as non-privatized space in which civic action or engagement can take place. A lack of civic, social, and political engagement, partially driven by decreasing social capital as a direct result from a crumbling public realm, only diminishes a perceived need for civic space. However, especially in a city, "politics, like other social relations, unfolds in space. To think about politics and power is nearly always to invoke a set of spatial relations... one of the most visible ways of exercising power is to occupy or control space; architecture, meanwhile, makes power legible in material forms" (Tonkiss, 2005, pp. 59-60). Therefore a brief examination of the common understanding of civic space and its shortcomings is a vital step towards devising a possible alternative to fit contemporary society.

In cities and communities of all sizes, there are areas that are commonly understood as civic, and yet only loosely officially designed as such. This area is recognized 
as somehow elevated in importance above other public spaces that land broadly along a gradient of public-private access and usage. The civic space is one that has a more specific meaning and purpose. As Denise Scott Brown writes, "Mark Lilla defines public places as those, like the shopping mall, marketplace and beach, that 'serve our shared but still private needs' whereas civic places are where we 'share places and purposes', by virtue of sharing citizenship" (Scott Brown, 1990, pp. 21).

Perhaps our greatest societal shared purpose is that of our own governance. Civic space then becomes government-centric, a tangible, shared place to connect the citizenry with the intangible structures that govern their lives. Upon entering or acknowledging these spaces, there is a heightened awareness of consequence of action that elevates the space above the mere definition of public. It is within these spaces that bureaucrats and constituents converge, diverge, discuss, argue, and have the opportunity to create change that is then reflected back in the city and society at large. These kinds of civic-centric activities can and do take place outside of civic-centric spaces, but typically with less gravity than when they are sanctioned by the communal understanding shared among those who enter the civic space. There is an innate understanding among those who share in the citizenry that the civic space is uniquely suited for sparking change and action that would not be as effective or moving may they occur elsewhere.

Consider the opportunity of voting in a municipal election, a very common, accessible, and widely exercised civic action. It is within an election that the citizen has the direct opportunity to affect change within a society, temporarily reversing the

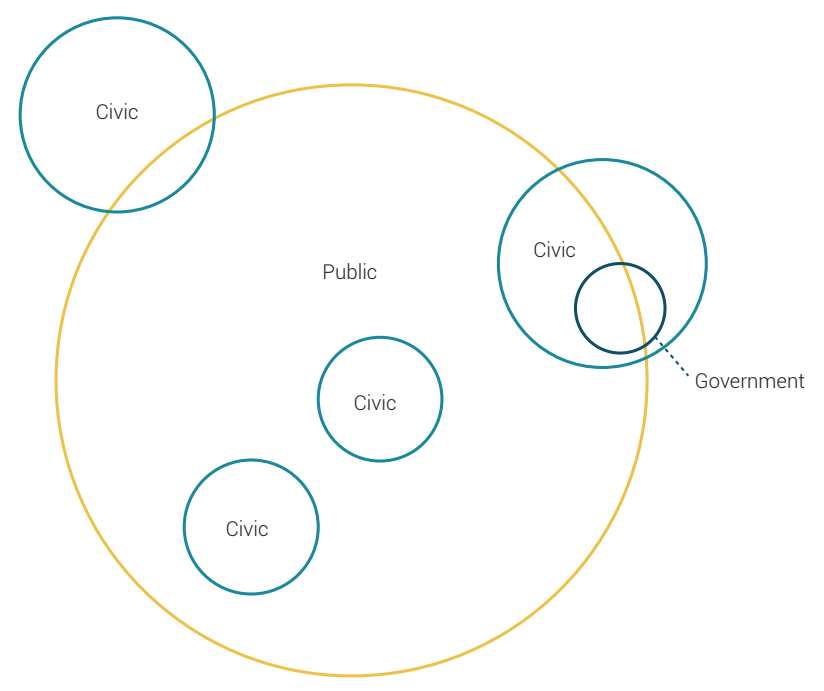

Figure 1.09: Civic vs. public. 
Figure 1.10a,b: When civic action can take place anywhere, how do we classify which spaces are specfically "civic"? power structure that places bureaucrats and politicians above their constituents. To make the elections and voting as physically accessible as possible, hundreds of voting centres are set up around a city to give convenient and close locations to the homes of citizens. Typically the voting centres chosen are those that are already understood to be central, open, or public, such as community centres or public schools.

This shift within a space that is at least semi-public, to one that is specifically civic, is an interesting phenomenon that suggests that "civic space" also has an intangible definition, one that is not cemented within a physical platform. Acknowledging this implicityl improvisational nature reveals the need to create explicitly "civic" arenas. Reinforcing the distinction of "civic" from "public" allows for the rethinking of civic spaces as a collective agreement undertaken and formally practiced by society, in order to fully exercise civic action and engagement.

It is in fact the elasticity of our notion of civic space that allows the practice to go forward. Upon conclusion of the voting process, citizens are completely cognizant of the contradictions of our own definitions. The rapid process of creation and erasure of intangible civic space within physical spaces of other typologies both supports the position that it is the action that makes a space civic, and highlights the fact that there is a shortage of space dedicated solely to the possibility of civic action.
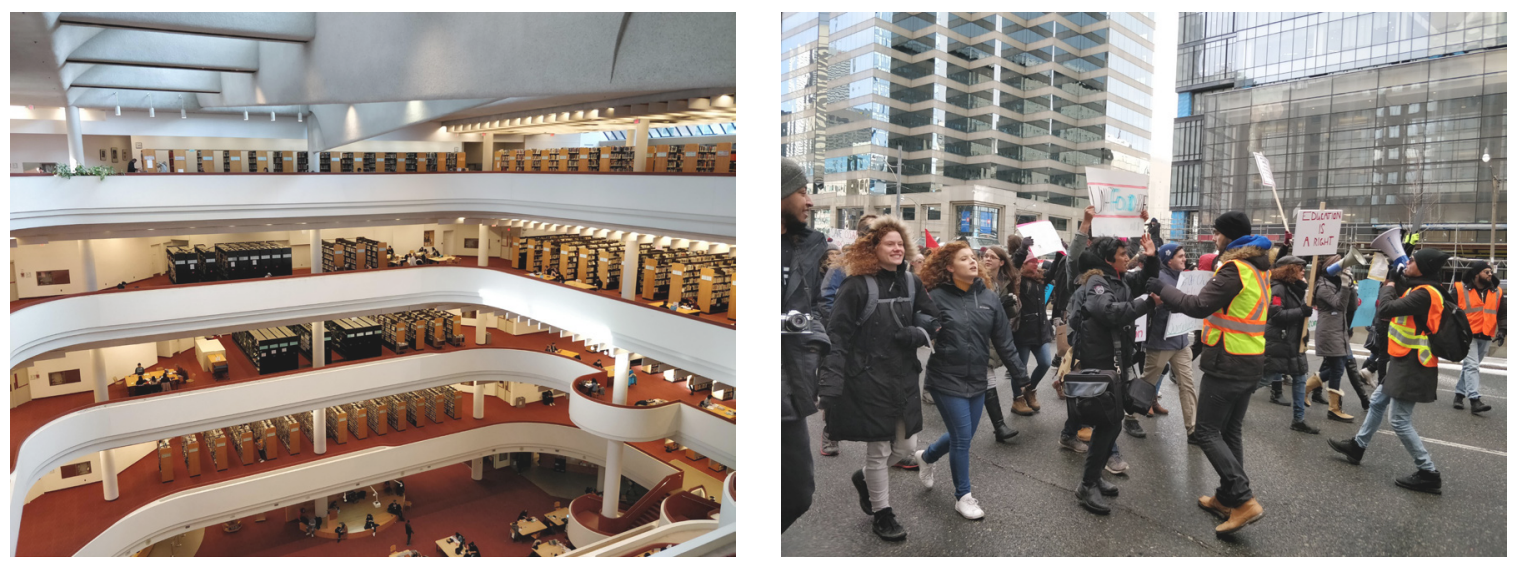


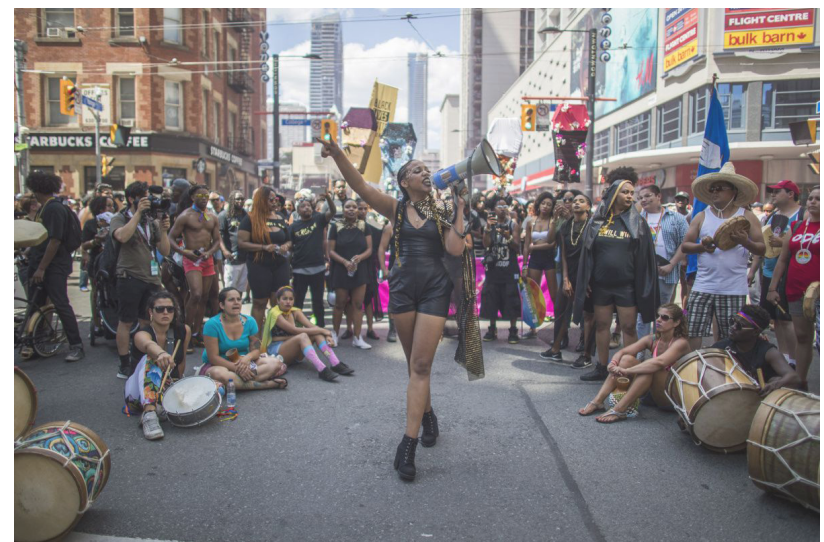

The ability for citizens to manipulate space is a key part of civic life. Awan, Schneider, and Till discuss architecture's role in establishing spatial agency in their book Spatial Agency and Other Ways of Doing Architecture. They define spatial agency as such: "agency is described as the ability of the individual to act independently of the constraining structures of society; structure is seen as the way society is organized" (Awan et al., 2011, pp. 30). This volume is invaluable to a discussion of civic space because it contains dozens of examples of designers of all areas of expertise who have pushed the boundaries of their professions to accomplish political goals that are not formed around typical structures of society. Awan et al.'s narration on these projects promote the taking back of space for purposes other than the conventional, a key component of creating a new definition of civic space for contemporary society that is no longer hinged on top-down institutional construction.

Awan et. al argue that architecture is inherently political and that all space has an interpretable political purpose, therefore it is the job of the architect to fully embrace the opportunity to affect societal change through his or her work. Awan et al. succinctly sum up the tricky position of the architect, one that is most commonly solely associated with the design and construction of object-buildings, when really the scope is much more broad: "there are many examples of how the architect can operate modestly and invisibly, but to great effect, through an intelligent and imaginative engagement with the economic social and political contexts of spatial production, and it is here where the architect regains a prominent role, and with it a social significance" (Awan et al., 2011, pp. 42). This shift in the architect's mindset for the formation of space then encourages citizens to do the same, to take up the reins and practice agency within a space overtly claimed as political.

Kurt Iveson provides an example of spatial agency through his reference to authors Nancy Fraser and her term "subaltern counterpublics" and Negt \& Kluge's expansion on the idea, who say we must work towards a production of counterpublic spaces and let go of our nostalgia/idealized striving for more perfect public spaces (Iveson, 2007, pp. 24). The creation of new public spaces that allow for action traditionally rejected or abhorred in the politely appropriate public sphere is crucial for the practice of contemporary civic action and public address. Focusing on this issue specifically in dense urban centres, this thesis addresses the question of how to provide that space devoid of barriers to entry, tangible or not, based on formal citizenship requirements.
Figure 1.11: In civil society, citizens have a level of spatial agency when manipulating or using public space. 


\subsection{Cities and Urbanism}

Studying the evolution of civic space specifically in the context of dense cities provides an opportunity to work within complex issues of contemporary society. In a smaller town, civics are often more directly physically expressed and understood through architecture that has a smaller built environment, and thus more simplified usages in landmark buildings. Urban settings can see more conventional mixes of internal activity with aesthetic typologies. The city provides a window into thousands upon thousands of different characters and their relationships with one another and with their surroundings.

There is an increasingly prevalent jurisdictional issue for the governmental tier system when confusion arises over rights and responsibilities that a citizen can claim and emulate according to their local or national ties. Susan Collins points out where Aristotle is clearly struggling with the concept of citizenship, and how this resonates with the current quandary of the city: "Moreover, by establishing rule and the virtues associated with it as the measure of the citizenship, his definition circumscribes the political boundaries of the city, excluding in particular many who labor for the city's preservation and prosperity. By what right, however, does such an exclusion occur? Is there not a just claim to citizenship by all who work in the political community's behalf?" (Collins, 2006, pp. 129). Continuing to attempt to define the split between legal and working definitions of citizenship, the city becomes the nucleus in which to work.

Two concepts linked with the physical formation of the city that are relevant to a discussion of civics are urbanism and urbanity. Urbanism can be defined as the "way of life of people who live in a large city", while urbanity is known by two definitions: the first is also simply "urban life", but urbanity can also indicate a courteous or sophisticated manner. The link between those two concepts cements the notion that civil, civic participation exemplifies city life. Fran Tonkiss writes on the relationship of the city structure to its citizens: "In providing a site for alternative forms of political organization and action, cities offer a number of spatial and social resources. First and most obviously, the city provides public space in itself - streets, squares, parks, bridges - and therefore provides an informal spatial infrastructure for political action and association. Second, cities offer information and mobilization networks... Third, cities bring together the social networks that support pressure groups, campaigning organizations and community movements" (Tonkiss, 2005, pp. 65). All three of these network systems have tangible and intangible components, which greatly benefit from the presence of high urbanism and urbanity.

Furthering Baliber's distinction between the ancient and the modern citizen, Thomas Bender has coined the phrase metropolitan citizen which further emphasizes the relationship of the citizen to a city. As dense urban centres continue to grow in the global economy for their prowess in attracting and hosting commerce, talent, and resources, the role of the city is beginning to rival that of a nation. Contemporary citizens have more reason to feel more allegiance to their home city than that of 


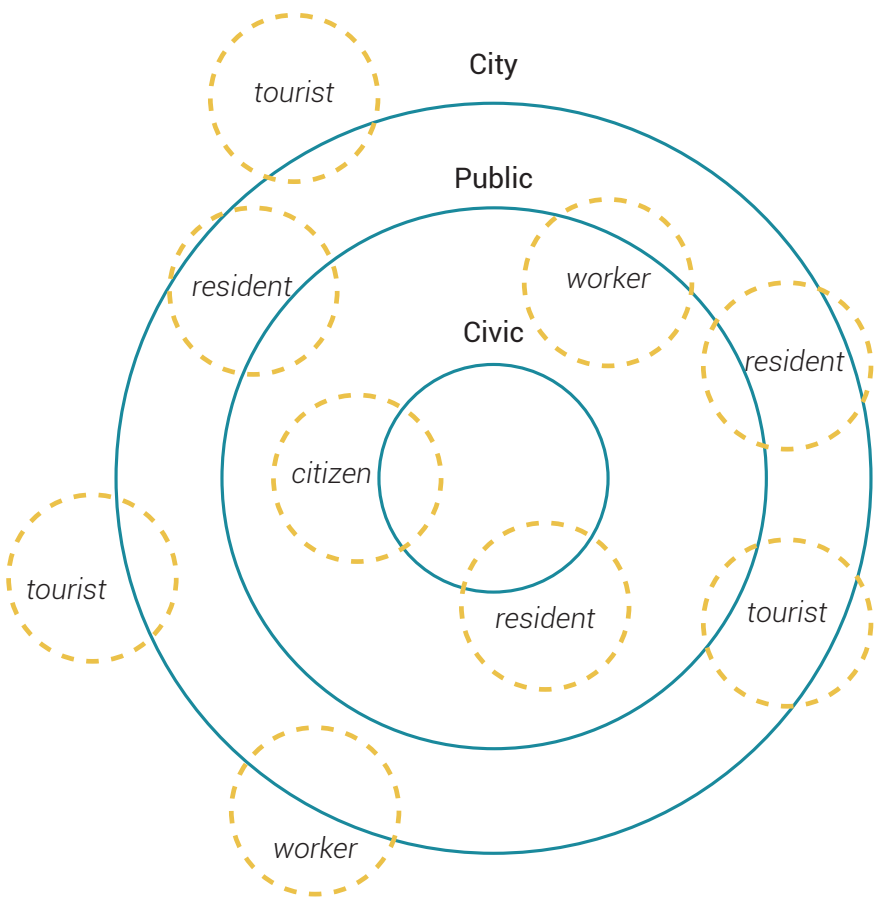

their country, especially when the collective values of those city dwellers are quite different from the reputation of the country as a whole. Bender draws a link between the city as an appropriate and increasingly relevant starting point for considerations of modern citizenship: "There has been a realignment of the relations and powers of cities and nations, and that circumstance invites a reconsideration of the city as a site for politics" (Bender, 1999, pp. 22).

Legitimizing the communal sense of urban citizenship felt among city-dwellers has the potential to lead to more local political engagement from those who feel lost in an attempt to align with a massive nation-state. Bender points out the advantage in reinforcing "a political definition of the metropolitan citizenship that will, in turn, enable a political mobilization to address the most serious social and economic challenges of our time" (Bender, 1999, pp. 39). Architecturally, Pier Vittorio Aureli makes the argument that such a feeling of collective civic engagement localized within the city can be manifested through a system of urban archipelagos.

In an Aristotelian vein, Aureli contrasts the original Greek polis, which remained central both physically and culturally in terms of a tightly knit form of community engagement, and the Roman urbs, which led to sprawling urbanization as a result of the shift from the techne politike to the techne oikonomike. He argues that unlike sprawling development, cities have the capacity to expose their own limits, which is necessary for citizens to grasp a formal and thus political sense of the city. An absolute version of clear and well-defined limits could be understood through an urban archipelago, a collection of islands that are formed around an absent centre, tethered together through a collective of civic engagement and shared values.

Aureli sees this as a solution to the modern problem of the citizen's retreat into their private denizens, instead providing an option to discuss difficult subjects with decreased risk of confrontation or judgement. This optimistic scenario shows a shifted polis that could be resurrected in the archipelago: "within this frame, any distinction between public space and private space, between political space and
Figure 1.12: How does one's formal status in a city affect how they interact in public and civic spheres? 


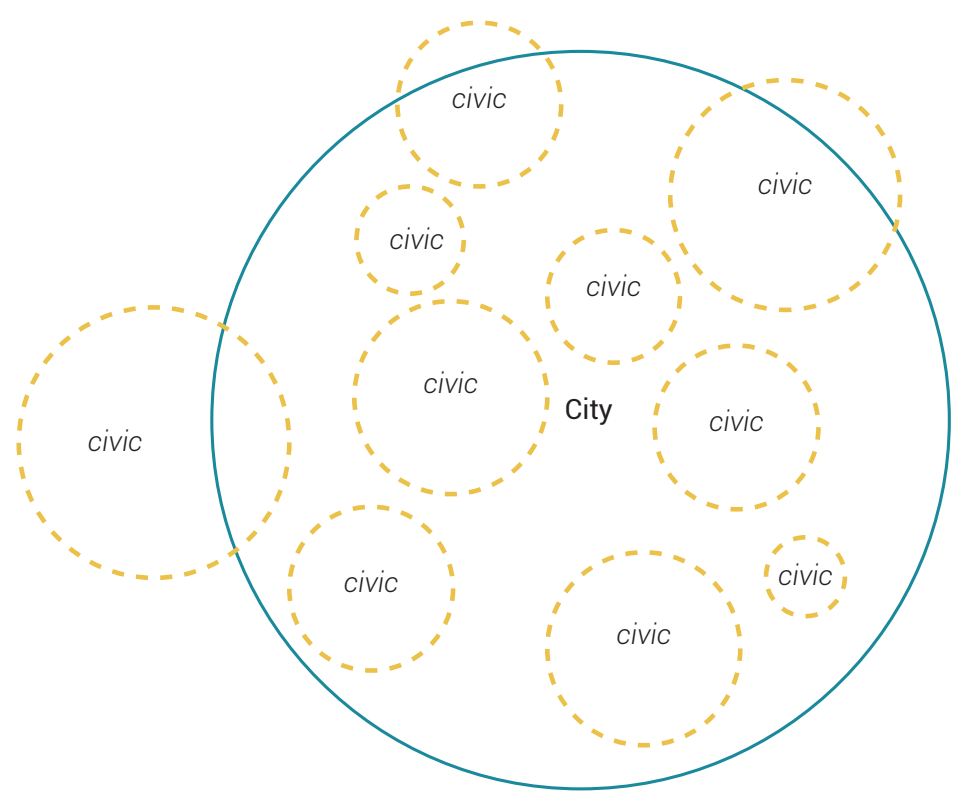

Figure 1.13: Urban archipelago of civic-ness. economic space, collapses in favour of a totalizing, organic understanding of the city as devoid of any limit, where urbanity itself is conceived of as one domestic space" (Aureli, 2011, pp. 15). Much like Awan et al., he vouches for the importance of spatial agency, and outlines the archipelago as an optimal method towards architectural self-organization.

Combining Bender's concept of the metropolitan citizen with Aureli's architectural proposal of the absolute archipelago creates a more clearly outlined understanding and vision of the future for citizenship in general and urban citizenship in particular. "Metropolitan dwellers may well have to develop a new political language that 'fits' the new social and spatial arrangement of their lives. That work will require an adequate language of metropolitan representation as well as a fuller sense of metropolitan political obligation" (Bender, 1999, pp. 39). Working within the specific context of city allows for traditional notions of citizenship to be discarded in favour of adapting a more relevant framework from which citizens can practice civic engagement.

Kurt Iveson discusses the specific relationships of public space and address within a city, and defines two approaches: "In topographical approaches to public address and public space, 'the city' features as a network of physical sites which serve as a stage for public representation and visibility. In procedural approaches, 'the city' features more as a kind of 'being together' that is as much a matter of public deliberation and collective concern as physical propinquity" (Iveson, 2007, pp 18). Both of these approaches form a symbiotic relationship that is necessary for the continual evolution of participatory democracy.

Within Iveson's topographical approach is where the discussion of spatial ramifications and opportunities can take place. Iveson distinguishes between "three distinct but related ways in which cities play a part in the formation and interaction of public social imaginaries - as venues of public address, as objects of public debate and connection, and as collective subjects which serve as the common horizon for diverse publics" (Iveson, 2007, pp. 21). These types of distinctions are extremely important when analyzing both the stock and the lack of civic opportunity that can happen spatially within a city. 


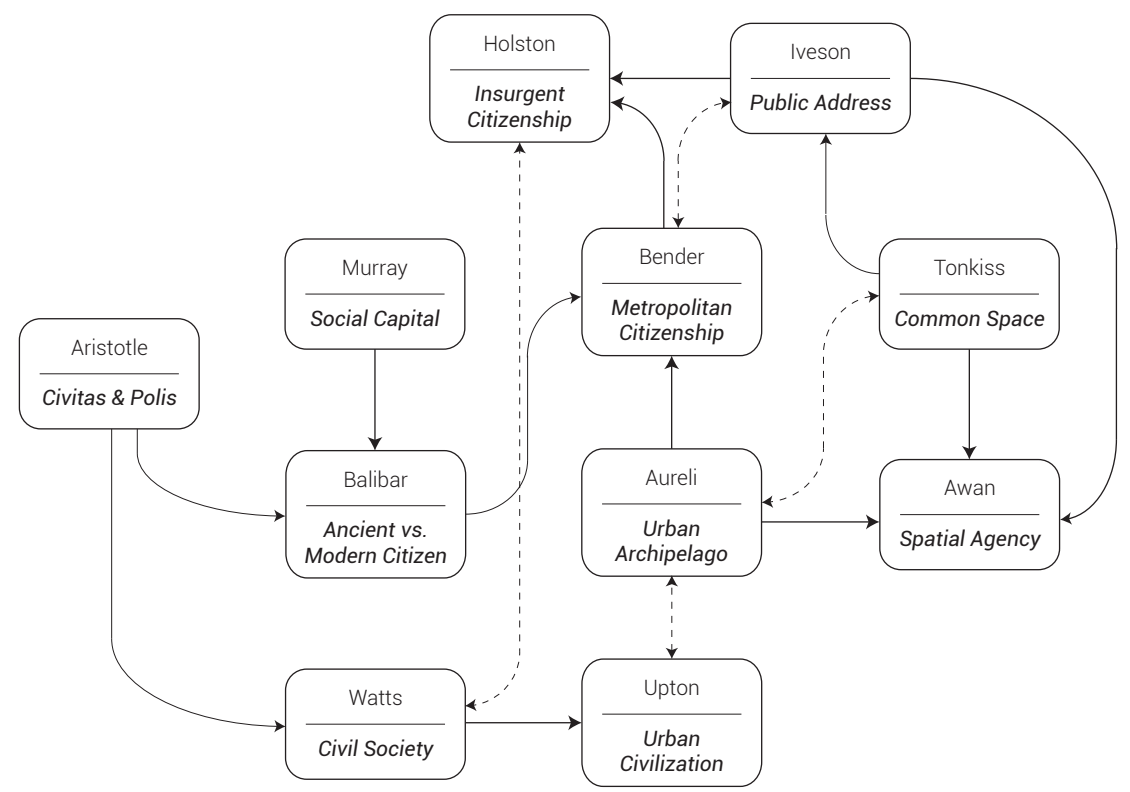

With the continuing rise of global cities, local governments are increasing their scope of services and power to be equipped to handle these sharp spikes in population, landed businesses, and community or cultural events. Fractures between those that govern and those who are governed are more dramatic and focused in a city, where there is a skewed juxtaposition of localized conflict with national or global repercussions. In his writing on the formation of cities during the American antebellum years, Dell Upton points out how early patterns establish contemporary modes of interaction within an urban civilization. Western urban centres were intended to be spaces for a productive balance of individual and collective freedom: "[with the] concept of government as a neutral intercessor, deferential to and protective of private goals but without vested interests of its own...urban fabric [was used] as a neutral environment within which many disparate goals could be pursued" (Upton, 2008, pp. 299).

However, despite the presence or absence of intentional diversion, there are many examples where the government has not remained a neutral intercessor, and regardless of the government body in question the typical site of conflict is within the city. The city is inevitably marked as inherently political, as the nexus of action, be it of economic, social, cultural, or architectural nature. Little has changed in a couple hundred years when considering the city as a political arena: "Politics encompassed every aspect of our urban life, from political organization to personal habits. The difference between electoral politics and street behaviour was only a matter of degree" (Upton, 2008, pp. 310). Thus the need for acknowledgement of the metropolitan citizen is great, and would be invaluable in spawning increased civic engagement.

When planning for new types of civic space that encourage local participatory democracy in a city, this thesis is oriented towards the modern citizen. Recognizing contemporary ways of engaging socially and politically is crucial to filling the gap in accessible civic space that acts as an effective platform for engagement. 


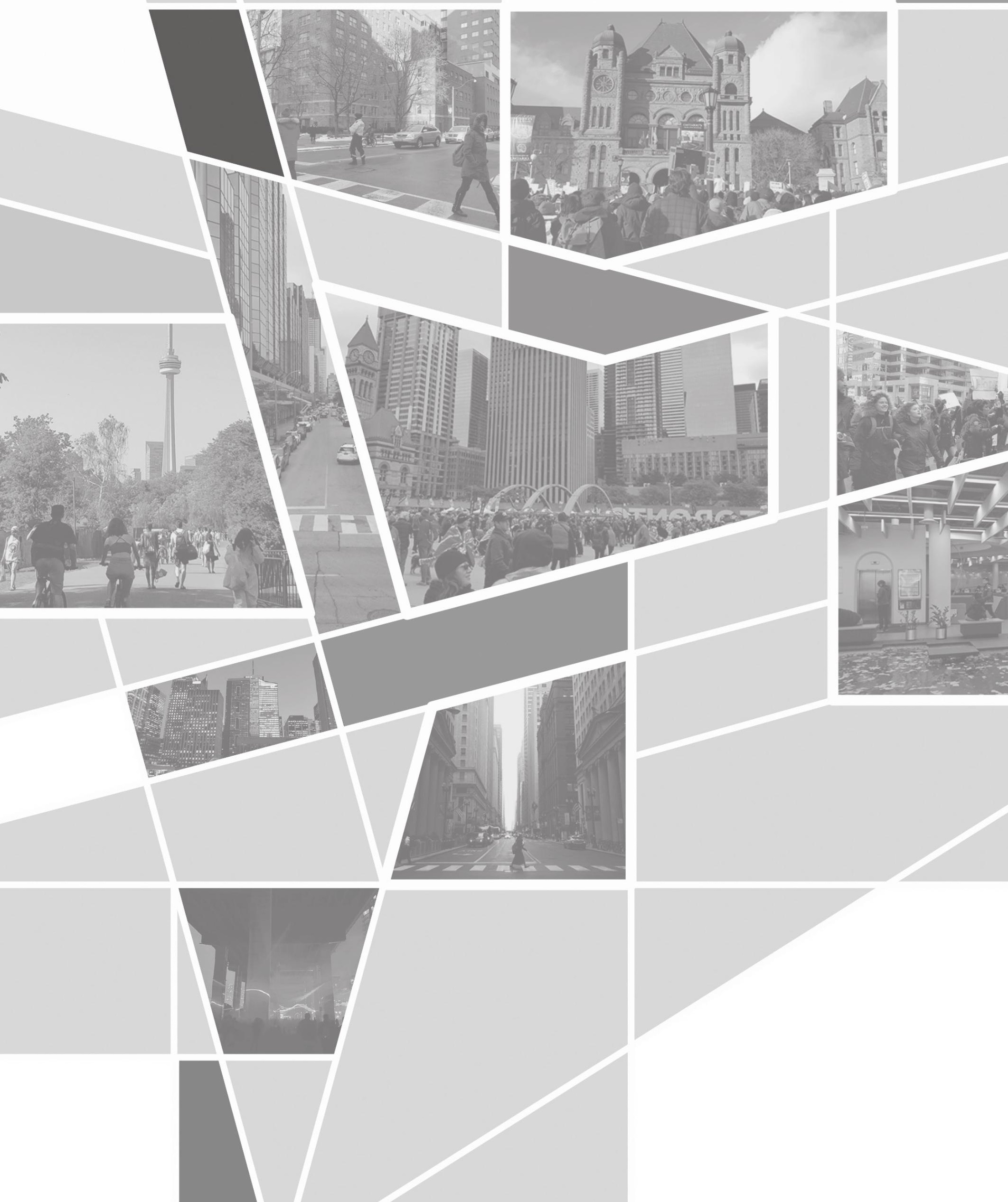



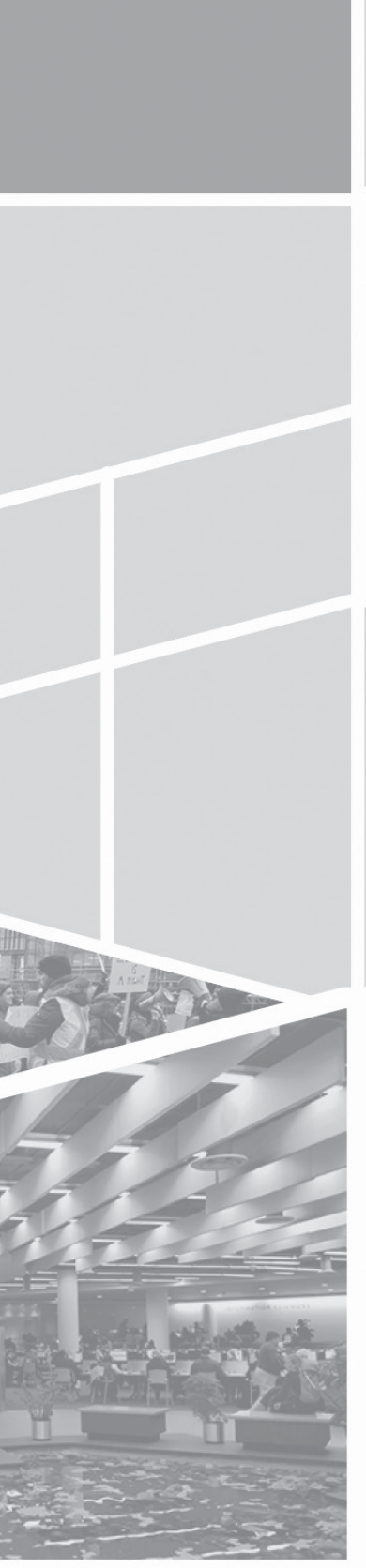

\subsection{Influences}

How are contemporary societies adhering to or deviating from foundational concepts of citizenship? In what ways are citizens exercising their democratic rights? 


\subsection{Social Movements}

Broadly, a social movement is a large group action, informally collecting those who wish to focus on a particular or several societal issues that they advocate require change. The larger umbrella term of "social" can be replaced with more specific intentions; this thesis focuses on democratic social movements which focus on the changing of political rights. As the movement grows or distorts, often the original reason for collecting is diluted among the many members, resulting in a possible lessening of specifically politically-driven intentions, but the movement can nonetheless still be effective.

A brief investigation of social movements is foundational for this thesis because they epitomize some of the most basic methods of practising civics of democracy. The first chapter explored notions of civic-ness in a historical and theoretical context. This chapter explores not only how social movements serve as examples of democratic practice, but also how current civic contextual factors can influence these movements.

The social movements studied here have been borne out of the convergence of two components: a particular catalyst that exemplifies collective dissatisfaction in the socio-economic sphere of society, and a spatial opportunity in which to express this dissatisfaction.

Often, the catalyst in question is a singular event or action carried out by a formalized establishment structure, which then spawns a grassroots response in the form of an extremely rapidly materializing collective action. This is in contrast to a more procedurally-oriented, slowly planned resistance against a larger cultural, social, or political status quo that is deemed as negative by potentially any number of citizens who see fit to take it upon themselves to resist or affect change.

Movements or actions that are borne out of pressure, frustration, and an urgent need to take action - in other words, primarily emotionally-based - tend to result in the deprioritization of proper planning. A weak foundation within the movement makes it all the more difficult to adapt a sustainable structure as more time passes.

This is where the second component of spatial opportunity becomes important. Well-known social movements are intertwined with a particular location from which they have sprung, or in some cases, continue to operate. Without a physical platform as a foundation, the biggest weapon in movement culture - sheer numbers of bodies - has no place in which to be wielded. Fran Tonkiss notes how "movements such as these politicize urban space as an object of contestation 


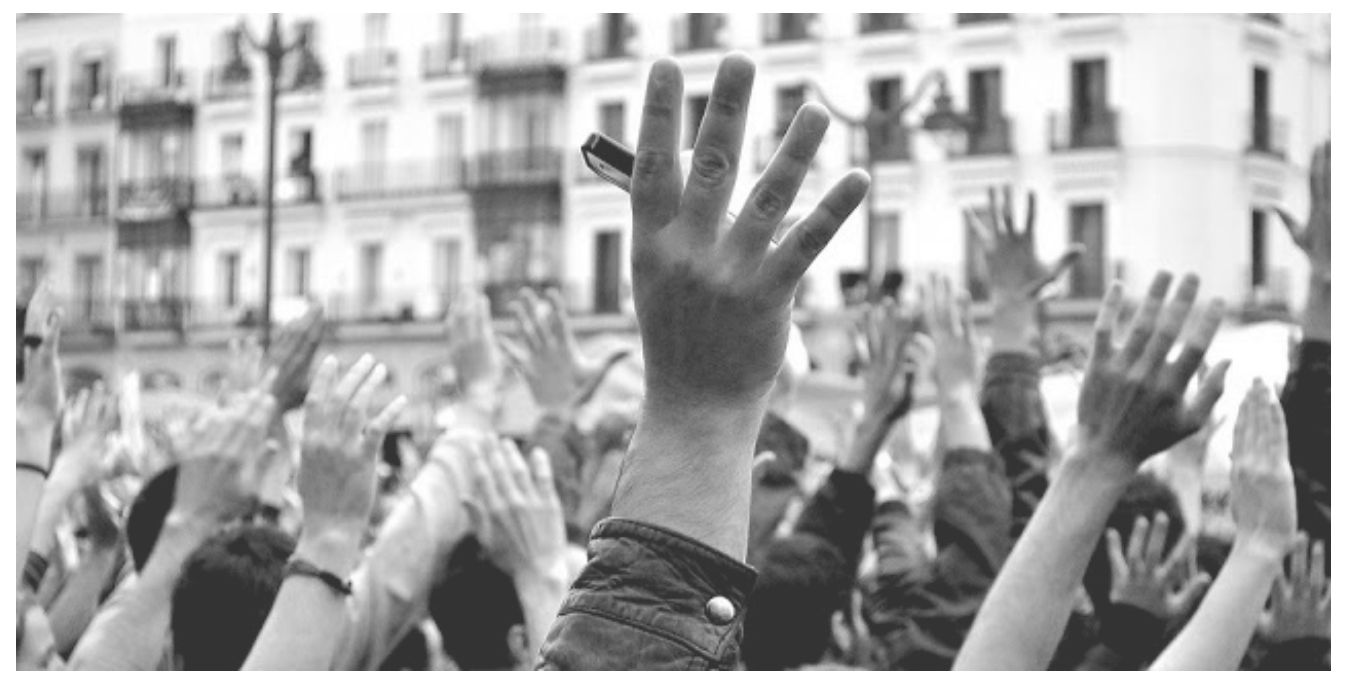

between private and public property...Urban space is both the object of political Figure 2.01: New urban activism. agency and its medium" (Tonkiss, 2005, pp. 63).

Internet connectivity and social media in particular has been extremely instrumental in organizing many variations of social movements. However, it is the organization with a tangible location or meeting ground that has proven the most successful. Promising beginnings can be borne out of digital resources, but physical civic space is necessary for continual citizen involvement or participation in government.

Attempting to classify or compare social movements in terms of their "success" is difficult. Many movements have a list of demands, but some of these are constantly changing as the movement evolves. What is important to consider and analyze are the components of the movement that have connected their energizing catalytic event to their spatial opportunity, and how this contributed to working towards or achieving the movement's stated goals.

The following are examples of several highly prominent social movements, their intangible socio-economic drivers, and their connections to space. These three examples were chosen for their unprecedented level of global prevalence, their demonstration of spatial and civic agency by citizens, and their continued relevancy as precedents for continued democratic practice. 


\section{The Citizen Movement of Madrid}

Who: The Citizen Movement of Madrid was composed firstly of lower-income Spanish militants, and then thousands upon thousands of citizens all over the province who joined.

What: A social movement with the main goal being to form citizen networks and associations that would be able to withstand and work against intense economic austerity and social issues arising as a result of the oppressive post-WWII Francisco Franco Spanish government.

Where: This particular branch focuses on Madrid, but several other regions such as the Basque and Catalan regions were also just as strong.

When: 1960-1979

Catalytic Event: The Movement had been alive since early 1960s as a result of the slow burn of inadequate infrastructure, but when leader Francisco Franco died in 1975 they could finally start working towards free elections.

Programmatic Components: Yearly elected steering committee with permanent working groups, steering committee combined with a sporadic/spontaneous decentralized organization, regular general neighbourhood meetings.

Spatial Components: This movement was both innovative and successful because it was territorially defined; this began to challenge a system that functioned much less on geographic constituencies we see today and with almost all emphasis on political parties (Castells, 1983, pp. 229).

Result: Neighbourhood associations were made legal in 1977 and the first free elections held on 1979 that combined political parties primarily spurred on by grassroots, and organized territorially. 


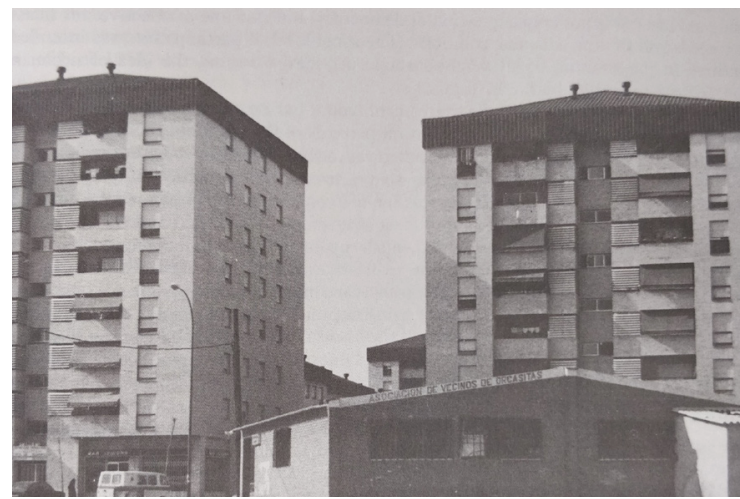

Figure 2.02: Public housing obtained by residents.

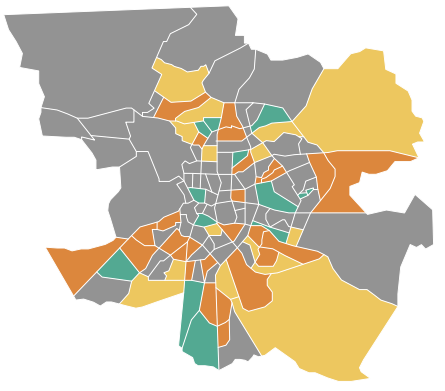

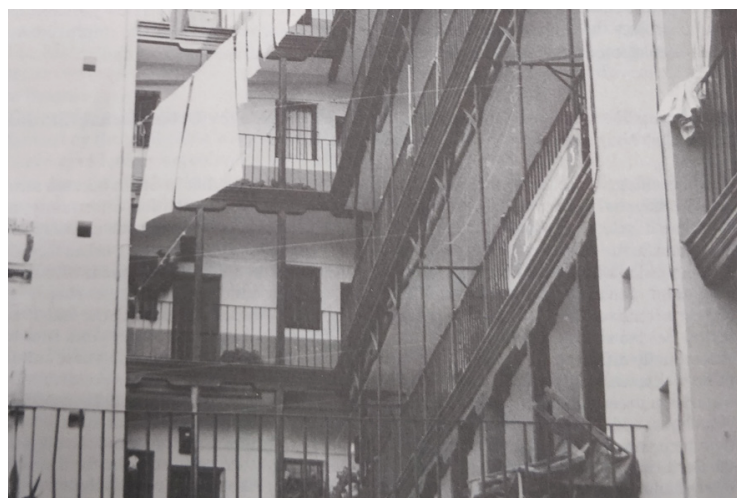

Figure 2.03: Historical buildings in Madrid as rallying points.

Figure 2.04: Various neighbourhoods in Madrid in 1979 shown by levels of mobilization, residential association headquarters, and physical condition of the built environment. 


\section{The Egyptian Arab Spring}

Who: Mostly young people and students but hundreds of thousands of Egyptian citizens converged.

What: Inspired by other countries in the region, Egyption gathered to peacefully protest corruption and waste in government at the expense of all citizens, and demand a return to democratic society.

Where: Cairo, Egypt

When: Began January 25, 2011 as a protest planned for Police Day, and festered on January 28, the "Friday of Rage"

Catalytic Event: The self-immolation of Mohamed Bouazizi in Tunisia December 17th, 2010 was the first act sparking the Arab Spring.

Programmatic Components: The spreading of communication through social media in order to alert international news coverage, encampments, marches, and occupations of public space that were all fighting against government blackouts and military power.

Spatial Components: March through the city to the Kasr el-Nile Bridge to Tahrir Square.

Result: Two weeks after the start of the protests Hosni Mubarak resigned as president, creating the first opportunity in decades for a shift back to democracy. However, military forces appointed a replacement, and there have been several contested elections since. Although the desired ceding of leadership occurred from the protests, there are mixed opinions about its overall benefit to modern Egyptian society. 


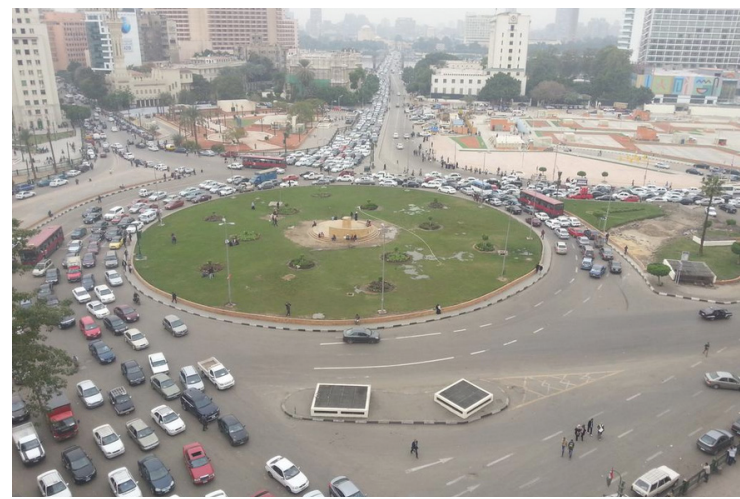

Figure 2.05: Tahrir Square Prior to occupation.

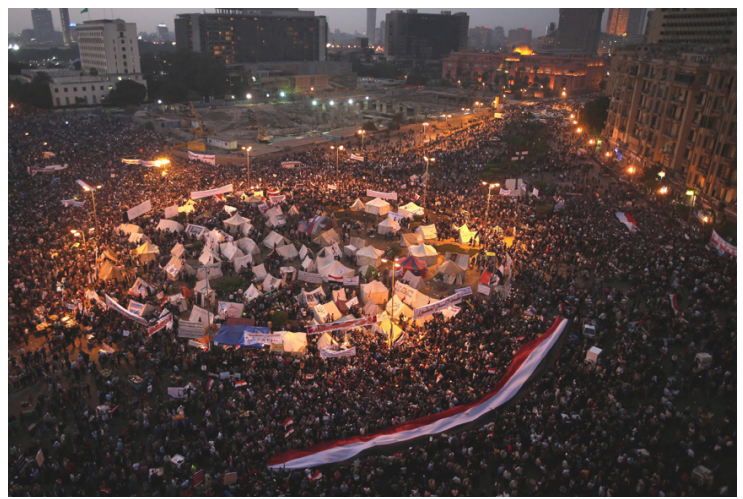

Figure 2.o6: Tahrir Square encampments during Arab Spring.

Kasr el-Nile Bridge Tahrir Square
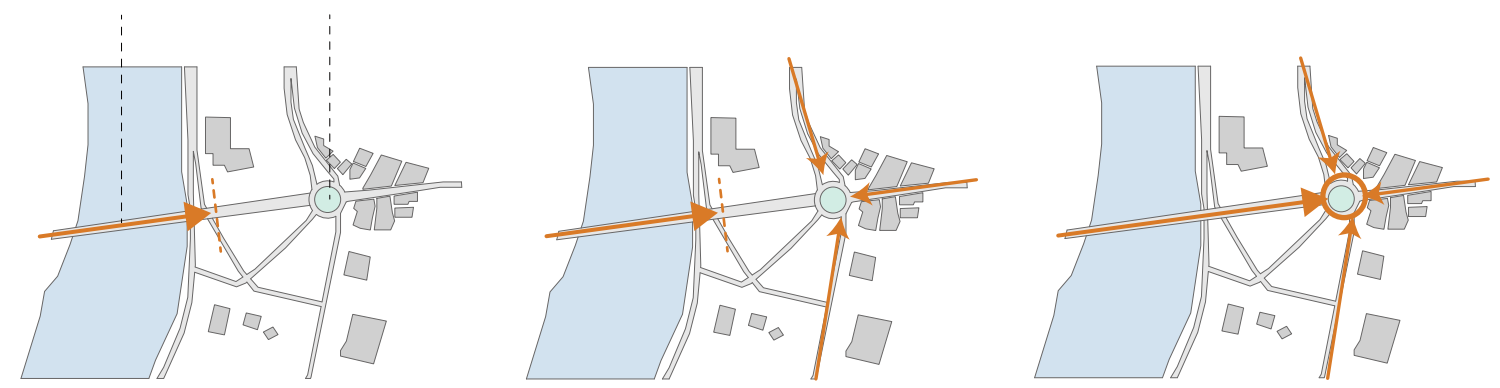

Figure 2.07: Main protestor line being met with a police blockagde, overcome with support from other advancing lines 


\section{Occupy Wall Street}

Who: The Occupy Movement started from a tactical briefing created and distributed by Kalle Lasn and Micah White, and the owner and editor respectively at the activist magazine Adbusters.

What: The one demand was "to get money out of politics", but the movement completely embodied radical democracy and was therefore leaderless.

Where: Washington, D.C., U.S.A., but quickly spread globally.

When: Began September 17, 2011 and is on-going.

Catalytic Event: The Arab Spring events in combination with recent US Supreme Court's Citizens United Ruling (2010) that granted corporations and labour unions the right to spend unlimited amounts of money influencing elections (White, 2016, pp. 16).

Programmatic Components: First organized occupation in North America, demonstration, debates, speeches, dance classes, libraries, cookouts and many other activities.

Spatial Components: Zuccotti Park September 17, 2011 until November 15, 2011 was the main and first hub, but hundreds of other sites popped around the world with the label Occupy.

Result: The mass participation and wildfire-like spread was both a curse and a blessing. The one demand was not achieved, but the movement was "a constructive failure" (White, 2016, 26) that trained new activists and gave hope, sparked many sustained local projects, and other cultural influences. 


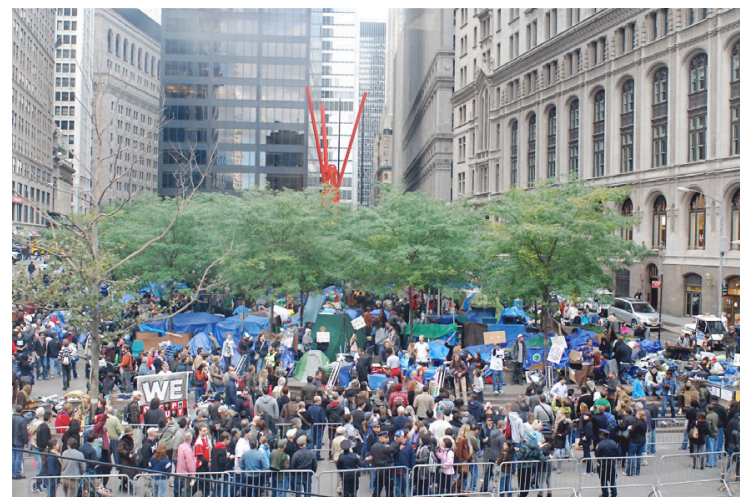

Figure 2.08: Zuccotti Park during occupation.

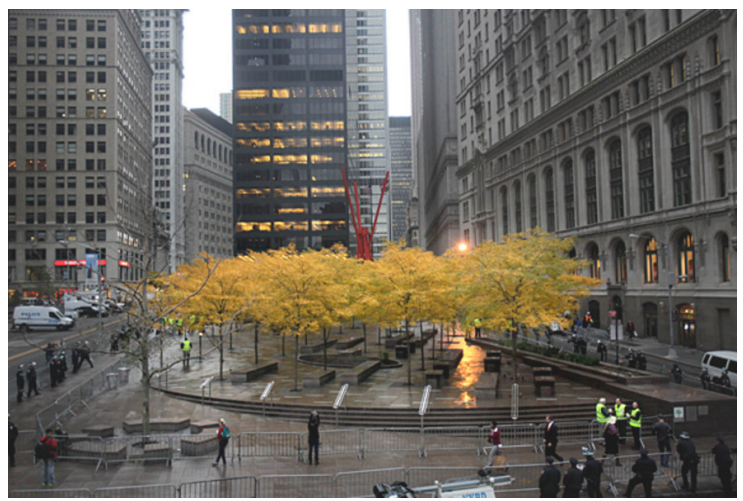

Figure 2.09: Zuccotti Park post occupation.
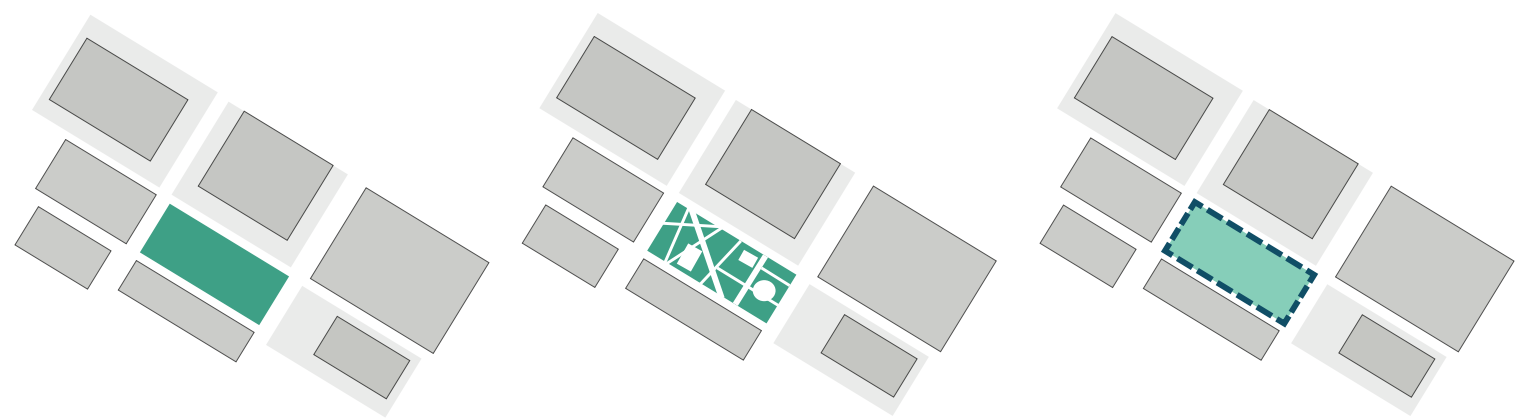

Figure 2.10: Zuccotti Park began as an open square surrounded by giant skyscrapers. Protestors occupied and reorganized the space as their own. After police broke up the camp the space became heavily guarded and dictated for both access and use. 
(Opposite) Figure 2.11: Social movements as democratic practices.
We can see how civics are practiced in real time through democratic or politicallyoriented social movements. We can also see the important role of space in shaping the foundation, the duration, and possible success or failure of these movements. Contemporary social movements have the advantage of online networks that provide valuable connections and methods of demonstrating, but the resultant actions take place in the physical sphere.

The spatial components of these social movements hugely influence many factors about the way democracy is practiced:

- number of citizens/size of group participating and varying levels of accessibility

- $\quad$ potential for security measures taken both by participants of the movement and those in opposition

- availability of press and media coverage, as well as physical observations by non-participants in the vicinity

These and many other considerations can be crucial to the success of a social movement.

In the three examples discussed above, the spatial components were not explicitly designed for the uses; citizens hijacked these areas of the public realm for their civic activities. This can create an atmosphere of illegitimacy that inevitably upholds the status quo of the political scene, which results in a massive handicap for many democratic social movements.

What kind of space can be provided that is dedicated to these types of contemporary democratic practices that is not bound by issues of ownership or "correct" intended usage? 

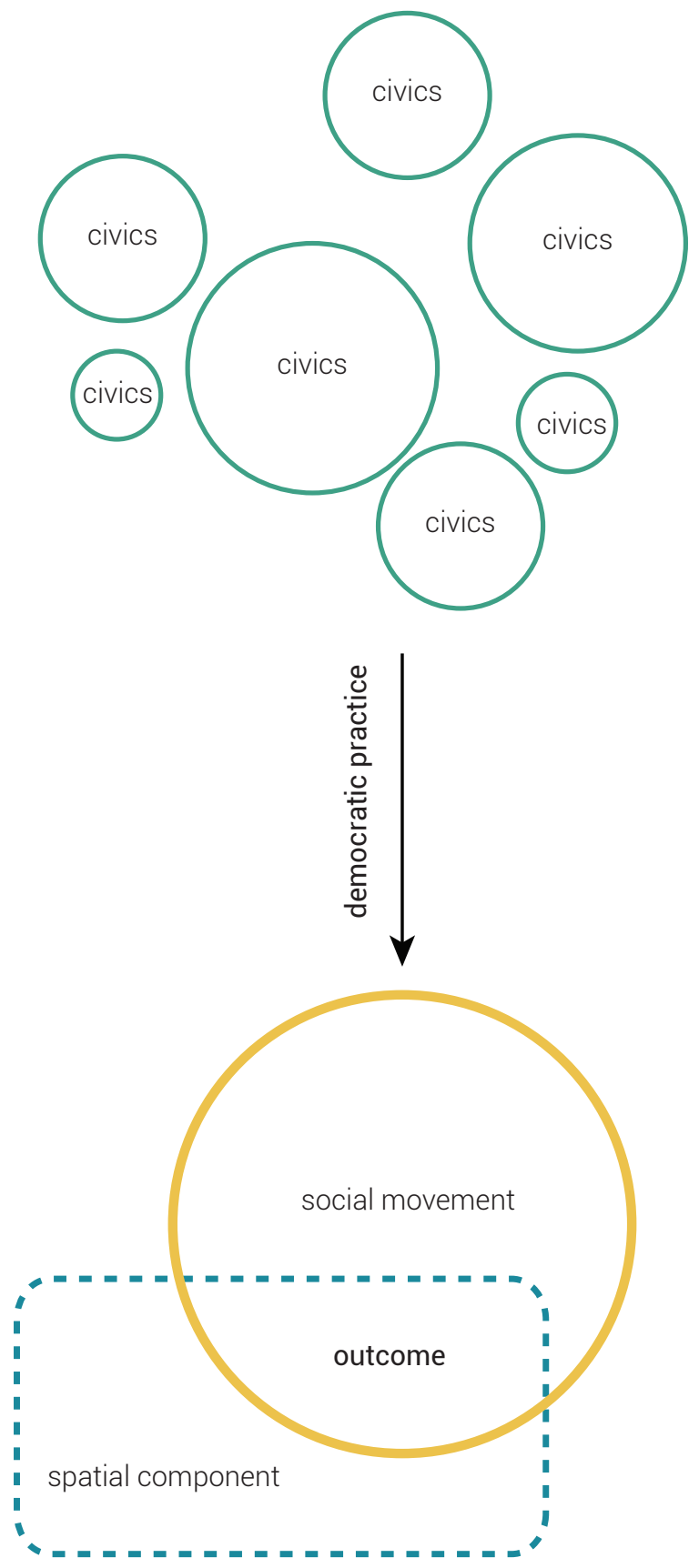


\subsection{Designing and Building Civic Space}

Many of the spaces that take on the intentional quality of civic-ness were not built specifically for that purpose; they were places of public congregation re-purposed for a certain directive.

Although public-turned-civic sometimes can be an attractive option, it is the space that is civically-oriented from its inception to completion that offers the best chance for a social movement's success-. What are the factors that go into designing such a space? What are the kinds of complications and influences on the design and construction of these spaces that are different from a typical public space?

Just like with any other architectural design project, an entire process of ideacreating, decision-making, and partnership-forming occurs prior to hiring an architect or designer for a project. This prior process typically encompasses and defines the entire "problem" (designated site, available resources, and intended program) with the architect being brought on to create and implement the "solution".

As disciplines and industries continue to splinter off into more niche-focused sectors, as seen especially in the architectural profession as a result of its broad mix of art and engineering, there is room to move beyond the conventional roles and relationships of client and architect into ones that approach the nuances and subtleties of design differently. This is becoming an increasingly common practice, with specialized and individualized approaches to project design that value a continual back and forth typological and programmatic development.

This slow replacing of conventional segregated or usage- or patronnagebased structures and spaces is especially advantageous when it comes to civic spaces, which often host contentious or non-normative activities. The inputoutput relationship of client to architect starts to blend together into a balanced partnership. This occurs in significantly different ways when this client or building partner is a corporation, a community, or a government agency.

\subsubsection{Corporatocracy}

First and foremost, a project requires a client, and is shaped by their needs and wants. In all architectural projects across the spectrum the profession is experiencing shifts away from traditional client-program relationships. When it comes to civic projects, the most notable shift is that from a government client with government-backed funding, to a corporate client. It is essential to understand the structure and nature of corporations that are looking to get involved with building or urban issues. There are divisions of corporatocracy that tend more towards getting involved in architecture and design. 
Corporations who wish to build spectacular architecture for profit or for their own programmatic uses is not a new phenomenon. However, it is becoming increasingly common for corporations to lead design projects focused on public or institutional space, which has major implications for the sub-category of civic space.

Gaining a baseline understanding of the corporate entity in question is the first step in analyzing its architectural motives. Interestingly enough, many precedents for corporate-led public construction come from technology or digitally-oriented companies. This industry has been extremely profitable and connected to the general importance of society's future, so it stands to reason that getting involved physically in the public realm is a natural next step. As Moore points out, "tech giants are now in the same position as great powers in the past - whereby, whether they want to or not, their size and wealth find expression in spectacular architecture" (Moore, 2017).

An extremely pertinent example of this type of corporate-dominated development is the Quayside neighbourhood project in Toronto, largely funded and led by Sidewalk Toronto, a partnership between Waterfront Toronto and Sidewalk Labs in New York. Waterfront Toronto is a tri-level quasi-government agency tasked with the remediation and development of Toronto's waterfront. Their largest and current project is the Eastern Portlands site at the end of Parliament Spit. Waterfront Toronto has named the planned development for this site Quayside, and intends to master plan an initial community of 12 hectares, with potential to spill into the surrounding lands. This task is a massive undertaking, one that requires private investment. It also serves as an incredible and unique opportunity to build a neighbourhood from the ground up, as there is currently no program on the site. The city working with Waterfront Toronto has the chance to employ new ideas and techniques for city building that could help solve some of the growing problems faced by Toronto and most other major cities in the world, such as lack of affordable housing, contribution to greenhouse gases, and gridlock.

Enter Sidewalk Labs, a sister company of Google and owned by Alphabet Inc., Sidewalk has been running since 2016 and has functioned as a think tank revolving around urban issues. Before this project, the think tank primarily has studied preliminary global "smart cities", the intersection of data and urban planning, and material innovation; all with the goal of creating a new baseline for contemporary city-building. The development of Quayside popped up as a perfect testing bed for all of this work, and Sidewalk Labs bid on Waterfront Toronto's RFP, was awarded the project in October 2017, and is the first design undertaken by the agency. Both organizations have come together to form the official group of Sidewalk Toronto.

The main theme and ultimate aim of Sidewalk Toronto in developing Quayside is to build a smart city: "As the innovation and funding partner for Quayside, Sidewalk Labs, an Alphabet subsidiary and sibling company to Google, will accelerate these plans for inclusive growth by merging the physical and digital realms, creating 

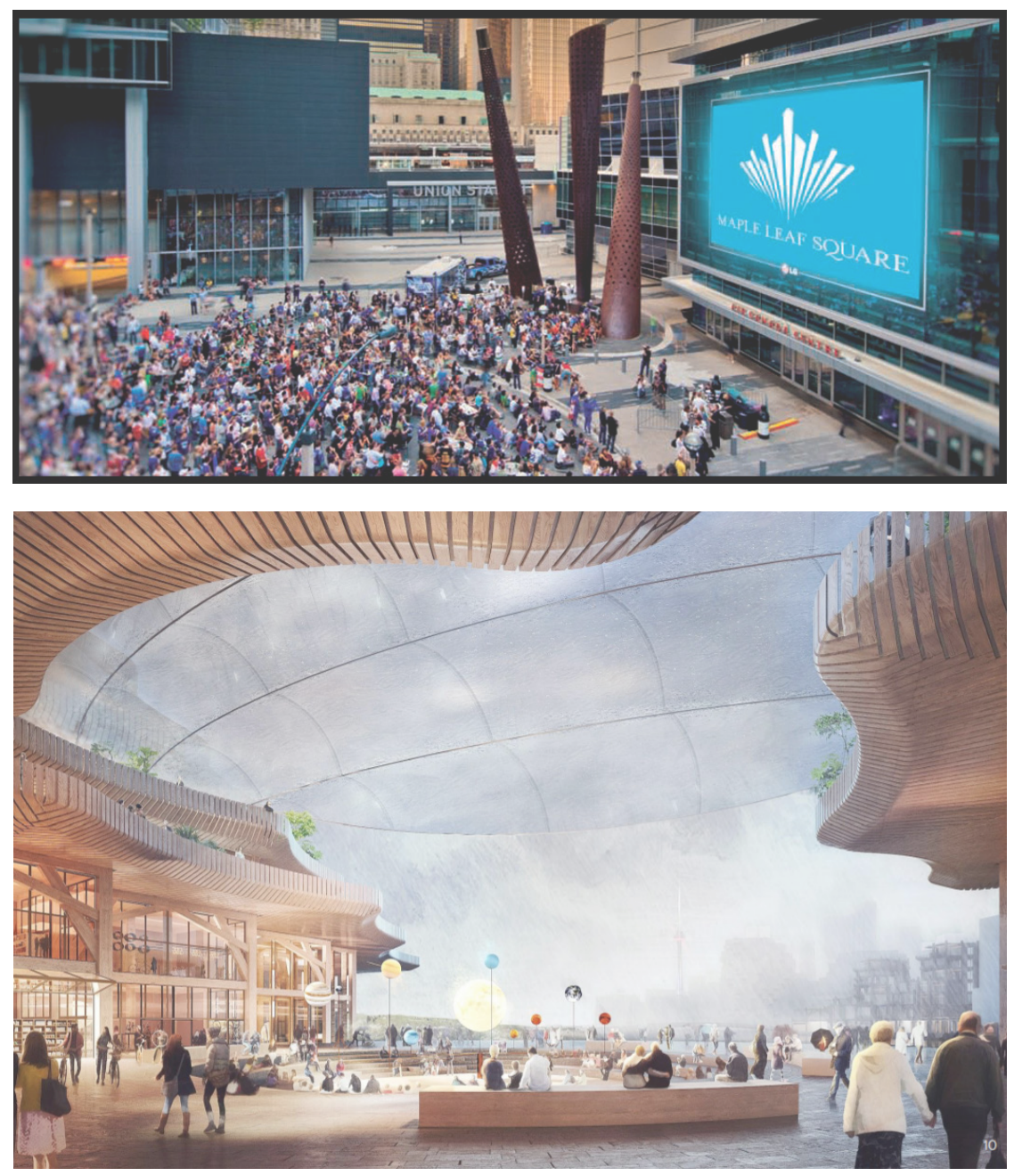

(Top) Figure 2.12: Maple Leaf Square.

(Bottom) Figure 2.13: Schematic rendering of a common public space in Quayside.

a blueprint for the 21st-century urban neighbourhood" (Sidewalk, 2017). In the years between being awarded the project and the unvieling of their initial master design and schematic plan, Sidewalk Toronto has focused on a large number of community engagement models, with the purpose of comparing that feedback to their own research to develop a number of starting principles for creating Quayside. A lot of this research has been focused towards a main goal of the project being improving the 'public realm', in which civic space particularly is highlighted with the rhetoric of the project vision. Sidewalk Toronto has published all of their own materials as well as feedback from various community engagement meetings. In reviewing all of these documents, discussion on the commons, public realm, and civic space come up often, starting in their initial project vision dated October 17th, 2017:

- The neighbourhood will be a bustling digital and civic workshop open to all, and its streets will be filled with exploration. (pg. 14)

- A close-knit community that uses data to improve city services. Social cohesion and civic engagement are an ongoing challenge in growing cities, but new data and digital tools can be put to work for a stronger community (pg. 19-20).

- Communities seek a greater level of control over their environment, with more 


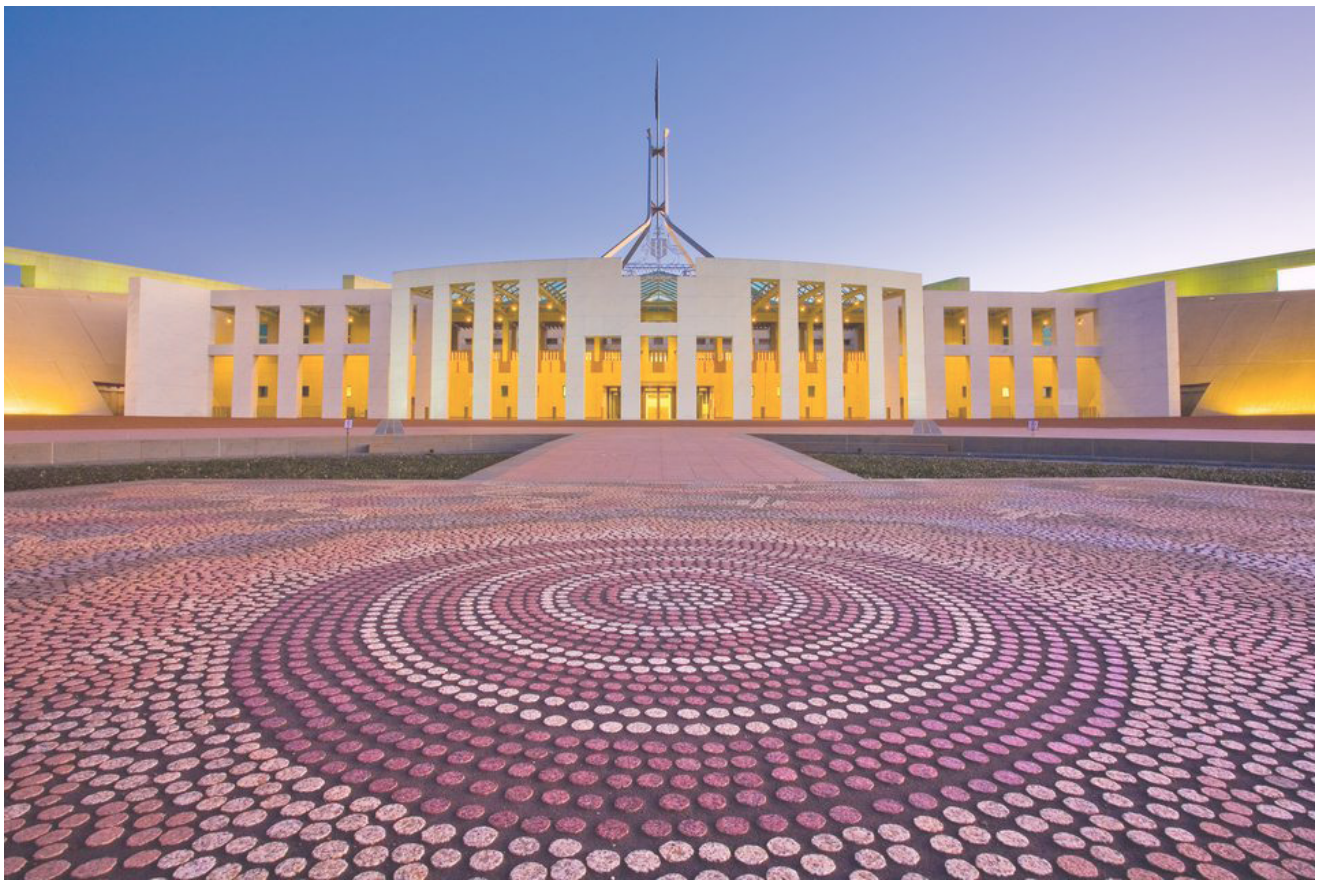

Figure 2.14: Possum and Wallaby Dreaming by Michael Jagamara Nelson. say over how the city is designed and managed, better access to information, and the ability to draw on their diversity to self-organize and plan cultural and civic activities (pg. 26).

- $\quad$ Civic engagement. Sidewalk's feasibility study estimated that residents in a large-scale district comparable to the Eastern Waterfront would show increased rates of volunteering and neighbourhood engagement compared with the surrounding metro area (pg. 33).

Two years later, the first draft of the master plan was released by Sidewalk Toronto in June 2019. Unlike its previous working iterations and stated goals, there is no separate section based on ideas of civic engagement or citizen-oriented culture. The terms "participation" and "engagement" are used primarily when discussing the physicality of the built public realm, with little indication of civic programmatic 


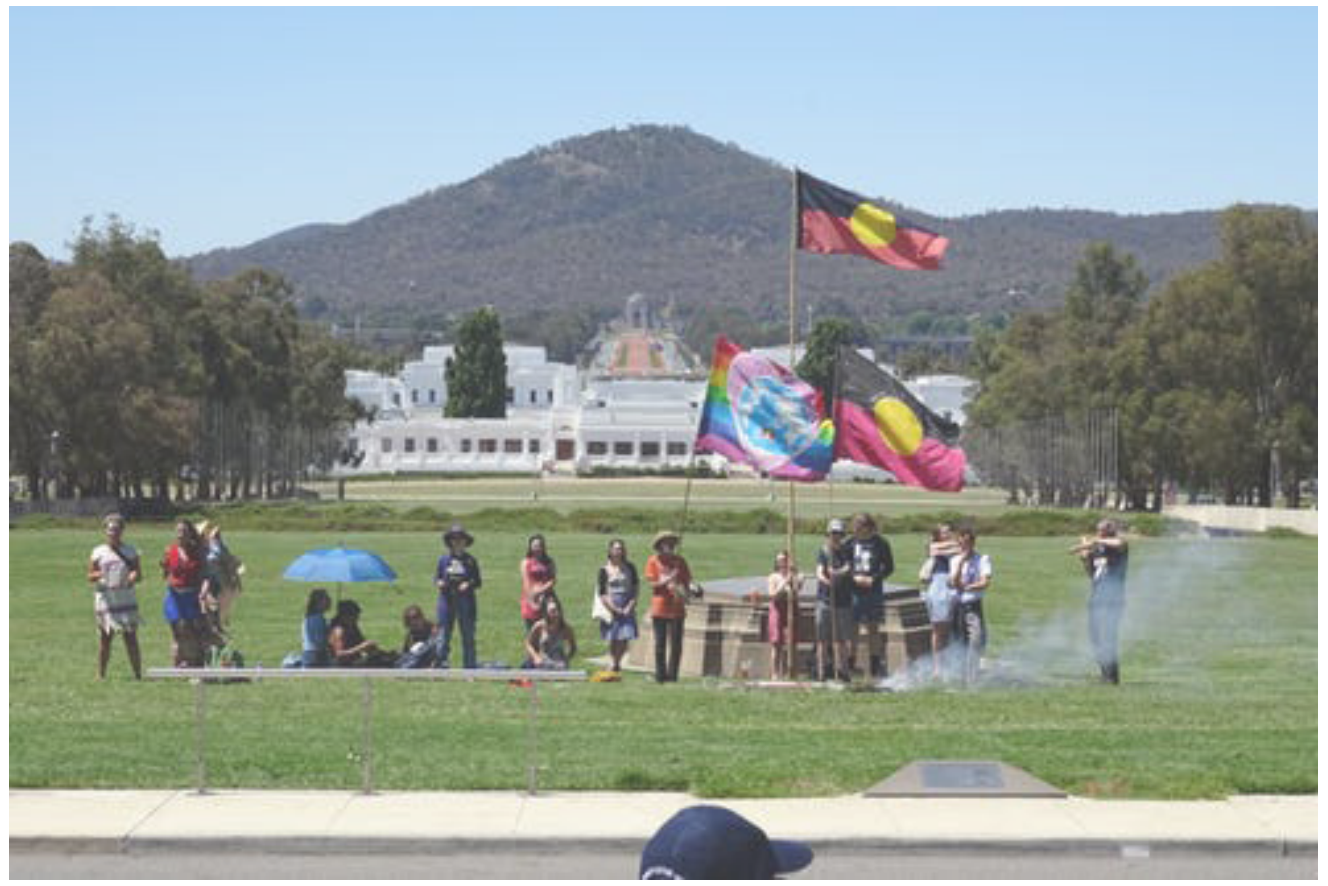

uses within that space (Sidewalk, 2019, pp. 192-198).

Figure 2.15: Protestors in front of Old Parliament. Regulations

Of course this is not the first of privately built public space in Toronto; Maple Leaf Square beside the Air Canada Centre was built and developed by the private company Maple Leaf Sports Entertainment. However, the intent with this public space is to blatantly showcase the interests of the builder and owner - there is the very real separation of the protest from the government building in question. a giant screen showing the games inside so that more citizens can participate in the event. This is not necessarily a negative attribute or detriment to a healthy urban fabric; this particular space has been a favourite of many citizens. However when considering civic space that could be politicized, it is important to note how the construction agenda by a corporation could be different than a traditional government-led model.

\subsubsection{Community}




\subsection{Toronto's Programmatic Civic Context}

In 2018, the city of Toronto saw a massive and swift change within its government structure. The provincial government imposed a new 25-ward structure onto the City of Toronto, striking down the proposed 47 -ward structure that was to be implemented with new councillors elected during October 2018 after years of study. One of the most troublesome consequences of this decision is the increase in ratio of one councillor to their constituents. What has always been an issue of accessibility for citizens to their local representatives has morphed into an even more mountainous challenge for councillors.
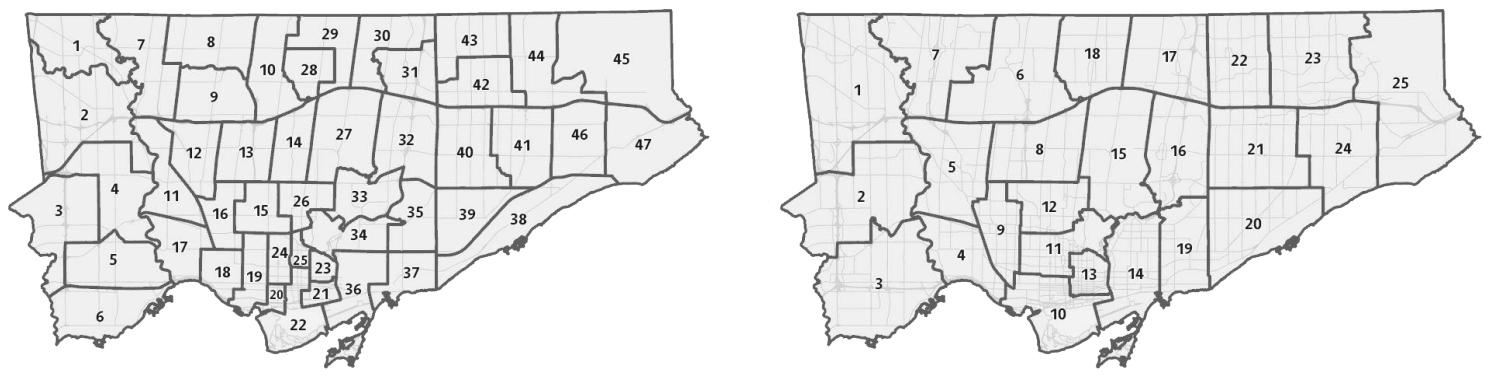

Figure 2.16: Toronto's planned 47-ward structure and the implemented 25-ward structure.
After taking one of the most basic civic actions of voting, citizens go back to their daily business, which for most has minimal conscious interaction with the municipal government. Unlike at higher levels or in the stories we hear from other countries, municipal government is least connected with politik and substantially concerned with the grinding tasks of keeping a city running. At a municipal level, Toronto politicians have no official party affiliations and are only rarely described with lower-case adjectives like liberal or conservative.

For citizens who wish to get more involved in civic issues, there are avenues available, such as open committee meetings at city hall, non-government-related policy initiative or community groups, or good old fashioned demonstrations. However, navigating these can be challenging, and many prefer to seek out the direct involvement of their respective city councillor, and responding to such solicitations is a job that Toronto councillors have always taken seriously. With the drastic council reduction, that becomes significantly more difficult.

The space in which these interactions take place also highly affects the nature and results of these encounters. City councillors all reside during their working hours at Toronto City Hall, arguably the most "civic" building in the city. This has the clear advantage of their proximity to one another and to the other city employees, but has the heavy disadvantage of being far from most of their constituents, a problem that will only get worse with the new 25-ward structure. As Fran Tonkiss explains, "Politics, like other social relations, unfolds in space. To think about politics and 
power is nearly always to invoke a set of spatial relations: from the surface of the body to the distribution of property, the spatial order of the senate chamber or the 'theatre' of war. There are real spaces which are also diagrams of social power" (Tonkiss, 2005, pp. 59-60). Urban strata both provides and influences the actions and options of those who want to create change or alter power structures within the city. Whether the task is intangible, such as starting a neighbourhood group, or very much physical, such as inhabiting a public place in protest, there are spatial requirements for each.

Such a drastic change to municipal government imposed by levels above, with little to no recourse for a metropolis as economically and culturally significant as Toronto, highlights the alarmingly low level of autonomy belonging to the city's council. This problem is twofold: broad visions for the city are difficult to design, much less act upon, as they take up much time and effort and do not yield immediately measurable results for councillors. On the other hand, those smaller, neighbourhood-centric concerns of constituent will continue to increase as Toronto's population continues to expand. A possible alternative for this situation is the creation of neighbourhood councils within Toronto.

Los Angeles in California, America, serves as an excellent precedent for this type of system. It places much more emphasis on participation from the citizens, and the division of its enormous county into many smaller constituencies. The city of Los Angeles is able to do this through the Department of Neighbourhood Empowerment, which employs government workers to train and oversee civilians in their own organizational practices.

The application of such a system in Toronto would be beneficial, both in terms of easing pressures on the municipal council so that productivity is not so beholden to such a small group, and equally important would be the recognition of the role citizens are playing in their own government. However, such a system requires designated space that is not readily available within Toronto. This then becomes the intersection of two needs: a consensual notion of civics, and a physically understood civic space.

However, in the interim before such a system could be dreamt up and implemented, providing space that existing organizations can properly flourish is essential. Toronto has many grassroots and larger organizations to serve the purpose of representing those whose voices may not be loud enough on their own. There are several organizations that function as representatives for people or social or environmental issues, with varying levels of government involvement or structure.

Taking Ward 10 Trinity-Spadina as a case study of these types of programs shows a snapshot of Toronto's complex civic layering. It is one of the fastest growing areas of the city with a mix of residential, commercial, institutional, and public spaces. 
Figure 2.17: Toronto's 25 wards with ward 10 highlighted.

\section{Structure Type A - Councillor}

The most direct path to municipal government in Toronto is through one of the 25 councillors. As in most democratically-principled municipal governments, it is the responsibility of the constituents to be organized and engaged in communicating their needs and views. The councillor's job is to represent the "best interests" of his or her constituents, while balancing all the typical politics of the office and job.

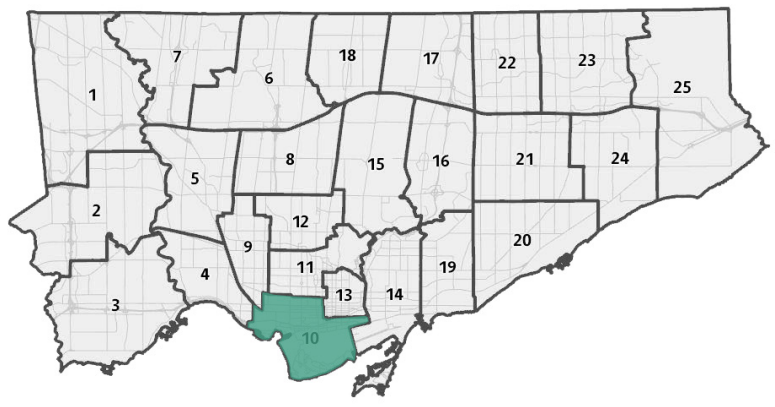

\section{Structure Type B - Community Councils}

Toronto also has four community councils that collect wards within each of the old city boundaries prior to the 1997 amalgamation. It functions similar to the larger city council but obviously with a smaller focus, making it easier for citizens to highlight and discuss their local issues with politicians who are more actively engaged in the area. In a city like Toronto, where geographic wards have a huge range of variance in literally every societal level, these smaller councils are very important. With the imposition of a much smaller ward structure, these councils are now about half the size they used to be.

\section{Structure Type C - Business Improvement Association}

The entire city is divided up into Business Improvement Associations, which are meant to forge relationships between the municipal government, private business, and the general citizenry and tourism industry participating in the consumption of these goods and services. Councillors act as middlemen between the churning municipal government and the interests of business owners. This organization 
begins to prioritize the needs of the private over the public.

Structure Type D - Residential Association

Toronto also hosts a large number of residential associations with no government membership or involvement. The purpose of these groups is primarily to solve issues internally, from problems as fussy as residents keeping clean balconies and walkways, to larger issues such as fighting against exorbitant city authorized rent increases. These organizations are entirely composed of residents volunteering their own time, but are mostly concerned with issues in their direct social and physical sphere, and not with much beyond. They also are able to represent large portions of the constituency to their corresponding city councillor, but there is no formal path for this.

\section{Structure Type E - Activism}

Toronto has been a city receptive to and involved into political activism, with many different varieties and manifestations of activist organizations. The structures of these groups are extremely loose and flexible, relying on very little physical infrastructure and altering its priorities depending on what is considered the most dire issue of the time by the members, volunteers, and activists at the time. Their involvement with government is constantly shifting and usually conflict-driven; interaction with councillors or other politicians comes after consistent onslaughts of protest rather than regularly scheduled meetings in expansive boardrooms. Most importantly, the number of people involved is constantly shifting and reaches beyond the confines of a single ward, unlike the four previous structures. 
A

City Council

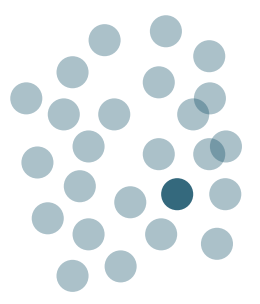

Joe Cressy

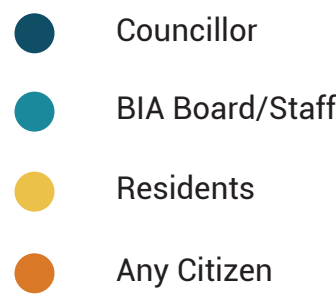

Community Council

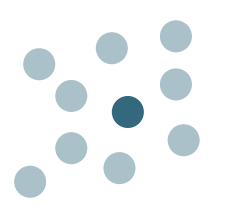

C

Business Improvement Association

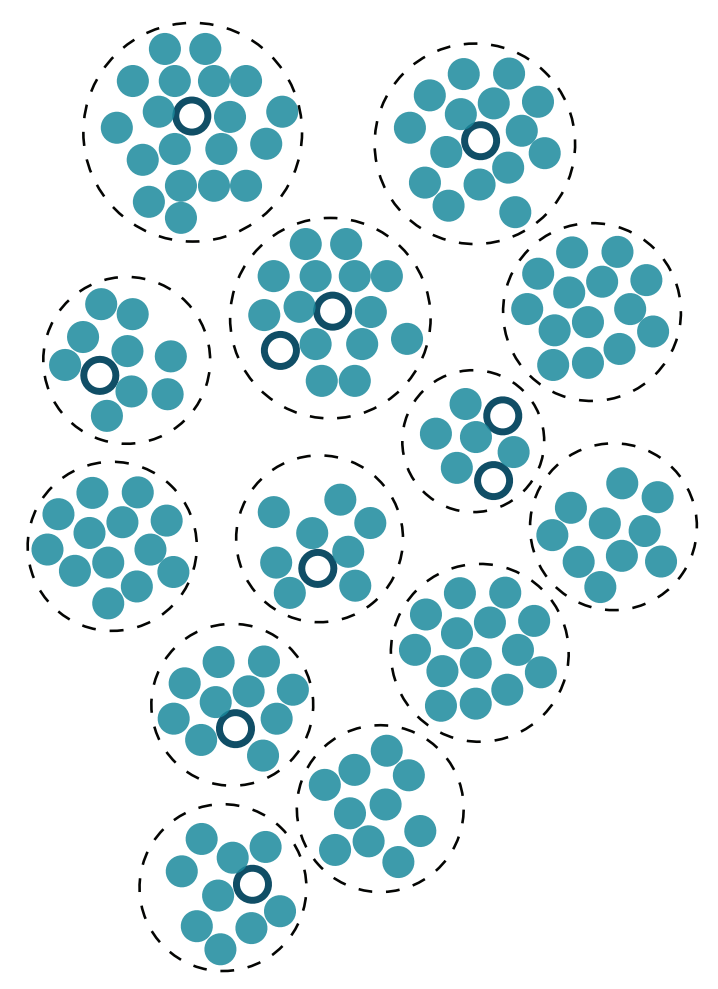

Chinatown BIA

CityPlace and Fort York

Financial District BIA

Liberty Village BIA

Little Portugal BIA

Ossington Avenue

Parkdale Village BIA

Queen Street West BIA

St. Lawrence Market Neighbourhood BIA

The Waterfront BIA

Toronto Entertainment District BIA

Trinity Bellwoods BIA

West Queen West BIA 
D

Residents' Association

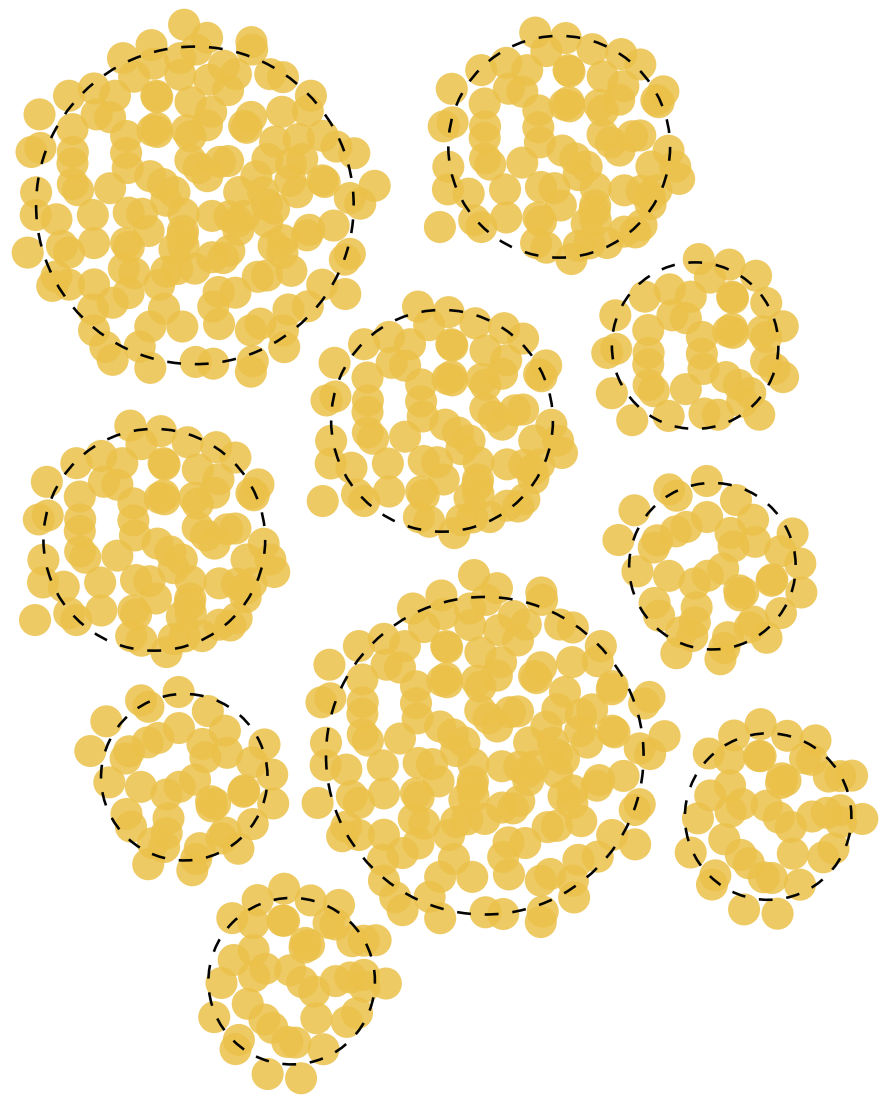

Ossington Community Association Liberty Village Residents' Association

Garment District Neighbourhood Association Grange Community Association Fort York Neighbourhood Association Bathurst Quay Neighbourhood Association

York Quay Neighbourhood Association CityPlace Residents' Association

Toronto Entertainment District Residents' Association Southcore Community Association
E

Activism

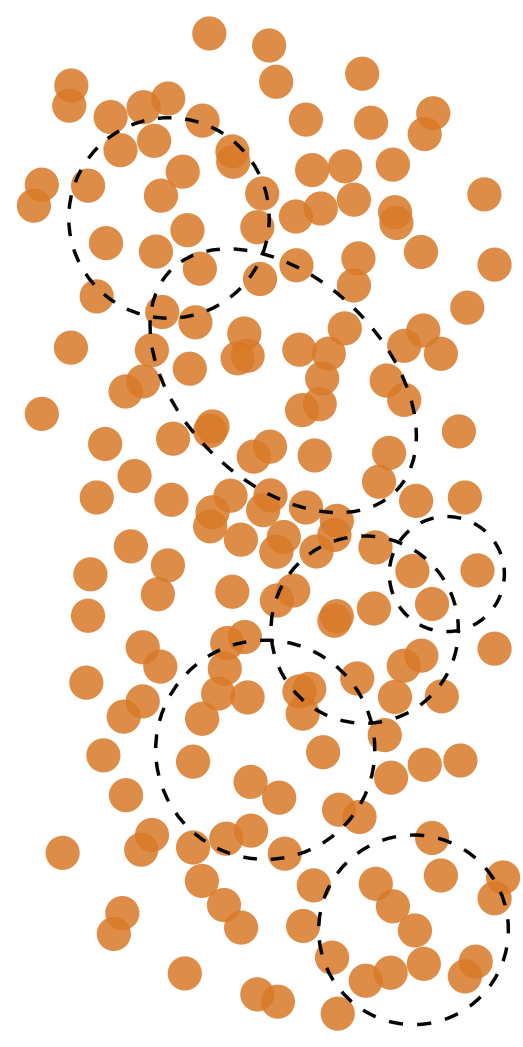

ANY / ALL 


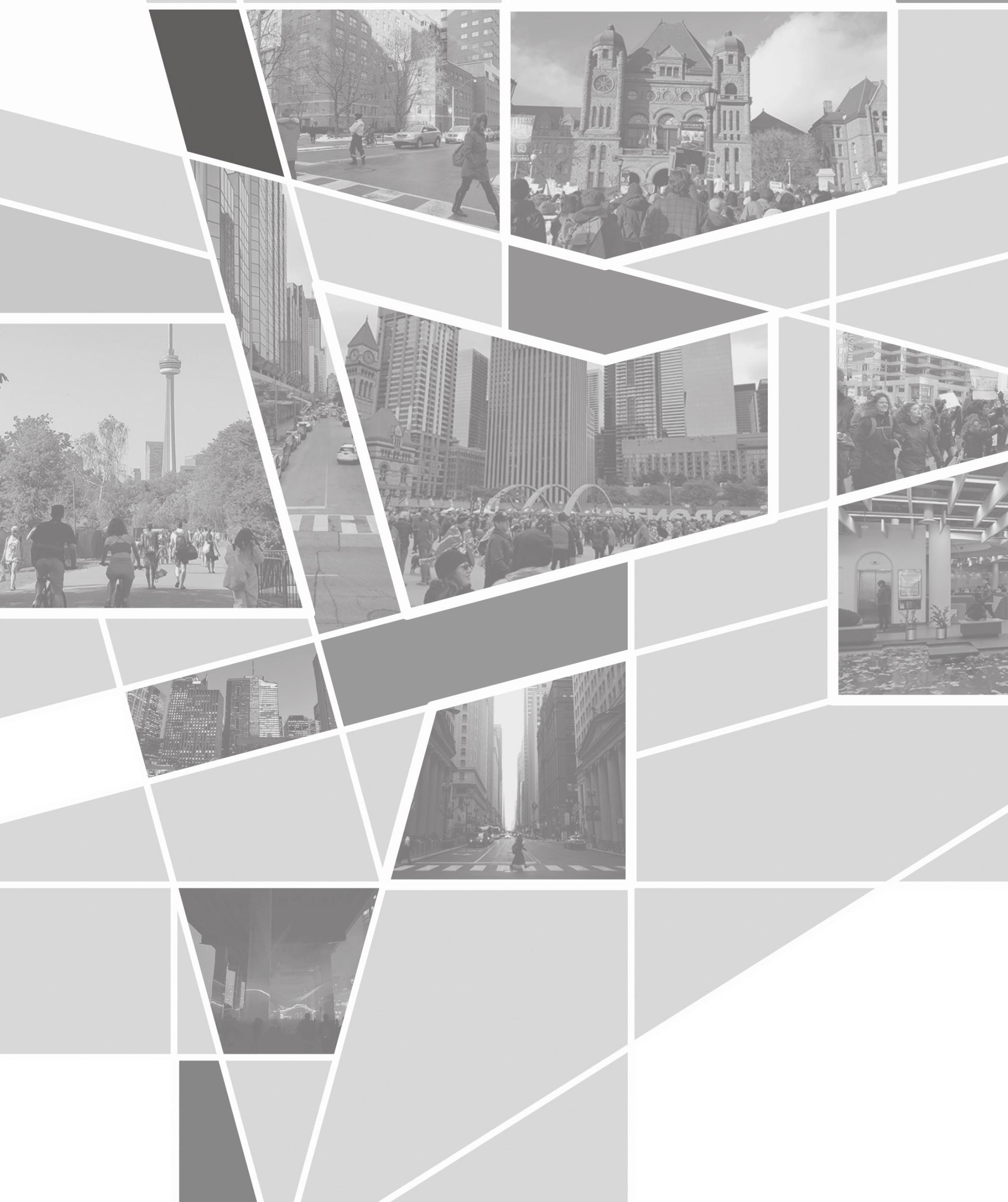



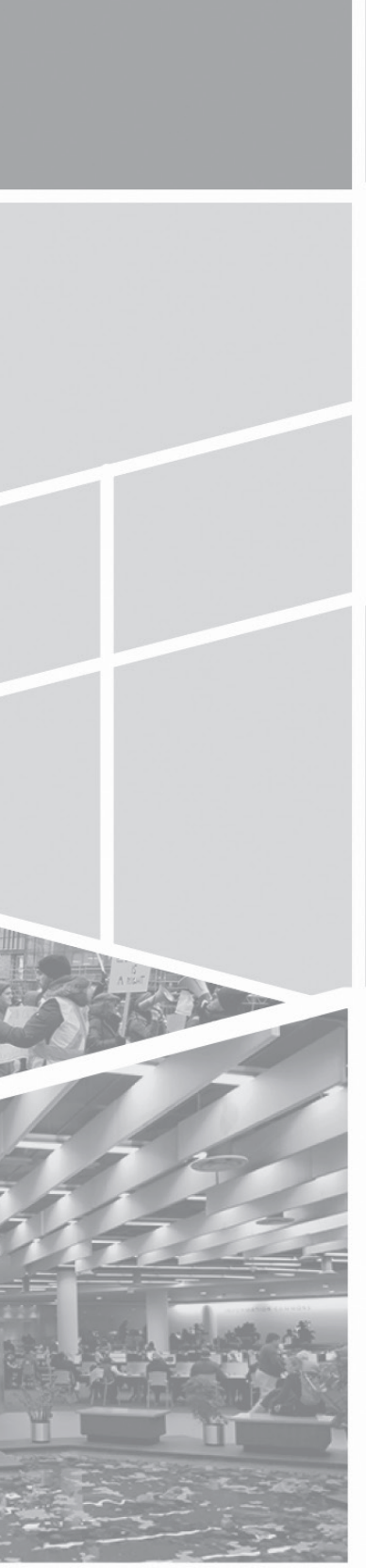

\subsection{Theories}

How does program and space begin to facilitate or restrict contemporary democratic processes? How are local and participatory methods of engaging in citizenship encouraged or prohibited because of different programmatic or spatial functions or conditions? Mostly, what is needed to make a civic space successful? 


\subsection{Contemporary Approaches}

Moving from a general discussion of protest or demonstration culture into specific examples provides a baseline for analyzing those cultural movements in connection to their physical spaces. How were the events shaped by the spaces in which they took place? This relationship cannot be understated in its importance. Demonstration sites are often chosen for the significance of their location, be it in a crowded city centre or in front of a government building, and these elements within these sites, the boundaries or circulation and countless other factors, heavily influence the action that can take place within and thus the outcomes or consequences of the action.

Additionally, for the projects and associations studied that were not a result of protest culture, there is a strong parallel of reliance on available space. The collectives of architects, community members, and government officials were forced to adapt their own methods and goals into existing spatial conditions if they did not have the opportunity to create their own. These available spaces heavily influence the projects themselves. Studying these spaces begins to lay the foundation of understanding the necessary spatial qualities, both tangible and intangible, that work towards the goal of a more balanced approach to municipal governance that includes local participatory democracy.

Analyzing social movements and other influences of civic space in tandem with the foundational concepts of citizenship leaves some gaps in our contemporary understanding of civic issues. It is necessary to investigate the tangible and intangible to uncover conditions that declare space appropriate as a foundation for citizen engagement, participation, or action, thus deeming the space "civic". This can be done with a study into the contemporary critiques of a multidisciplinary spectrum of authors who write on urban, political, and civic issues from architectural perspectives and beyond. 

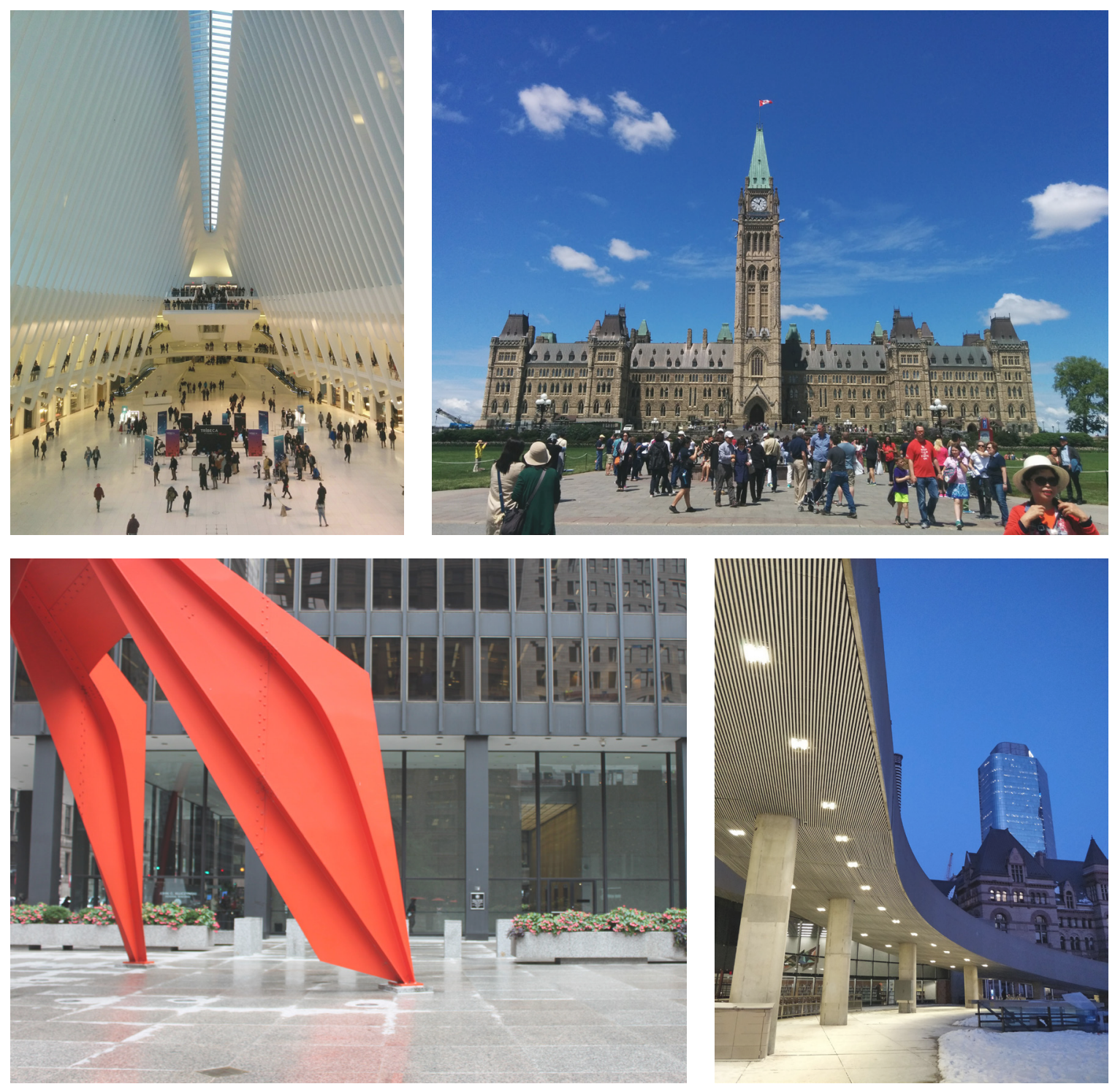

Figures 3.01a,b,c,d: How to

differentiate public spaces that

are "civic"? 
Figure 3.02: Public space and power.
Dell Upton has researched and written extensively on how the structure of citybuilding in the American antebellum years still affects how we build today, in terms of public and private power structures. He notes that "the street setting was critical to the interpretation of these rituals, for it supplied two fictions on which they were based. The first was that as a 'public' space the street was a neutral zone, which implied that any ritual that took place there was an image of a unified citizenry and its values, and that marchers and watchers were two parts of a single whole" (Upton, 2008, pp. 313). The tension between those two groups of marchers and watchers may be belied by their co-existence on a neutral plane, but it is the very existence of a space that allows users to both see and be seen that creates the opportunity for conflict, sometimes necessary and sometimes not.

The symbiotic relationship of seeing and being seen occurs very differently in a typically public setting versus a typically private one; the former both allows and forces citizens to participate, whereas action taken place within the private realm, or even a private section of the public realm, has much less influence or possibility for pressure on a local government body.

In an attempt to quantify the complex role of the public realm in an also increasingly digital world, Kurt Iveson distinguishes two approaches for discussing public spaces: topographical and procedural (Iveson, 2007, pp. 7). The former is primarily concerned with the vernacular understanding of physical public spaces, and the

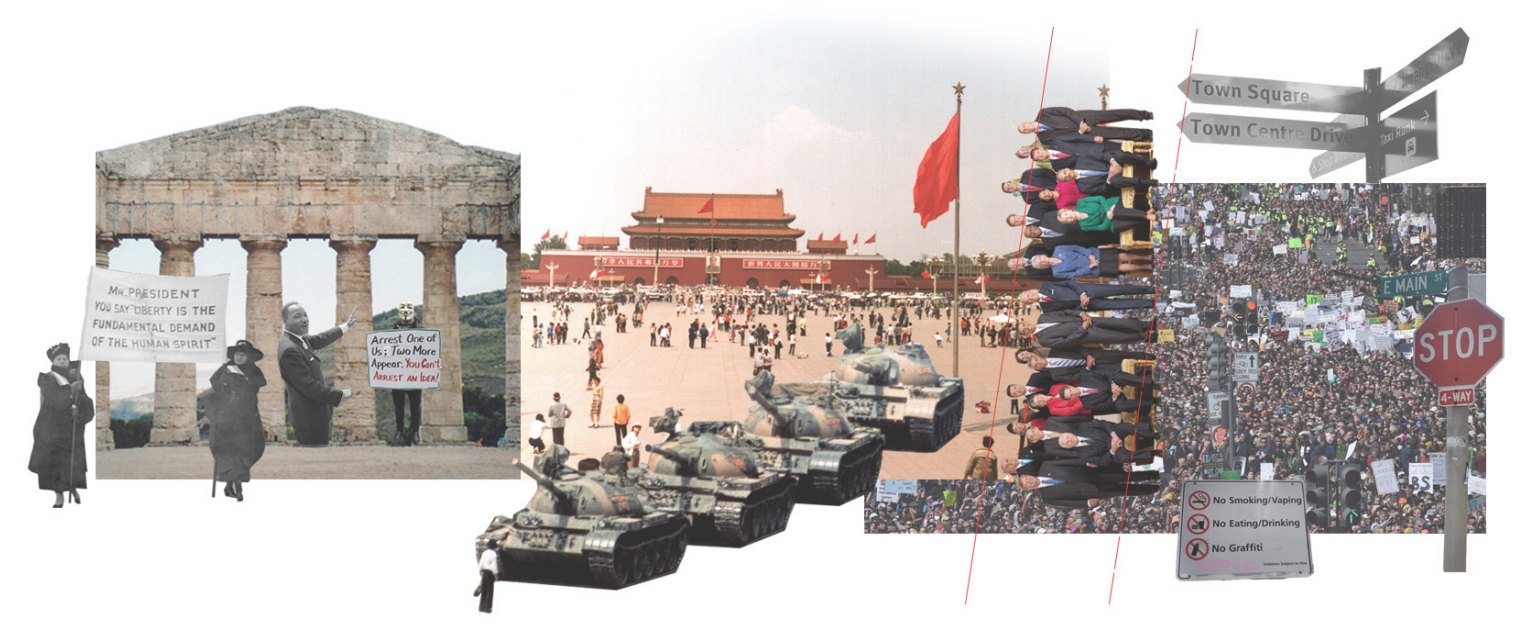


various ways in these are both stations for an object of public address. The latter concerns the idea that any space can become 'public' and be considered as such through its interpretation by the collective as to be containing or enabling a political action.

Iveson is fascinated by the way in which procedurally-categorized public spaces allow citizens the opportunity to both address and be exposed to any manner of media or information that is not limited to our conventional conception of a singular public space: "topographical approaches miss the messy and dynamic urban geographies of publicness" (Iveson, 2007, pp. 8). The link between power, and the ability to access, and move through, around, within public spaces, then expands as a giant network over an entire city. Citizens have the opportunity of experiencing the public space or event secondhand, be it externally in the public city, or internally in a private bedroom with a computer hooked up to the internet.

Manuel Castells has written extensively from an economic and sociological background about the relationship between power structure and social organizing, and how that is manifested within and influenced by physical space. In the City and the Grassroots, he succinctly notes "the fifth element that results from our historical investigation [of social movements] is the importance of space as a material basis for all forms of social organization" (Castells, 1983, pp 69). His trailblazing documentations and analyses of social movements emphasize the city and urban settings as a background, which is integral to the proliferation of movements that strive to affect power dynamics within municipal governments.

The role of the city as a uniquely significant but importantly devoid of ostentatiousness is essential in Pier Vittorio Aureli's work, The Possibility of an Absolute Architecture. Aureli champions the moving away of top-down approaches to the administration of a city and its built stock, asserting the position that continual and fullness of citizen involvement affords the best possibility for a once-again functioning polis. The rapid shift into an economically-focused urban core, rather than a politically-focused one (political here indicating the governance of and choice of those within a community) has resulted in a push of "political issues" into private spaces from public ones. Rather than despairing at the alternate patterns of spatial usage occuring that are indicating a current decline in traditional, normative venues of public address, Aureli asserts that designers can and should take advantage of this phenomenon of decentralization in the form of connected archipelagos. The schema produces an intervention in the form of a group of islands within a sea of architecture, with these islands being connected by a non-hierarchical structure rather than dictated, top-down format.

This type of decentralized design within an urban public realm is best felt by its citizens when they have the freedom to self-organize. Aureli's idea of the archipelago is reminiscent of Herman Hertzberger's theories on structuralism. The production of identical elements forming an archipelago of sorts allows the 
ultimate level of flexible and evolutionary organization that is more readily able to respond to externalities. "Just as a language is subjected through use of something of an evolutionary principle, structuralism is about structures that are not only open to influences from their users but are actually dependent on them. Although that input can change over time, the whole essentially remains the same" (Hertzberger, 2015, pp. 33). Exercised correctly, the collective is not either lost or overwhelming, but balanced and made stronger by all the individual contributions to a subconsciously agreed-upon collective understanding.

"Open structures as understood today are structures open to interaction with the world at large: unlike closed structures, they can influence their surroundings and in turn be influenced by them." (Hertzberger, 2015, pp. 56). It is this quality of prioritization of open-endedness that creates public space in which real civicness can be formulated and properly distinguished as a platform for the shared purposes of citizens, who now have constantly repetitive elements acting as platforms which they can customize but remain within the functional archipelago.

Pushing the concepts of decentralization and self-organization further, Keller Easterling has coined the phrase "infrastructure space" to attempt to examine and classify these in-between spaces with the same level of concreteness and significance as conventional structures (Easterling, 2014, pp.13). Infrastructure space is the reverse of a figure-ground system, with the difference being that system is constantly changing with layers upon layers of subliminal, non-static entities; the dynamism present with the 'ground' far exceed that of the 'figures'. Certainly the study of infrastructure space does not automatically preclude the principles of architectural design; it is here that we can discover how in-between spaces can hold their own as programmable areas in their own right that are just as worthy of destination. These organizational and 'in-between' design considerations become crucial for their capacity to allow the continual change and involvement from many different parties.

The public realm, our definition of and interactions with it, are fully contingent on the people with which we share it. Every citizen in a dense urban city has felt that strange tension between overcrowding and loneliness, surrounded by strangers at any time in public. Navigating through our physical interpretations of the city and what our shared purpose may be, uncovers the ennui of 'civic' pockets within public space.

In her writing, Denise Scott Brown articulately characterizes the complications associated with the phrase 'the public realm'. There is an innate acknowledgement that spaces that are physically 'in public' have in fact different levels of publicness: things like banks, shopping malls, or institutions may have components that are allowed access by certain members of the public, but not all, and this kind of choice-making or discrimination is evident physically in things like doors or other barriers. Conversely, elements of the public can't help but seep into what is 


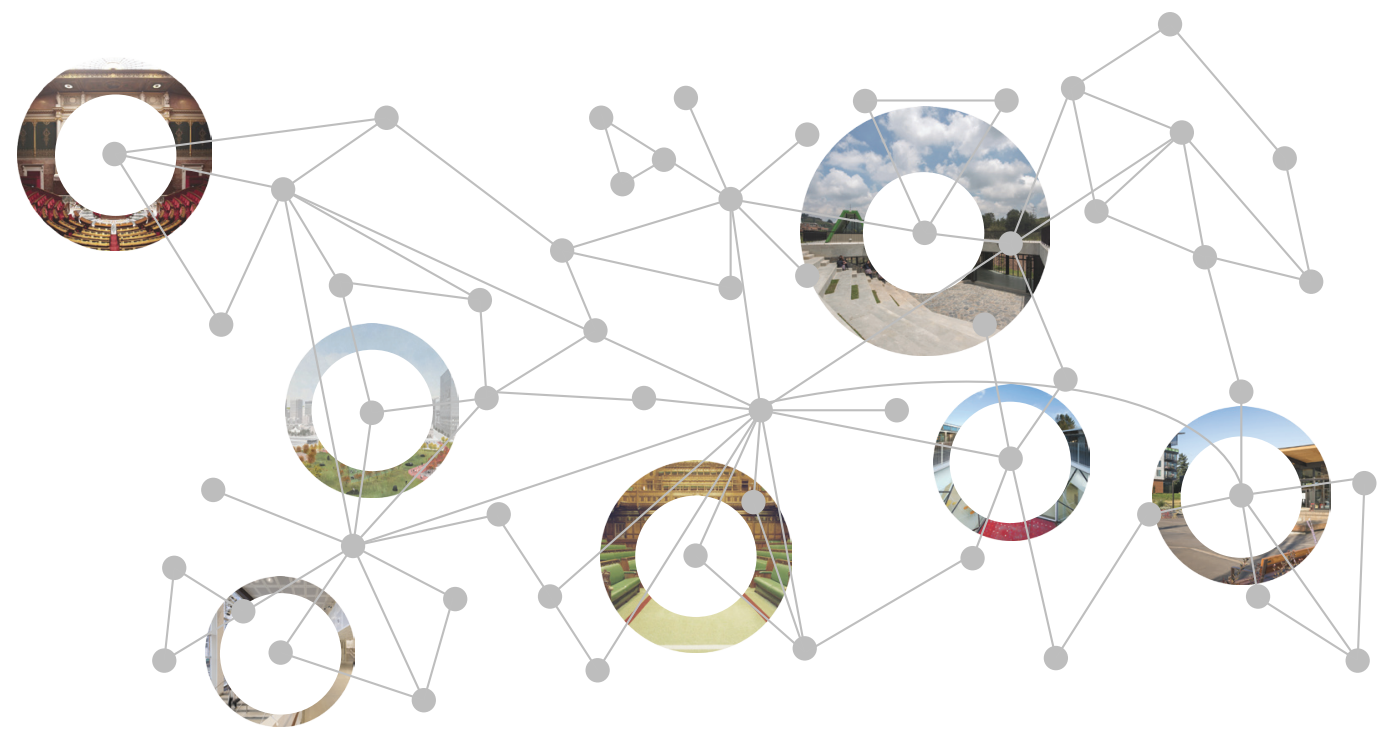

considered the 'private' domain. Things like zoning codes or governmental/state oversight have direct influence on even the most intimate of spaces: "some private or semi-public institutions can be affected with the public interest" (Scott Brown, 1990, pp. 22). decentralized, repeating, and self-organized system of urban archipelagos.

Because our idea of political and public space has grown to include digital realms that are physically manifested in what used to be considered strictly private space; computers or televisions in private living rooms, acting as windows into the publics, have blurred previously hard distinctions. This creates a unique opportunity both for the analysis of spaces not previously understood to be civic, and the implement of new civic spaces; spaces that are not bound by traditional typologies but one that can morph and change to fit the needs of citizens whose access to normative "public" spaces may be limited.

The melting pot of various public and private spaces has direct impacts on the roles of the collective and the individual in a society. Ideas of what are appropriate behaviours in public space that for most of history were defined by a normative majority are slowly changing, and discussions or issues that were once banished from public life and and into the private domain are slowly coming to the forefront. More openness between individuals is able to be manifested in the collective, which still plays a necessary role in our civic spatial interpretations of the city.

Those who do not at all participate in a large 'collectivism' of the city inherently contribute to a certain level of commercialization that steers resources away from public space: "where middle-class residents opt out of forms of collective consumption in urban neighbourhoods - choosing private schools over local state schools, private health and support over local services, private leisure over municipal clubs and facilities - the collective and public infrastructure of urban areas tends to decrease: schools 'fail', services cut back or close, amenities degrade or disappear" (Tonkiss, 2005, pp. 55). Rather than limiting or restricting these choices of more individualistic gathering, designers should ensure public spaces contain appeals to both the collective- and individual-minded citizen. Spaces that have been selected for citizen action that already achieve some sort of balance between the collective and the individual succeed in championing civility. 


\subsection{Programmatic Explorations}

Each of the authors discussed and highlighted in the first chapter touch on a number of overlapping and prominent concepts that begin to suggest the potential of elevating a public space into a successful civic one. The organization, prioritization and degrees of these concepts that can outline the availability of program within a given public space. Key themes emphasized within those contemporary approaches that are important design considerations include visibility, accessibility, social hierarchies, decentralization, self-organization, infrastructure space, participation, the public-private gradient, and collectivism versus individualism. Some of these concepts are more abstract than others. Several have very clear design orientations or relationships, while others are more in reference to the display of cultural or personal attitudes within space. Within both cases, exploring possible applications of these concepts within a civic urban site lays the groundwork for understanding and implementing civic-ness.

The following is an exploration of sketch models, set in a nondescript urban context, meant to begin to inform possible design scenarios based on programmatic considerations that specifically civic-oriented, beyond activities or situations that are simply more broadly public. 


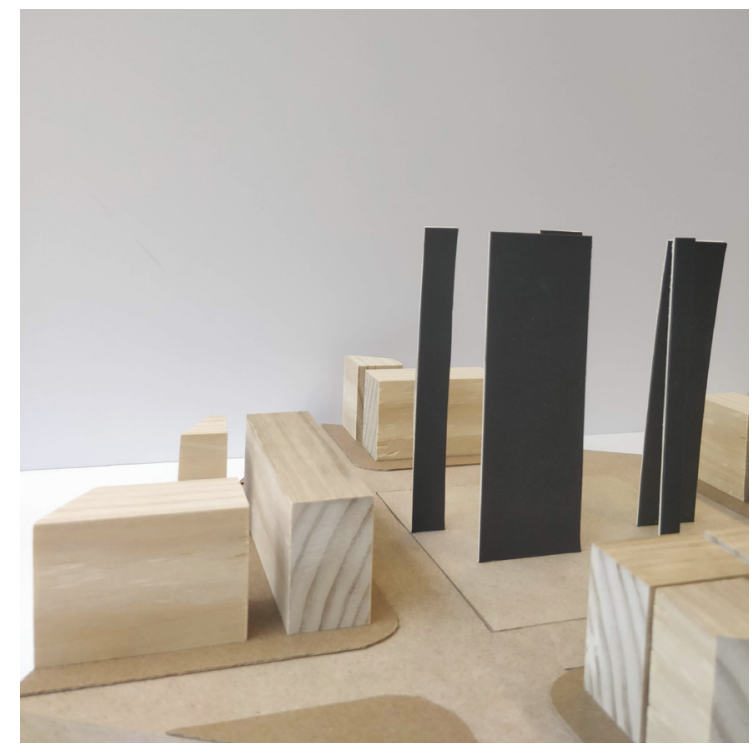

Visibility

A person's ability to see or be seen is constantly shifting depending on their own placement and perspective within a situation.

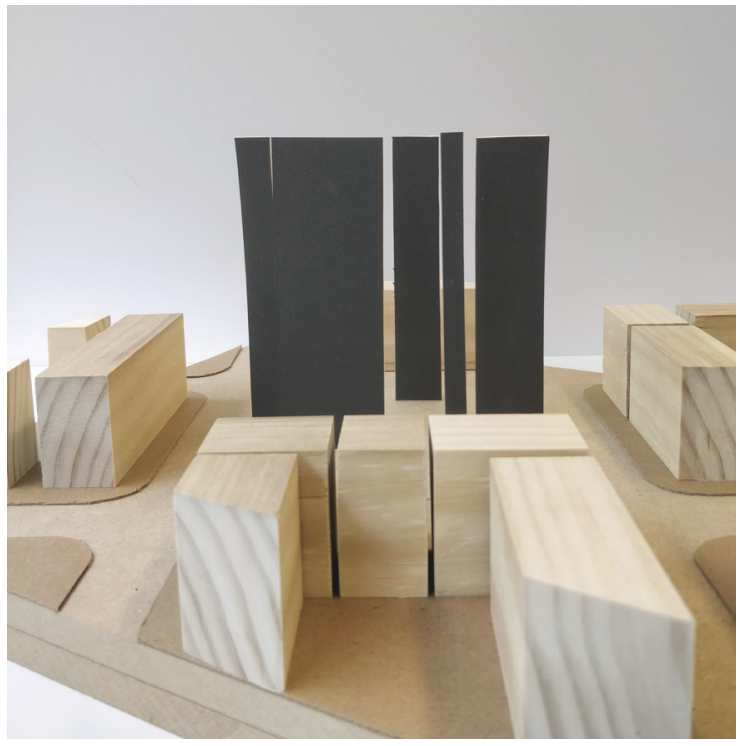

Figures 3.04a,b: Visibility 

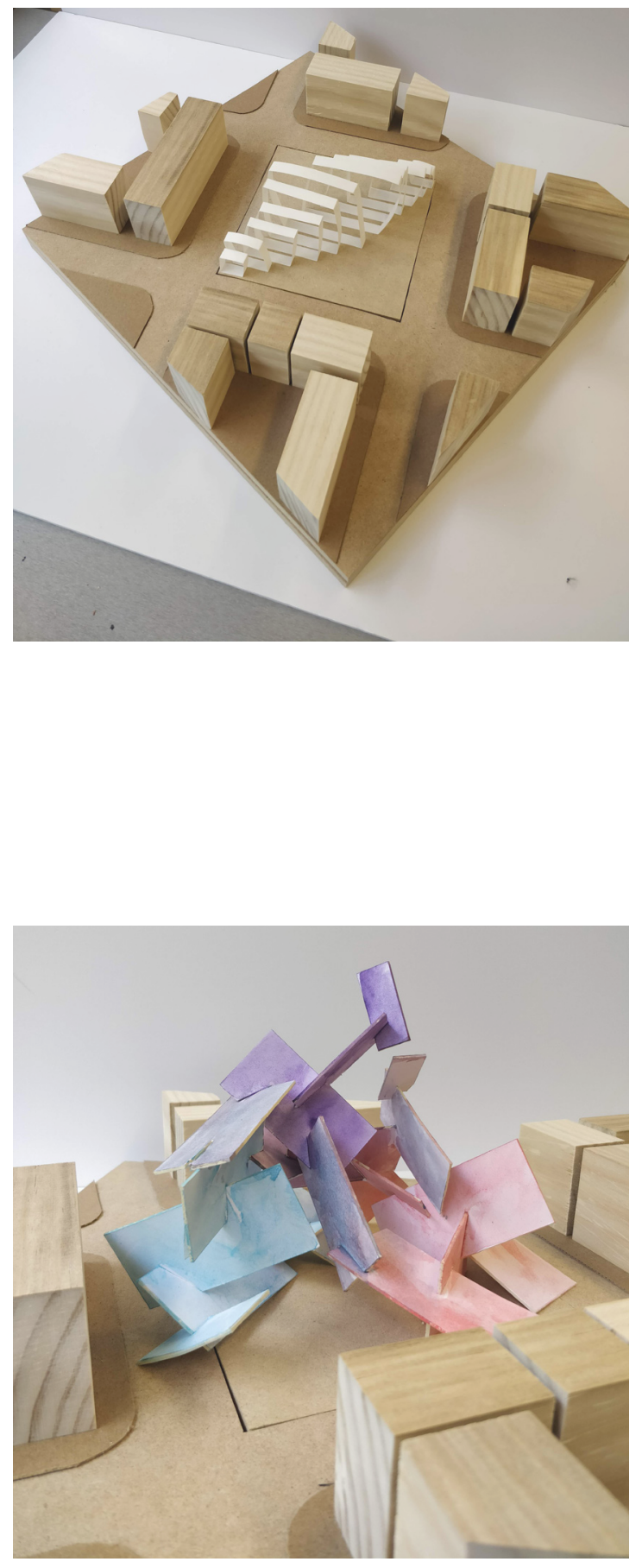

Figure 3.05: Accessibility

Figure 3.06: Social Hierarchies

\section{Accessibility}

Having various options of physical or conceptual accessibility creates different atmospheres for users with different intentions or abilities.

\section{Social Hierarchies}

A successful civic space is one in which all types of people can gather together, regardless of any kind of societal status or class. 


\section{Decentralization}

Allowing for multiple areas of activity increases potential for engagement, from a purely physical sense as well as for greater potential in range of activities.

\section{Self-Organization}

Giving citizens the ability to organize themselves within an easily understood framework is the basis for greater initiative and responsibility.


Figure 3.07: Decentralization Figure 3.08: Self-organization 

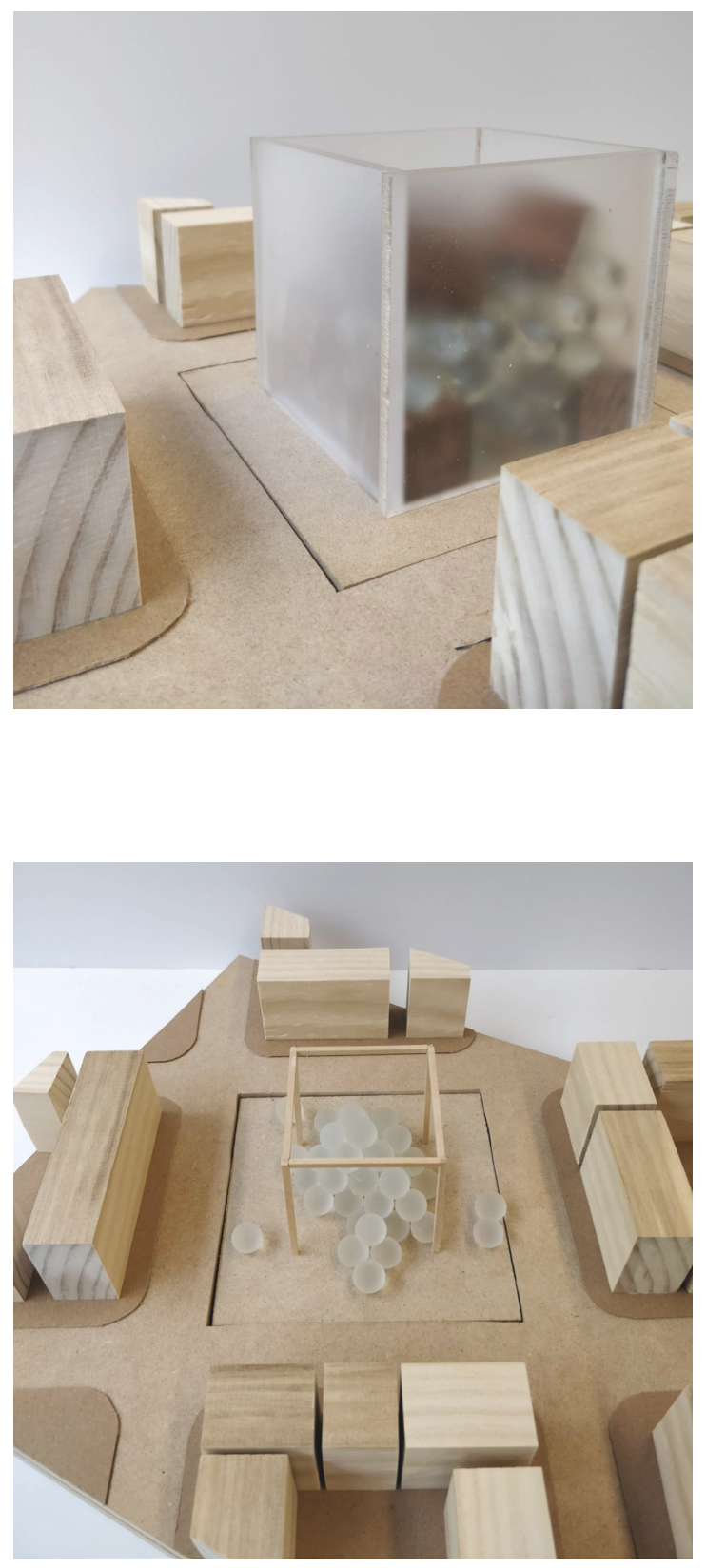

Figure 3.09: Infrastructure space Figure 3.10: Participation

\section{Infrastructure Space}

Emphasizing the value of all space and dissolving the destination/journey dichotomy encourages citizens to engage creatively with outside-the-box ideas.

\section{Participation}

Further encouraging of civic engagement happens when the barriers to participation or broken and there are clear methods of involvement. 


\section{Public-Private Gradient}

Having a healthy balance of open or intimate settings allows for a greater spectrum of activity that may be limited by starkly conventional notions of public private.

\section{Collectivism / Individualism}

Different actions can be taken by a collective or an individual with different consequences, and a successful civic space allows or both.
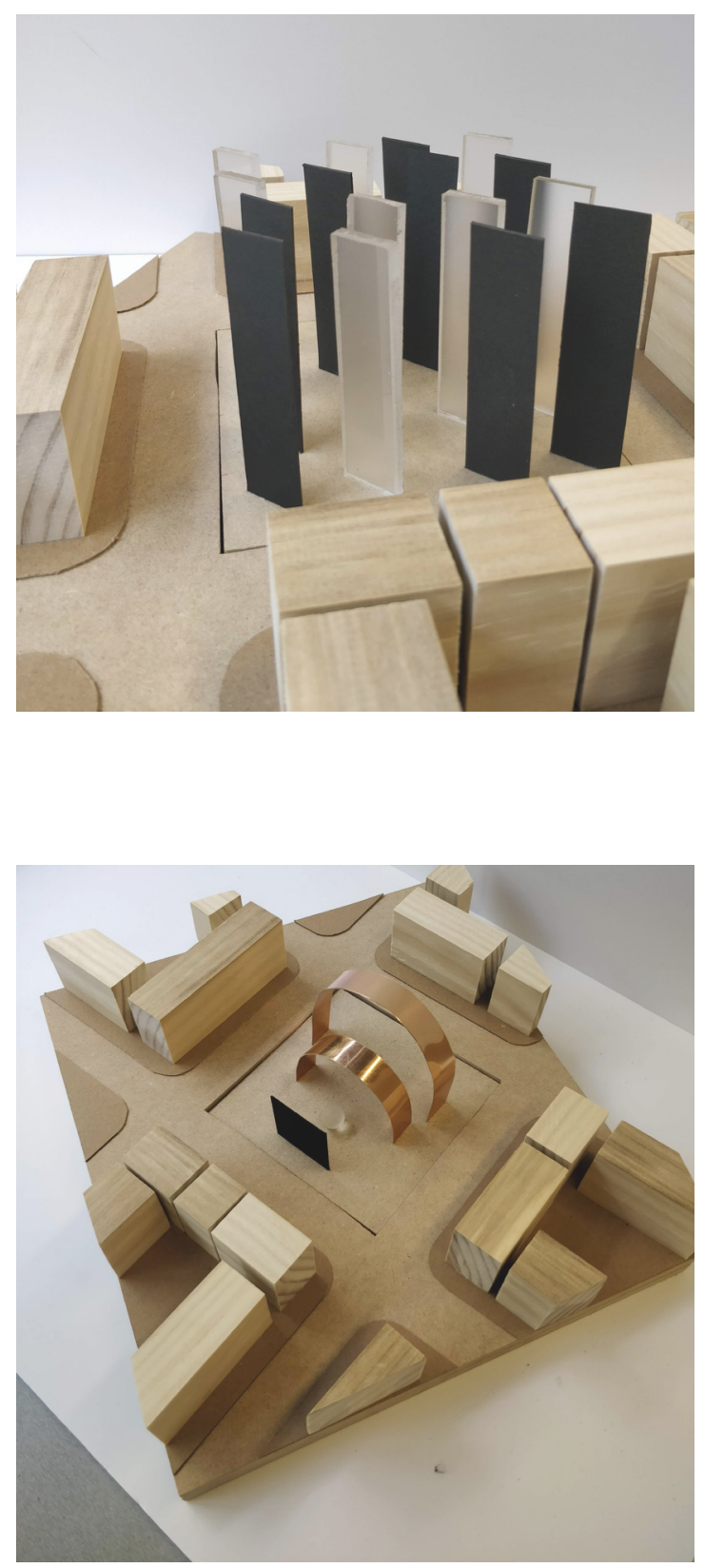

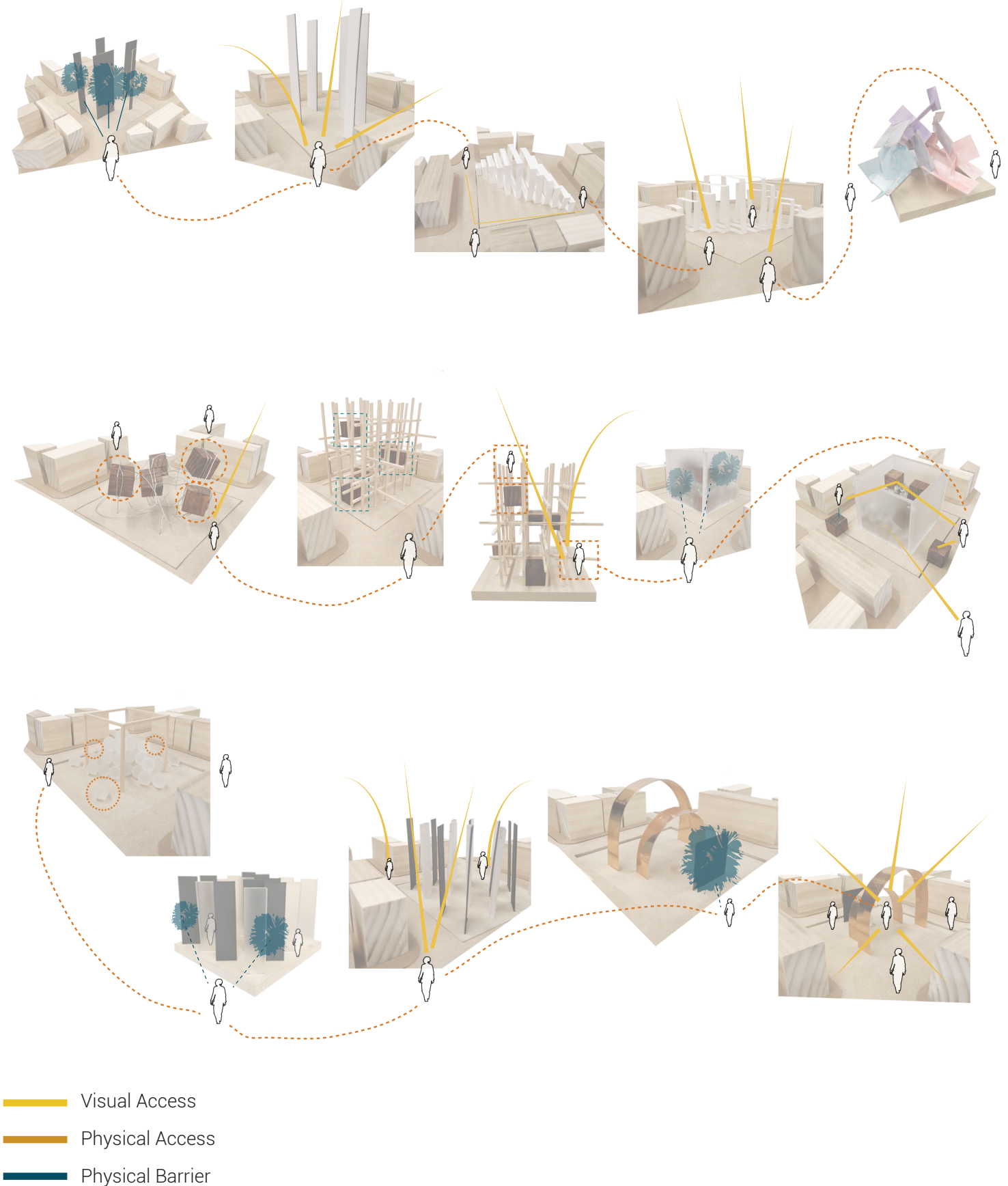

Figure 3.13: How do we study the ways in which these programmatic explorations affect levels of access vs barrier? 
In studying social movements and other types of civic programming, visual and physical access and barriers became the most basic spatial indicators of success or failure for those organizations. The models could then serve as investigations further into the nuances of these indicators in various combinations and degrees. Stitching together the individual concepts into more complex scenarios began to lay the groundwork for understanding various advantages and disadvantages of each programmatic exploration and how their adjacencies and interactions set the stage for citizen participation. 


\subsection{Spatial Explorations}

Several of those nine concepts have both intangible and tangible meanings that can translate directly into spatial considerations when designing. This next series of models begin to demonstrate how to prioritize spatial aspects that are important to curate when designing for civic architecture. These models are kept purposely abstract, with materials that could vaguely resemble certain building elements but have no sense of scale or application. They are simply representative of spatial ideas.

The two metal models represent opposite ends of a spectrum of permeability, with one situation being much more permeable than the other. The two conditions create their own opportunities and challenges. More permeability leads to ease of access and abundance of circulation. Less permeability creates more structure and covered areas.
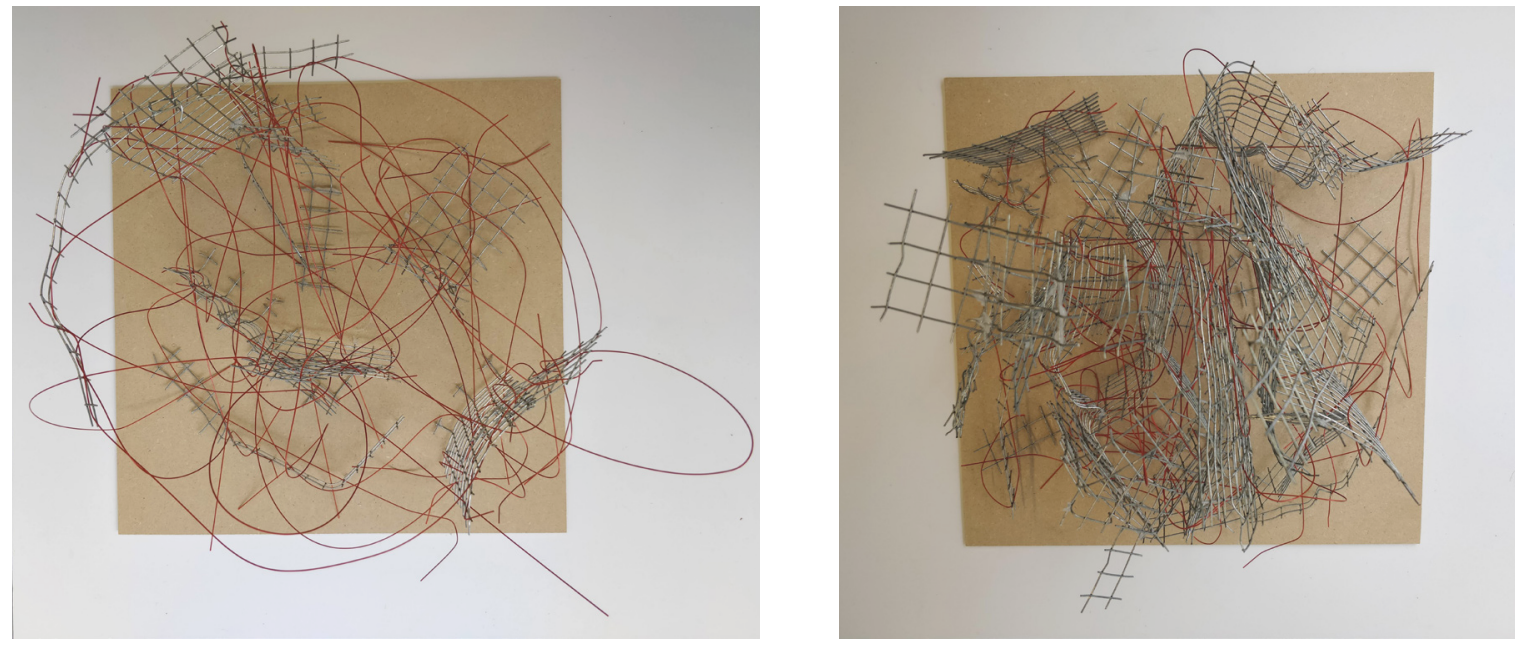

(Left) Figure 3.14: Porosity

(Right) Figure 3.15: Enclosure 

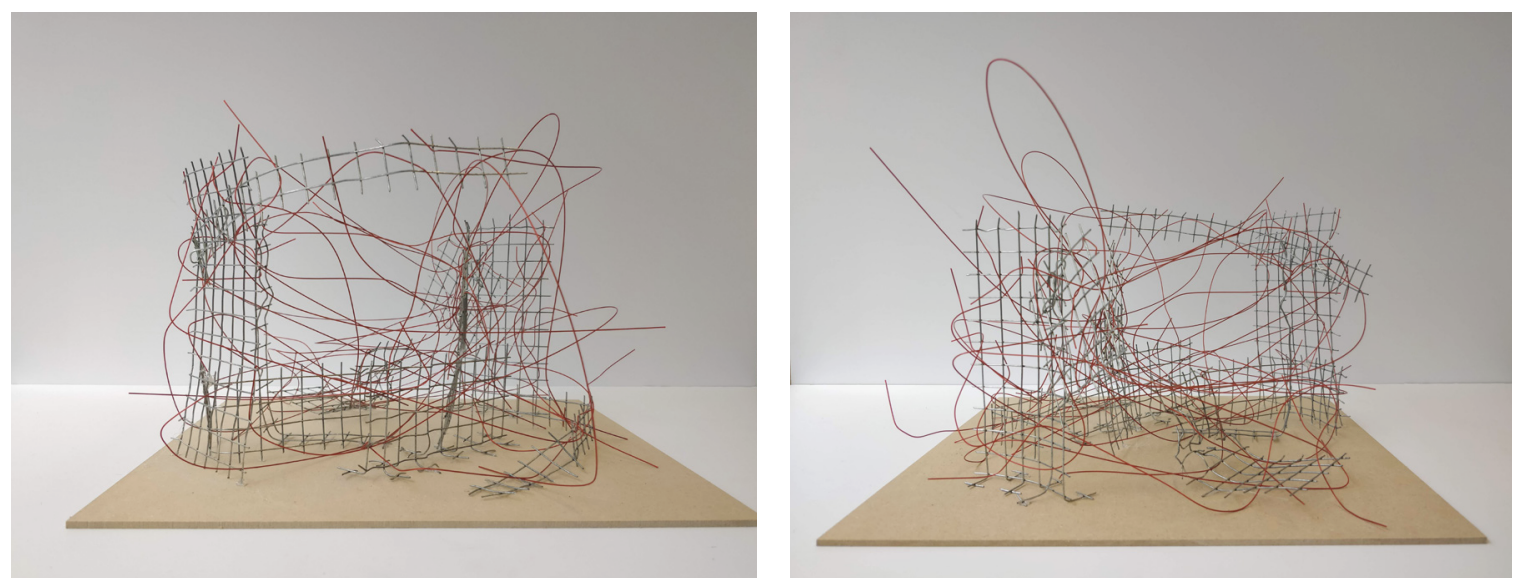

Figures 3.16a,b: Studies in porosity.
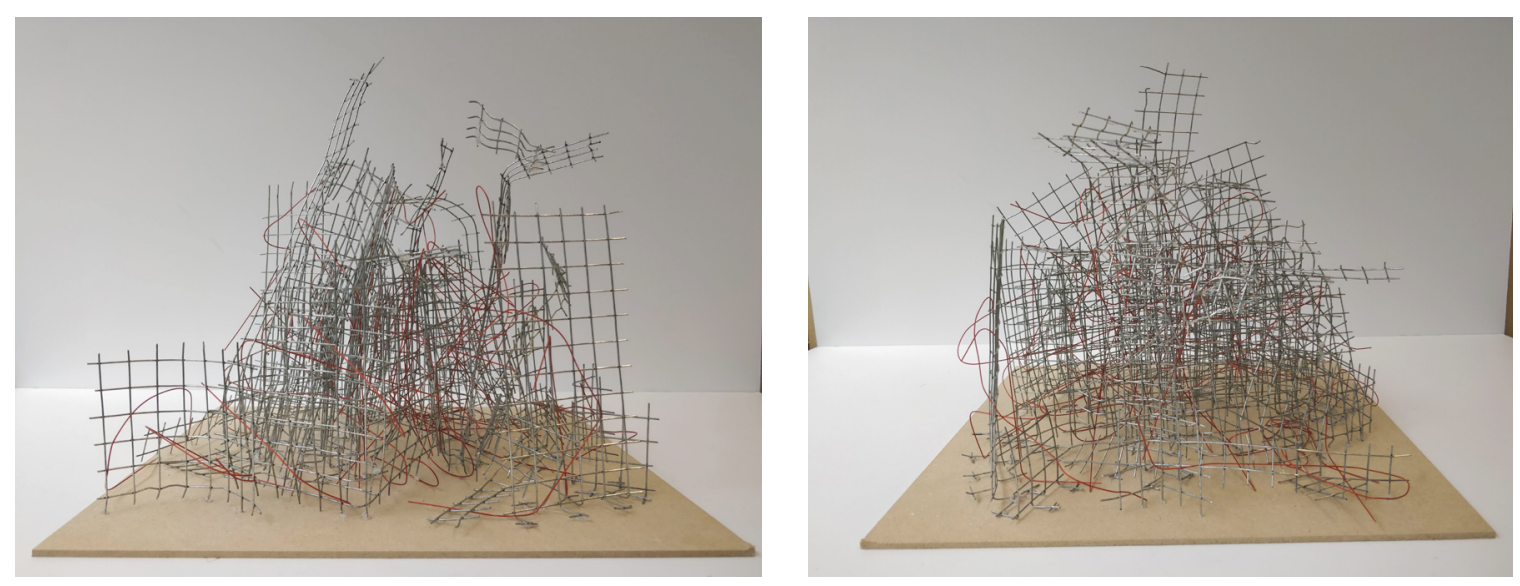

Figures 3.17a,b: Studies in enclosure. 
The two acrylic models represent opposite ends of a spectrum of transparency. Through a combination of various colours, levels of material opacity, object sizing and placements, one condition emphasizing transparency while the opposite represents opacity. Unintentionally, this second set of models was more difficult to design as the chosen objects could vaguely resemble certain building elements, and thus more weight was placed on the assemblage of the model object. Not only did end results of both models yield particular design research discoveries, but the process of building paved the way for the thesis design.
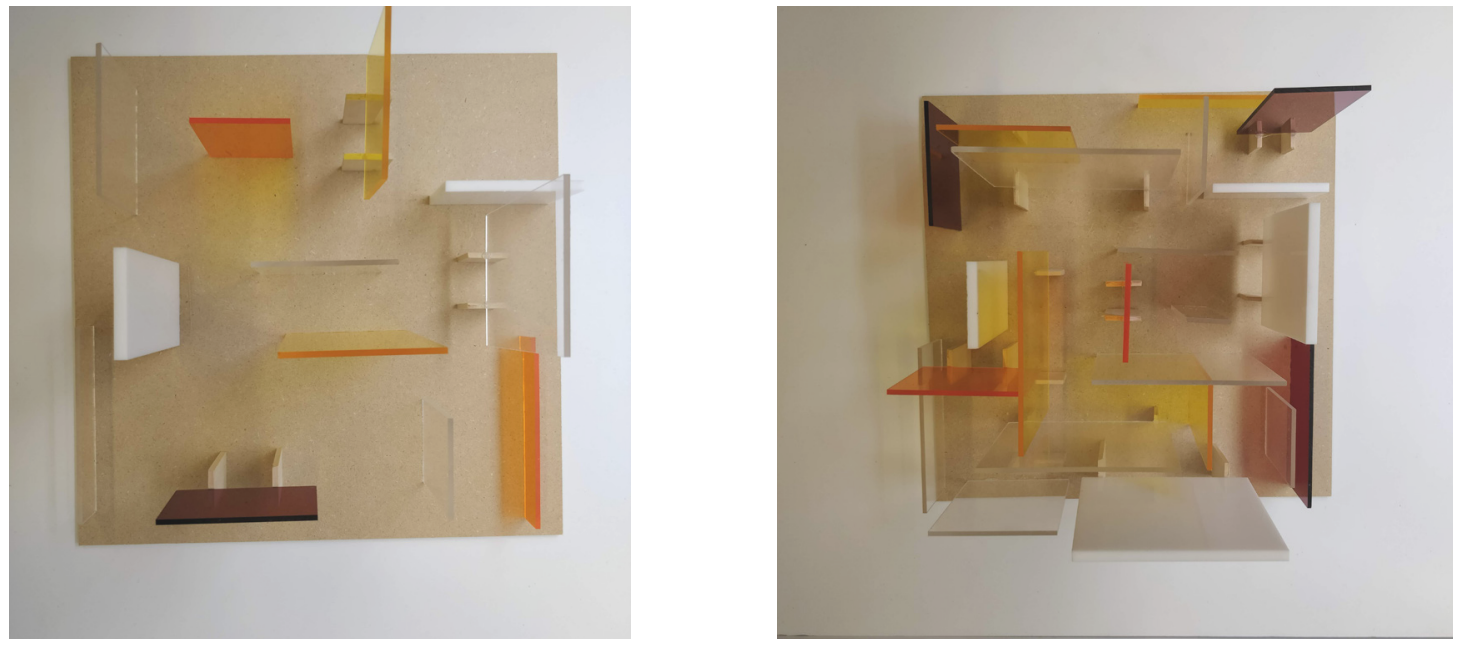

(Left) Figure 3.18: Transparency

(Right) Figure 3.19: Opacity 

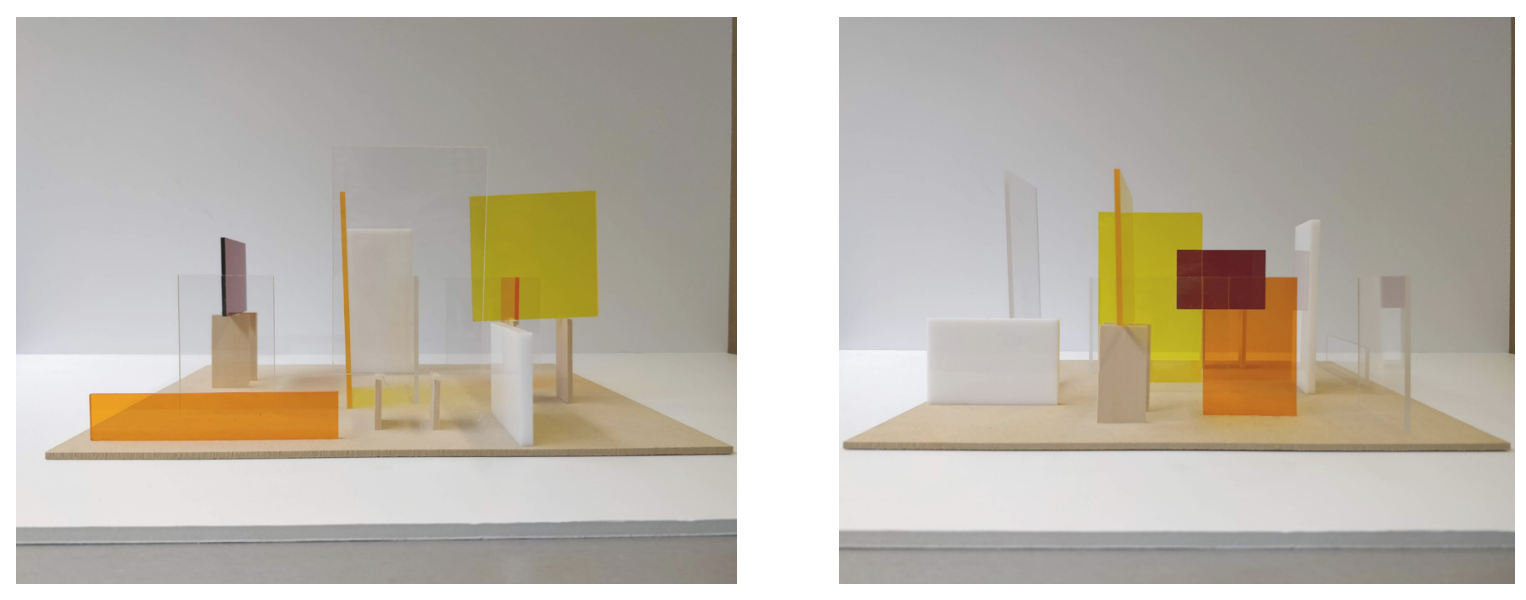

Figures 3.20a,b Studies in transparency.
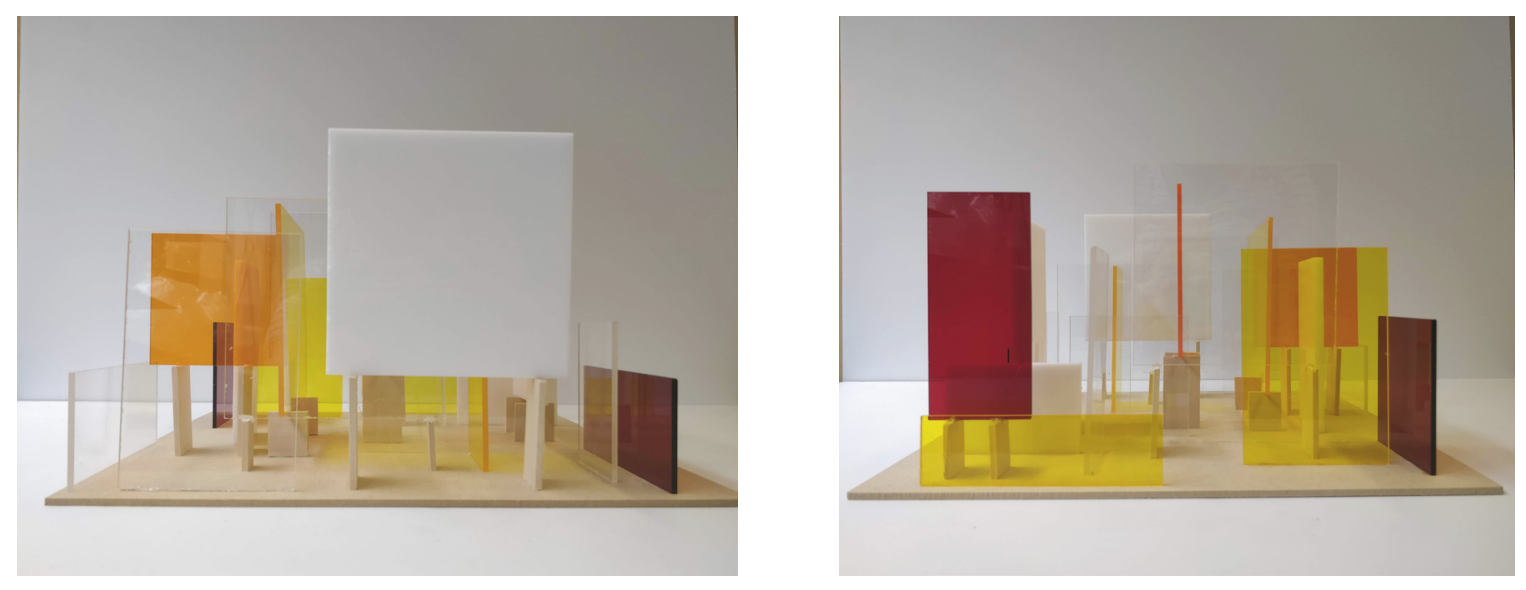

Figures 3.21a,b: Studies in opacity. 
The two acrylic models represent opposite ends of a spectrum of transparency. Through a combination of various colours, levels of material opacity, object sizing and placements, one condition emphasizes transparency while the opposite represents opacity. Unintentionally, this second set of models was more difficult to design as the chosen objects could vaguely resemble certain building elements, and thus more weight was placed on the assemblage of the model object. Not only did the end results of both models yield particular design research discoveries, but the process of constructing each one paved the way for the thesis design.

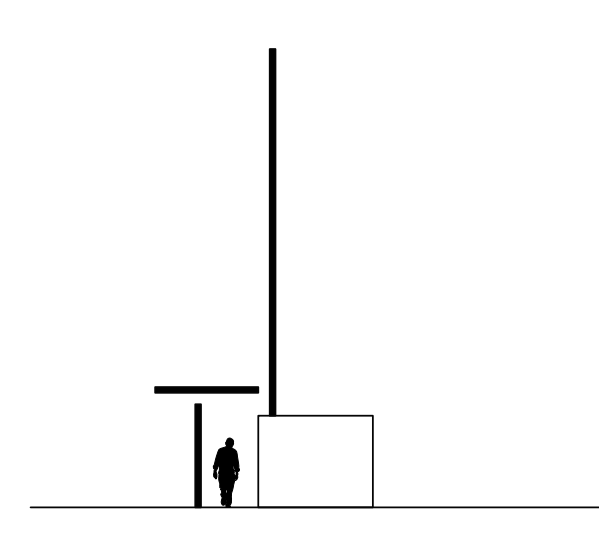

Figure $3.22 a$

\section{Attributes}

- $\quad$ long \& short element

- minimal physical/visual barrier

- $\quad$ short \& elevated element

- $\quad$ visual access throughout entirely of model

- $\quad$ boundaries are less defined

- $\quad$ shelter witout compression

- $\quad$ large transparency-opacity ratio

\section{Possible Spatial Moments}

- small landscaping barrier

- overview from one type of program into another

- defined but open entrance into internal foyer 
Attributes

- open/porous at edges

- $\quad$ large gaps between elements

- oversized for human scale

- $\quad$ large opaque expanse

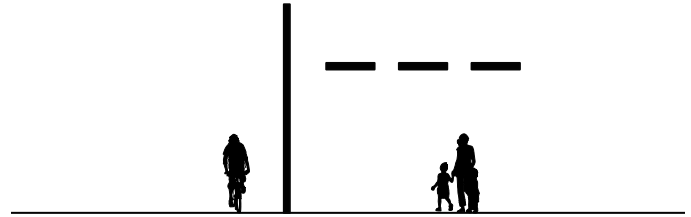

Figure $3.22 b$

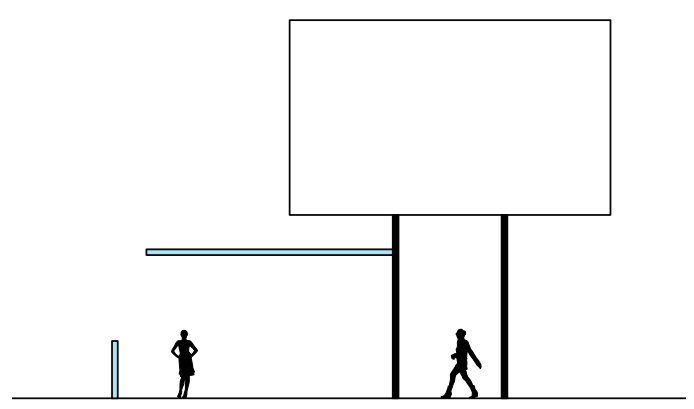

Figure 3.220
Possible Spatial Moments

- transition from external plaza to internal module element

- defined but open entrance into internal foyer

\section{Attributes}

- $\quad$ narrow \& long

- limited views around corners etc.

- large vertical plane

- $\quad$ spatial dividers

Possible Spatial Moments

- hallway to basement podcasting/sound tech areas

- $\quad$ intimate/private working spaces 


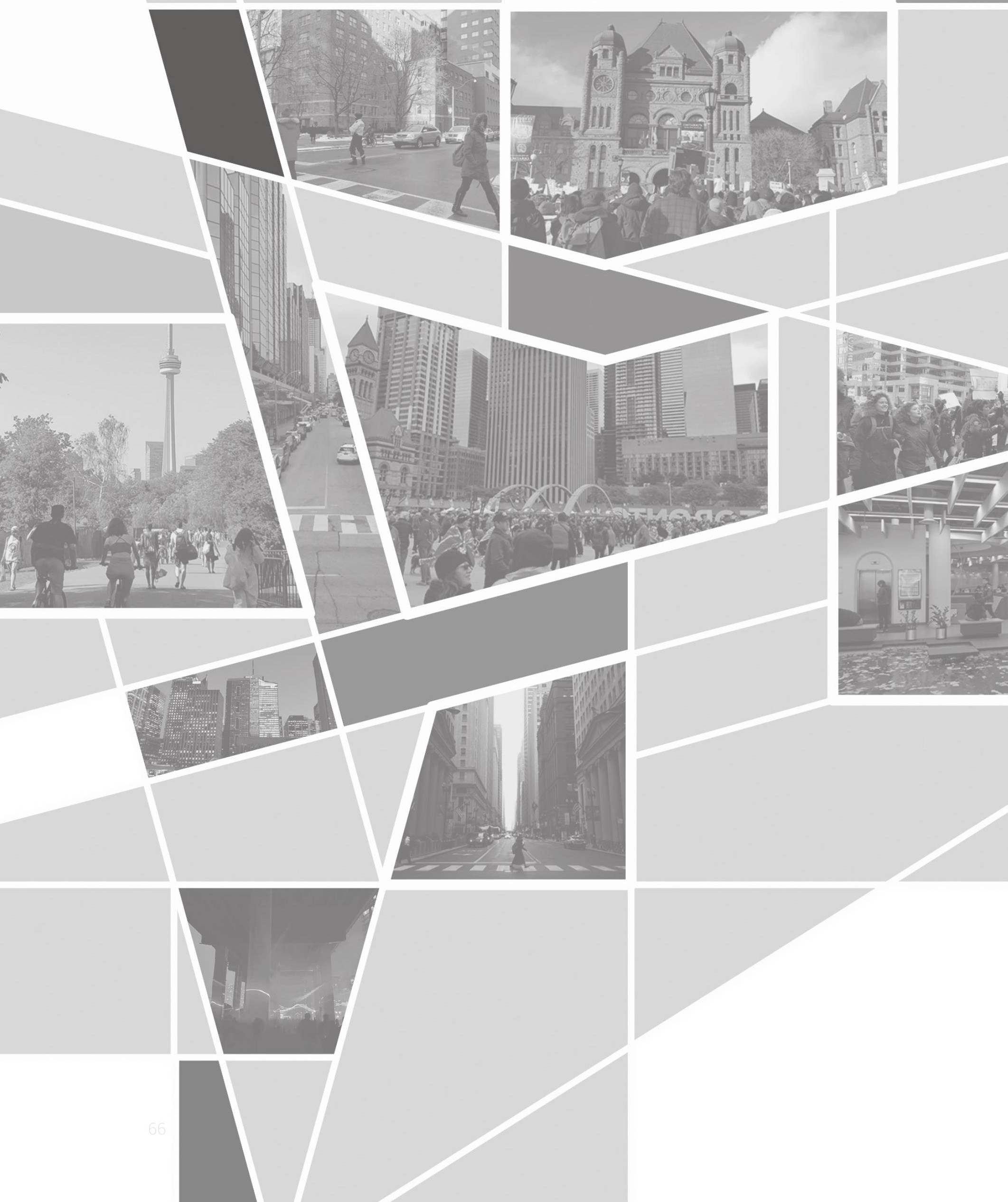




\subsection{Manifestations}

What constitutes examples of local participatory democracy, and what are they lacking in terms of either program or space? 


\subsection{Programmatic Precedents}

In 2.0 Influences, it was argued that social movements have typically met one of two endings. Those that have prioritized remaining sustainable and active beyond spontaneous or sporadic demonstration events have necessarily morphed into a more formalized organization. Those that were unable to establish an acting framework, long-term goals, or resource procurement, have simply burnt out. This is not always a negative or unintended side effect; some social movements have existed solely for singular purpose, event, or message.

Social movements that are concerned with governance and politics and have followed the former route of successfully formulating sustained action can be observed following two different types of approaches. The first can be termed a working group, implying formality or structure, acting as social organization which includes those who also share a collective attitude and perspective on the world and wish to affect change. The second approach is a structured partnership between an established governmental body or agency, and a grassroots community group. Both of these classifications can manifest with different amounts of longevity, sustenance, or resources, i.e. as spatial projects, specific events, or sustained collections of activity.

\section{Working Groups}

The products of working groups may be theoretical, lacking in relevant shareholders, or molded outside of the norm. These types of organizations produce work in a wide range of media, typically with a not-for-profit intention, as a models from which more formalized work can spring. These collectives also have the potential to form into a partnership between government and citizens, or at least serve as a private group in a consulting or advocate position for, with, or against a governmental body.

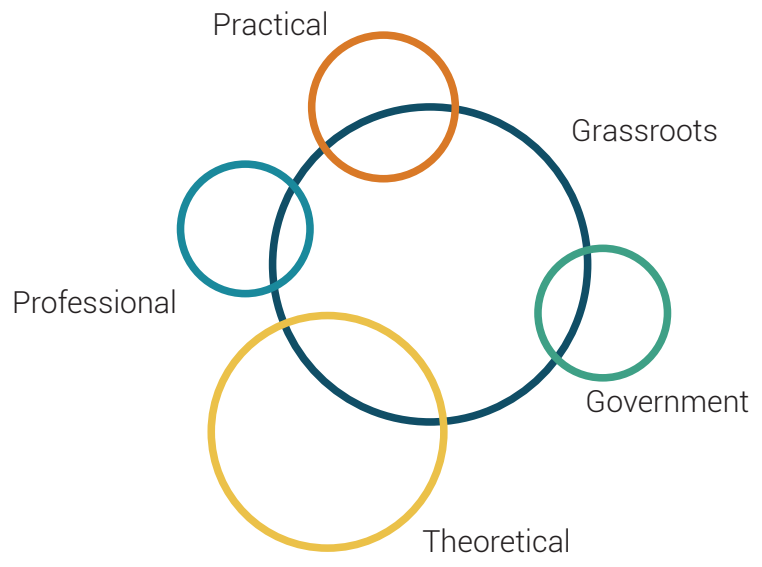




\section{FREE SPEAKERS SERIES}

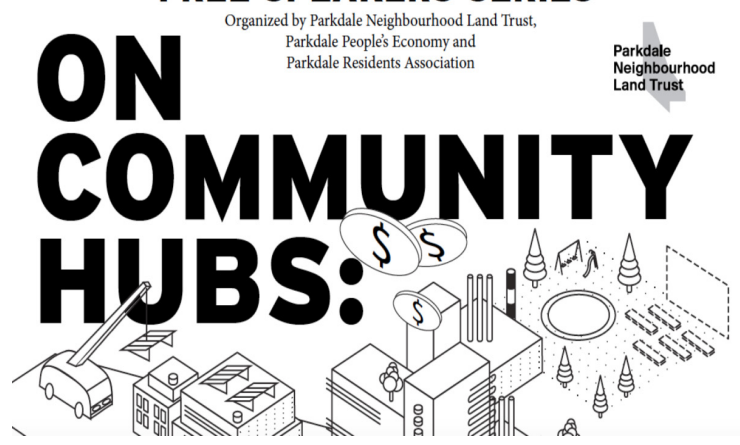

Figure 4.02

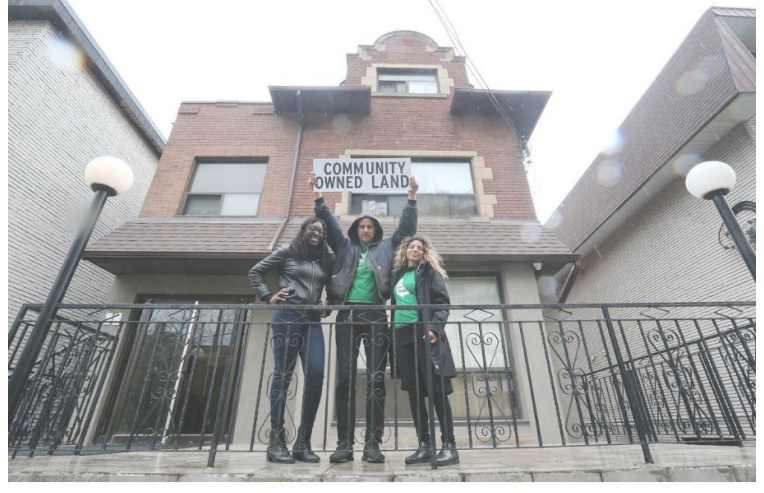

Figure 4.03

Parkdale Neighbourhood Land Trust

Who: Board of directors consisting of representatives from Parkdale Activity-Recreation Centre (PARC), The West End Food Co-Op, Greenest City, Roncesvalles-Macdonell Residents Association, Parkdale Community Legal Services, Parkdale Village BIA, West Neighbourhood House (formerly St. Christopher House), and Sistering What: Think-tank and advocacy group

Where: Toronto, Ontario, Canada

When: 2010 - Present

Programmatic Components:

- Think-tank of research and writing for advocation of a community land trust model for land ownership to be legalized and wide-spread throughout the city of Toronto

- Parkdale Free School teaches community members about their rights within the city of Toronto, workshops of things like zoning/planning issues etc.

- Involved in city hearings etc.

Spatial Components:

- Currently working to acquire a small plot of land called the Milky Way Gardens with the goal to acquire other properties as well

- Function primarily out of the Parkdale Activities-Recreation Centre.

Result:

- $\quad$ Continual education and support programs for residents

- Progress being made on changing policies in the city 


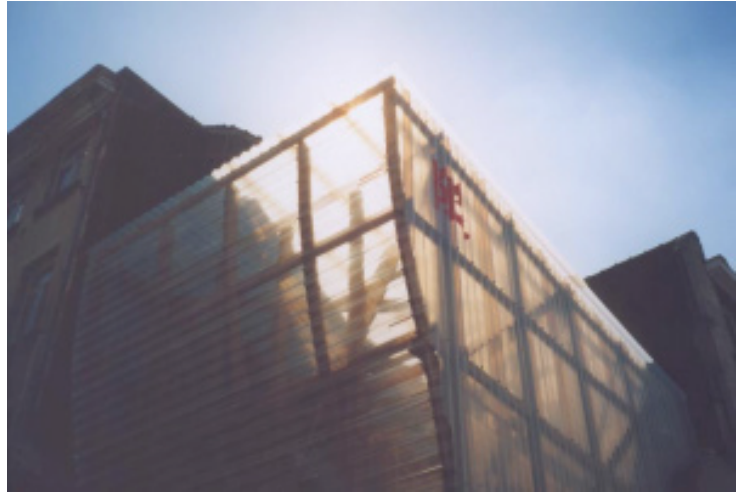

Figure 4.04

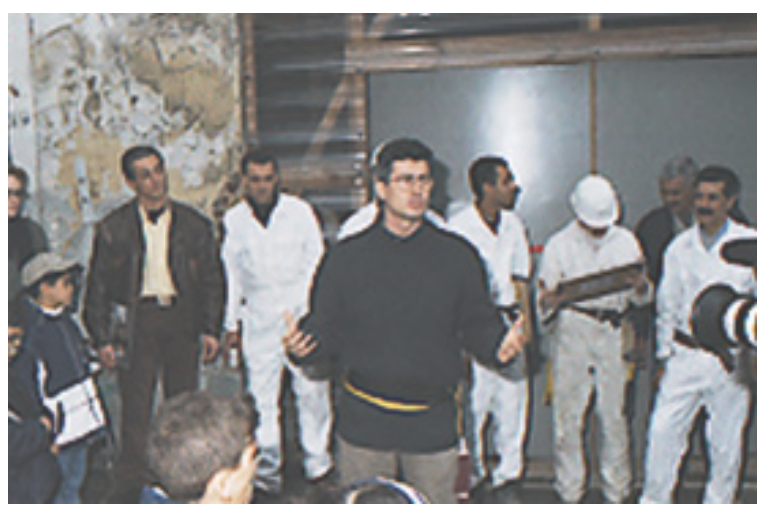

Figure 4.05

\section{Limite Limite}

Who: City Mine(d)

What: A non-profit arts, civil society and urban development organisation that designed several physical interventions and events in the neighbourhood that aimed to bring together people of local politics and business Where: Brussels, Belgium and London, United Kingdom

When: 1995 - Present

Programmatic Components:

- As a shelter [the tower] hosted meetings, performances and events, and completely closed it worked as an exhibition space.

- The local women's organization hosted intercultural breakfasts in the tower

- Architecture workshops with architecture students, mostly specifically about that space

Spatial Components:

- The Tower, a nine-meter high wooden structure clad in corrugated plastic was the central component of the project; it was located right on a commute path to offices and a school which garnered a lot of participation and eventually was shipped to and rebuilt in Belfast

- A local newspaper was published along with branding in the space

Result:

- $\quad$ Served as a physical forum from which to establish a non-profit organisation that has continued to operate since

- Group is taking things into their own hands to provide services that are lacking 


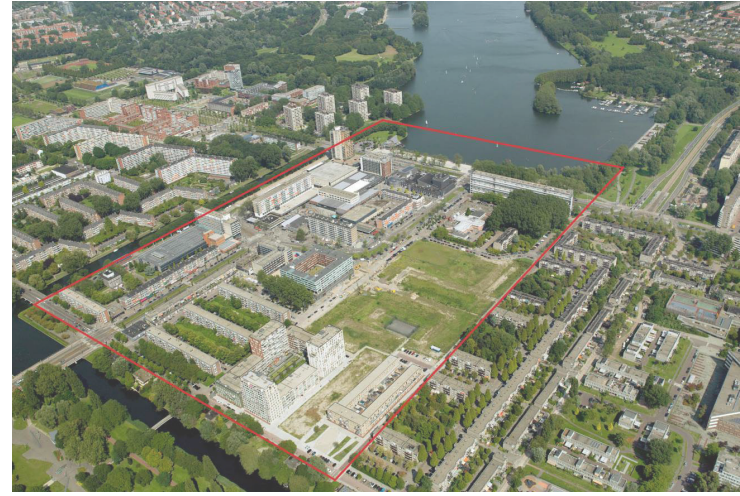

Figure 4.06

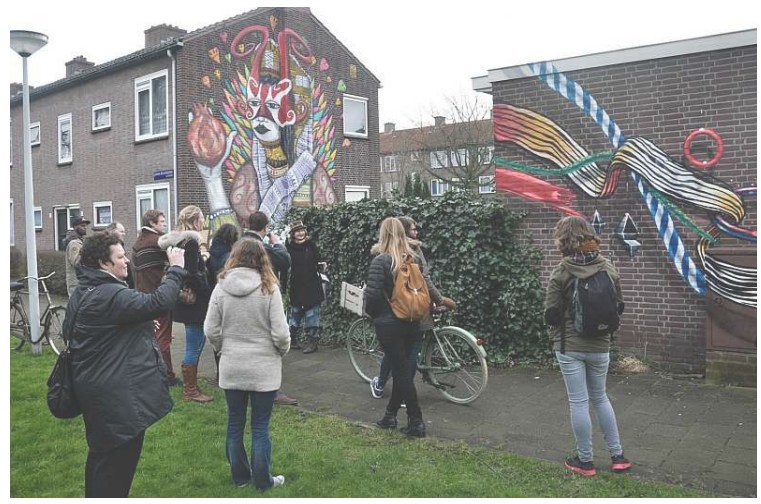

Figure 4.07

\section{Amsterdam Nieuw-West Neighbourhood}

Who: Casanova \& Hernandez

What: Post-graduate studio led by Casanova \& Hernandez to rejuvenate Amsterdam Nieuw-West

Where: Amsterdam, The Netherlands

When: N/A

Programmatic Components:

- Different schemes had different components but all included outdoor space, education opportunities, and meetings facilitated by the municipal government for the purpose of community input

Spatial Components:

- $\quad$ Abandoned, empty, and underutilized public spaces were adapted for green areas or parks, classrooms or meeting areas, art installations etc.

- Mix of indoor and outdoor spaces

Result:

- $\quad$ Pilot for a more formal and organized structure of citizen input into planning

- Residents felt more in control of their own environment and the planning

- Community relations and faith in municipal governance was fostered 


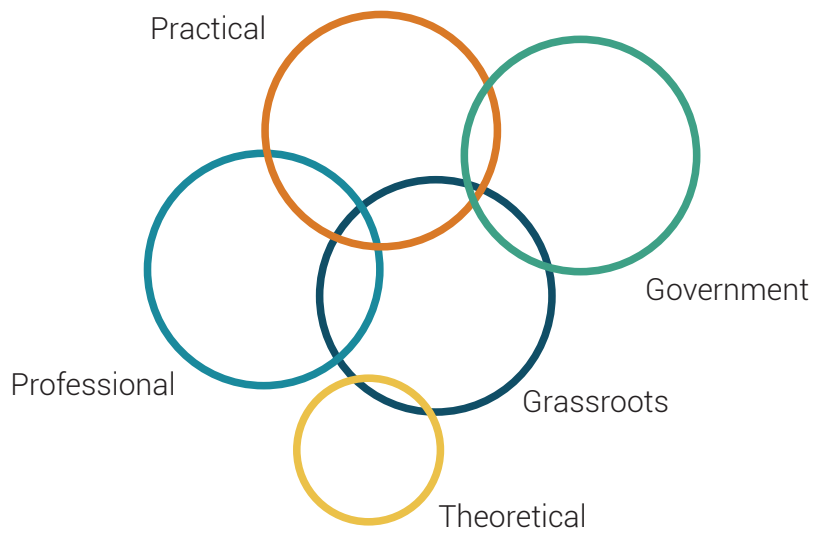

Figure 4.08: Structured Structured Partnerships

partnership.

The ability for citizens to alter the physical make-up of their city is often the most easily understood and accessible way to affect change. Architects are already in a position to act as a facilitator between clients and regulations, and those designers who are very proactive will seek out a community client with whom they can work together to affect physical change in urban spaces. This example of a partnership is easy to grasp from a design perspective, with community members and government officials or employees working together with a designer or architect to achieve change throughout an urban place or space.

It is also important to look beyond the lens of urban interventions and explore partnerships with other realms of city governance and especially those that tackle social issues, such as communities who work together to maintain or create recreation or education programs, or traditional activist groups who lobby for other types of legislative changes. 


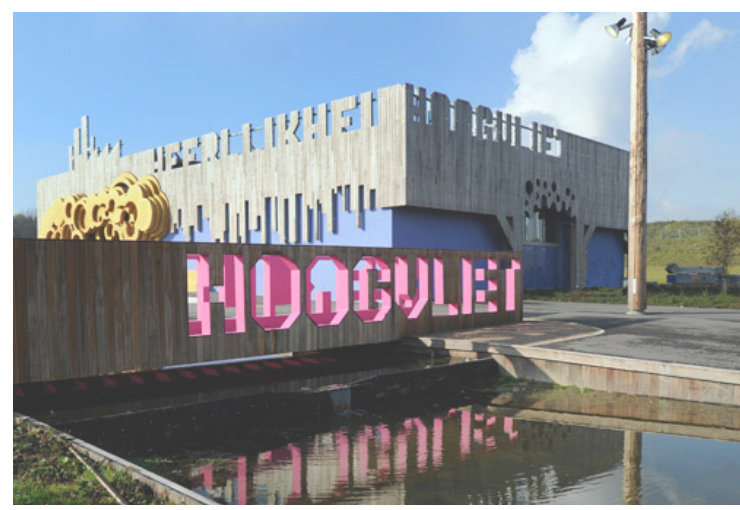

Figure 4.09

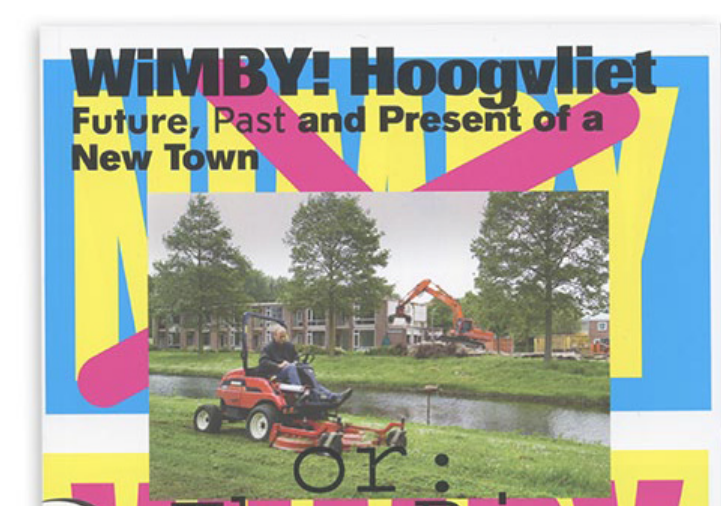

Figure 4.10

\section{Welcome Into My Backyard!}

Who: Crimson Architectural Historians (designer) in tandem with residents of Hoogvliet

What: Continual redesign and rethinking of portions around the town redeveloped with the residents

Where: Hoogvliet, The Netherlands

When: 2001-2007

Programmatic Components:

- Open park space more attractive to use

- Cultural centre with residences

Spatial Components:

- Parks and urban spaces developed

- Older/abandoned buildings repurposed

- Art installations

Result:

- Residents felt more in control of their own environment and the planning and thus more receptive and open to change

- The history and story of the town is rejuvenated and kept very much alive instead of crumbling into oblivion 


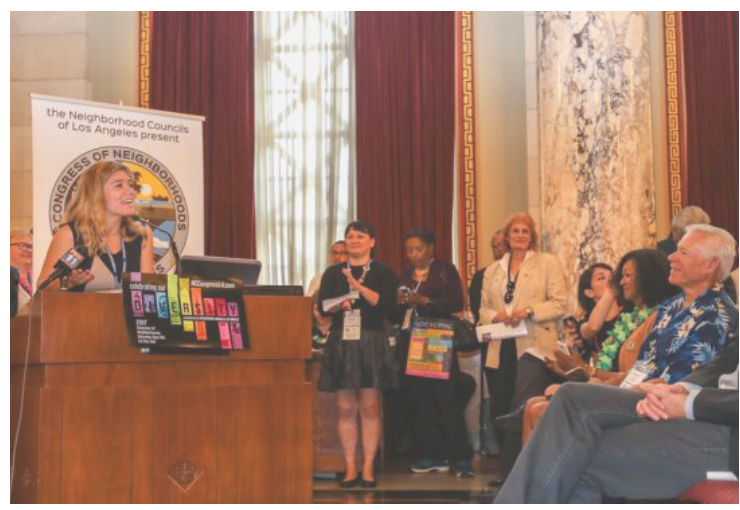

Figure 4.11

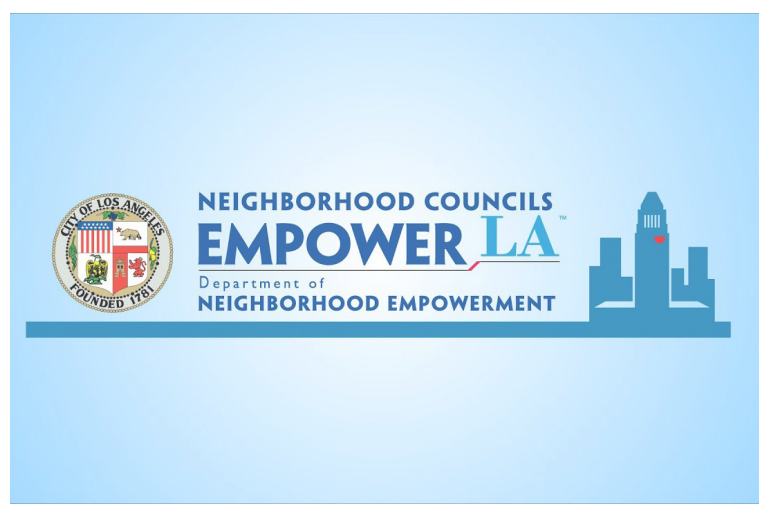

Figure 4.12

\section{Neighbourhood Councils of Los Angeles}

Who: Organized with Department of Neighbourhood Empowerment but composed of all citizens

What: "Neighborhood Councils are the closest form of government to the people. They are advisory bodies, who advocate for their communities with City Hall on important issues like development, homelessness, and emergency preparedness. Neighborhood Councils are part of the Los Angeles City government, and have annual budgets funded by taxpayer dollars.

Where: Los Angeles, California, U.S.A.

When: 1999 - Present

Programmatic Components:

- Department of Neighbourhood Empowerment within the Los Angeles City Hall

- Councils are empowered to elect or select their own leaders, boundaries, and issues; the City provides them with the resources, training, and access that they need to hold their elected officials accountable, and ensure that their neighborhood priorities are given proper attention."

- Neighborhood councils receive annual public funds from the municipal government

- 5 Empowerment Congress Councils

\section{Spatial Components:}

- Meetings happen in community buildings in that neighbourhood, such as churches, synagogues, community halls, libraries, elementary schools, etc.

- "More than half of the Department's employees are the community organizers who form the field staff. They operate from a main office in Downtown Los Angeles, and out of five additional access centers located throughout the City in Van Nuys, Reseda, Boyle Heights, the Eighth District Constituent Center, and San Pedro. The field staff, known as Project Coordinators, work closely with over 100 groups that are Result: preparing to be officially certified as neighborhood councils." (Dept. of Neighbourhood Empowerment)

- A continued system of citizen-oriented government with a very dense and populated urban centre 


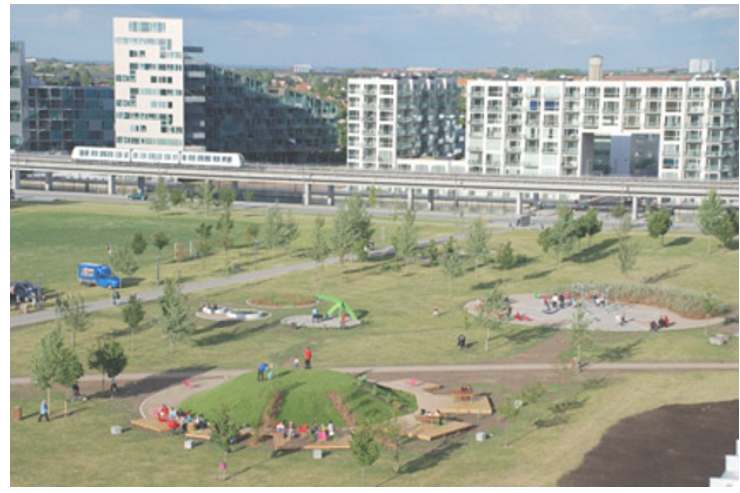

Figure 4.13

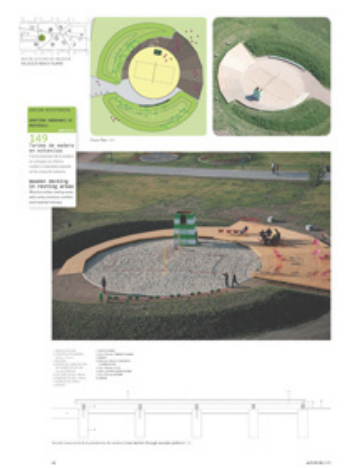

Figure 4.14

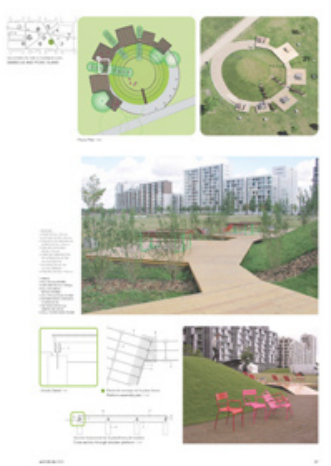

\section{City Park Orestad}

Who: MUTOPIA (designer) in tandem with residents of Orestad and the municipality

What: Design and construction of a large park

Where: Town of Orestad, Copenhagen, Denmark

When: 2005-2008

Programmatic Components:

- Residents planned the park out with a significant amount of input, with MUTOPIA as the designer, builder, and mediator between the clients and municipality (Casanova and Hernandez, 2015, pp. 128)

- $\quad$ Ongoing project with the addition of new residents arriving to the neighbourhood

\section{Spatial Components:}

- $\quad$ Large open areas of undeveloped land

- $\quad$ Recently developed portions of a new, master-planned neighbourhood

Result:

- $\quad$ Residents felt more in control of their own environment and the planning

- Community relations and faith in municipal governance was fostered 
Throughout research and precedent study analysis, there are clear spatial tendencies for both of these approaches to participatory democracy. In a working group where the ideas being discussed and acted upon have more to do with intangible cultural issues, the location of the work taking place is quite scattered. Proximity and tightness within the community are paramount, and so this often results in things like church basements, elementary school gyms, or recreation centre atria becoming meeting headquarters. There is no dedicated space for these activities.

Within the structured partnerships studied, the majority of these examples are concerned specifically with the development and change of urban spaces or architectural interventions, and thus have a physical location from which to act. However, this is only possible by virtue of the work and/or projects being architecturally-focused enough to bring in those types of professionals. As discussed, there are examples of sanctioned structured partnerships between citizen groups and government institutions, and often these that are not focused on urban development have the same issues with space as working groups.

The operating spaces or lack thereof of both approaches has made clear the basic barriers to entry for citizen government from an architectural perspective, and identifies a gap between them that can be foundational for the design of new civic spaces. 


\subsection{Programmatic Principles}

Combining spatial theories with programmatic precedents allows civic spaces to be better understood for their attraction to citizens and ability to achieve various definitions of success for citizen action. Delving deeper into these ideas leads to the defining of specific programmatic qualities, which is necessary to lay a foundation from which to design. Four main principles of programmatic intangibility have been identified whose implementation allows for activity to be distinguished as civic, as opposed to simply public. Each of these four principles embodies a further breakdown of specific qualitative elements that when designed purposefully and in consideration of one another, serve as building blocks for successful civic space that would encourage local participatory democracy.
(Below) Figure 4.15:

Programmatic civic engagement.

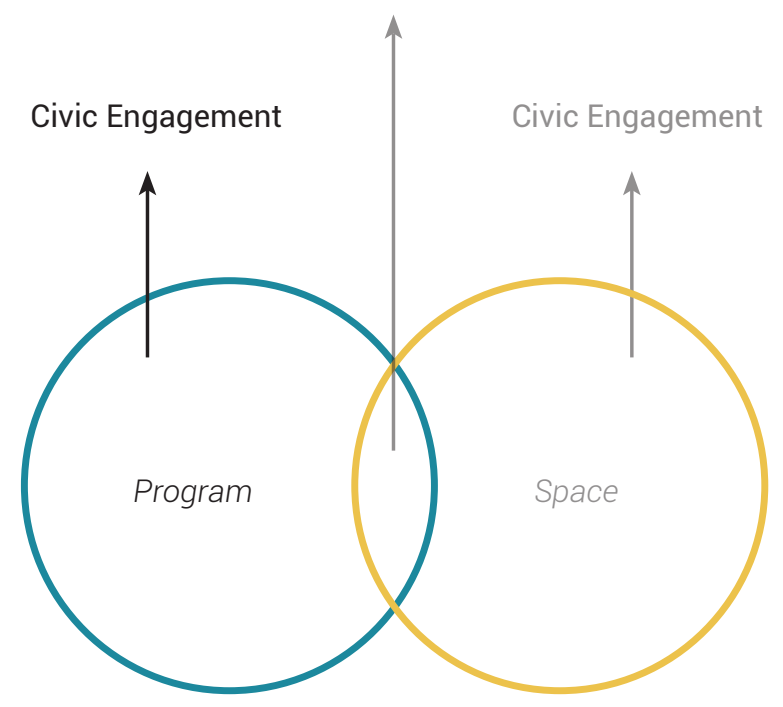



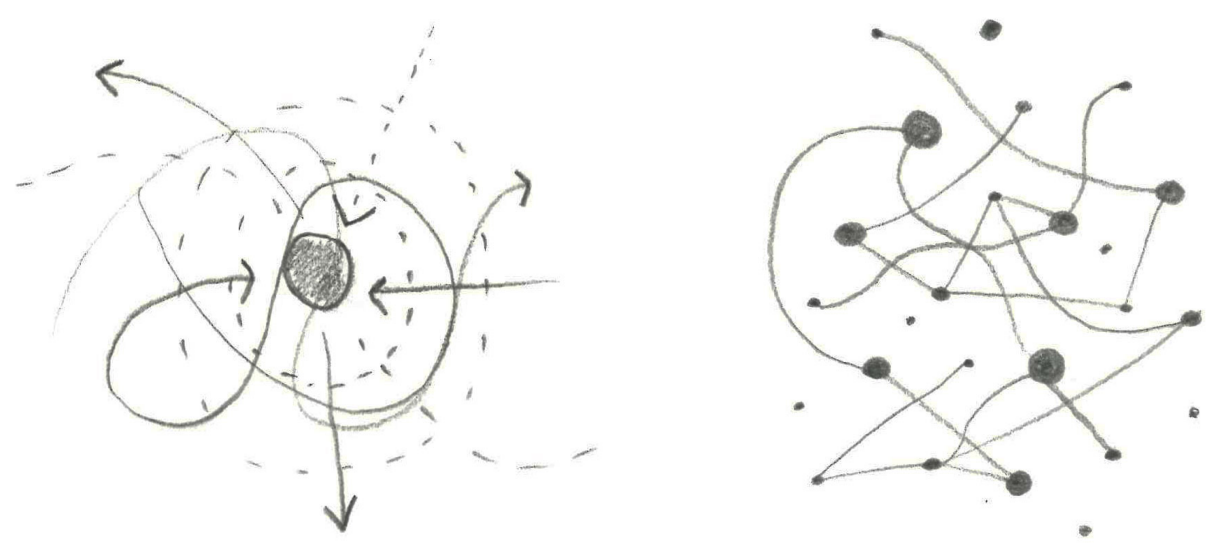

(Left) Figure 4.16: Accessibility (Right) Figure 4.17:

Decentralization

\section{Accessibility}

The concept of accessibility has a far deeper significance beyond the code definition ordering that a space is able to be reached, entered, and used by all. There are cultural or social barriers that hinder the ability of one to use a space that manifest in various ways and can be directly addressed (i.e. entrance fees, travel distance, exclusionary security tactics), but there is also a unique opportunity to highly increase accessibility when this becomes a design goal from the start. The flow of people through the building's openings, or the ratio of intimacy against exposure achieved through materials and orientation of building elements, are variables that can be optimized to ensure that citizens are provided with all necessary means of participating in the space.

\section{Decentralization}

Many outdoor spaces are designed to serve a specific purpose, and this design can often be resistant to change. Streets are a good example of a rigid component of the public realm that then fades into the subconscious background of city dwellers due to its singular purpose of circulation. Other outdoor spaces such as parks or plazas have the ability to become destinations in themselves rather than existing on the periphery of city life, and this is largely due to the decentralized nature of the space. This shift from bypassing to intention begins to signify the presence of the civic embedded within the public. Organizations of citizens are required to alter these spaces, but those that facilitate re-configurations, designs, or functions that are not only limited to top-down impositions have the potential to be very successful. Decentralized spaces, both indoor and outdoor, are those that eschew building with hierarchical spatial planning in favour of a design approach that allows for multiple uses and users existing simultaneously in one space. This foundation is physically manifested with a consistency of building elements, transitions between indoor and outdoor space, and an abundance of immediately apparent but never confining parameters within which to function. The ability for citizens to affect physical change within a space, or otherwise fit their own programming into an existing condition, clearly demarcates a civic space designed to serve the needs of a collective citizenry. 

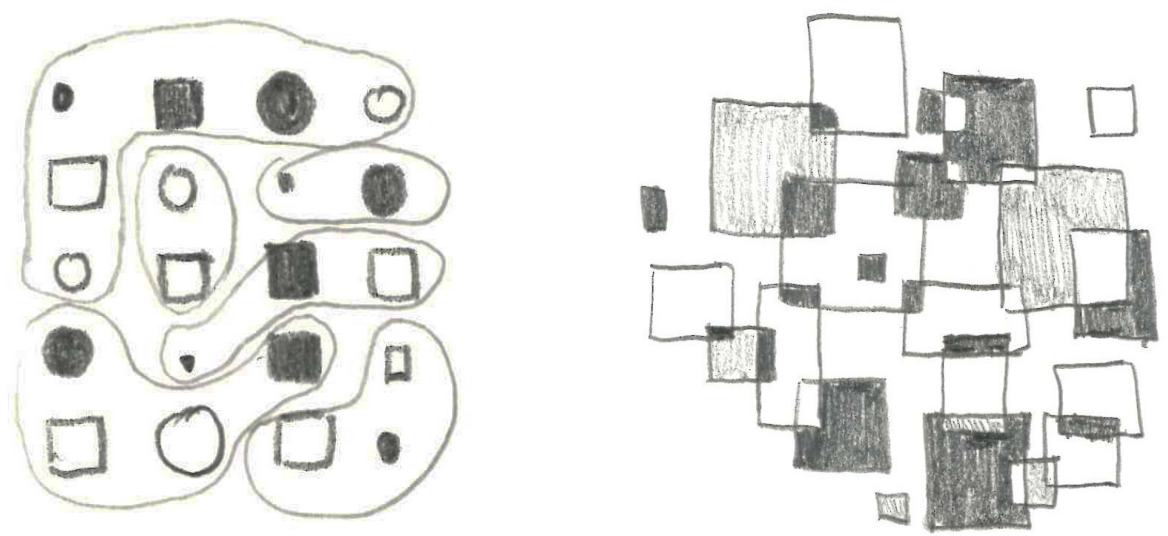

With the presence of accessibility and decentralization, the advent of self(Right) Figure 4.19: Urbanity organization is possible and then crucial to the success of the civic space. When it comes to civic spaces, the specific activities or functions in the place are quite wide-ranging, but the overarching intention and orientation of users towards civic involvement remains the consistent programmatic factor and thus spatially binding. The way in which citizens coordinate themselves and their activities, and endless combinations of people and attitudes, is the fundamental purpose of a civic space and the inability to do so freely is its antithesis. The intent is to remove binary concepts of public or private, collectivism and individualism, and work in the gray zones of where those things can usefully overlap, separate, or coexist. The management of the space is where the power to self-organize truly lies: the desired level of flexibility does not rely solely on the physical attributes of customizable building portion, but rather indicates a shared foundation upon which users are free to work, collaborate, and otherwise engage however they see fit.

\section{Urbanity}

Within a city, the sense of what makes one a citizen or part of community is much more complex, which makes the intentionality with which one decides to use a civic space all the more valuable and significant. A successful civic space projects the notion of the civil community and civil society as being essential for the completion of the shared project of the city, inviting in those who wish to participate and affect change. Cities also provide spatial opportunities of insertion or innovation land use that often become the grounds for civic space, citing the importance of contextual coherence and acknowledgement (cultural and aesthetic/formal = intangible and tangible). Large contemporary cities are quickly embodying a sense of the quasination state, one whose values may clash with those of its actual nation but can remain an individual entity nonetheless, and it is this phenomenon that further justifies the need for urban/urbane civic space. 


\subsection{Spatial Precedents}

Civic space can manifest in a myriad of ways to varying levels of success. The range of civic-related activities and participation in space, and their relationships to physical construction and placement, has been a constant influence on society's evolution towards contemporary citizenship. Several categorizations of global spatial precedents have served as both inspirations and drivers of this project: global assemblies, collective structures, and public arenas. 

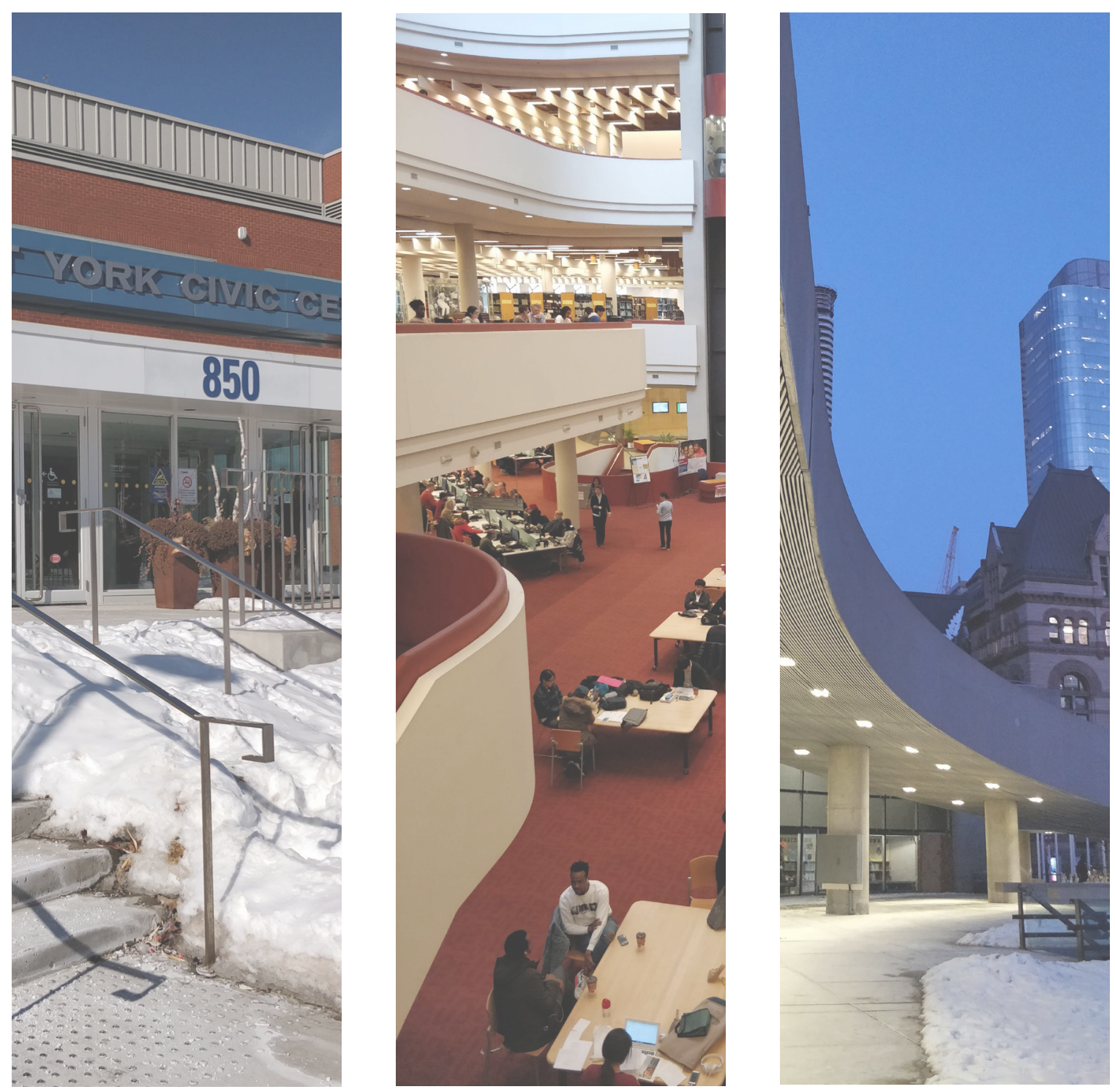

Figures 4.20a-c: Quasi-civic spatial precedents. 


\section{Government Assemblies}

The most prominent buildings of formalized civic dealings are those of federal government assemblies within the capital of a nation, the parliament buildings. Federal parliaments have a very specific and unwavering purpose and use, typically revolving around one person speaking at one time in front of a large audience. This continual architectural rigidity undoubtedly leads to a major roadblock in the ability to rethink the role of governance to its populace, but also provides a clear opportunity for architectural change to lead the way to political change.

Max Cohen de Lara and David Mulder van der Vegt from XML Studio in the Netherlands have spent the past decade studying this relationship between space and politics and its manifestation within the parliament buildings of all countries that belong to the United Nations. They have discovered through this research that every one of the 193 parliaments around the world fit into one of 5 categories, and the countries within each category of building design are consistently lumped together on The Economist's Democracy Index (XML, 2017), explicitly implying a relationship between spatial parameters and democratic success. That work concludes with a hopeful sentiment: "In a time in which democracy is under increasing pressure in different parts of the world, it is time to rethink the architecture of assembly". (XML, 2017).

Takeaway: Specific aspects of parliament buildings are transferable into a more localized and informal place of democracy: the ability to see and be seen, hear and be heard, and centrality of location.
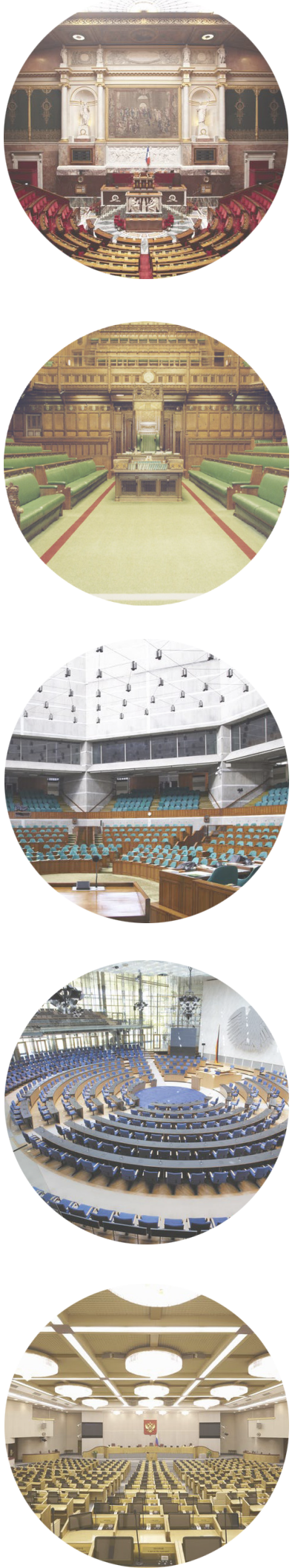


$\begin{array}{rll} & \cdot & \\ \text { French Parliament } & & \begin{array}{l}\text { Grailings / high } \\ \text { ceilings }\end{array} \\ \text { Semi-Circle } & \text { - } & \text { High table } \\ & \text { Massive skylight } & \text { Moderate visibility }\end{array}$

- $\quad$ Aesthetic features

- Comfortability

- Natural light
- Exposed and directed central podium

\begin{tabular}{|c|c|c|}
\hline & $\begin{array}{l}\text { Grandiose / high } \\
\text { ceilings }\end{array}$ & $\begin{array}{l}\text { Aesthetic features } \\
\text { Natural light }\end{array}$ \\
\hline $\begin{array}{r}\text { Bangladesh Parliament } \\
\text { Horseshoe }\end{array}$ & $\begin{array}{ll}\text { - } & \text { Many levels of } \\
\text { - } & \text { seating/audience } \\
\text { Open central space } \\
\text { (no podium) } \\
\text { - } \quad \text { Many access points }\end{array}$ & High accessibility \\
\hline
\end{tabular}

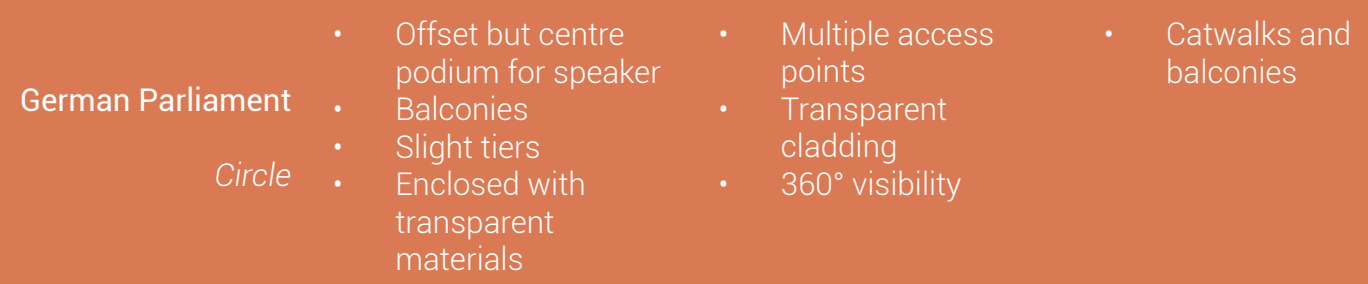

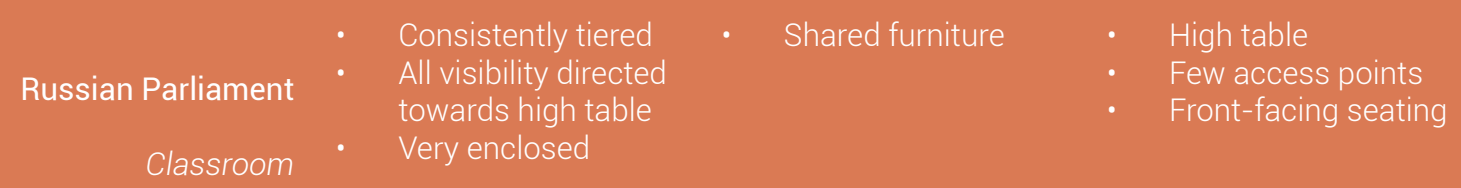




\section{Collective Structures}

These precedents have been categorised as such for their purpose of providing space for collective activities of a wide range. Taking a step back from civic-centric spaces and investigating buildings that are not specifically civic-oriented provides a refreshing look at design for gatherings in general. Part of the approach of the design of a new civic space needs to prioritize creating spaces in which people desire and feel free to congregate in. Design drivers or considerations that achieve that goal are universal regardless of program.

There are many types of buildings or spaces that house program with similar requirements to local or participatory democratic practices. Schools, public squares, or libraries all function as spaces where people voluntarily visit for a purposeful but perhaps as of yet unstructured intent. Learning how these spaces draw people in and provide a fruitful and encouraging atmosphere that encourages returning is essential for a softer and informal democratic space.
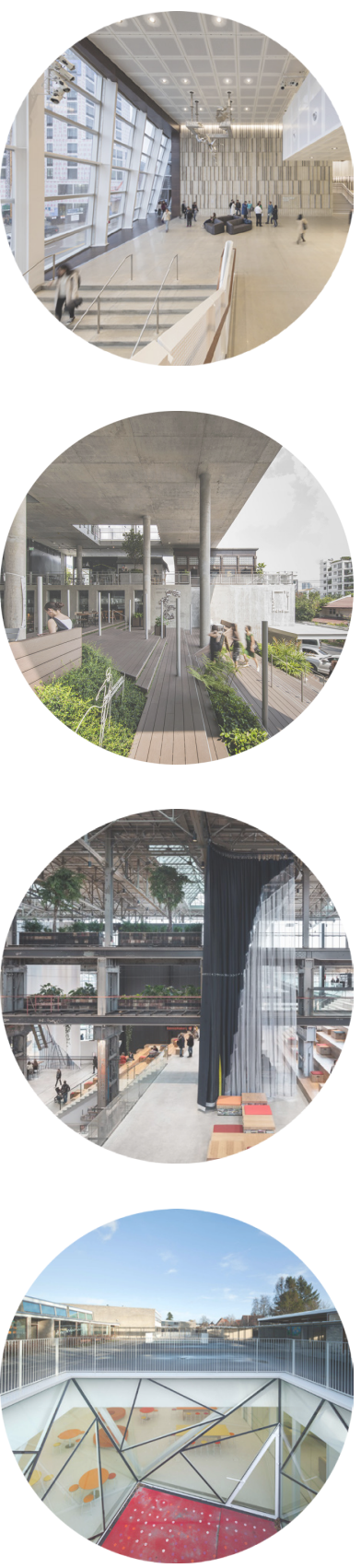

Takeaway: Liminal urban public spaces emphasizing porosity, decentralization, and accessibility.

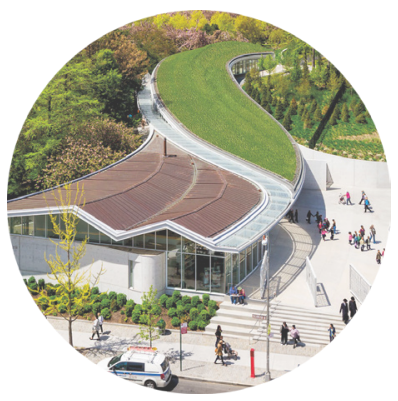




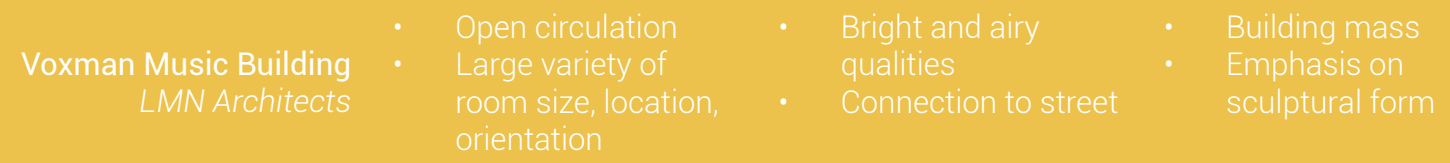

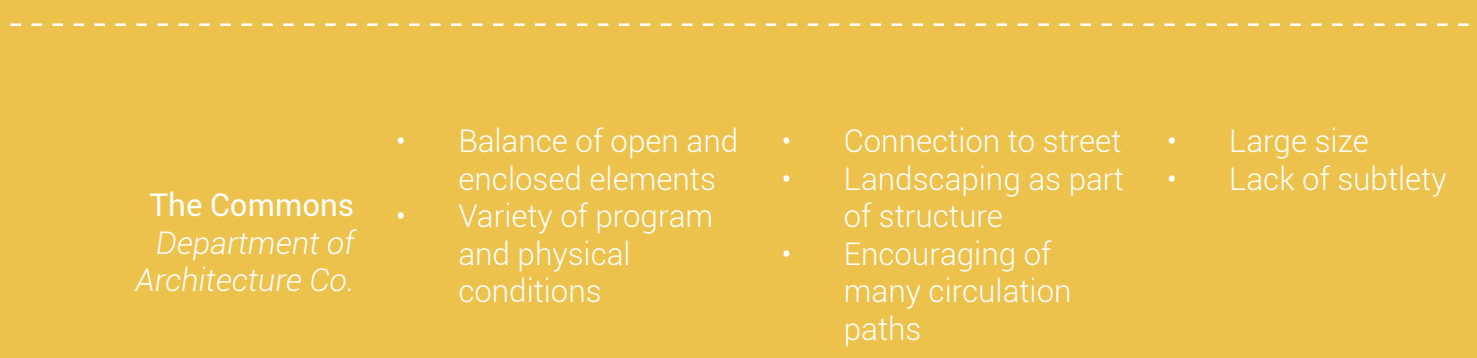

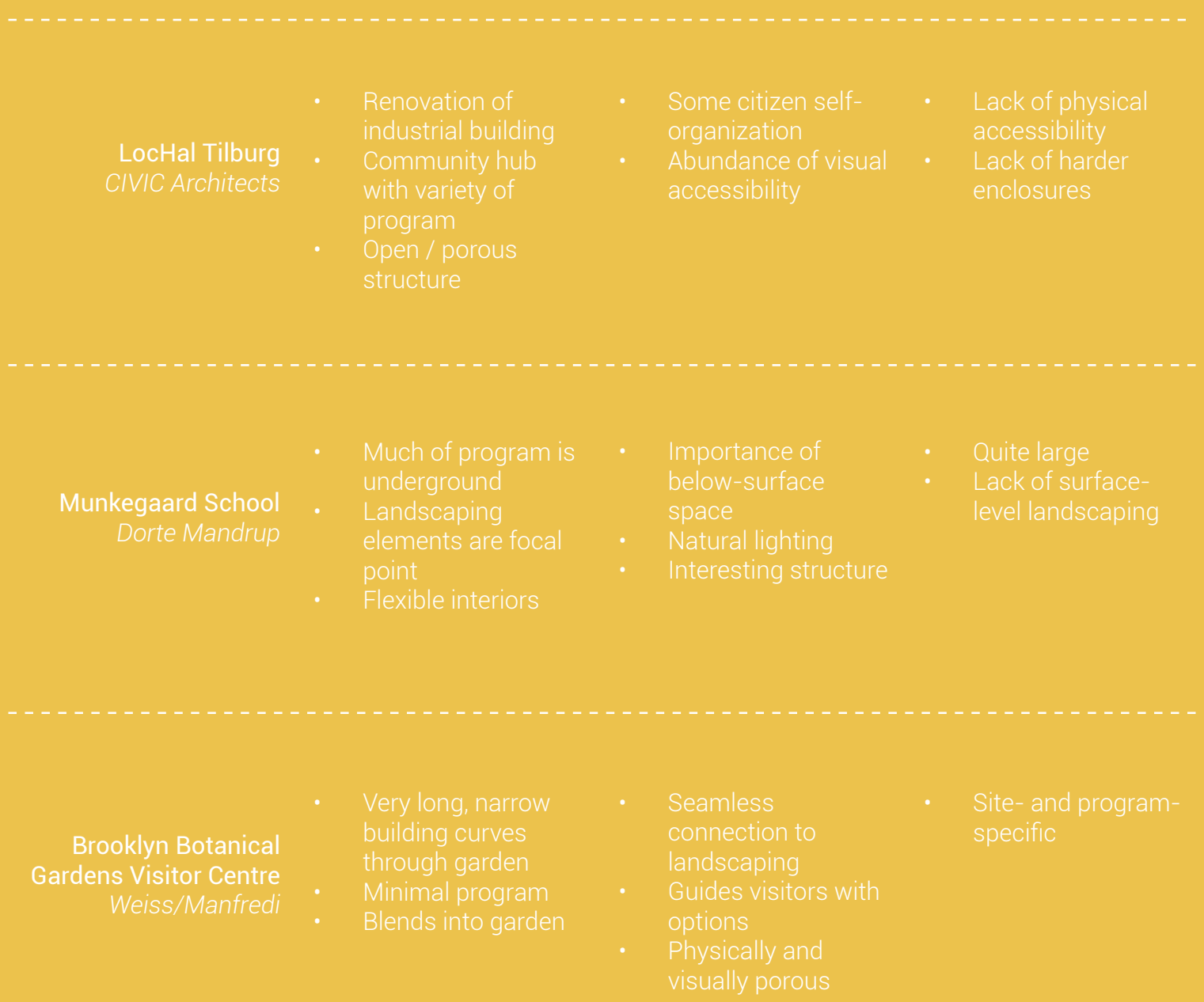




\section{Public Arenas}

This third category of spatial precedents is the least structured, blurring boundaries between indoor or outdoor. They serve as examples of communitybased or fluid public spaces that could possibly contain civic activity. These can include city plazas, community centres, city halls that contain other, less exclusive programming, or other structures that are a focal point in their public realm. Studying these precedents that may contain civic-oriented functions but are less institutional than overt containers for government activity begins to fill in the blanks of where and how citizens can become involved outside of political or bureaucratic systems.

These public spaces place equal emphasis on interior and exterior elements, free movement throughout both, and the encouraging of autonomy and agency for citizens who visit.

Takeaway: Using landscaping and building elements that dissolve boundaries to achieve seamless blending into the urban neighbourhood context.

(Top to bottom) Figures 4.23a-e: Public realm precedents. 

Rafael Arthur
- Connection to street

- Landscaping

- Colour contrast to context
- Lack of physical and - Singular use / room visual barriers

- Simple aesthetics

- Open / unprogrammed space
- Minimal connection to landscaping
- Embedded into the landscape

San Vicente Ferrer Community Centre Plan:b arquitectos
- Transparency

- Porous accessibility

- Landscaping as part of structure
- Lack of enclosure

- Location on main thoroughfare visible and physicl accessibility
- Materials and construction reflect neighbourhood

- Thin and winding design
- Small addition accompany plaza 


\subsection{Spatial Principles}

(Opposite) Figures 4.24a-f: Spatial principles.
The programmatic principles of accessibility, decentralization, self-organization and urbanity discussed previously have architectural implications, but sit on a more macro scale to inform the designer of general functional intention. Shifting into a spatial intention, there are clear parallels for these concepts that become integral to the design process of each new local democratic zones.

These spatial principles are organized into three spectrums upon which various portions of the building will land. Both ends of the spectrum become essential considerations for designing civic space: there is no good or bad end of the spectrum, rather both ideas are necessarily used in different ways for different programmatic and spatial intentions.

Porosity to Enclosure: The former indicates building elements are arranged in such a way that allows for the occupant to feel a dissolution of boundaries in each space and when moving between spaces. There is no sense of being bound in a space, rather the occupant can sense interstices through which spatial qualities flow in and out. The latter is a measure of a space on a range from complete impermeability to complete openness. The occupant is able to discern the intimacy of the function within a space by its level of enclosure.

Transparent to Opaque: Either the removal/blurring or the addition of spatial limitations, boundaries, or markers. Not just a quality applied to a physical material or element within a building, but also the inherent properties of being inclusive of and accessible to the occupant, or indicating the need for privacy and intimacy.

Transition to Threshold: Diffuse areas opposing the normative notion of stark barriers between spaces, transitions are not reliant on regular architectural circulation that is designated as spatial destinations in themselves for the sole purpose of moving. They serve as linkages between more defined portions of the building that can be defined as thresholds which clearly demarcate a rapid and short shift from one type of program or space into another. Both ends of this spectrum can be engaged without relying on traditional indoor/outdoor barriers as indicators of spatial placement.

One of the most important distinctions within the design of these buildings is the dissolution of traditional ideas of spatial arrangement, both conceptually and spatially. Dichotomies such as private/public, interior/exterior, and open/ closed are replaced with subtle gradients that allow occupants to infer most appropriate places for their desired function without being jarred by harsh signage or meandering corridors. 


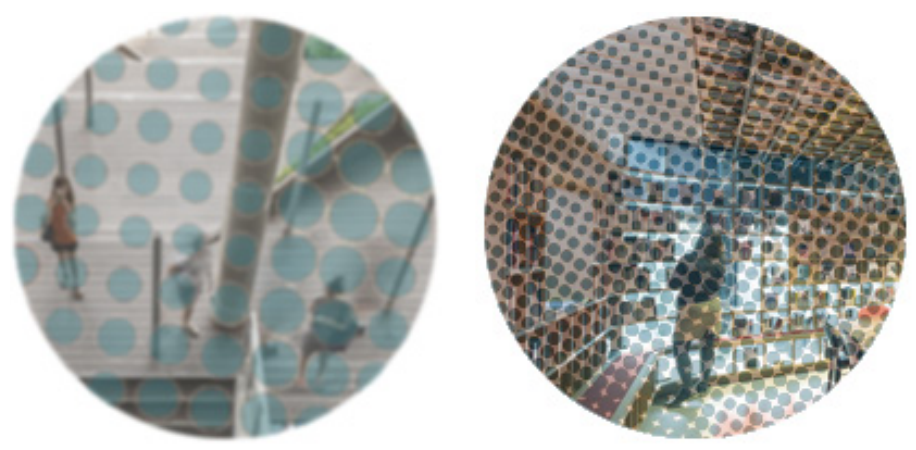

Porosity / Enclosure
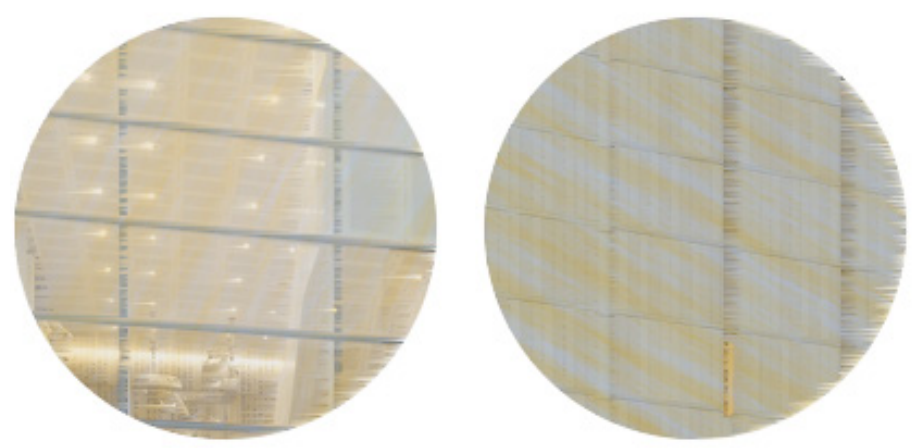

Transparency / Opacity
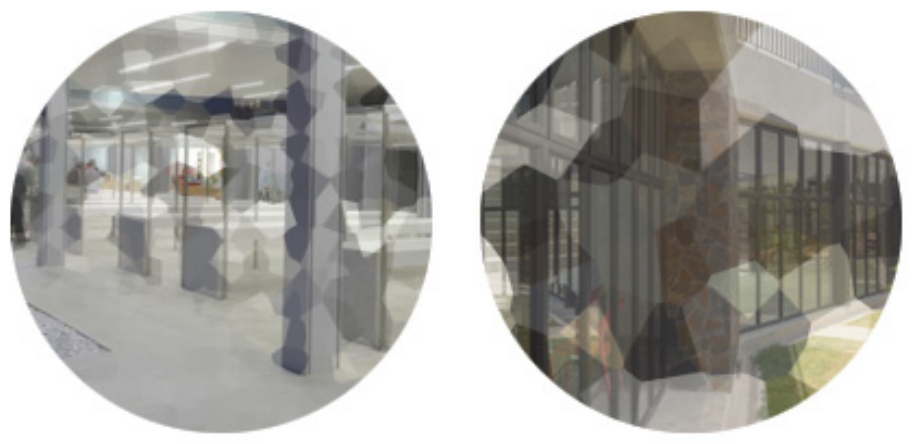

Transition / Threshold 


\subsection{Toronto's Spatial Civic Context}

(Opposite) Figure 4.25: Toronto's civic spaces.
Inspired by the global study of spatial precedents that do already or could act as quasi-civic, a look into Toronto's own spatial civic context is essential for identifying the city's gap in civic-ness. Toronto has equivalents of the three precedent categorizations that are able to be analyzed more directly for their placement in context. These are institutions, civic centres, and public plazas.

Institutions

Government spaces that are represented through institutions like Toronto City Hall, Queen's Park, or Metro Hall embody the most conventional, top-down methods of both building and municipal governance. Similar to the study of global government assemblies, Toronto's institutions can be unyielding and exclusive. These buildings were created to house both those who form bureaucracy and civil services, and large portions of these buildings emphasize on privacy and enclosure.

\section{Common Centres}

Just as in the global precedents outlined, Toronto is rife with common areas that could be primed for civic activity. They are referred to here as common centres for their operation as places of purposeful collective gathering within conventional buildings. Their designs can sometimes similarly to institutions in their grandiosity, but circulation around adn within makes both program and space much more citizen-focused. Common centres have in the past and could potentially be hijacked by citizens wishing to exercise specifically civic activities.

Public Plazas

Often directly adjacent to an institution or civic centre, Toronto has a plethora of public spaces, but some are difficult to place in a specifically civic context. The study of these specifically outdoor and open spaces provides a different perspective than the previous category that including a broader swath of the public realm. Many serve as places of congregation for civic action, but would they function as such if not for their proximity to clear places of government?

These three spaces each are lacking in a full serving of amenities or components that would encourage an uptick in local participatory democracy. However, there are elements in each that can certainly contribute to a new type of civic space that would serve this purpose. Looking at each type of civic space in terms of their programmatic and spatial elements makes clear the components that would be successfully implemented into a more combined and open civic space. The three types of civic space also fit very neatly onto a gradient of enclosure; the institution typically operates with the most enclosure, and the plaza with the most porosity.

The following are abstract, observational investigations of one example from each of Toronto's three categories. 


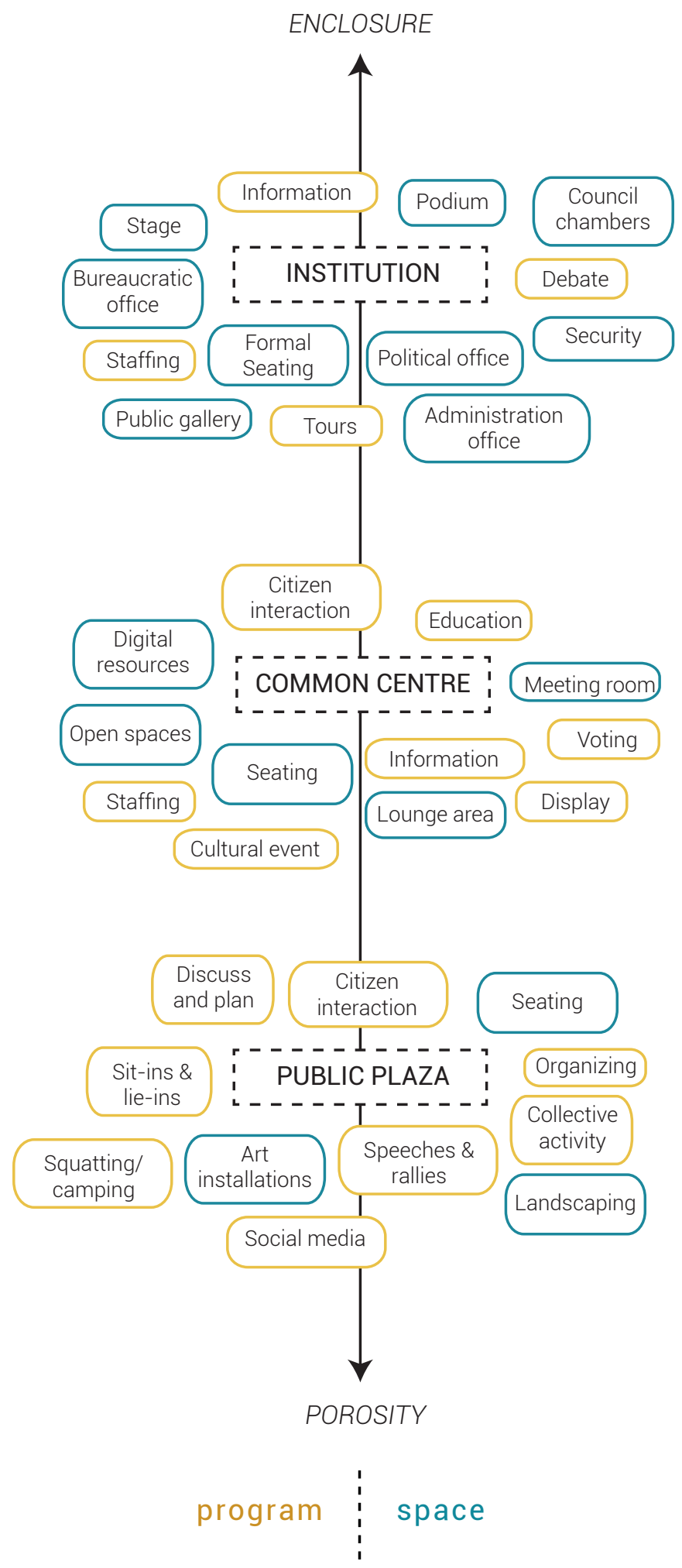


(Below) Figure 4.26: A walkthrough of the East York Civic Centre.
Institution: East York Civic Centre

Observation during March 8, 2019 @ 10:14:00-10:48:00

Toronto currently has five civic centres that represent the preamalgamation areas of the city. They do not serve as the main municipal hubs of bureaucracy and civil service, thus their design appears as a cross between government institutions and community centres. Despite lacking in typical types of community amenities they often appear more open and inviting to citizens. However, they still exist for the purpose of government functions and are run by the municipality.

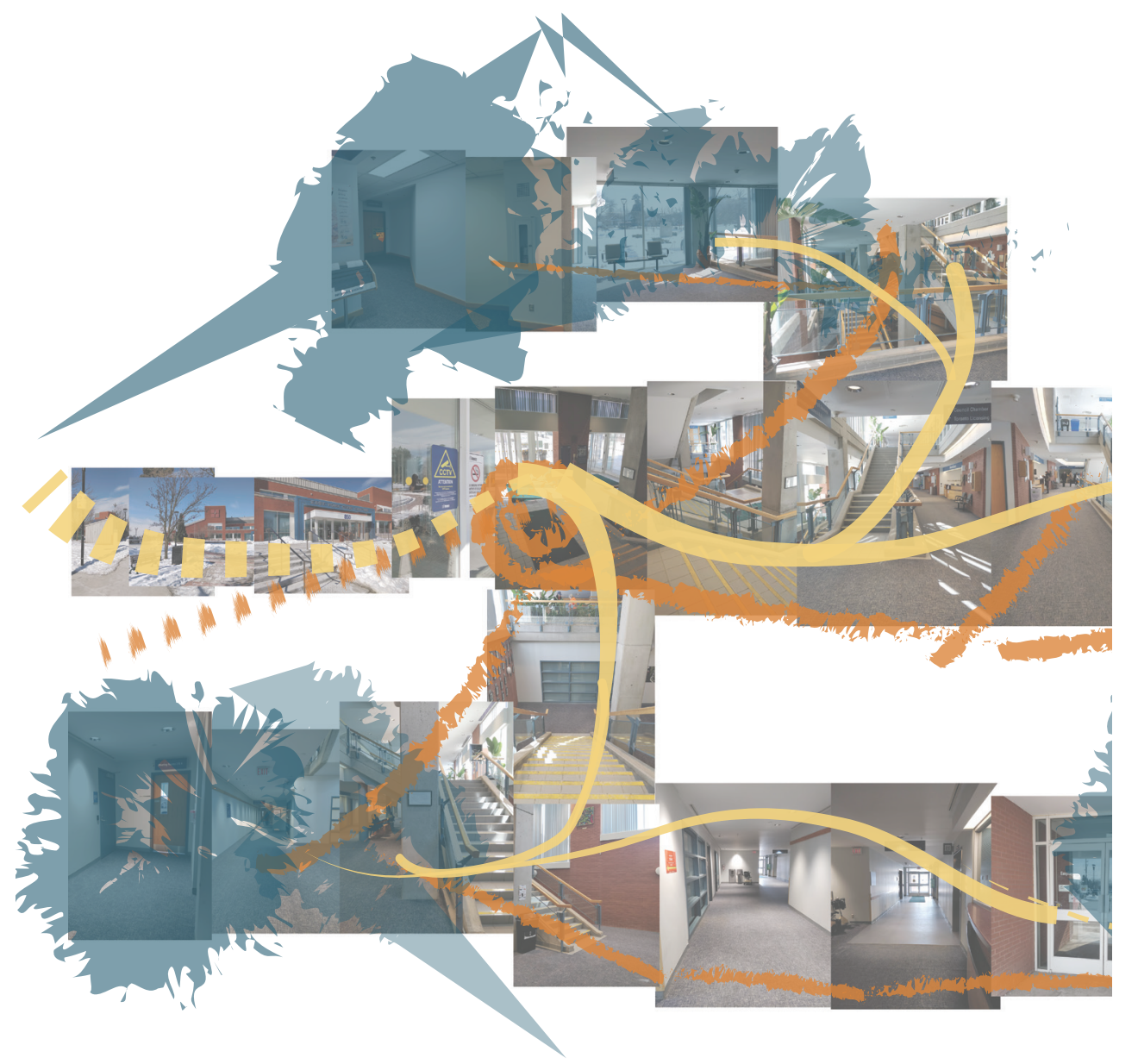


A walk-through of these spaces measures the presence or absence the five spatial principles. In particular, mapping out visual access, physical access, and physical barriers provide a quick and succinct summary of the strengths and weaknesses within Toronto's current stock of civic spaces. For instance, the East York Civic Centre that is meant to serve the Toronto/East York wards has an interesting mixture of porosity, enclosure, transparency, thresholds, and landscaping. Many elements in this building spatially work quite well, but because the building and land are still tightly controlled by municipal bureaucracy, the spatial openness is diluted by an intangible barrier to entry for citizens.

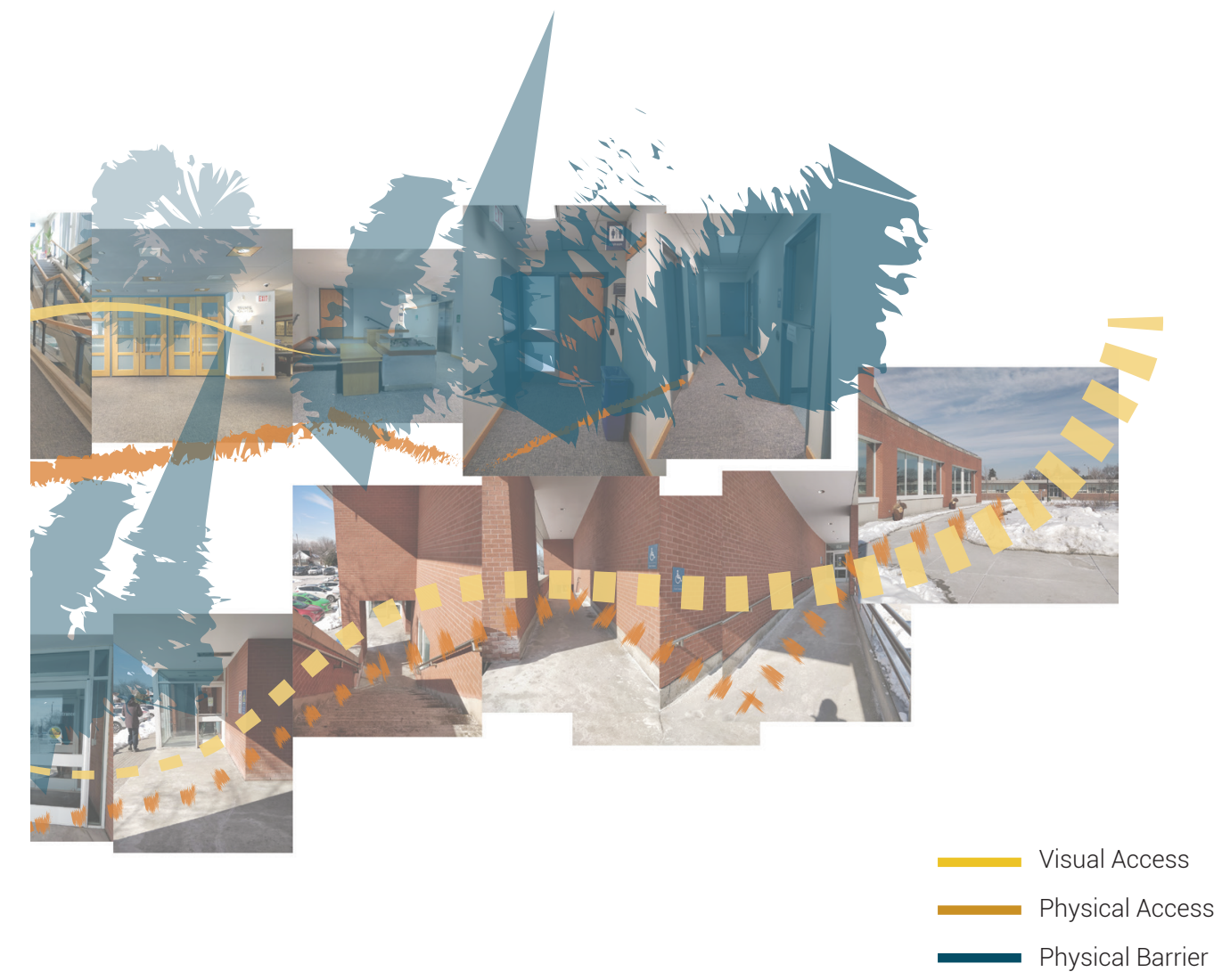


(Opposite) Figure 4.27:

Toronto Reference Library, first abstraction.
Common Centre: Toronto Reference Library

Observation during November 19, 2018 @ 13:47:00-14:36:00

A library hovers on the edge of being quasi-civic and simply public, and the Toronto Reference Library especially blurs this boundary, as it is home to many different spaces and functions above and beyond that of the traditional library. Many of the entire library system's administration offices are here, acting as a sort of outpost from Toronto City Hall, and several boards and committees from across use the various spaces to conduct civic business on a regular basis. In Toronto, the library system and the reference branch especially serve as a source of civic pride, and often as a site for specifically civic-oriented activity by citizens. The reference library has long been an architectural draw for Toronto, contributing to the intrinsic mix of grandeur aesthetics representing institutional functions. 

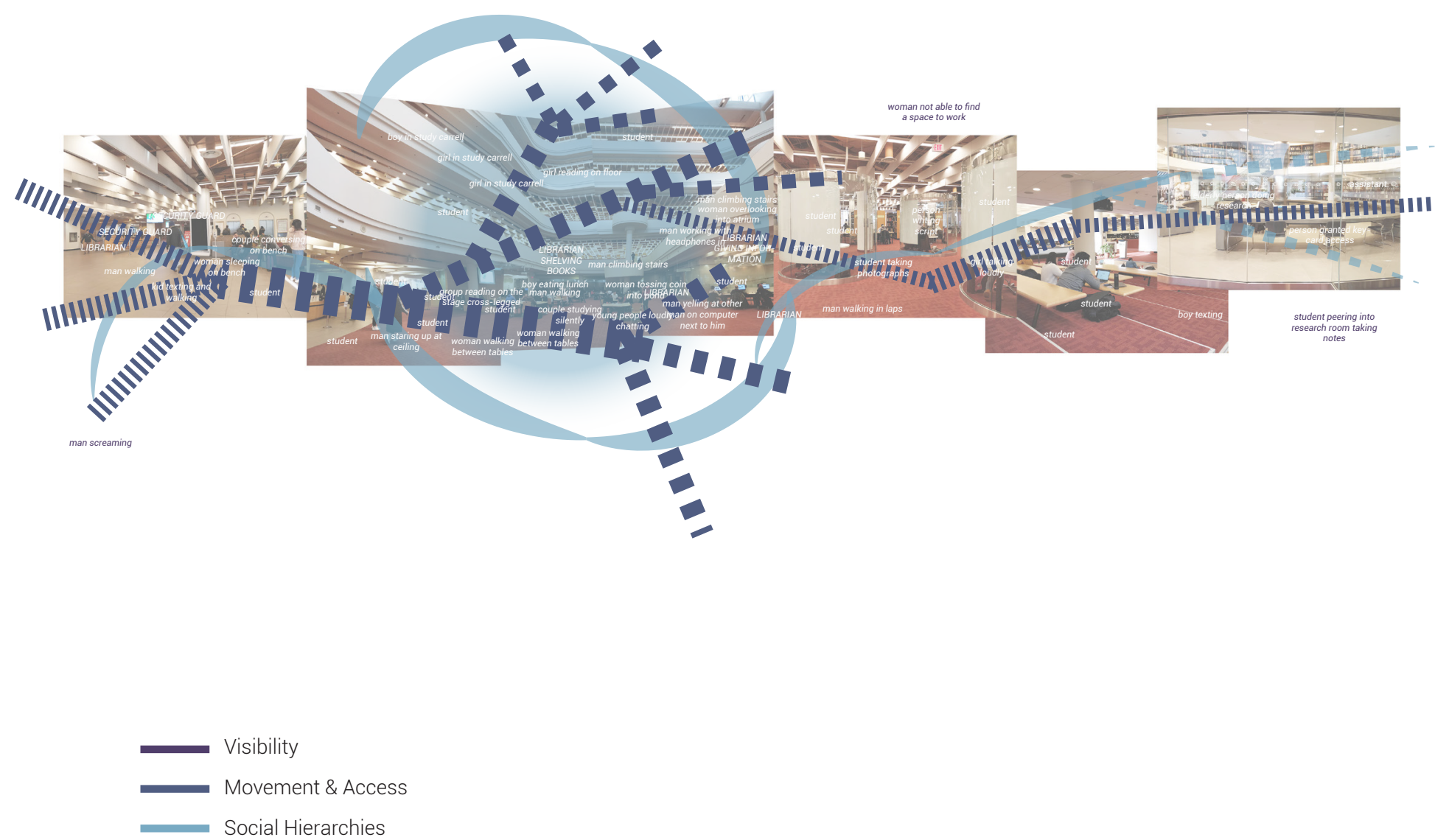

The Toronto Reference Library is known for its giant atrium space, a lovely mix of 'open' and 'closed' spaces. The rather compressed entrance opens into the space from which the occupant is immediately viewable and can get a sense of the entirety of the space, but there are still side periphery spaces that are quite hidden from view. It is only once the occupant begins to move around the space that certain areas become accessible, but movement is extremely free within this building. A social hierarchy is felt to some extent in this building, but this library hosts a hugely diverse mix of citizens from all over Toronto and beyond. 


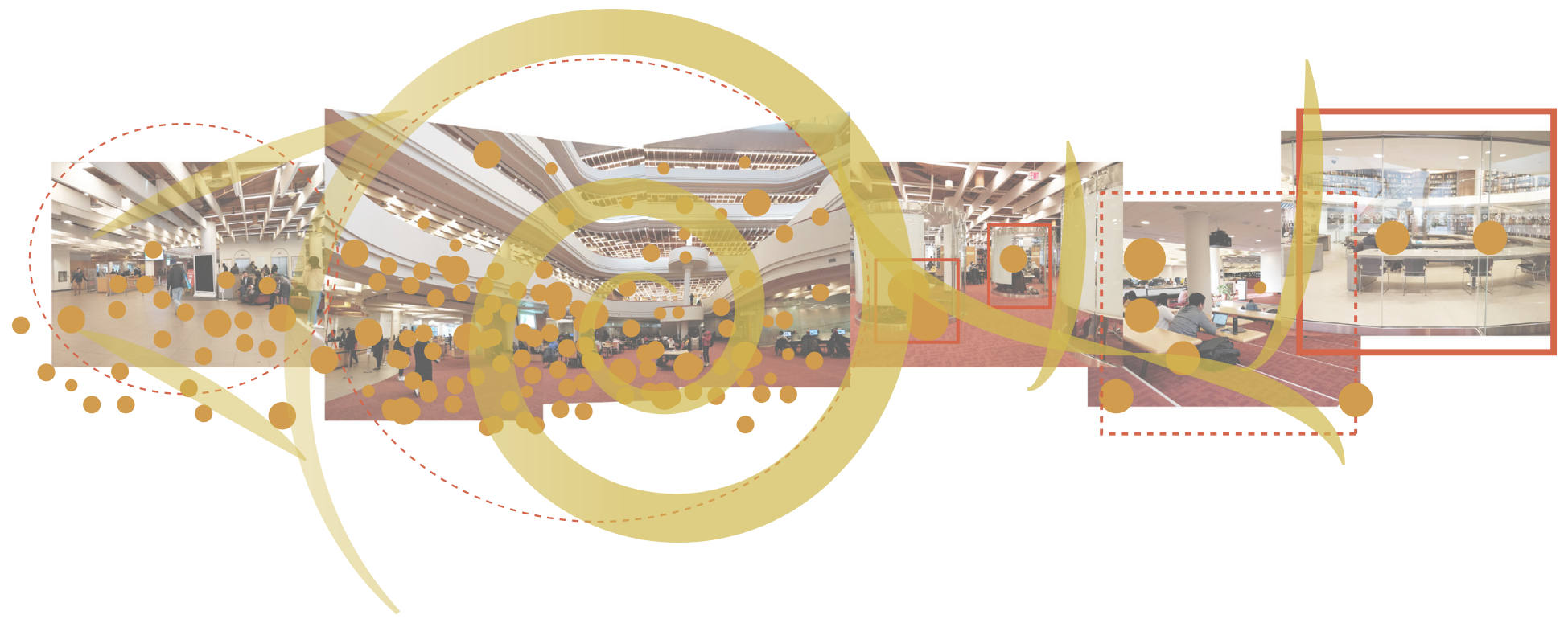

Figure 4.28: Toronto Reference Library, second abstraction.

The vast variety of work or activities that are able to take place within this one building makes it an advantageous case study for decentralization. Even so, the space still harkens to some level of central involvement. Although citizens may organize themselves, it is still within parameters very much controlled by a small number of people; to a considerable extent the architect and other designers contributed to this level of control. The library's infrastructure space mostly does act as traditional circulation space, but because the large majority of the library is completely open concept, the work areas designated by their furniture blend with and spill over into the in-between. The design of the library is one that celebrates all of this space as equally valid. 


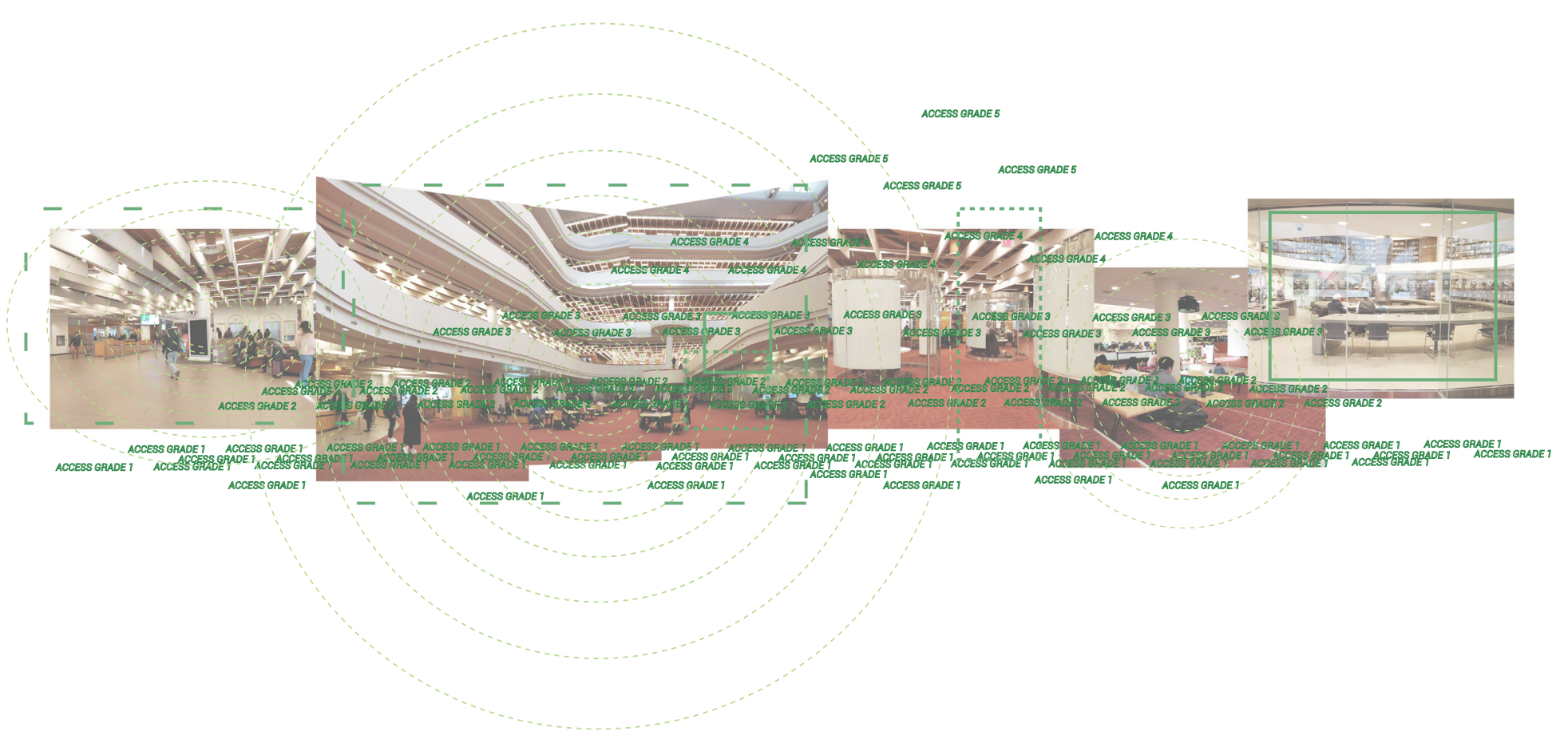


(Opposite) Figure 4.30: Nathan

Phillips Square, first abstraction.
Public Plaza: Nathan Phillips Square

Observation during November 19,2018@12:02:00-12:45:00

One of the most politically-oriented sites in Toronto, Nathan Phillips Square serves as highly manipulated, wide open public space directly in front of the governing body housed in City Hall, offering an ideal ground for any kind of public action or address. Aside from a small auxiliary building on site that is only accessible for short periods of time, any uses of the square are externally exposed.

The site's status as a distinct place of civic-ness begs the question of why; what is it about the site designates it as such, aside from its proximity to a major governmental insitution for the urban centre? This investigation also acts as an informal and externally-focused exploration of city hall itself, and how it is served by the large outdoor space of Nathan Phillips Square. 

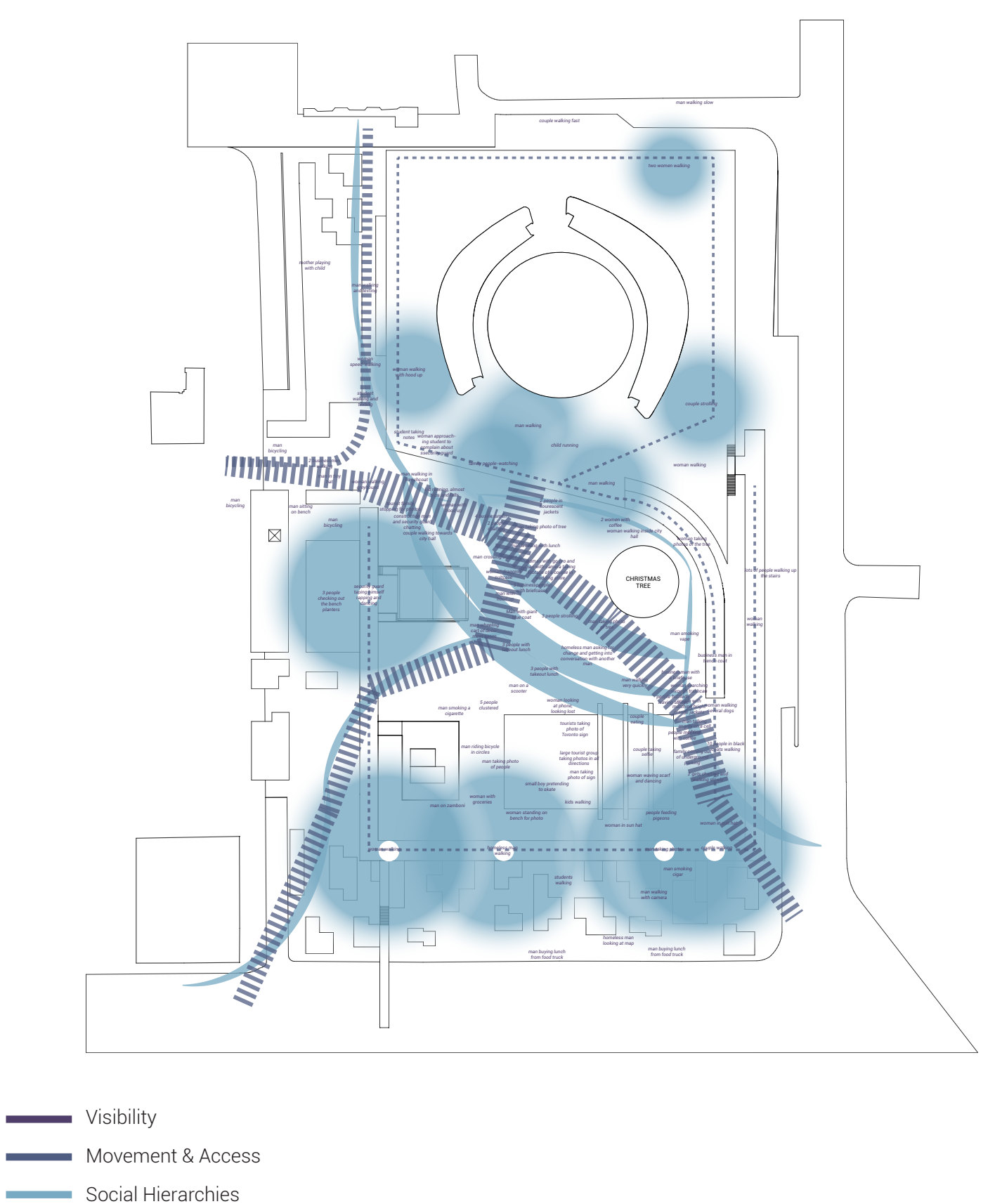

There is very little in the way of citizens being able to both view and be visible to anyone else in the vicinity; on a regular day this makes for great people-watching. Surveying the site during the weekday lunch hour revealed that several hundred people crossed the square in all manner of directions. This is of course because of the positioning of city hall as a workplace, but also because the square is a convenient shortcut for many people, indicating its high rate of accessibility and ability to facilitate movement. Because of the ease of understanding and utilizing the many various methods of visibility, movement, and access, normative social hierarchies seem to matter less in this space: citizens of all manner of differences in demographics utilized the space equally. 

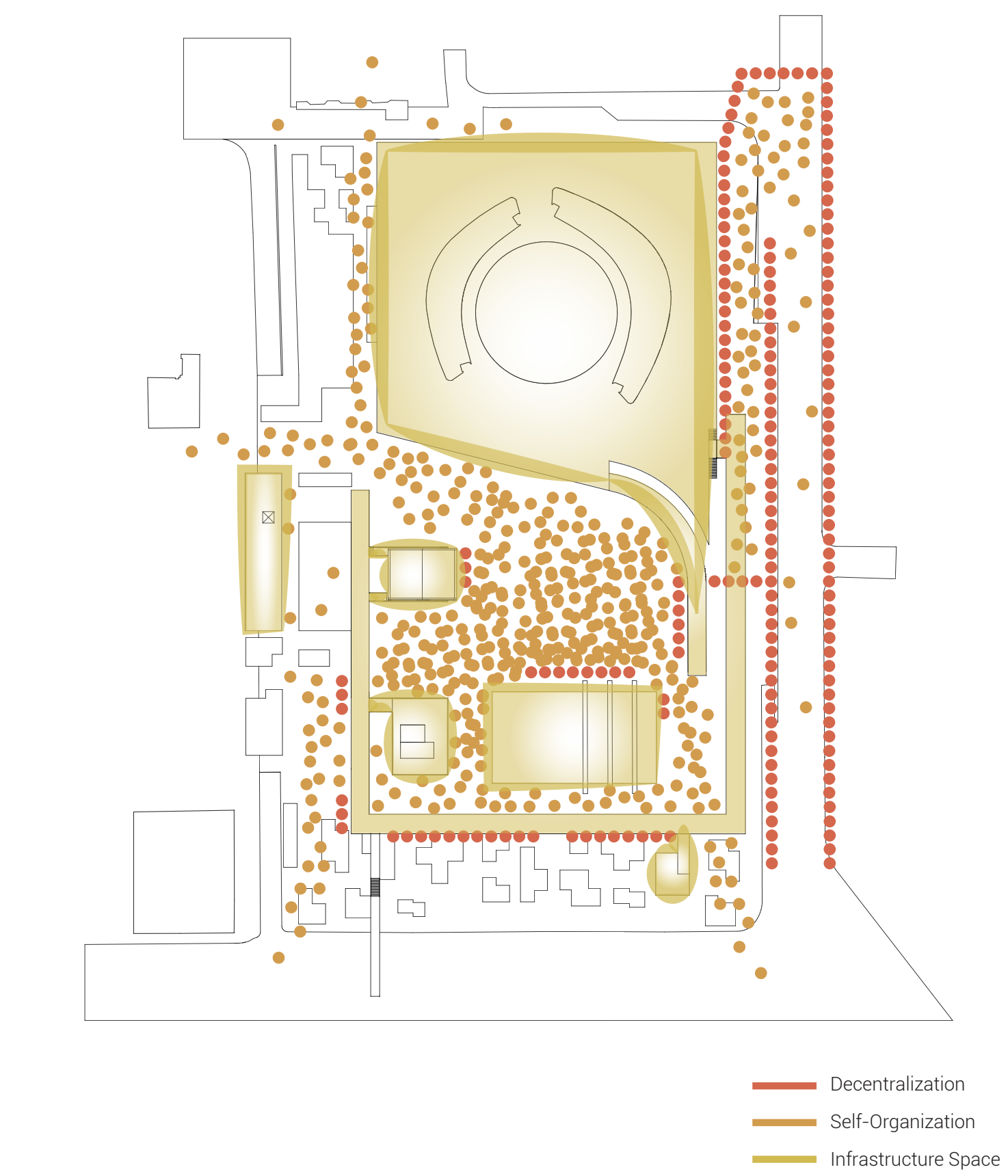

Figure 4.31: Nathan Phillips Square, second abstraction.
The vast openness of the square neither discourages nor reinforces centralization, but de-centralized structures are chosen as the most beneficial way of managing the large crowds. All categories of people at any event, be they participants, supporters, or simply bystanders have organized themselves spatially, whether consciously or not. The unique components of the site that are often at the forefront of attention can be secondary, during an event and provide infill as infrastructure space in-between the sporadic and temporary 'key' spaces, but still act as destinations within their own right. 


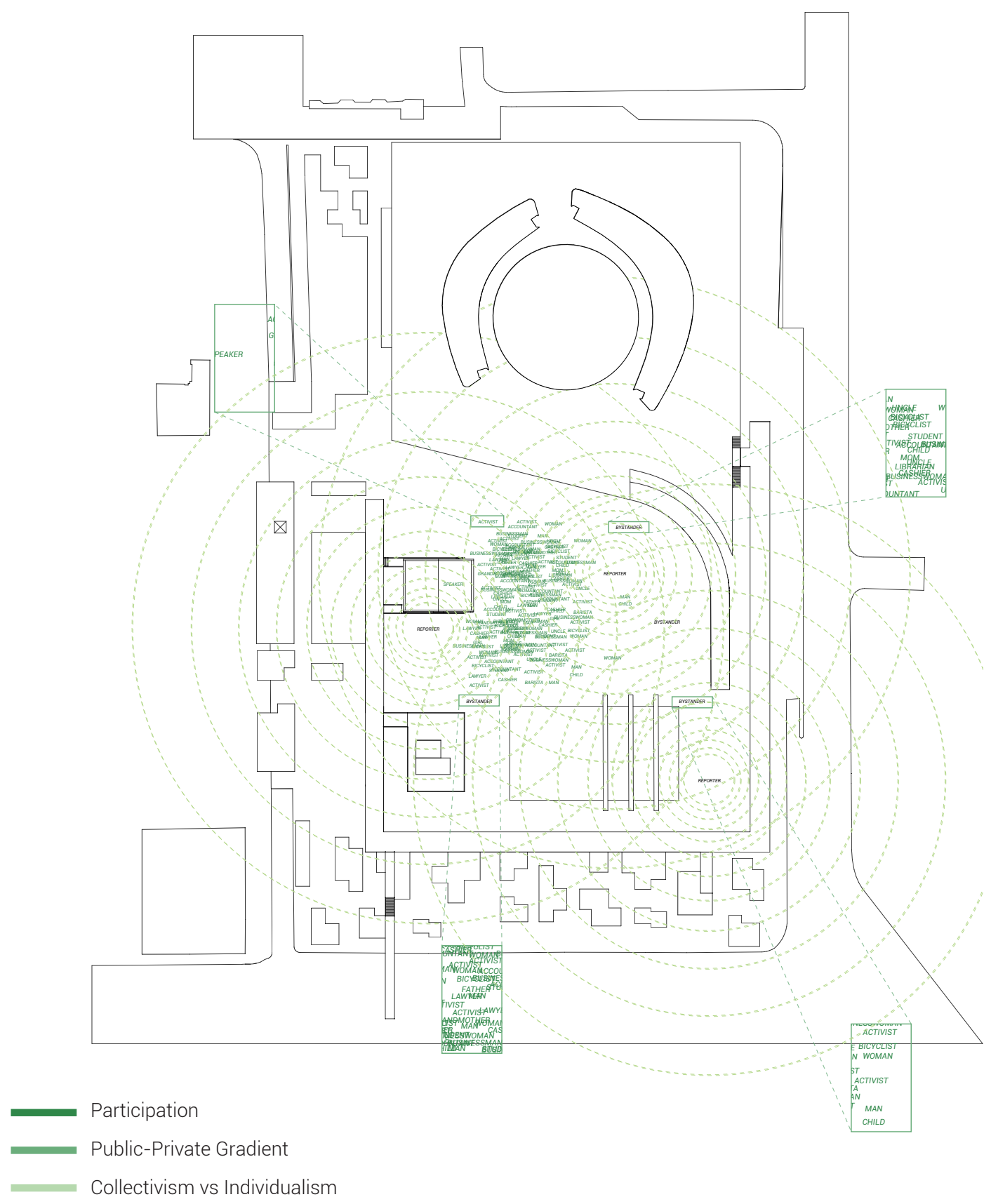

Anyone who comes through the square becomes a participant in some capacity, but there is also the option to choose non-participation and to act as simply a Figure 4.31: Nathan Phillips bystander. There are rarely urban actions in the city that occur without some kind of documentation, usually on cell phone, and this has the power to transcend the boundaries of public space.The collapsing of these boundaries forces the link between the collective and the individual into more bright light. In a lot of cases there is one individual or a few leading a collective that spreads out in a much larger radius than just within the space at hand, and the process of individual action leading collective action is apparent.

Square, third abstraction. 


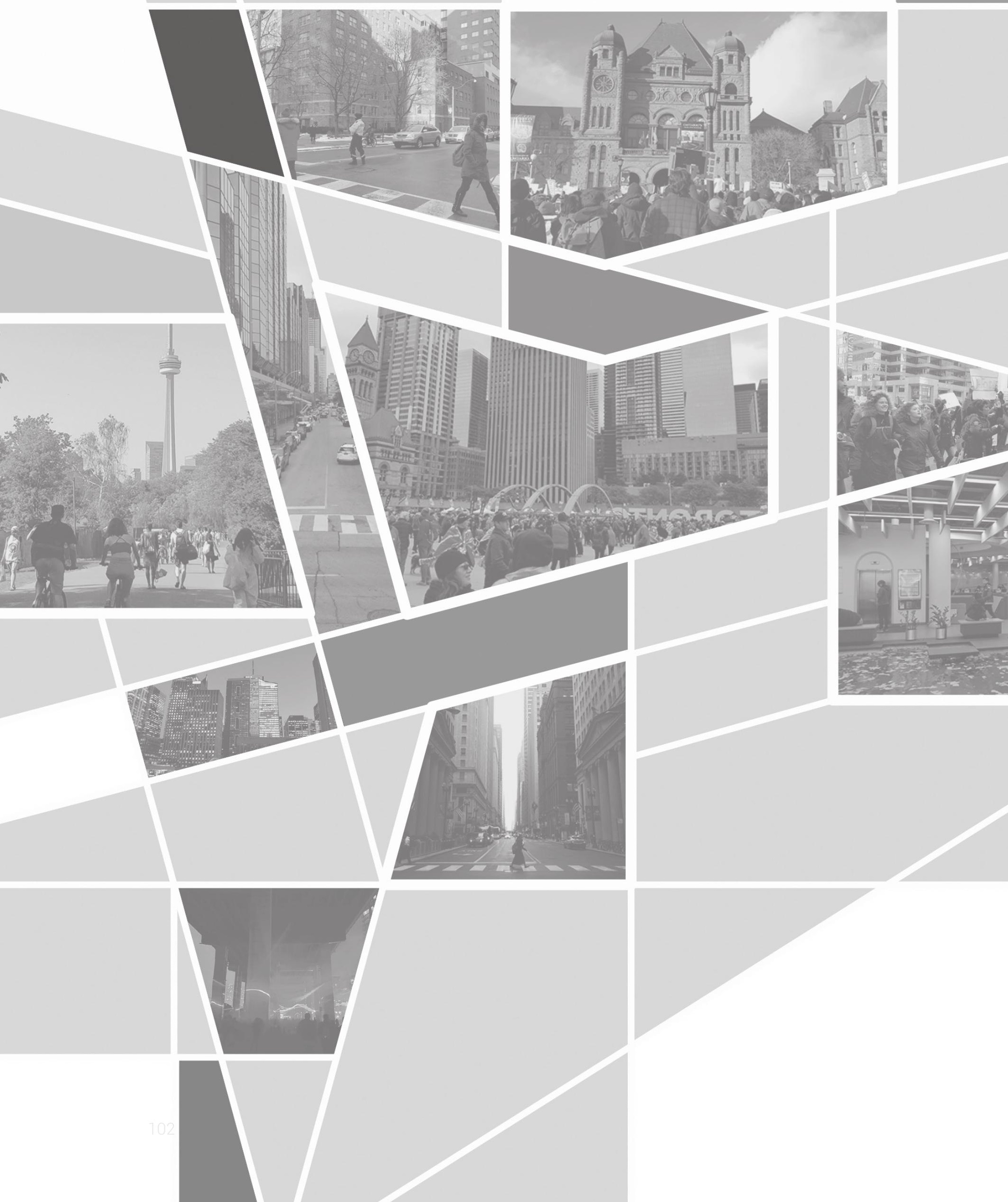



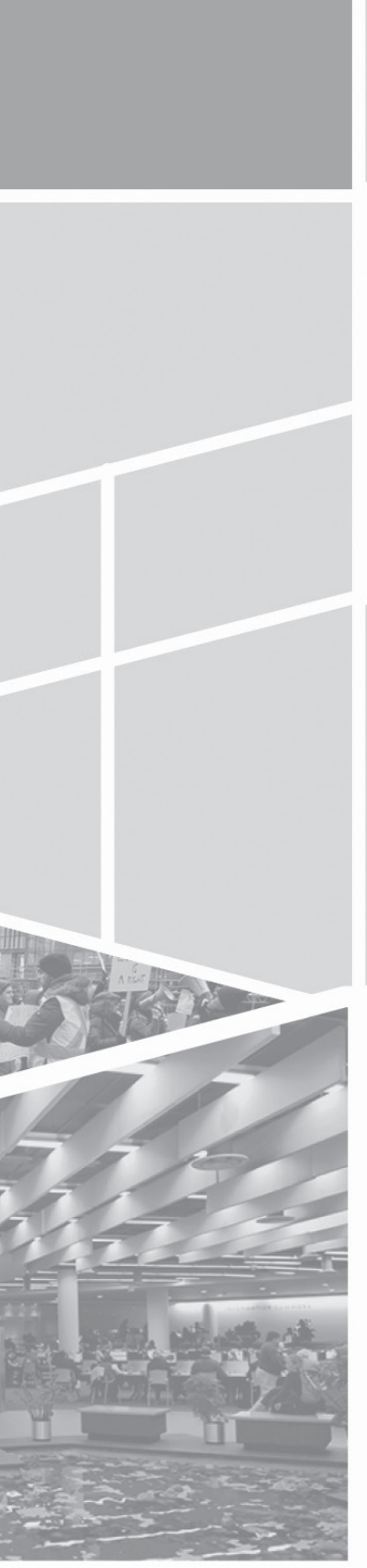

\subsection{Constructions}

How can programmatic and spatial qualities come together to manifest civic-ness and encourage local participatory democracy? 


\subsection{The Local Democratic Zone}

In the current rapidly shifting political climate in Toronto, there is an opportunity for re-imagining civic space. We can shed our conventional notions of government activity being sequestered in intimidating structures and imposing architecture, and design civic spaces that more blatantly connect government to our daily lives by inserting it into our neighbourhoods. This thesis is exploring a new method of public design, one that redefines our notions of civic space by making it more accessible, intimate, vernacularly-focused, and self-organized.

On a broad level, we can consider five different actions that lead to civic engagement:

1. Communicate: resources required to discuss and plan with one another, other organizations, cities, countries, etc.

2. Collaborate: room to organize within groups in a physical context

3. Create: freedom to produce material of any sort without restriction

4. Participate: functions related to government such as voting, debates, speeches, etc.

5. Demonstrate: flexible and equipped spaces to protest, discuss, debate policy.

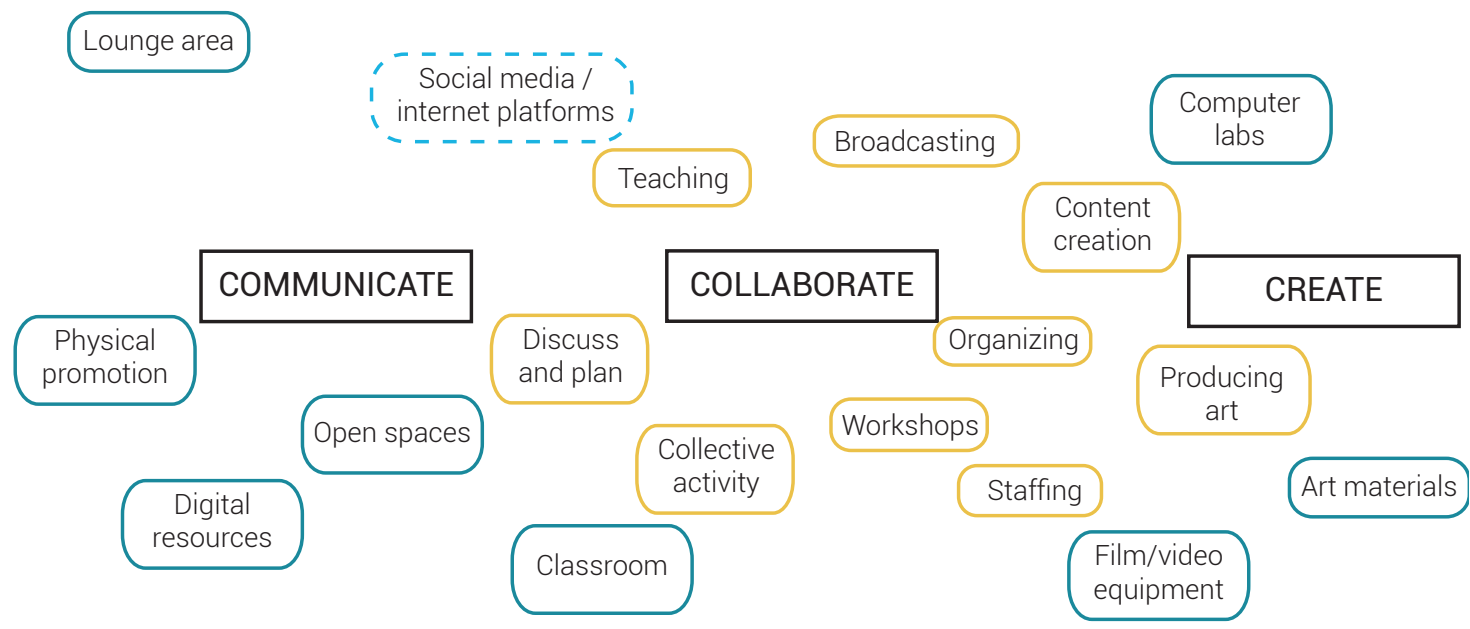

Figure 5.01: General functions. 
Having one centre for all of these possible actions to come together in whatever ratio or priority is required for the area/citizens of that ward is the fundamental design challenge and basis. This project will serve as a holding centre for a new definition of civic engagement: one that prioritizes citizen participation in their city, neighbourhood, avenue, and building at any conscious or unconscious level.

These five actions can manifest in both tangible and intangible ways. This thesis is investigating design methods that bring together those functions on a physical platform that re-emphasizes the importance of a collective, public urban gathering space.

Design explorations began with breaking up the five general actions into more specific programmatic and spatial ideas.
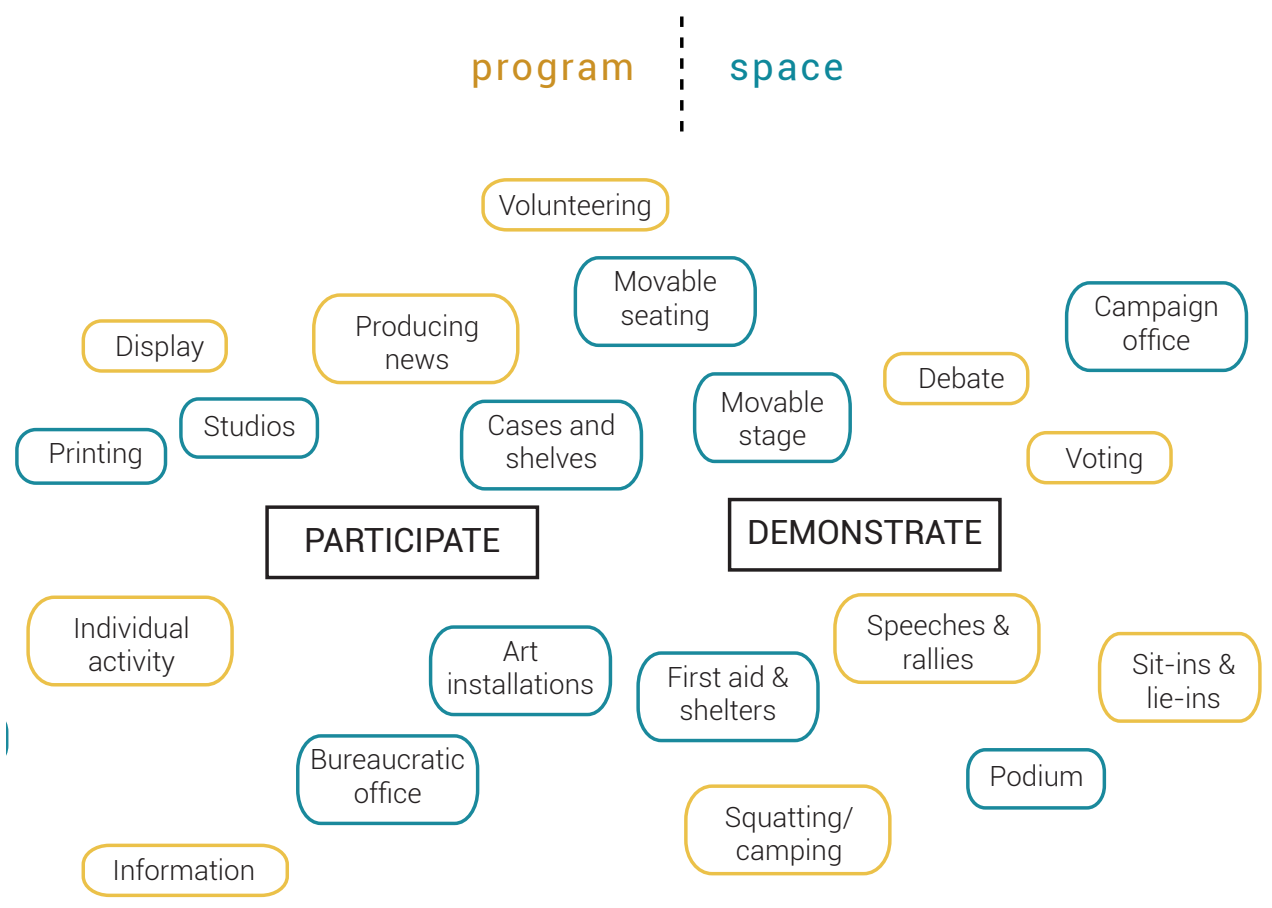
(Opposite) Figure 5.02: Module and liminal elements.
The inclusion of the final programmatic elements is based on ideas of civics, societal and architectural influences, programmatic and spatial theories, and the manifestation of precedents, as well as earlier design iterations. Module and liminal elements are arranged based on the programmatic priorities of those particular wards, with the spatial principles serving as a descriptive guide for the laying out of space.

This new local democratic zone will be able to facilitate a variety of civic actions. Allowing this flexibility and choice for citizens to participate in civic and city life in ways they see fit ensures the continuation of active contribution, essential to keeping the city alive and well. Fran Tonkiss summarizes the need for balance in the contemporary age of civic engagement: "One of the primary rights to the city is the claim to common public space. A division between public and private has been a key device used by social theorists in analyzing social relations, but it is not always clear how this dualism relates to actual public places in the city." (Tonkiss, 2005, pp. 5) This balance is highlighted in the local democratic zone; transition spaces that may have boundaries blurred but are still open and accessible.

There can be many types of civic activity, but this project is concerned with providing space specifically for government-oriented civic activities. For instance, citizenship grants those the validation needed to encourage or in some cases even permit participation in various civic activities such as using a library or signing up as a youth sports counselor, but these things are a necessary (though not mandatory) first step into wanting to participate in governance.

Citizens who work, reside, or otherwise civically participate in that particular ward can be a member of the local democratic zone. This affords the ability to book space throughout the zone. Staff for the building is minimal; there is administration and information volunteers but membership is granted regardless of normative societal status, such as things like formal citizenship, visas, income levels, etc.

This openness in program reflects an openness in architecture meant to encourage local participatory democracy. This could be the first step to decentralized and selforganized neighbourhood councils, with the help of the councillors for Toronto's ward system. 
Module

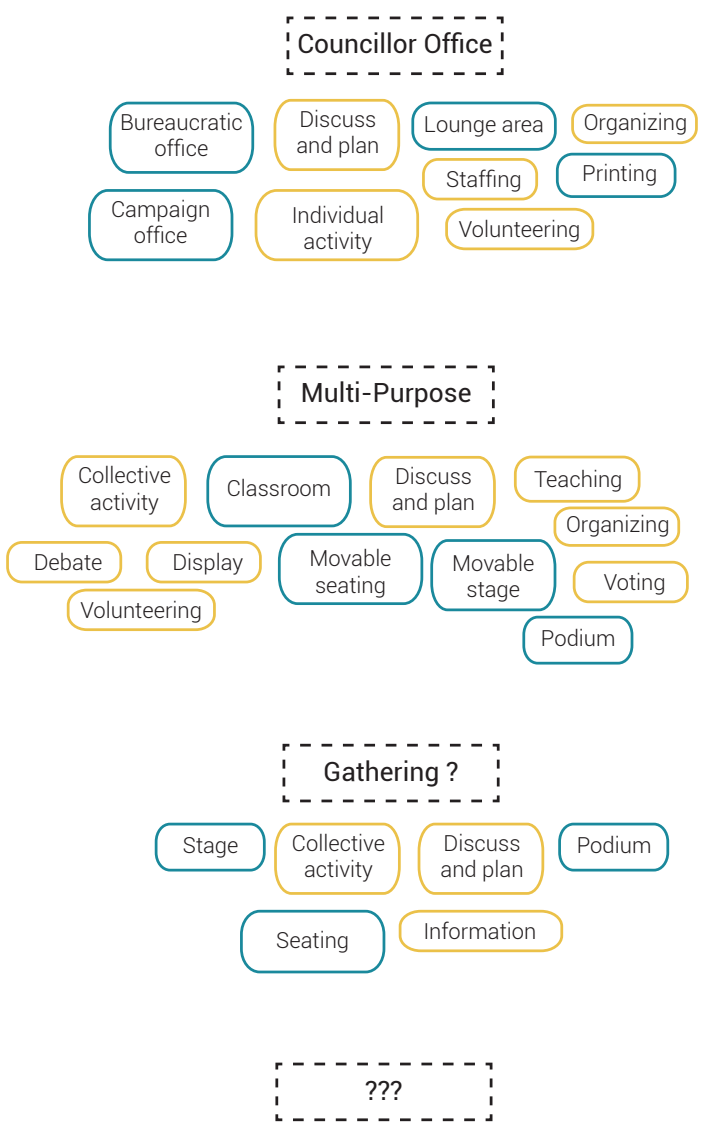

Liminal

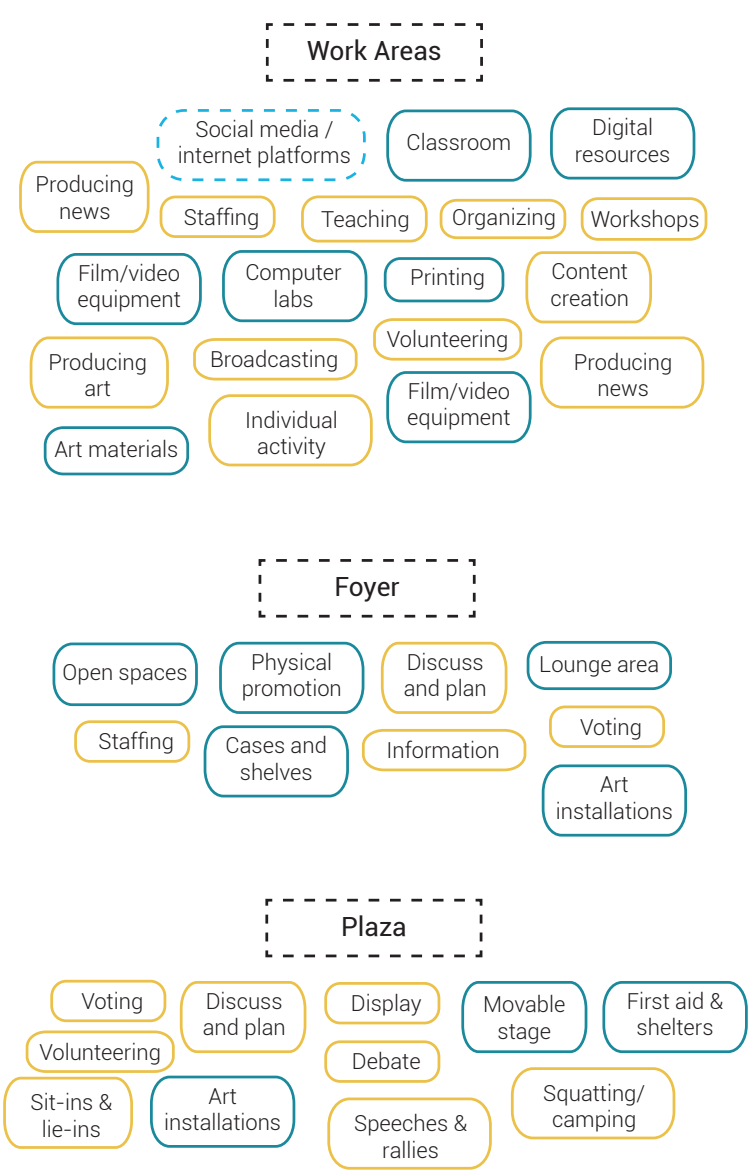

$\begin{array}{c:c} & \\ \text { program } & \text { space }\end{array}$ 


\subsection{Sites}

(Opposite) Figures 5.03a,b,c: site context and maps.
Creating a multiplicity of constituent-centric spaces through architecture that acknowledges and enhances opportunity for civic action and engagement, returns power to the people whom the municipal government is meant to serve. Each ward of the city has a unique identity and unique needs. Creating a framework for this new typology that can be organized and built upon differently in each ward ensures a consistency of civic-ness throughout the city with differentiation among neighbourhoods.

The abrupt shift from a municipally-planned ward structure to a provincially imposed reduction makes clear that civic culture must remain separate from partisan politics. These local democratic zones will exist in each ward, regardless of the number or sizing of the ward system. They create a system that can elastically respond to shifts in leadership.

As discussed in Chapter 2, Ward 10 Spadina-Trinity has been the fastest-growing ward in Toronto under the new 25-ward structure. The rapidly increasing density, the lack of developed public space woven into the city's accessible fabric, and the overwhelming demographic of precariously housed and working young people makes it an ideal testbed for new civic space.

A key component of the design schema of these buildings is their non-imposition into the neighbourhood. When choosing a specific site, the goal should be to interrupt as little as possible. Whether the building becomes a renovation or adaptation, takes over an empty parking lot, or occupies green space, attention needs to be given to a replacement strategy.

The site chosen for the local democratic zone in ward 10 is Osler Park, a rundown green space commonly used as an unofficial dog park with no playground or seating. It is bordered by Argyle Street to the north, and alley flanked by private garages to the west, and a small Catholic elementary school with a fenced-dirt running track to the southeast. Providing fresh landscaping and maintaining existing green space was a foremost design consideration.

This site was chosen for its proximity to the variety of building uses in the area. Maintaining and forging new connections to different types of urban conditions is essential to the management and use of the building. The site is a short walk from the much-frequented Trinity Bellwoods Park, and does not require the removal of existing built program. 
Toronto Ward 10
Trinity-Spadina N.T.S.

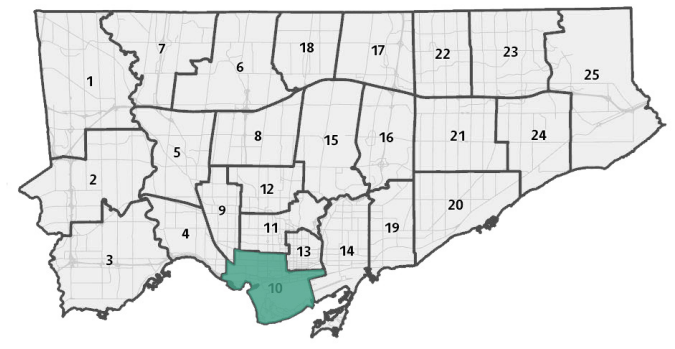

Northwest Corner
N.T.S.

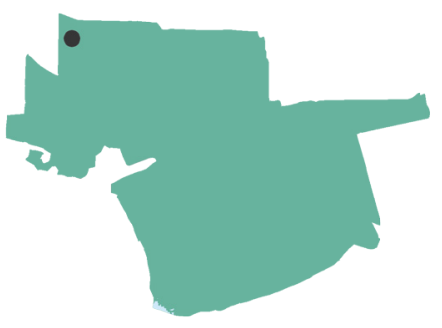

(1) Site as Existing

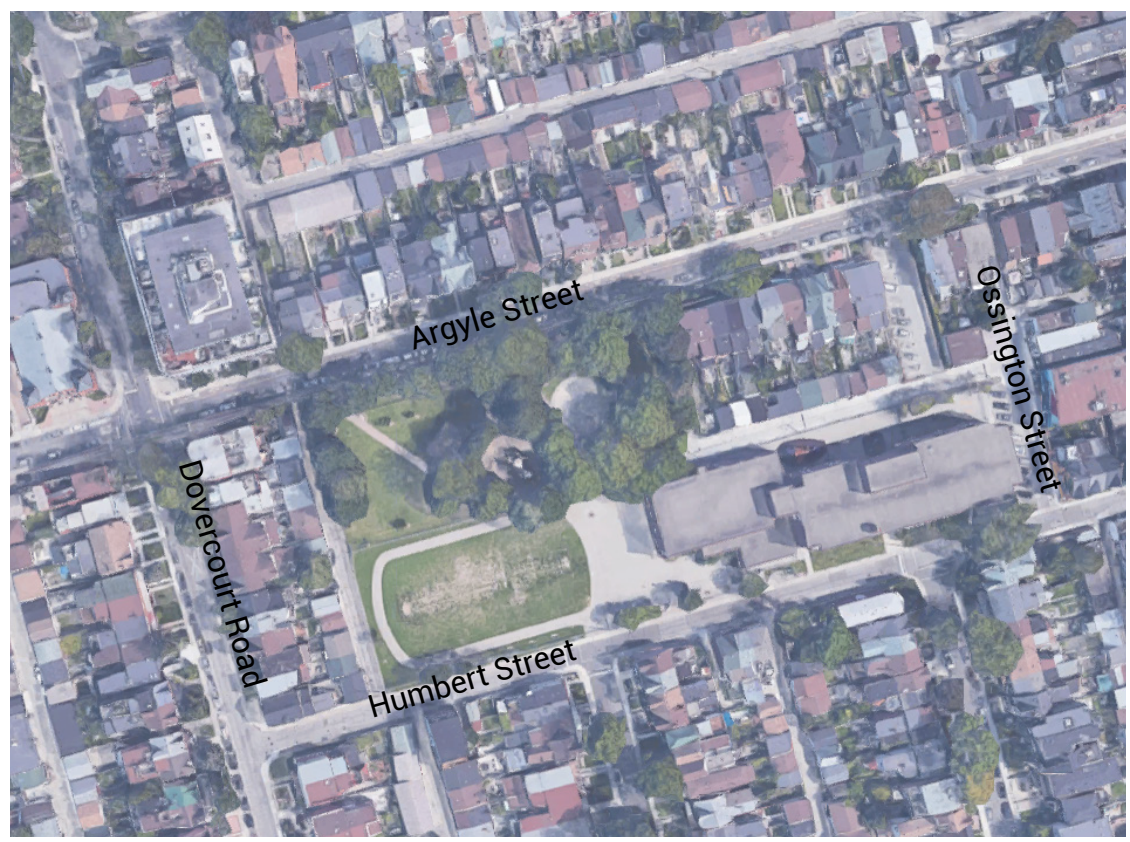




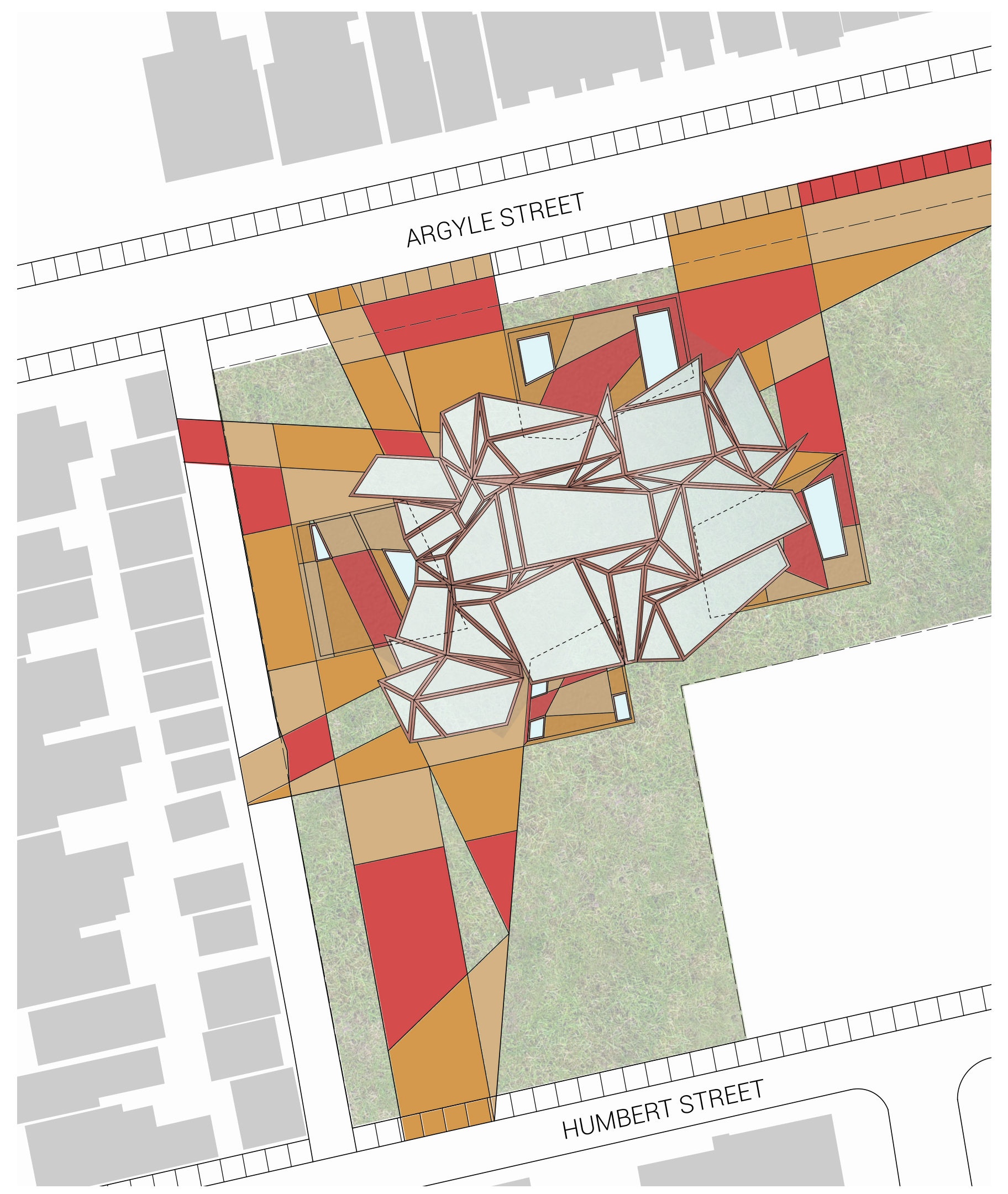




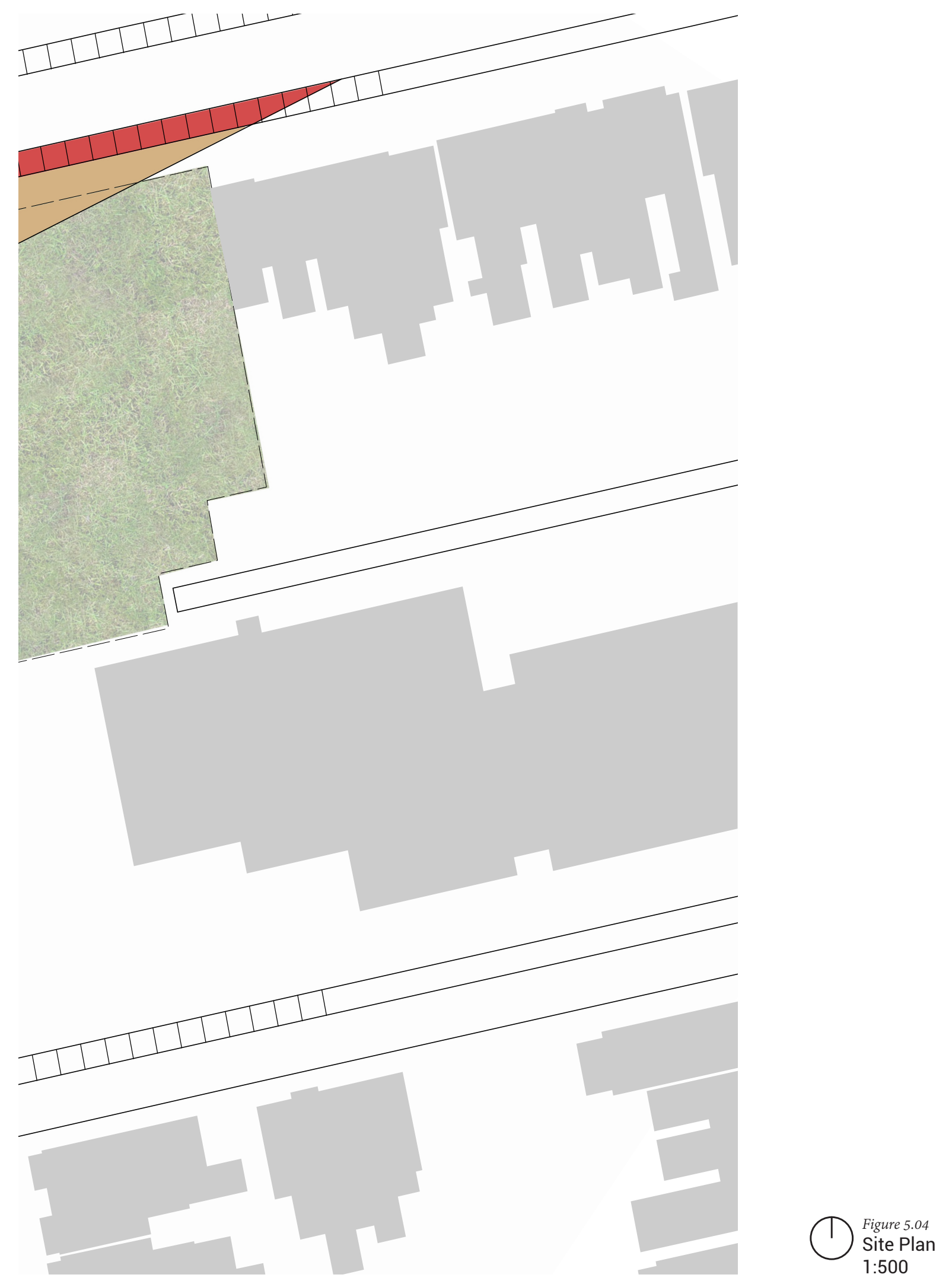




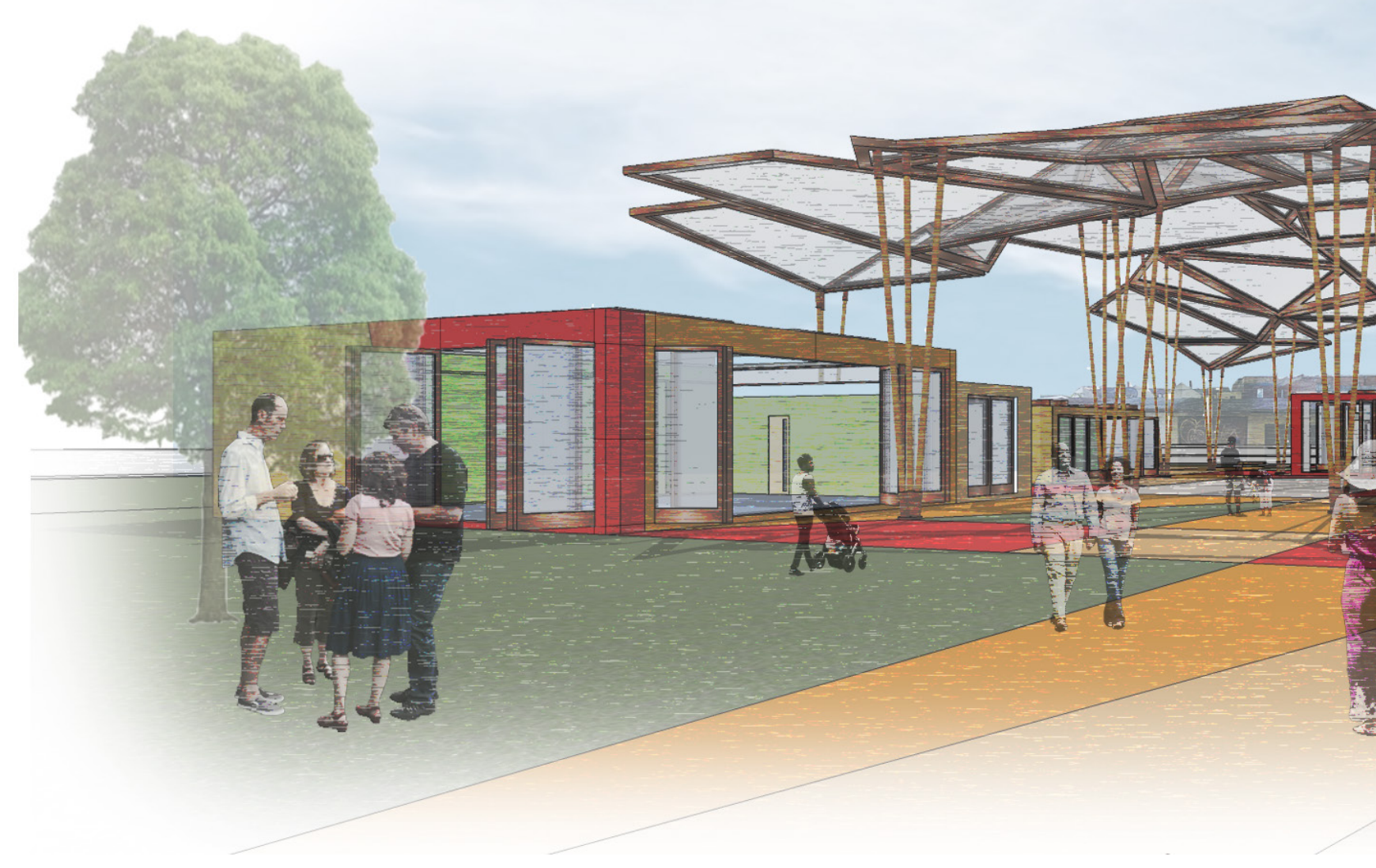

Figure 5.05: The ward 10 local

democratic zone situated in

context.

\section{Approach to Site}

Each local democratic zone emphasizes its site's characteristics for as little disruption as possible. The Osler Park project maintains shaded green space as a priority, building up the rest of program and space around it. This results in a covered park, with enclosed programmatic elements taking up a small footprint and being distributed around sweeping landscaped pathways and open areas. The design of a local democratic zone respects the neighbourhood's aesthetic context by eschewing a particular form. The landscaping and design integrates and slowly alters existing streets and lanes to lead into the heart of the site, without interrupting their own natural flows. 


\subsection{Program and Space}

(Opposite) Figure 5.06: Project diagram closing the gap between program and space.
The local democratic zone uses the five general functions of communicate, collaborate, create, participate, and demonstrate as a baseline for successful civic activity. Quantifying these paths to engagement is done by the same method of precedent analysis and critique throughout the first four chapters: how does the design combine both programmatic and spatial functions?

Dissecting the five general functions into specific examples of programmatic or spatial functions made apparent the required framework for design. Here the designer can bring together all the desired portions of Toronto's civic spaces into one building. The local democratic zone does not rely on a conventional labyrinthine organization of centralized rooms, but rather implements gradients resulting in a dissolution of traditional boundaries between areas and activities. These programmatic and spatial functions begin to naturally group together to form recognizable categories or elements within the design, with an even dispersion of both throughout the site.

The site includes a physically encompassing ceiling, both indicating the entry into the zone from the street outside, as well as linking together the smaller building structures with the more open and directionless portions of the design. The effect is reminiscent of a much larger open porch room, an area that is neither indoor nor outdoor, open or closed, but exudes an atmosphere of comfort, security, and civility in which to engage with fellow citizens. 


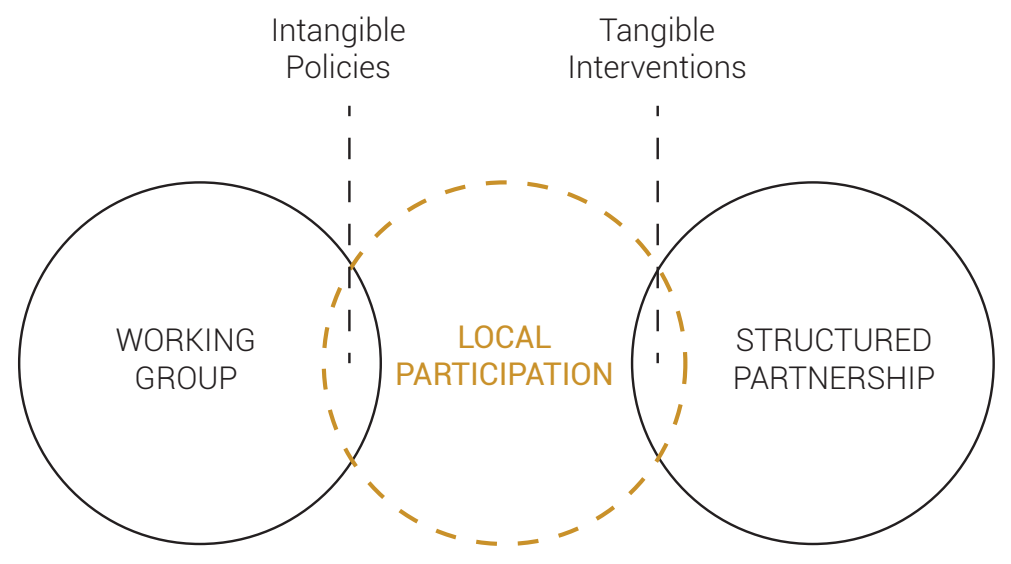

Current Program Potential Program Current Program

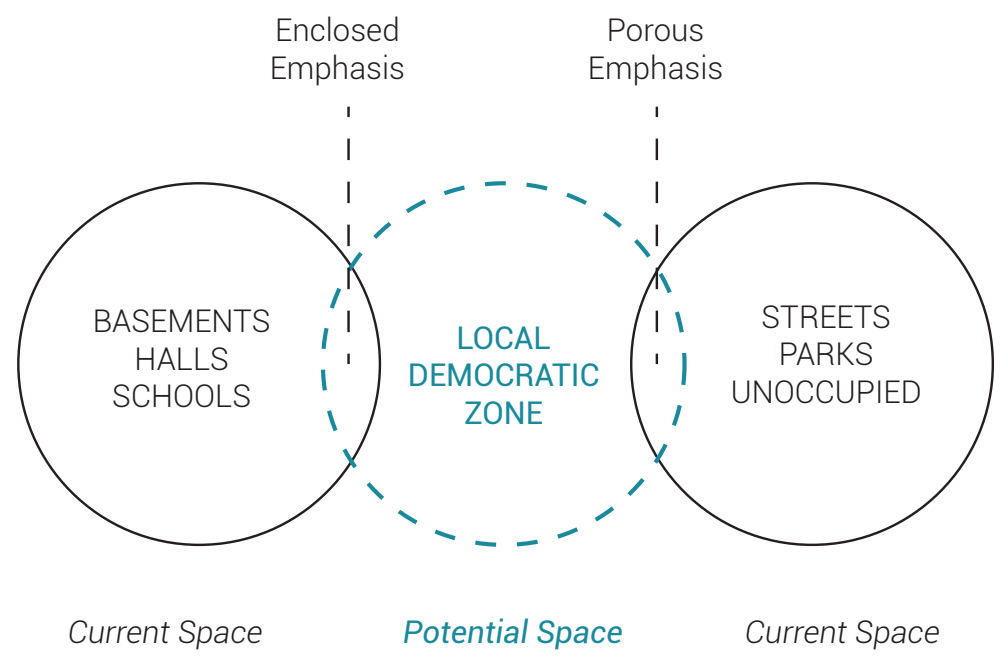




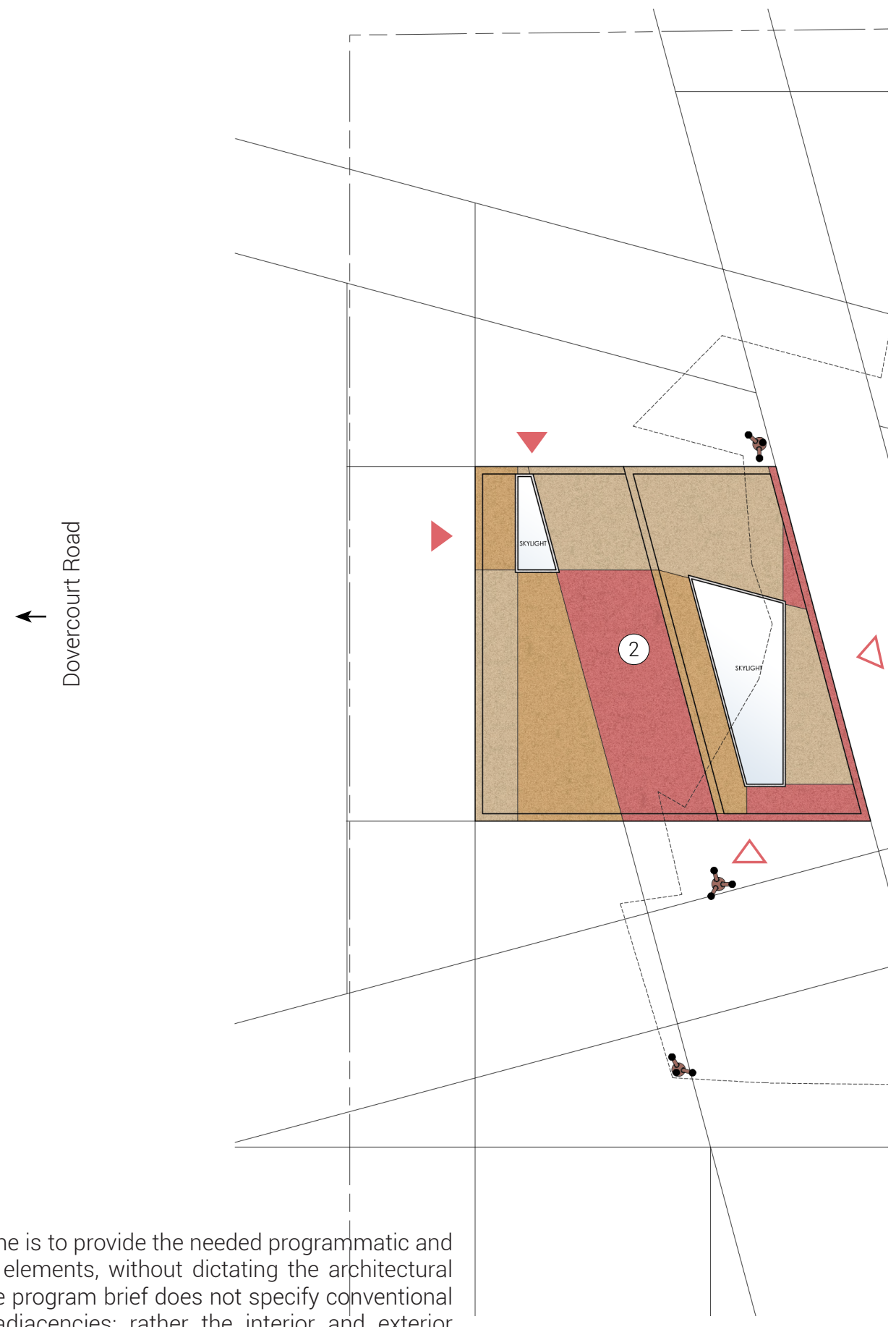

The idea of the local democratic zone is to provide the needed programmatic and spatial functions of each of these elements, without dictating the architectural assignment in a top-down way. The program brief does not specify conventional conditions like specific sizes or adjacencies; rather the interior and exterior elements are to be prioritized, arranged, and implemented in any possible way that follows the schema discussed in chapter 4 and includes the necessary specific functions. This method of designing is open, descriptive, and adaptable to different sites and communities. 







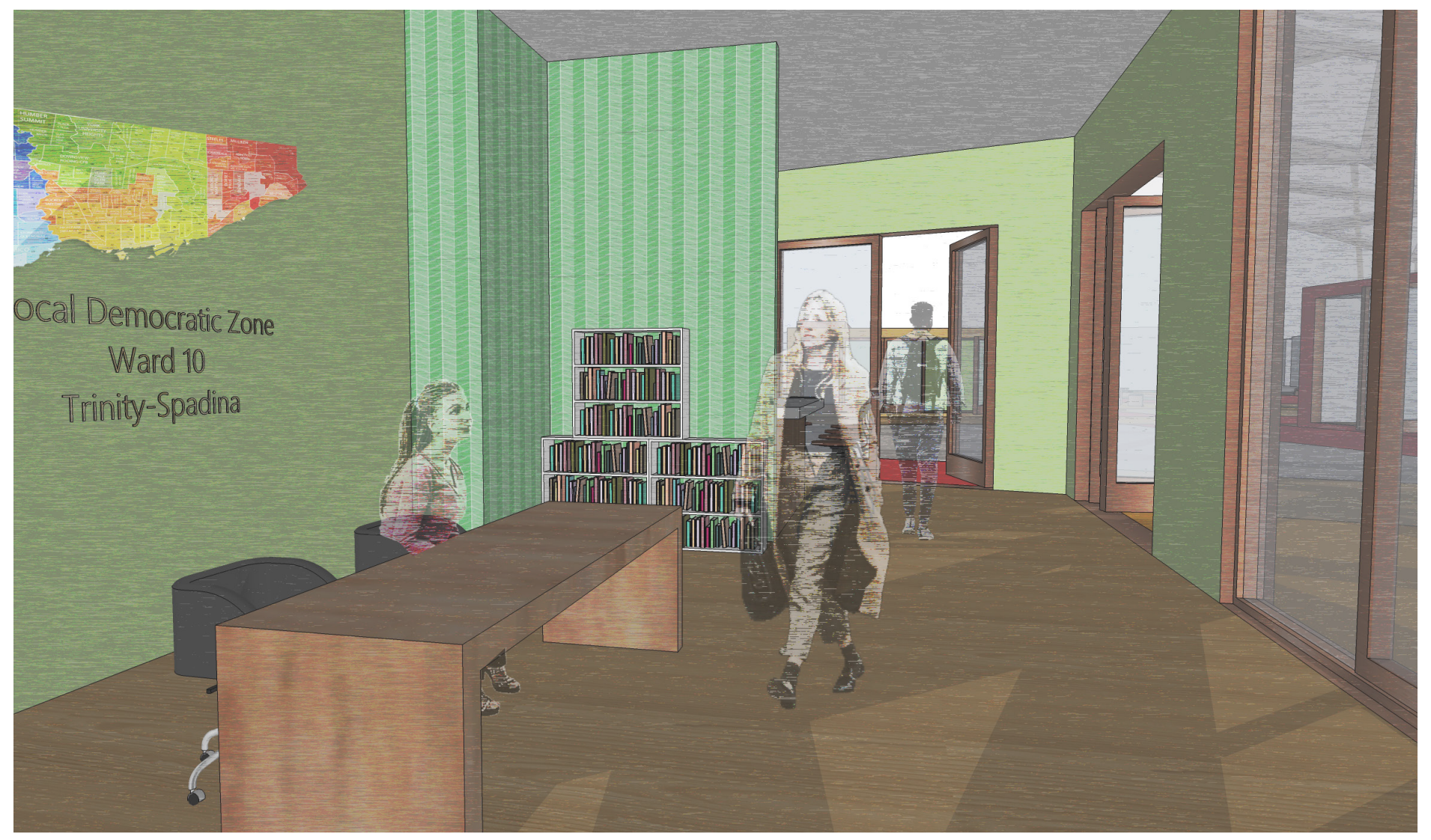

Figure 5.08: Entry into pavilion 1.

\section{Entry}

Pavilion 1 houses the main administrative entry, restrooms, a food nook, and areas for art and information display. This building has a large transparent facade facing the street and is the the first point of entry for most of the visitors to the site. 


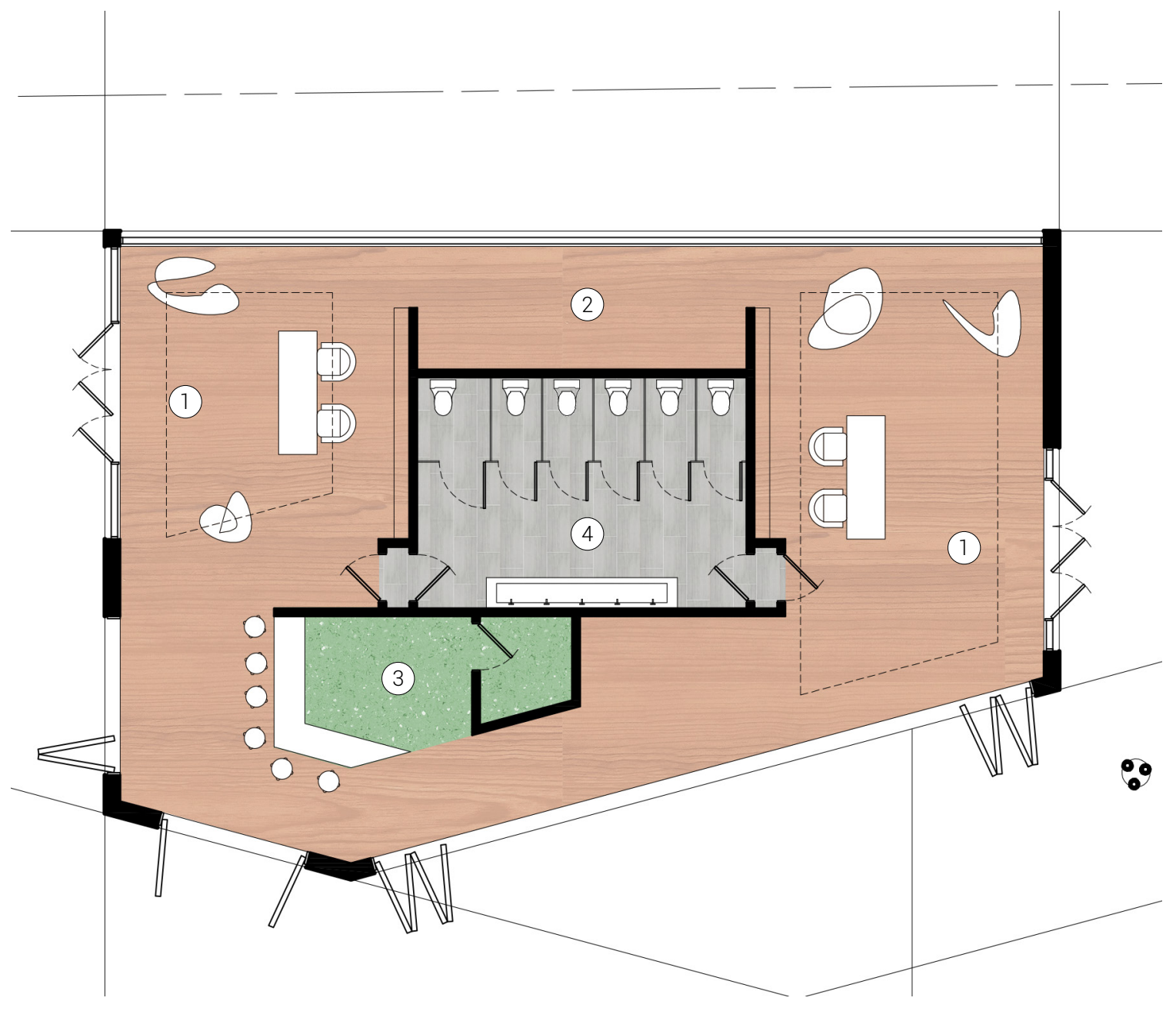

Figure 5.09

(1) Pavilion 1

1:150

Entry Foyer

Information/Display

Food/Beverage

Restrooms

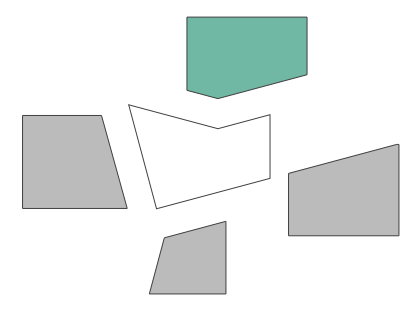




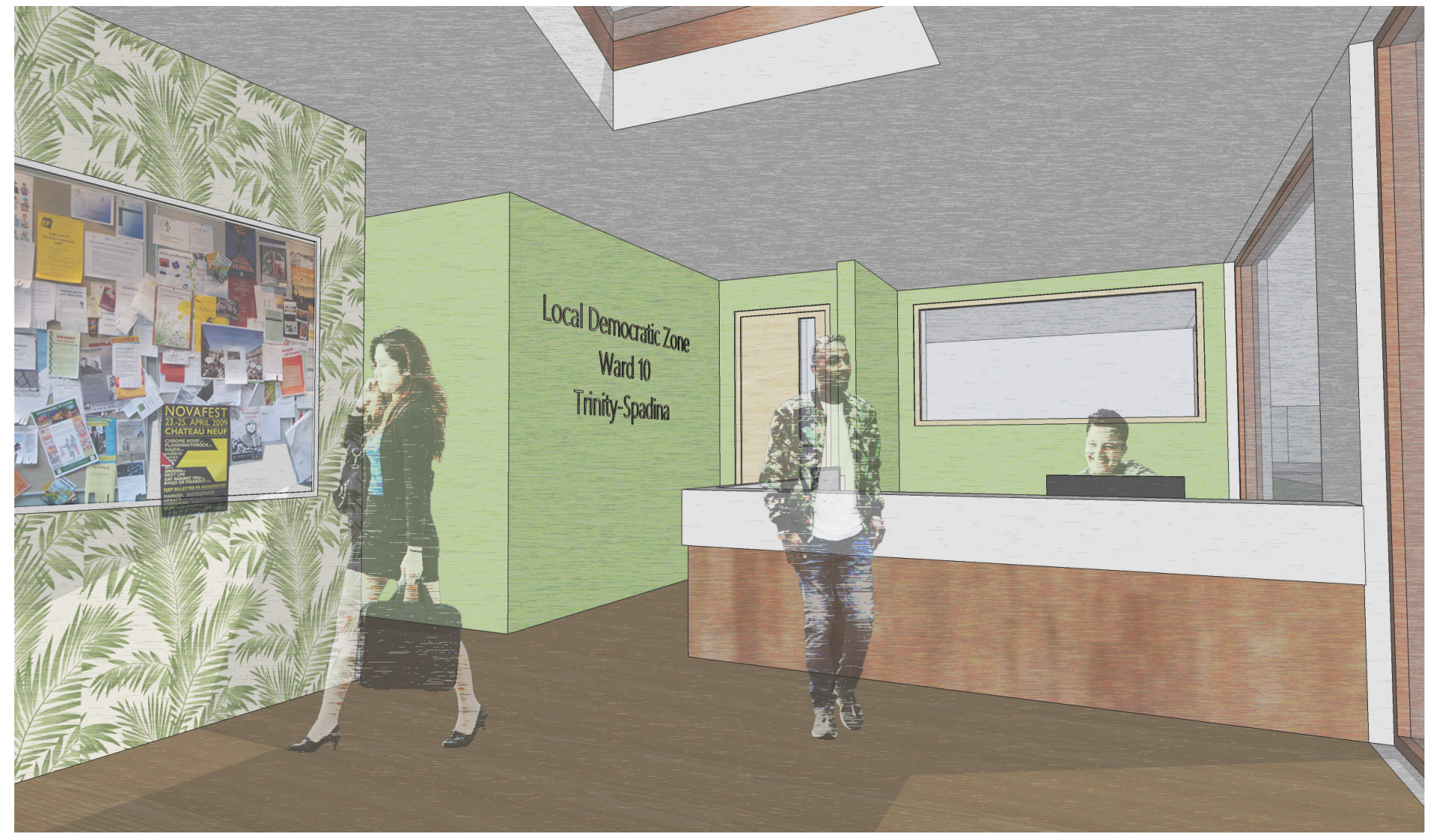

Figure 5.10: Administration area

in pavilion 2.

\section{Councillor's Office}

The foundation of this project is the ability for citizens to have a more direct line with their councillor, in response to the new system of municipal governance that has almost cut council in half. By providing an architectural solution that allows for the councillor to reside within their ward rather than always within the city centre at Toronto City Hall, citizens have a physical manifestation to more easily guide them in their interactions with government. 


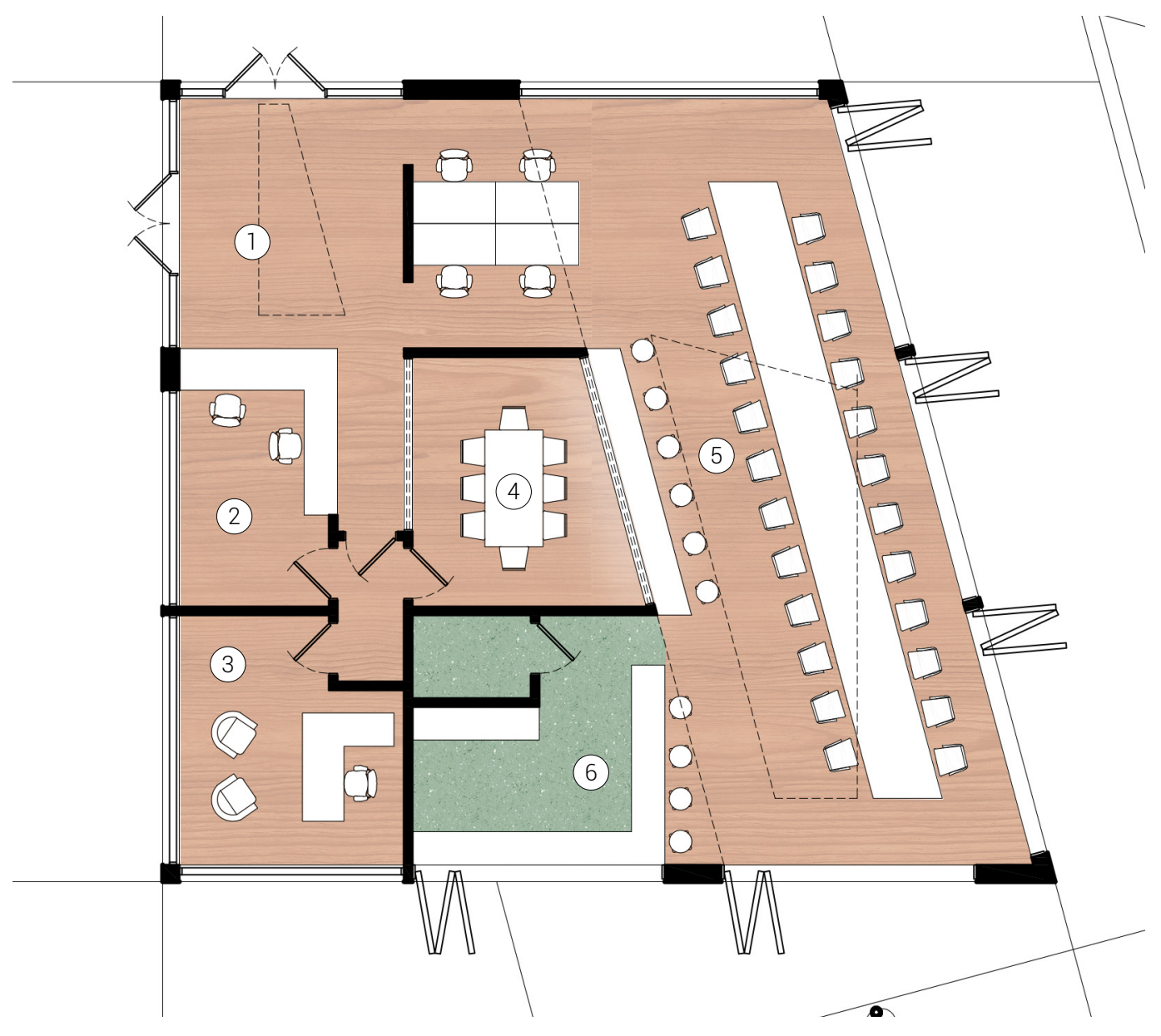

Figure 5.11

(1) Pavilion 2

1:150

Entry Foyer

Administration

Councillor Office

Meeting Room

Open Work Space

Food/Beverage

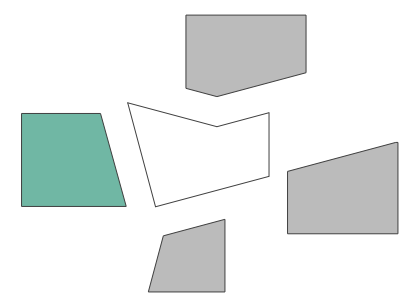




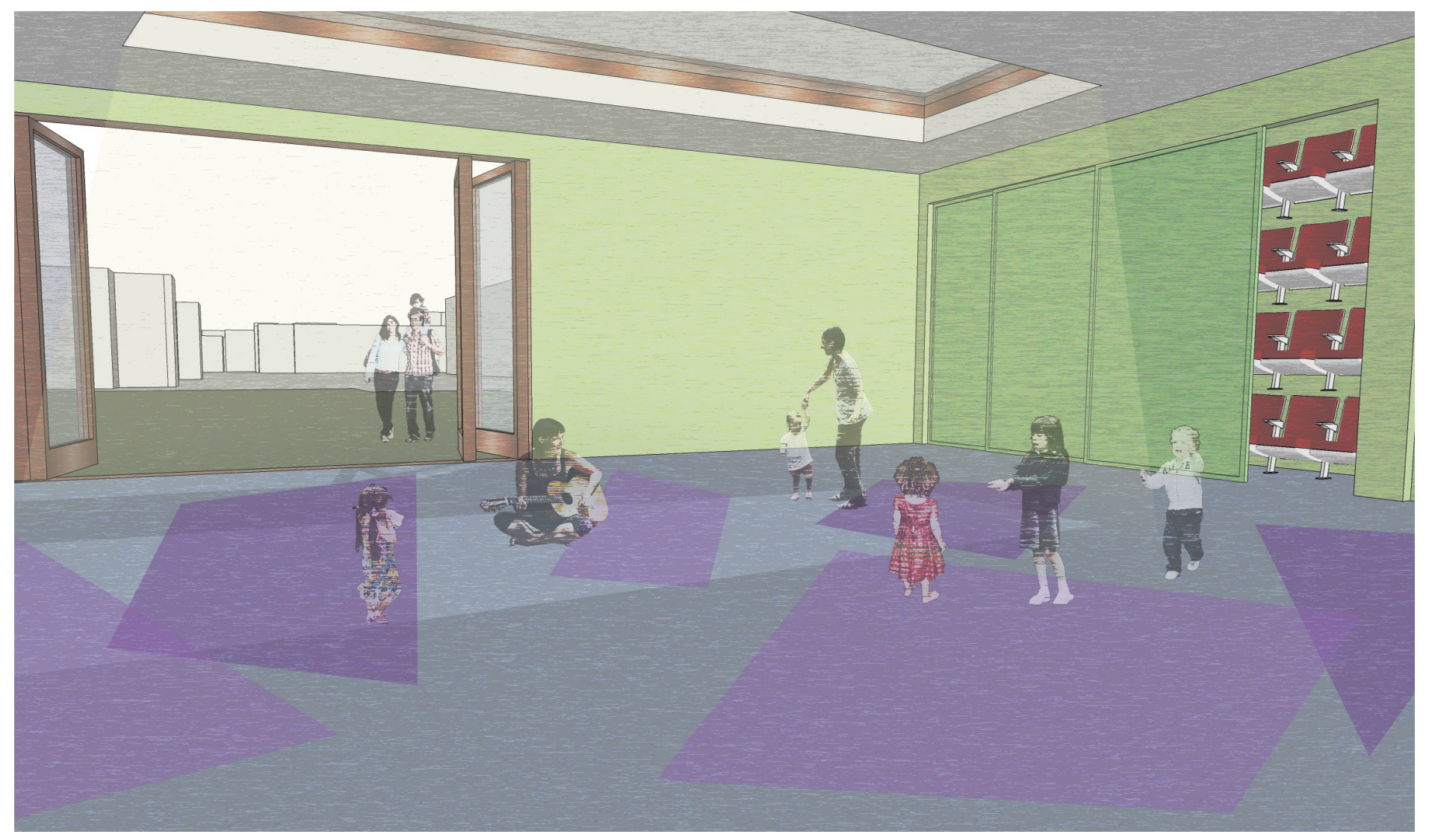

Figure 5.12: Multi-purpose space being used for children's activities.

Multi-Purpose Space

The gathering of citizens is a constant driver for this project: providing space for people to come together that has no overarching influential actors in charge or rules set in place that may curb the kind of action in which citizens wish to engage. The large multi-purpose space is one of the most important spaces of this project as it represents a completely open area built for the purpose of accommodating large groups in a completely neutral setting. Organizations who have struggled to find large space unoccupied by other primary programs, such as public school gyms or church basements, can transform this space to fit their specific needs. 


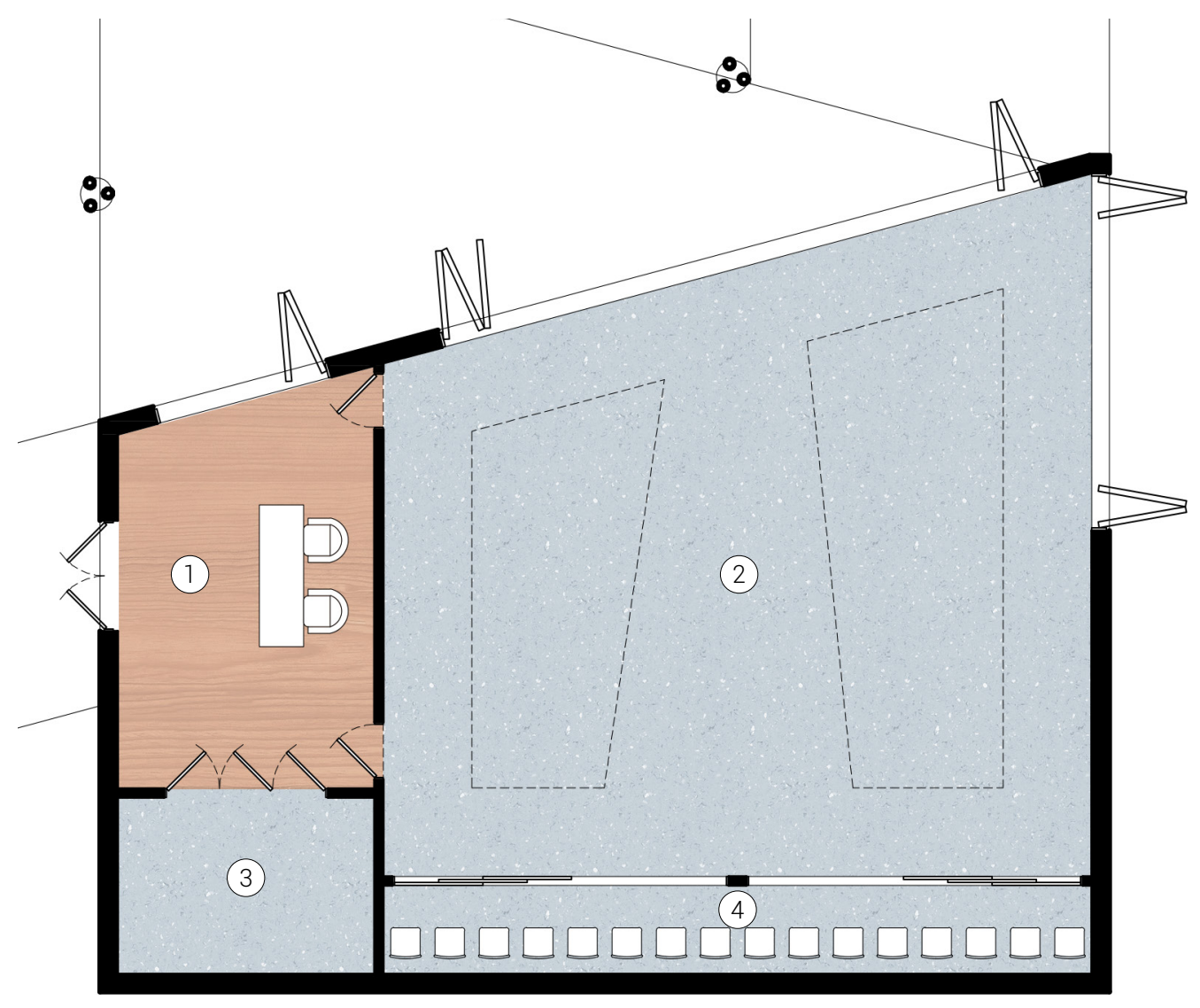

Figure 5.13

(1) Pavilion 3

$1: 150$

Entry Foyer

Multi-Purpose Space

Equipment Storage

Chair Storage

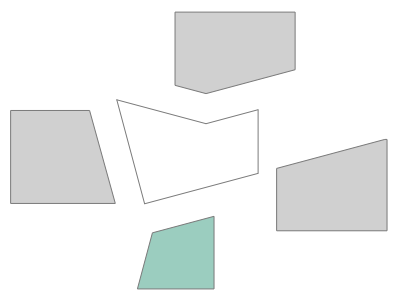




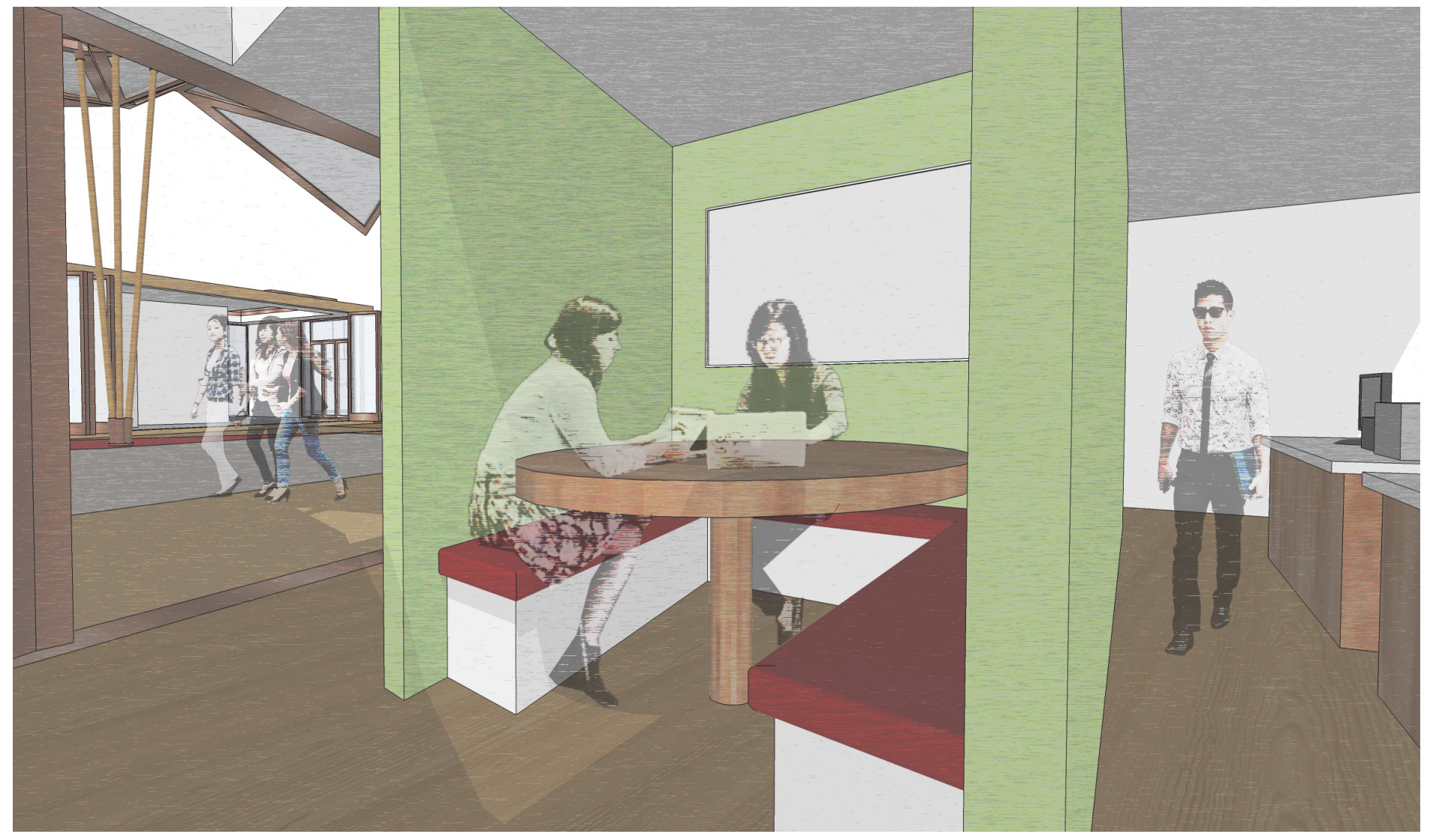

Figure 5.14: Members planning

civic activity.

\section{Work Areas}

The possible occupiers of this space as discussed in chapter 2 hail from a variety of backgrounds and circumstances, and the consistent lack of large operating space is in direct opposition to their ability to connect and organize themselves. Having many different orientations of work space with a focus on civic engagement will enable activists, community organizers, or even boards of resident associations to carry out their tasks and functions how and when they see fit. 


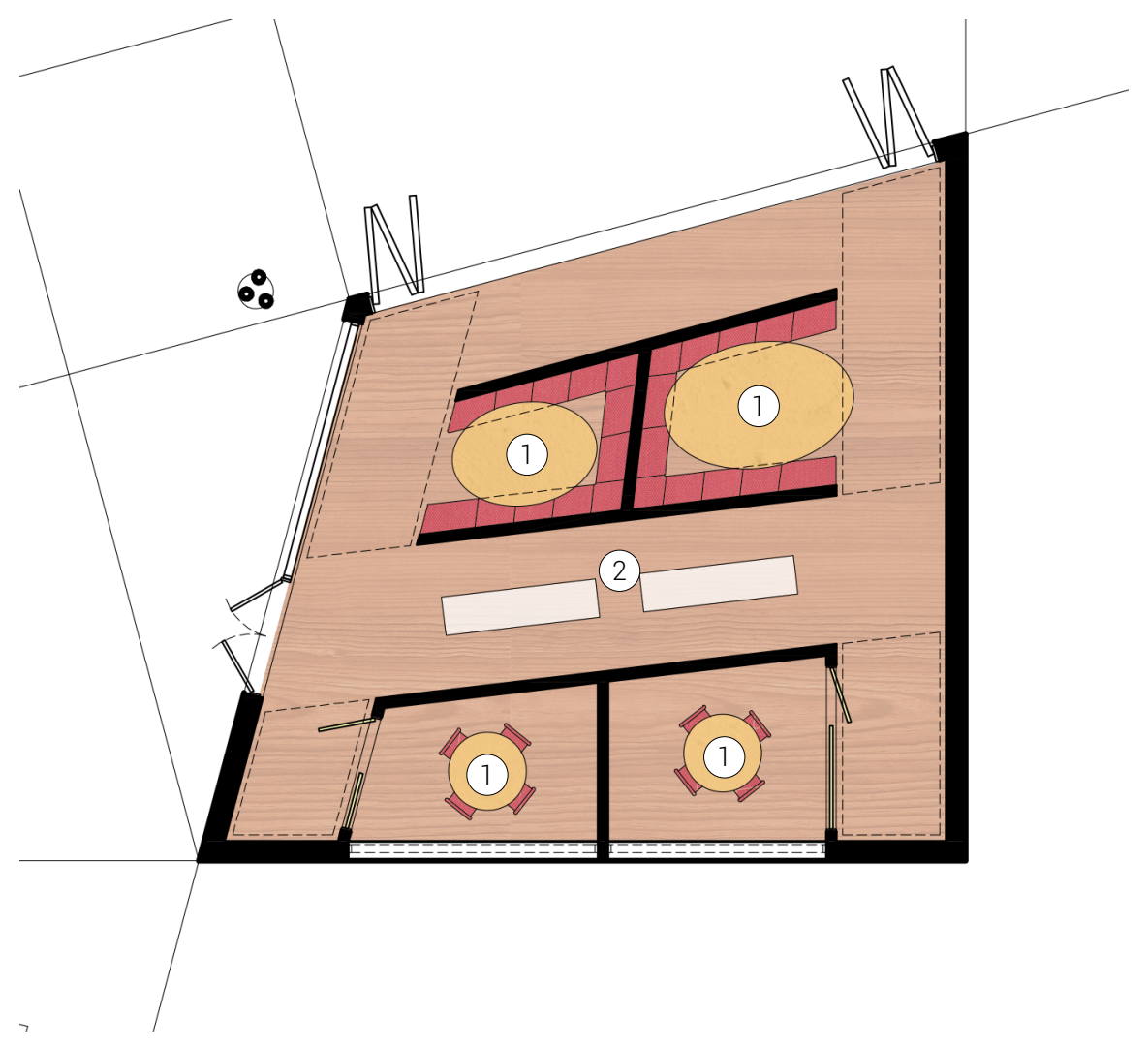

Figure 5.15

(1) pambion

1:150

1 Work Pods

2 IT Equipment 


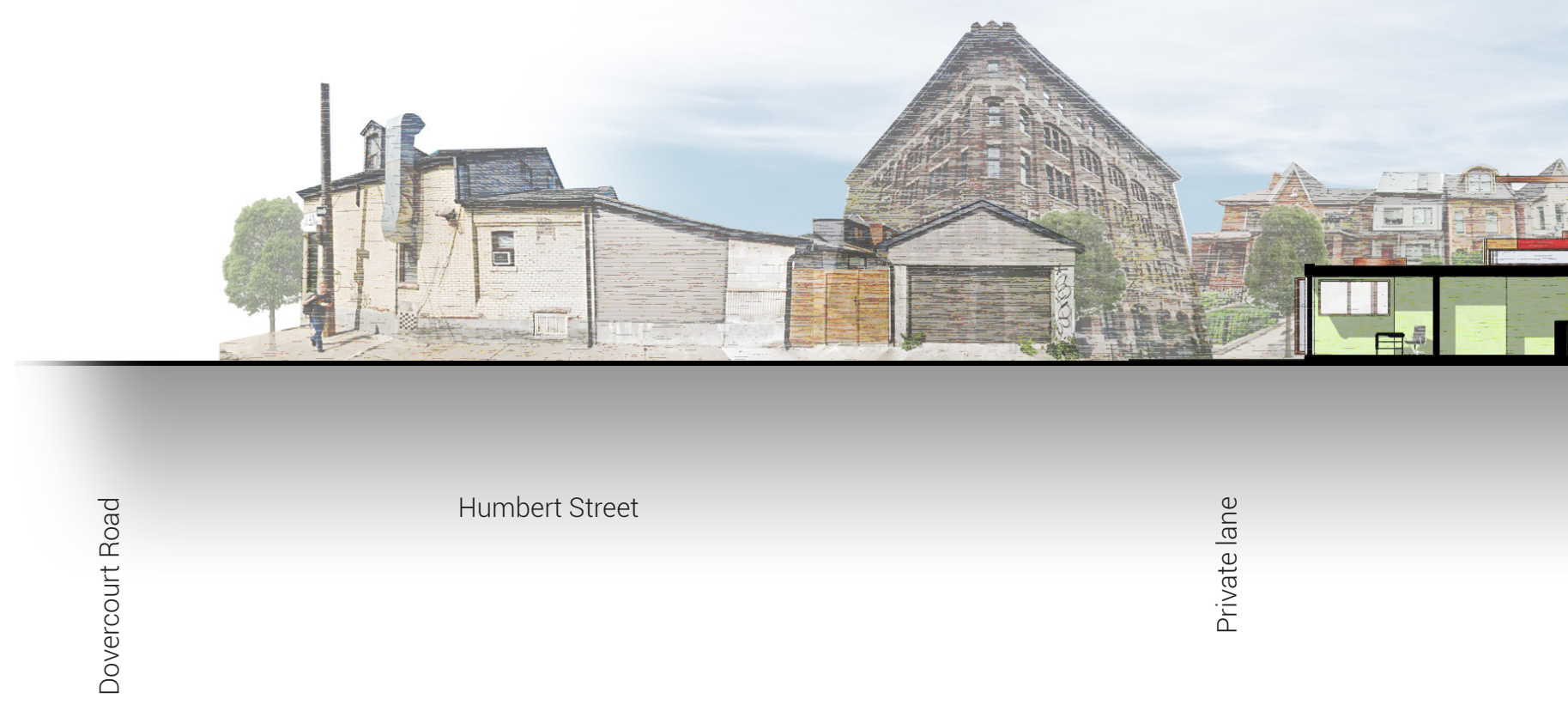

Figure 5.16: Site section.

\section{Operations}

The local democratic zone represents a model of substantive citizenship in Toronto. Membership is required to book the pavilions, indoor areas, and other equipment, but signing up for membership requires no formal citizenship caveats. Contact information is given by the applicant, who is granted membership after verification by staff. The non-enclosed portions of the local democratic zone are never closed; just like other public spaces or parks in the city they remain constantly accessible. The fully enclosed portions have functioning business hours, but members are able to access the facilities 24/7. Signing in and out is the responsibility of the substantive citizen; activities are not monitored, but entry, exit, equipment moved or spaces used are linked to the key cards of the users. 


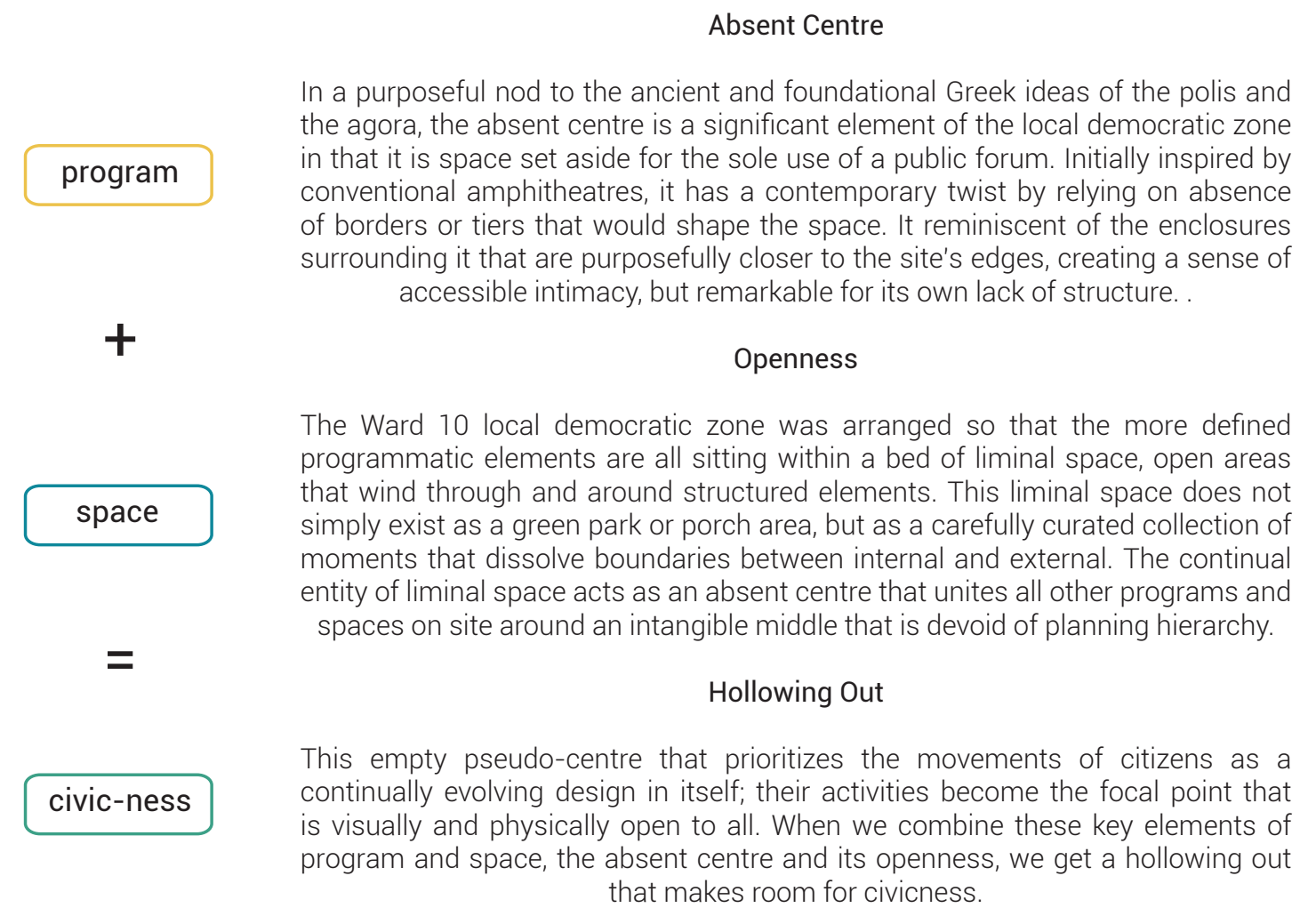

In a purposeful nod to the ancient and foundational Greek ideas of the polis and the agora, the absent centre is a significant element of the local democratic zone conventional amphitheatres, it has a contemporary twist by relying on absence surrounding it that are purposefully closer to the site's edges, creating a sense of accessible intimacy, but remarkable for its own lack of structure. .

\section{Openness}

The Ward 10 local democratic zone was arranged so that the more defined programmatic elements are all sitting within a bed of liminal space, open areas that wind through and around structured elements. This liminal space does not simply exist as a green park or porch area, but as a carefully curated collection of moments that dissolve boundaries between internal and external. The continual entity of liminal space acts as an absent centre that unites all other programs and spaces on site around an intangible middle that is devoid of planning hierarchy.

\section{Hollowing Out}

This empty pseudo-centre that prioritizes the movements of citizens as a is visually and physically open to all. When we combine these key elements of program and space, the absent centre and its openness, we get a hollowing out that makes room for civicness. 


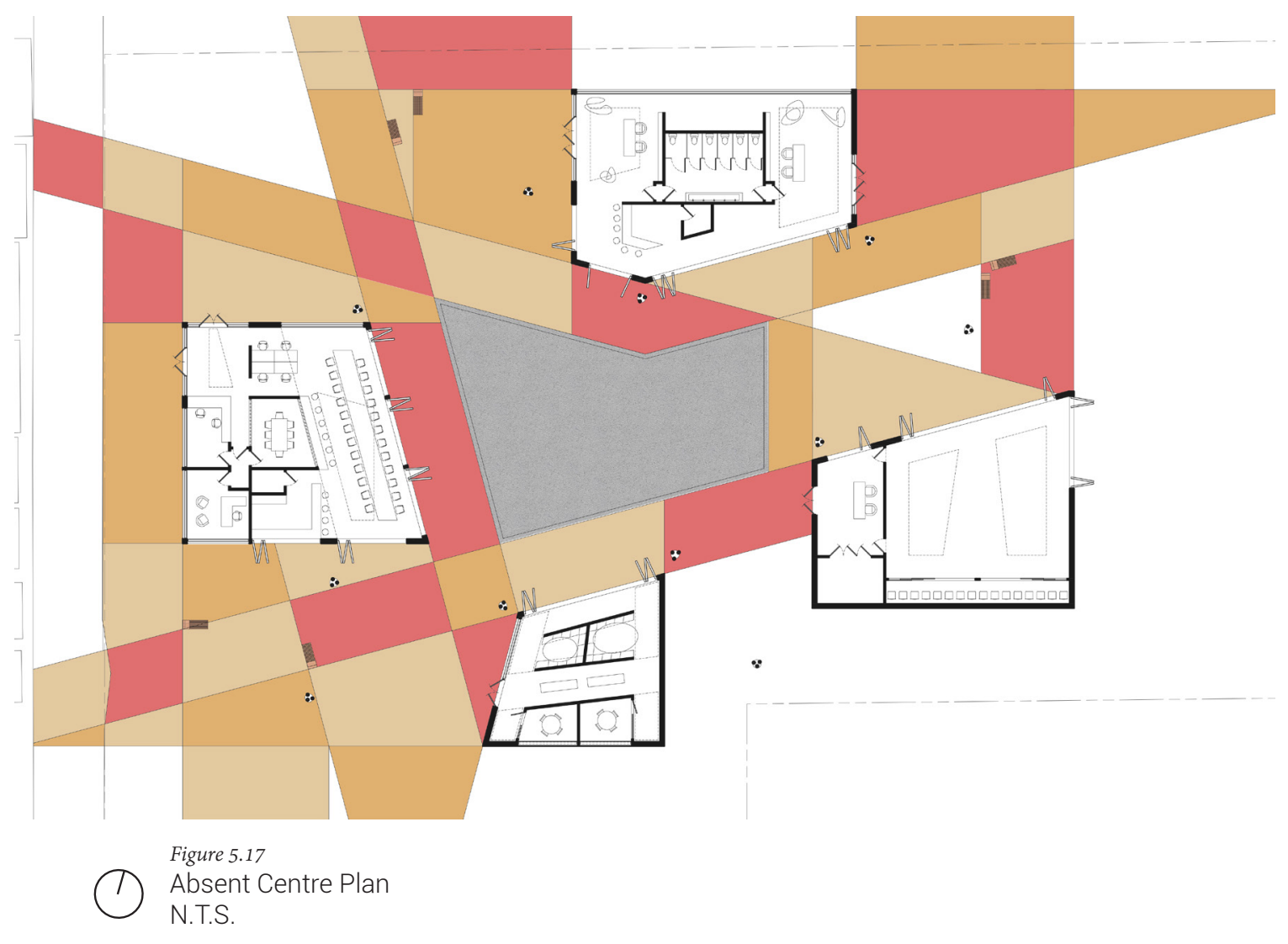




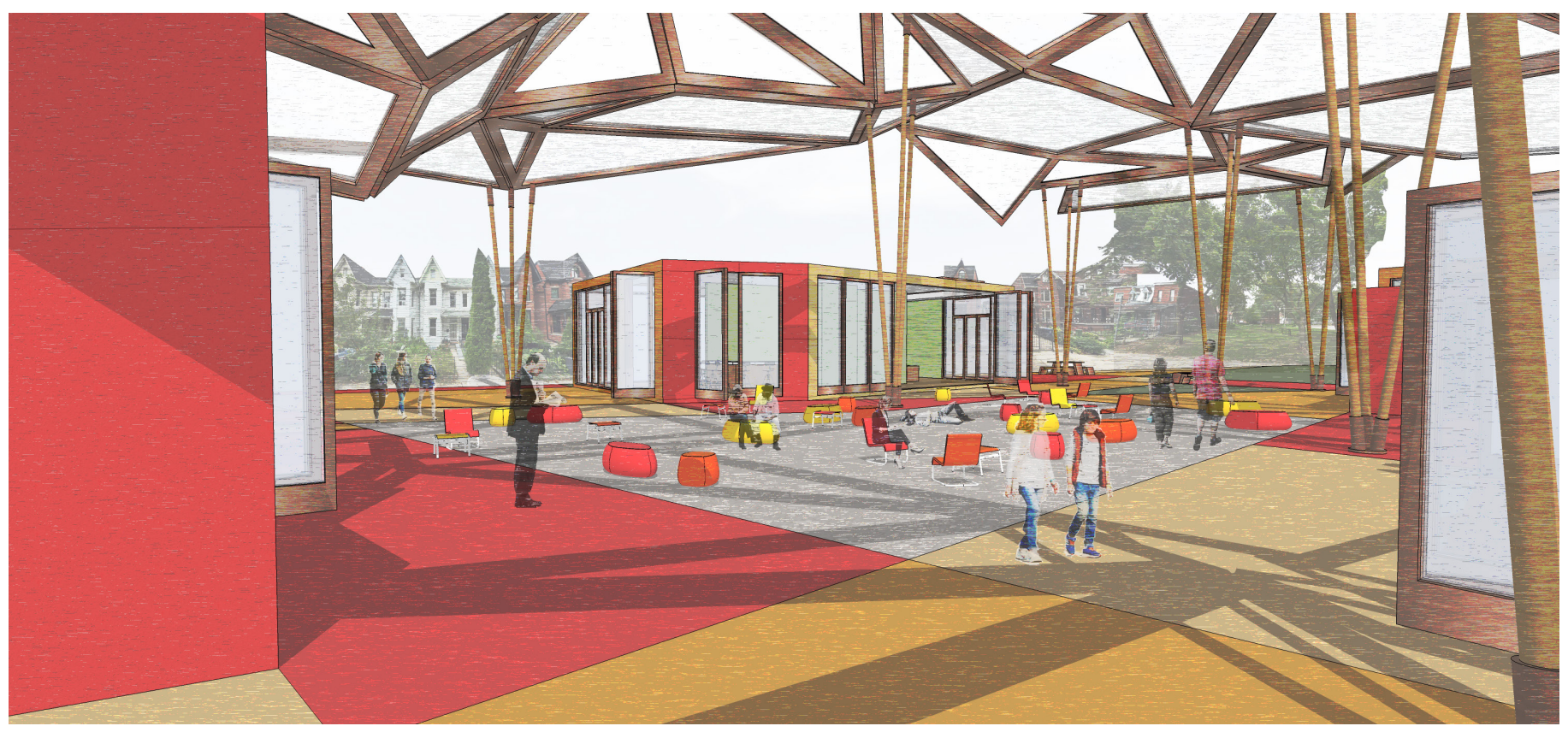

Figure 5.18: Citizens using the absent centre to relax.

When there is no scheduled programming and users can relax or mill about the space, the staff can put the movable furniture out to be used with the existing landscaping and furniture

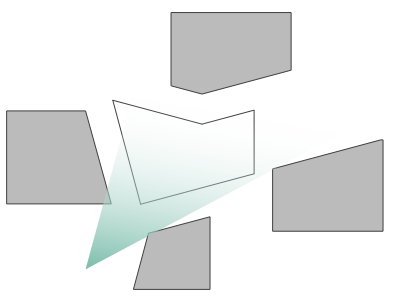




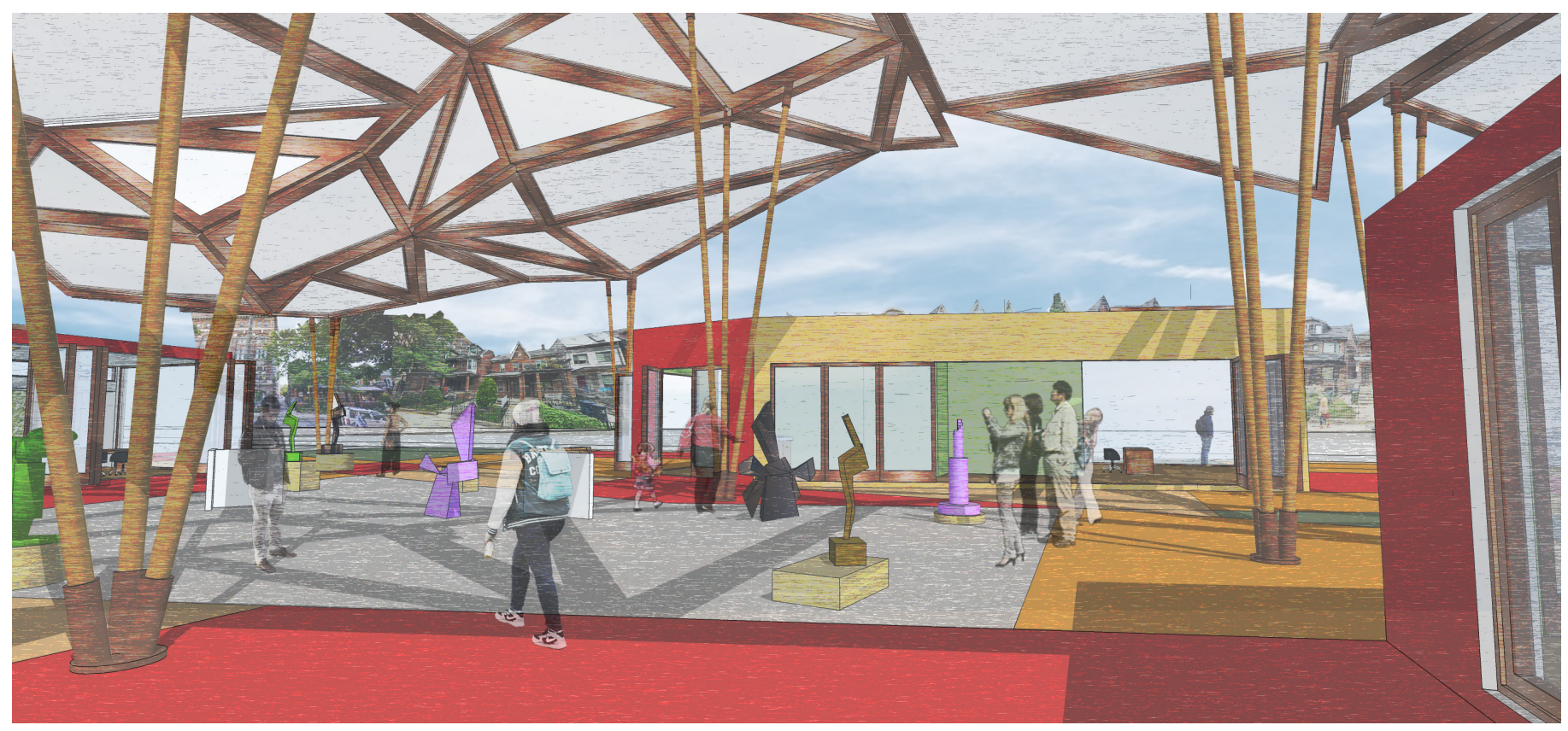

Figure 5.19: Citizens using the absent centre to display.

During any kind of art or performance event, display furniture can be used and left on site, by staff, community organizers, or other types of groups.

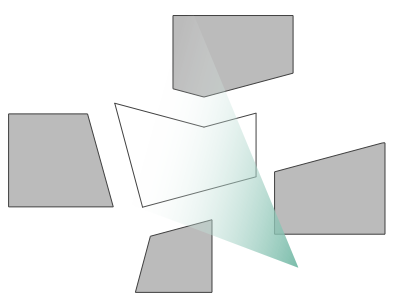




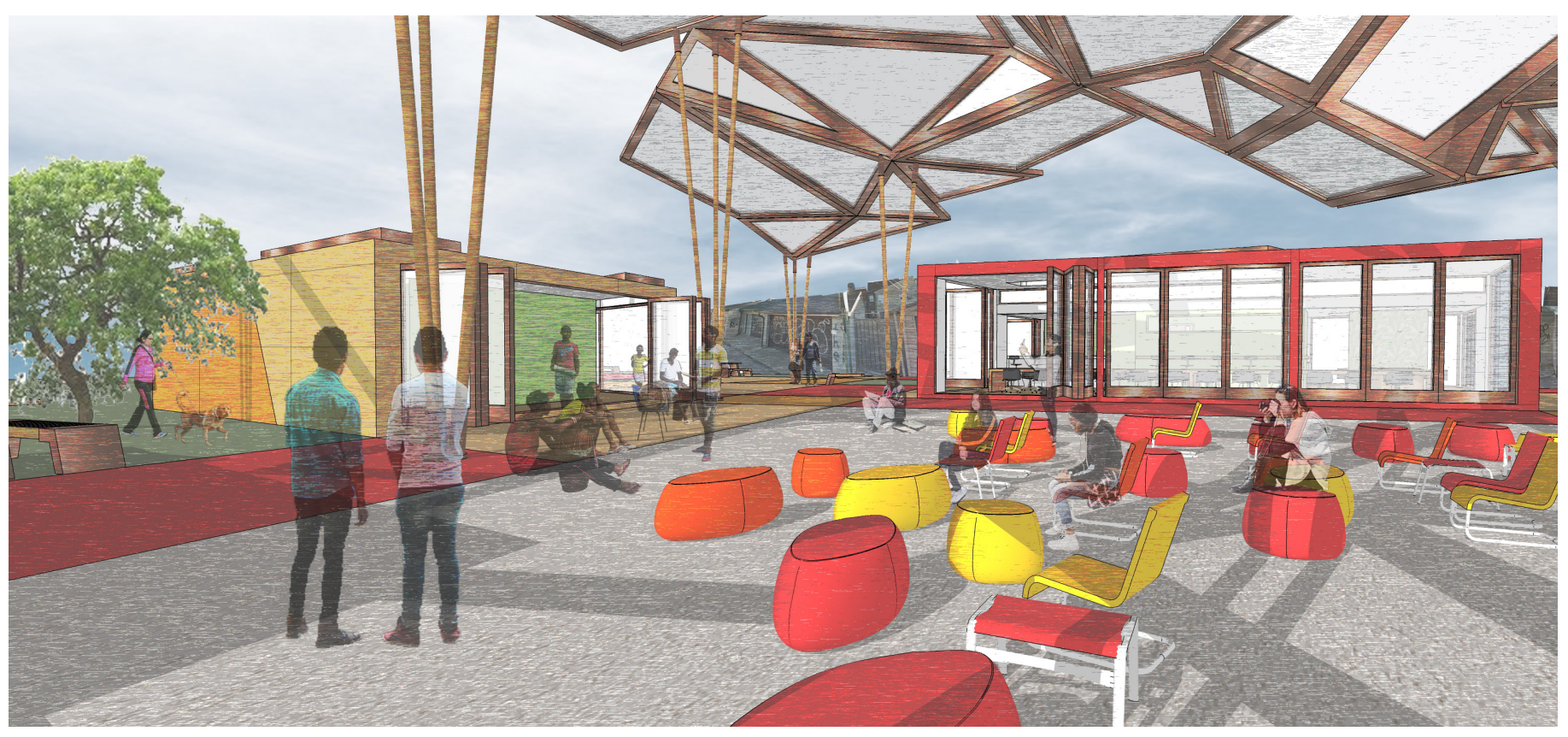

Figure 5.20: Citizens using the

absent centre to present.

if a citizen wishes to present, or lecture, or hold any sort of group gathering, they also have access to the movable furniture and equipment in order to arrange the space how they like.

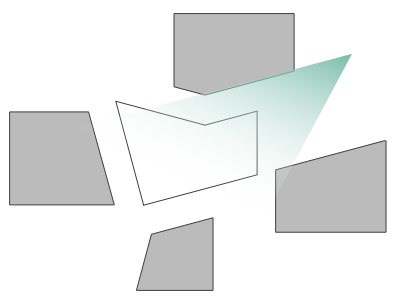




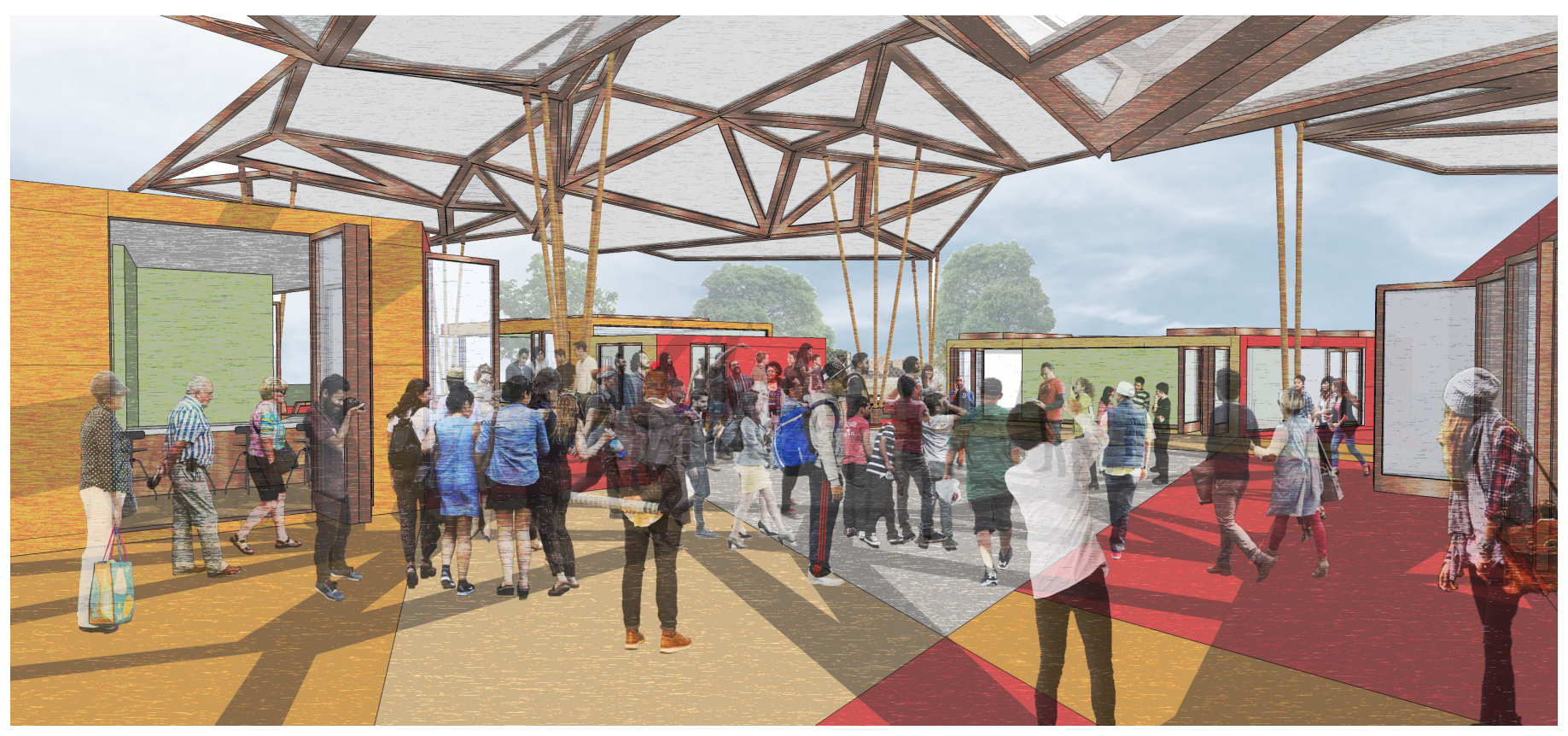

Figure 5.21: Citizens using the absent centre to demonstrate.

The space is also an optimal one in which to demonstrate. There is a balance of porosity and enclosure that frames the hollow centre from all site angles, lending both shelter and ample circulation for those demonstrating and others who may wish to join

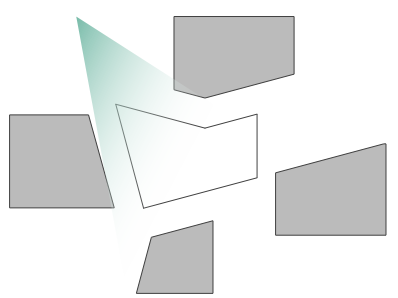
or observe. 


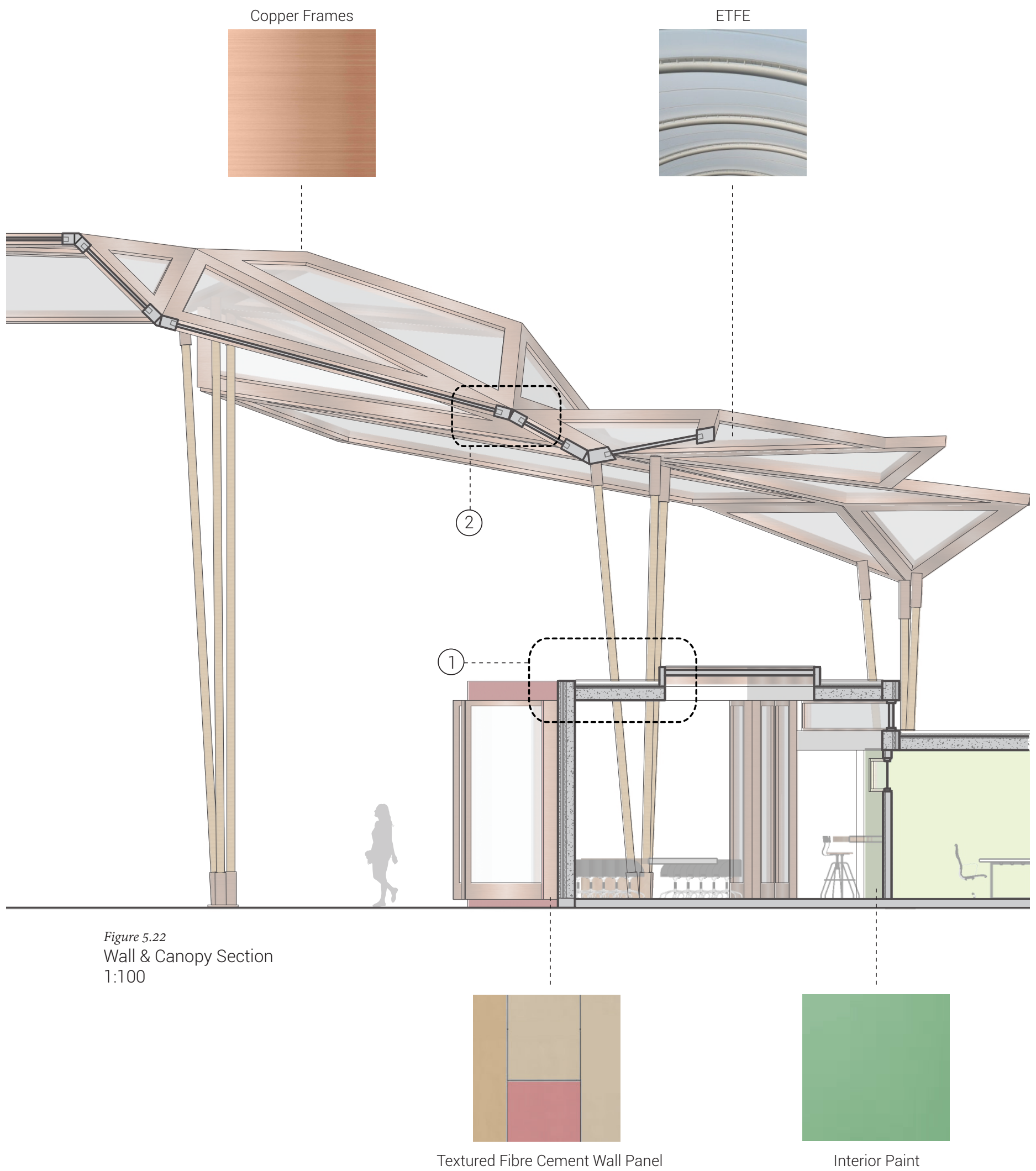


(1) Figure 5.25

Roof \& Wall Detail

$1: 15$

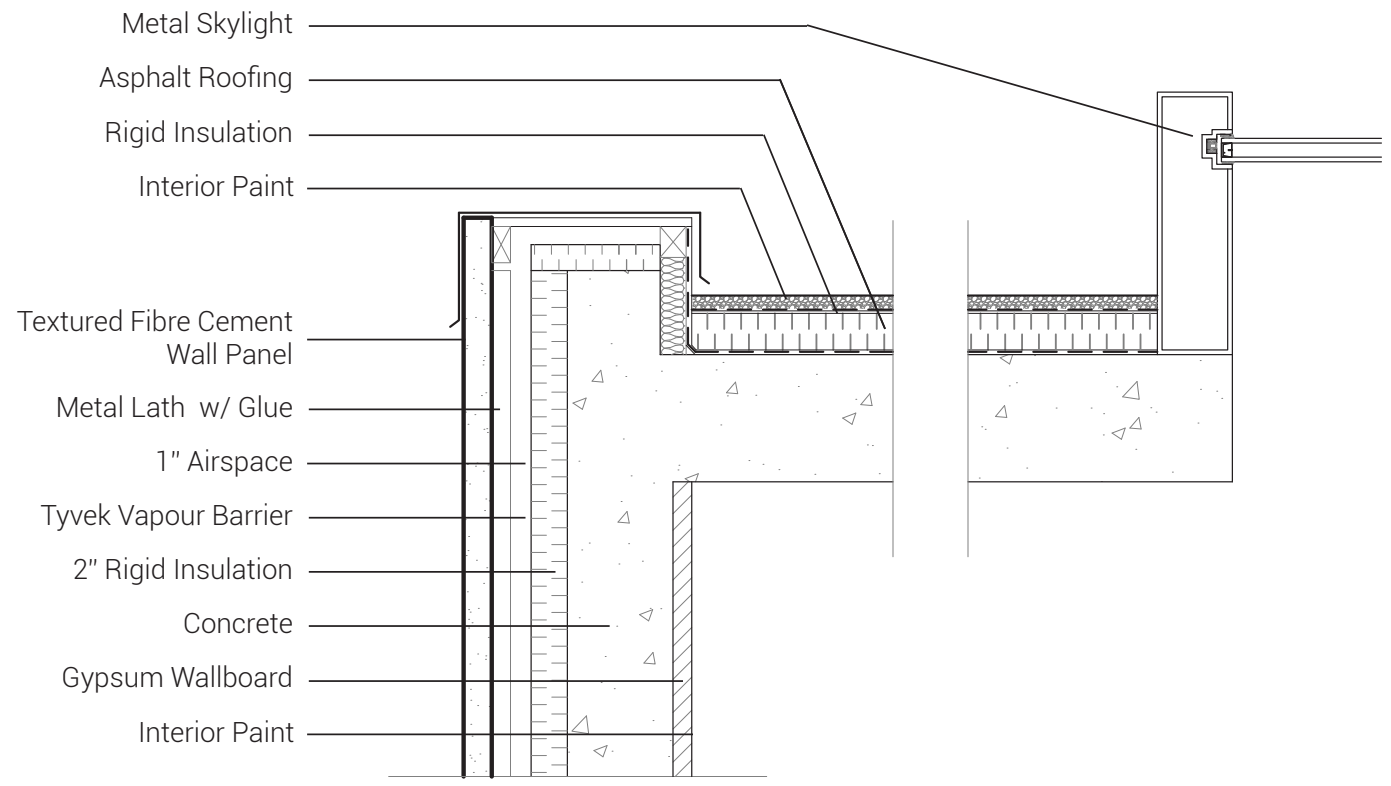

(2) Figure 5.24

Canopy Connection Detail 1:15

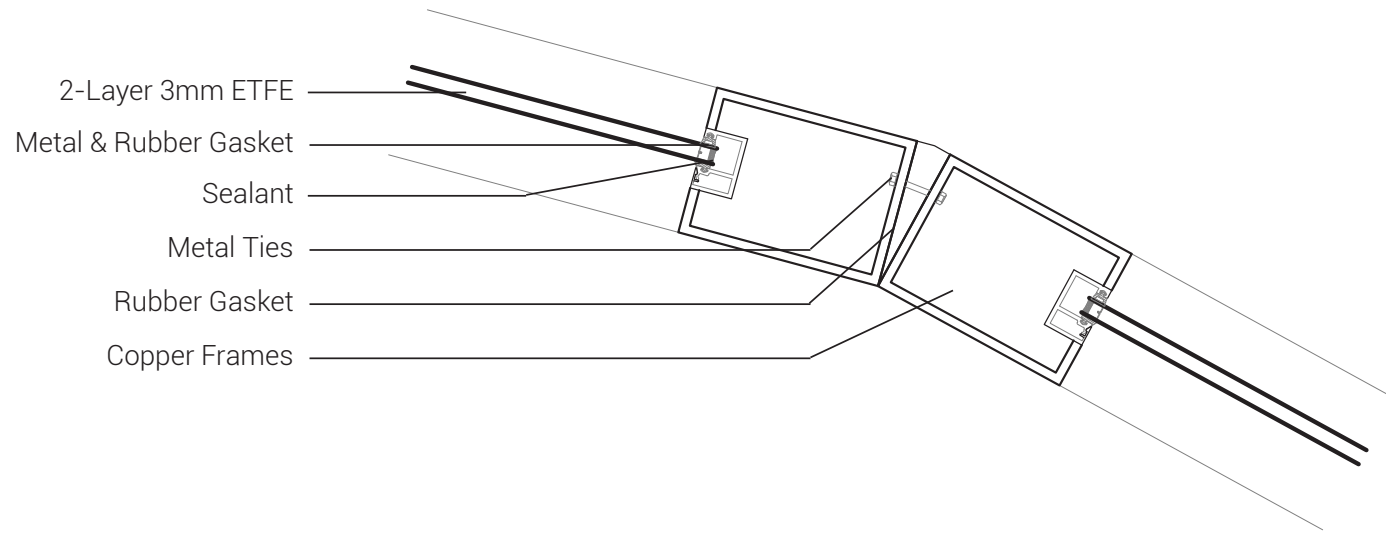


(Lower, clockwise) Figures $5.25 a, b, c$ : Ward 2 context maps.

(Opposite) Figures 5.26a,b: Potential arrangements for ward 2 local democratic zone.
These programmatic and spatial principles can form the foundation for new civic interventions around a dense city like Toronto, as platforms for citizens of all statuses to come together and work towards a more participatory democracy that moves beyond formal citizenship and rather focuses on substantive.

These three parts of ground plane, porous pavilion enclosures, and an encompassing external canopy form the core of Ward 10's alternative architectural response. These main building components change from site to site, and from ward to ward, and it is the programmatic and spatial principles that remain.

We can start to imagine the variations in design and function in other wards. Ward 2 Etobicoke Centre is packed with roadways and industrial buildings, quite different from the dense urban conditions of ward 10. The rooftop of a large industrial building is a potential site for a local democratic centre.

The five initial general functions can still work on such a different site. Here, the main components become a rooftop arrangement with direct access that does not interrupt the current roadways. More specific module or liminal elements can be organized with varying levels of porosity or enclosure, just like in Ward 10.
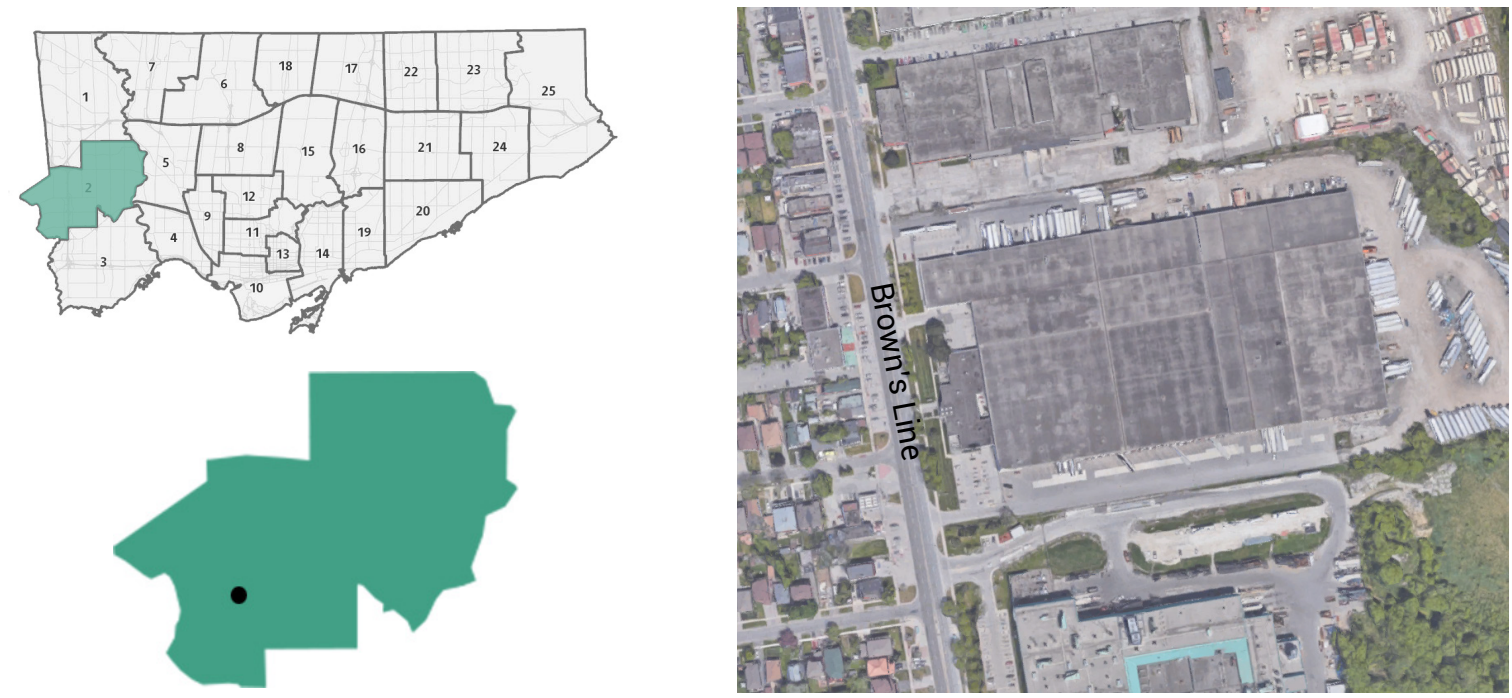

Toronto Ward 2
Etobicoke Centre

1 Site as Existing 

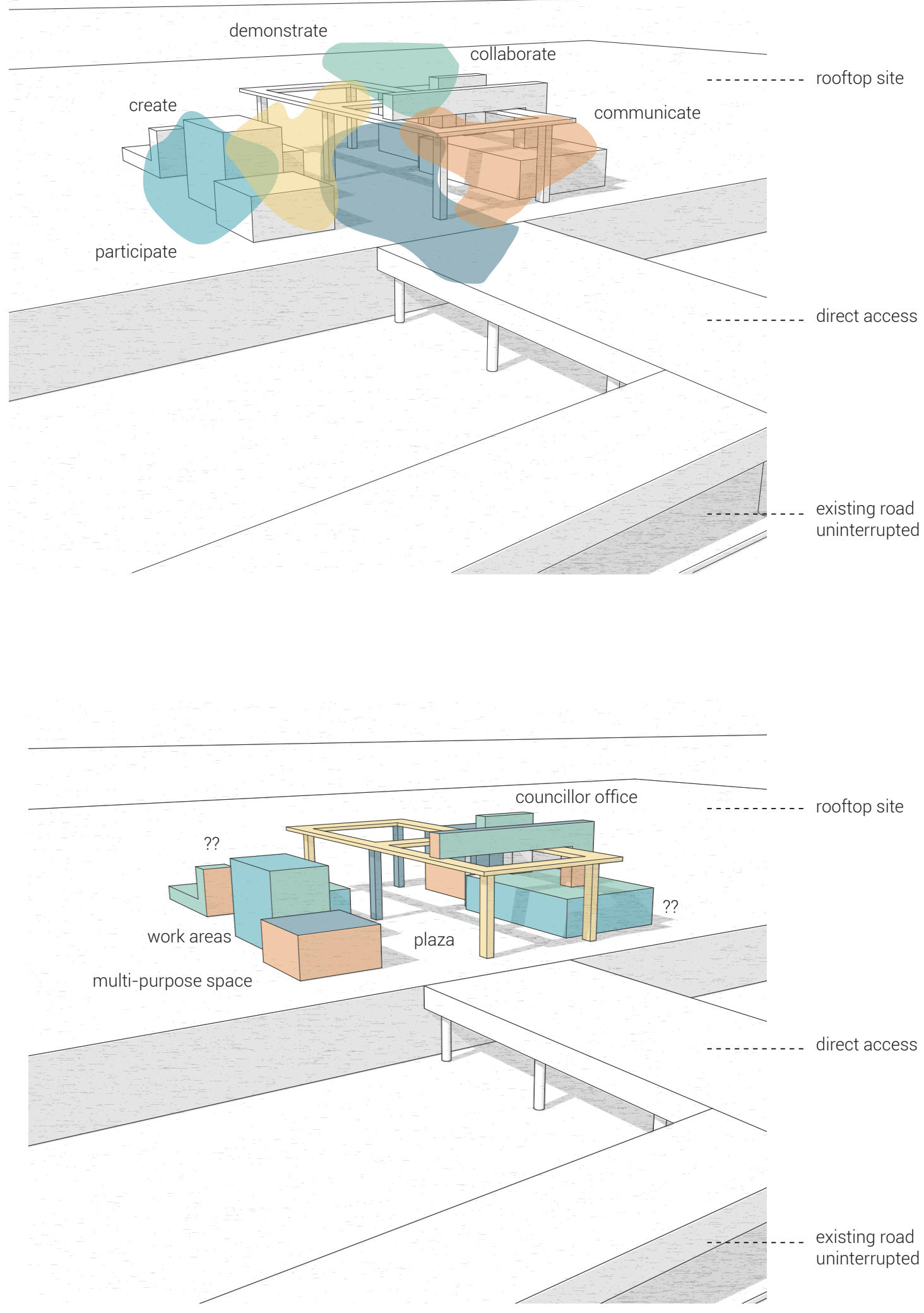
(Lower, clockwise) Figures

$5.27 a, b, c$ : Ward 23 context maps.

(Opposite) Figures 5.28a, b: Ward 23 local democratic zone general functions.
Toronto is a city of extremely different neighbourhoods, and Ward 23 Scarborough represents another kind of built environment, focused on suburban homes, large retail space, and lots of parking.

A local democratic zone in ward 23 could serve as a civic intervention that inserts itself on a ground plane currently taken up by parking, which could be relocated below grade. Elevated real estate could still be claimed by commercial or other occupants, leaving a more conventional podium to be filled with civic uses.
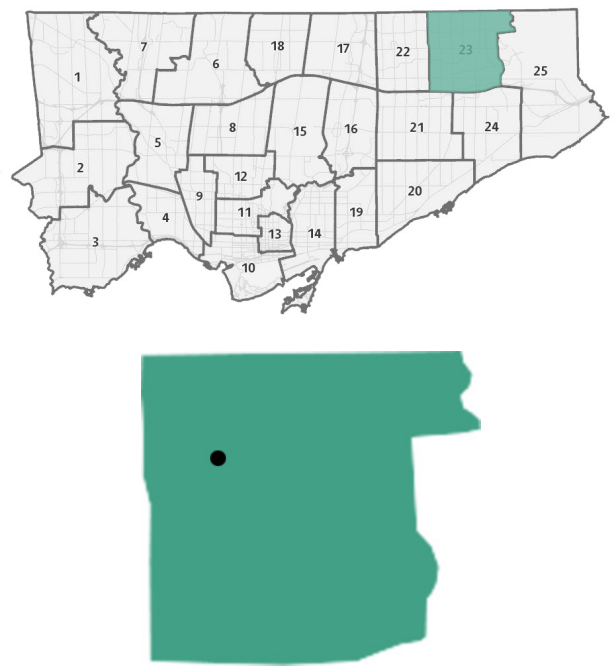

Toronto Ward 23
Scarborough North

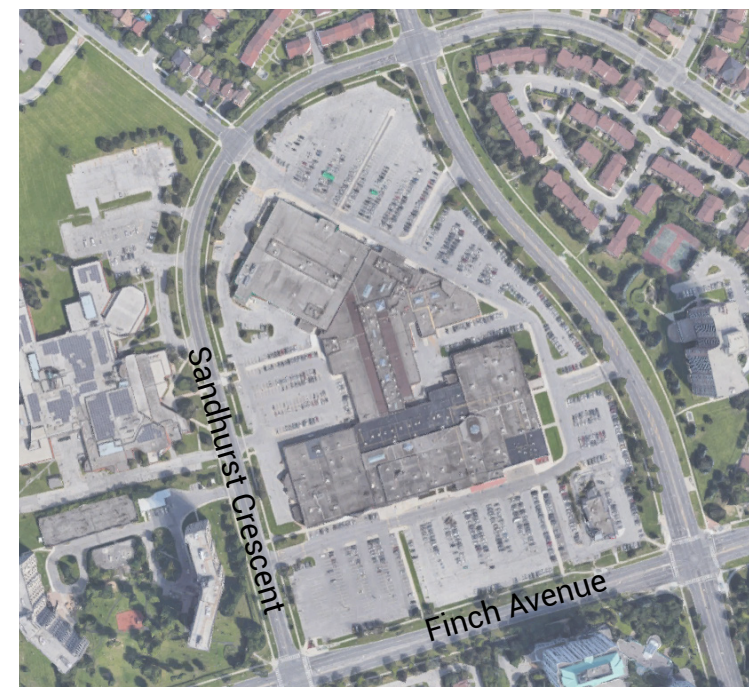

(1) Site as Existing 

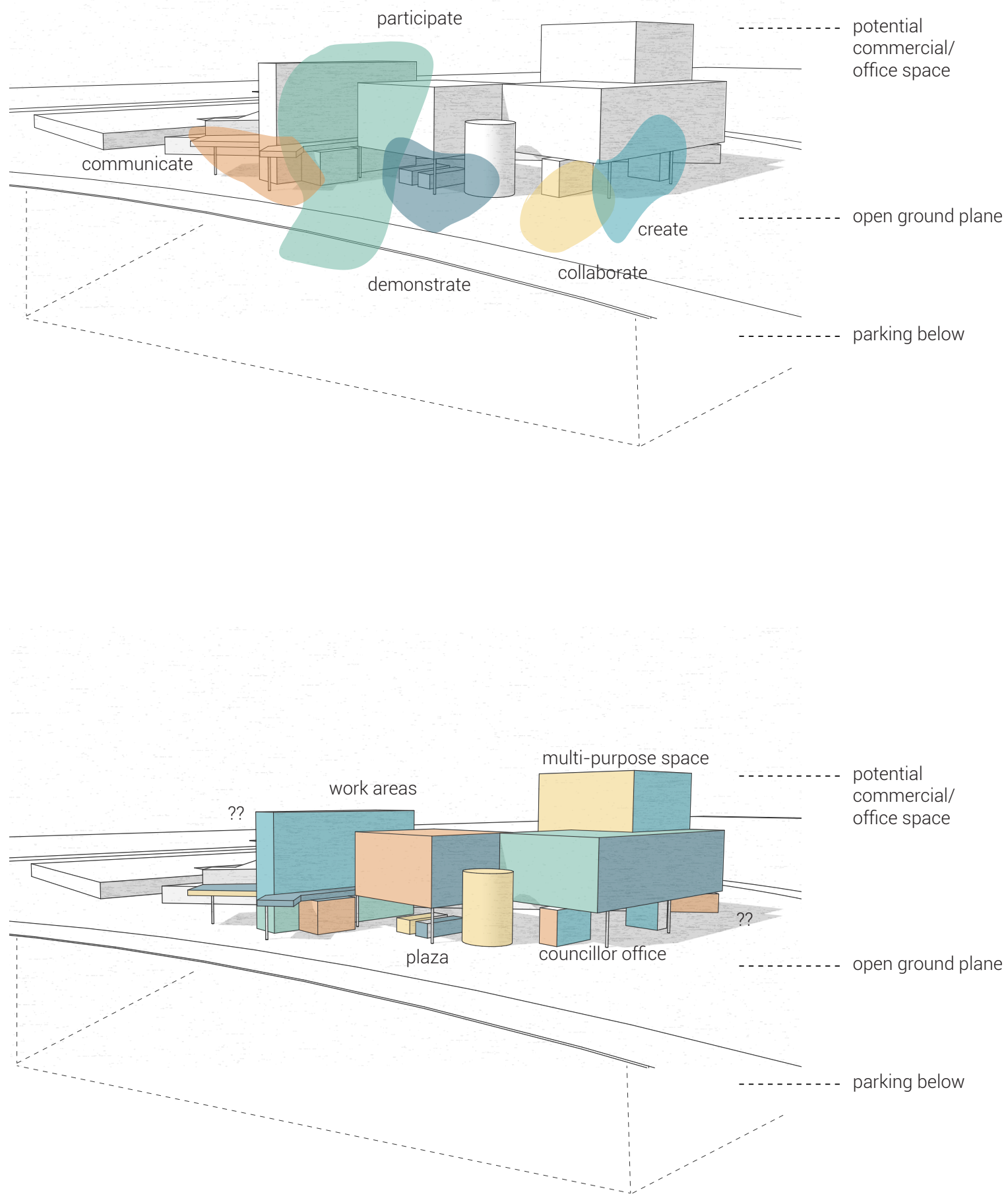


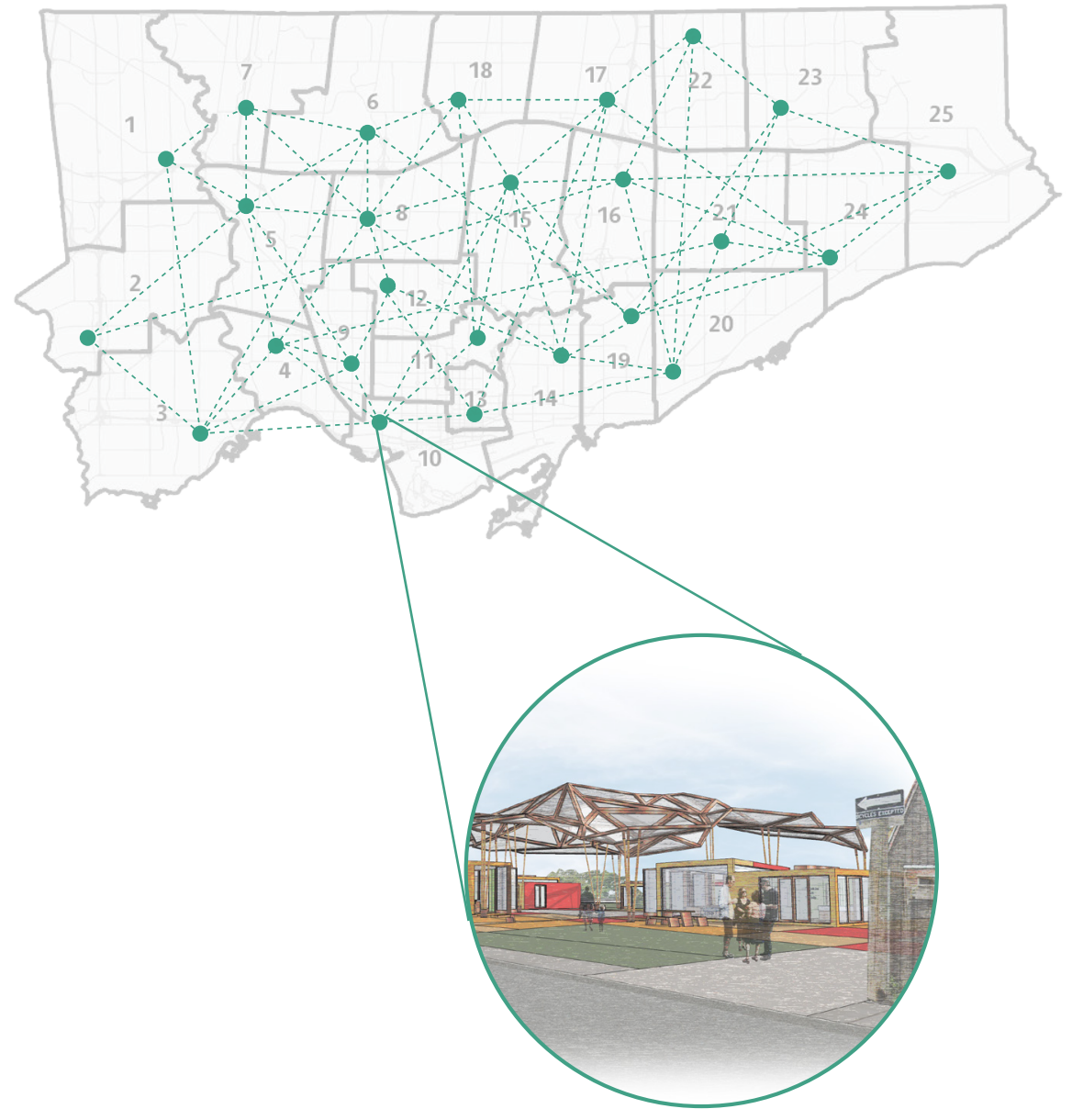




\section{Conclusion}

(Opposite) Figure 5.29: Local democratic zones forming a network across Toronto.
Within my research, I've seen over and over again that when it comes to civic-ness in urban centres, operational considerations are often separated from spatial ones, both by designers or architects, and by citizens themselves. This happens most strikingly in cities, where the relationship of the built environment to functional practices is constantly and continually affected by all citizens. As Dr. Michelle Provoost asks in her 2017 essay titled Bottom-Up is Not Enough, "is democracy spatial? Are the physical aspects of our cities, houses, streets, and public spaces the bearers of our values? Or is it rather the way our cities are being conceptualized, built, and managed that determines their Democratic content?" (Provoost, 2017, pp. 81). As architects, we can assist in encouraging that democratic content with spatial ideas.

My alternative architectural response is centered around the notion that we need to dissolve the labyrinthine and exclusive atmosphere of most civic institutions. Instead, we need to build spaces that embody principles of accessibility, selforganization, and decentralization both intangibly and tangibly. Intangible atmospheres of inclusivity have been formed by hollowing out the interiors of sites around the city, providing good bones that allow for citizens to in-fill whatever operational requirements they deem fit. Spaces have been created that are tangibly more encouraging of civic participation by making them physically and visually accessible by everyone regardless of their formal citizenship status, devoid of checkpoints or entry requirements. It is this civic space in which all citizens should feel comfortable occupying, in order to learn and then act on the governmental processes and systems that affect our real lives.

When designing government-centric spaces meant to serve and be used by citizens, it is crucial to design based on principles of spatial gradients, rather than adhering to stark and outdated dichotomies. My overall goal with this type of work is to bridge the gap between non-architect bureaucrats who have heavy influence and thus political power when planning a city, and those who are architects and designers that have practical experience and ideas about urban public space and its civic and political connotations.

In combination with a framework such as Aureli's archipelagos, these operational and spatial principles form the foundation for new civic interventions around a dense urban city like Toronto. Having a series of connections throughout Toronto, focusing on these principles of openness, fills the spatial gaps in the current programmatic civic culture. These new civic zones serve as a network that shifts the emphasis from exclusivity to engagement, returns the local citizenry to the core of the project, and acts as a space in which to see substantive citizenship take place. It is a platform from which to manifest civic-ness. 
Appendices 


\section{Appendix A - Site Context}

Osler Park @ 123 Argyle Street, Toronto, Ontario, Canada

Photographs created by author.

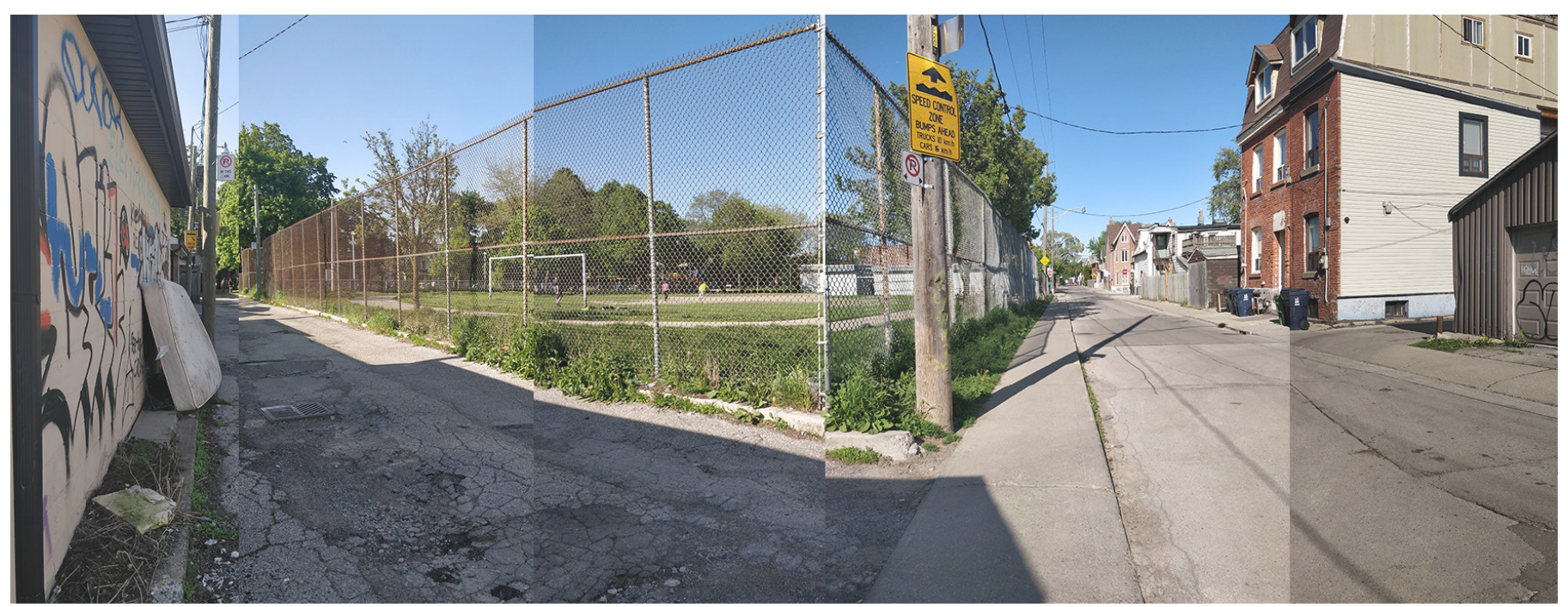

Private laneway

Humbert Street

Southwest corner of site 


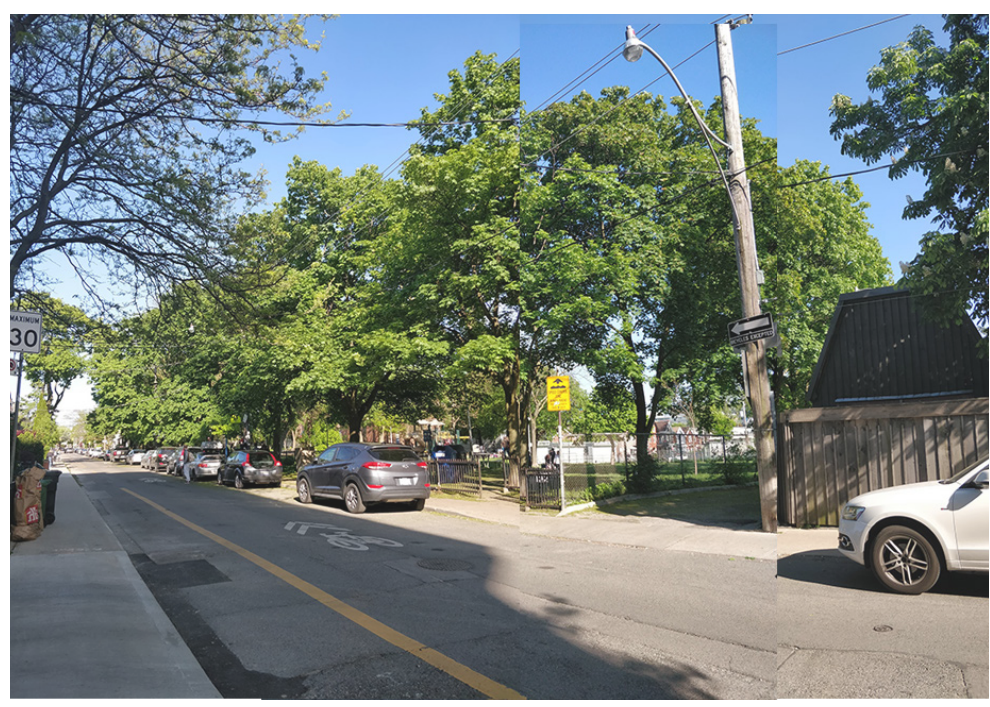

Argyle Street

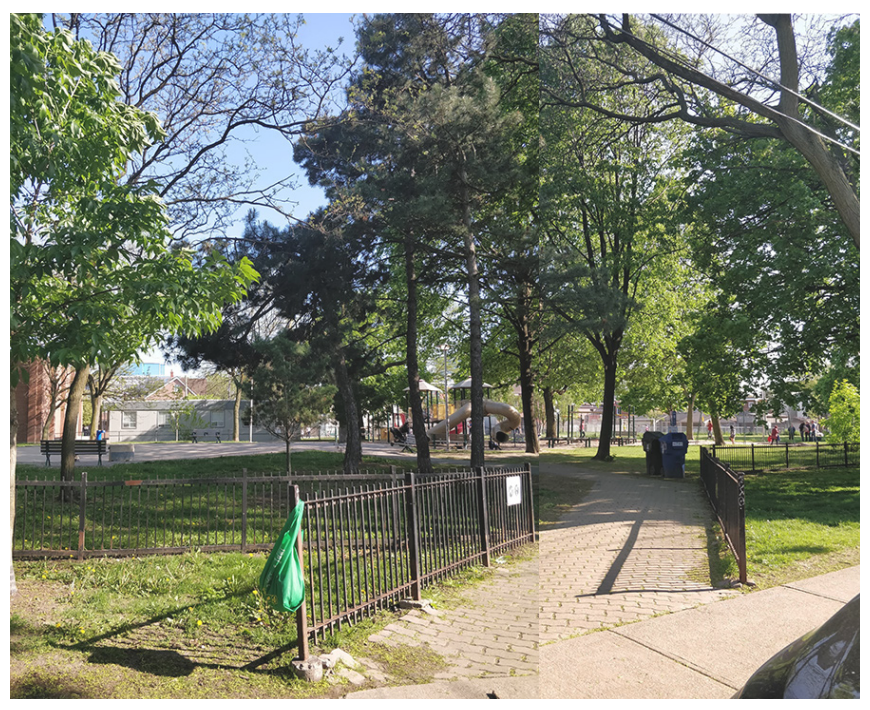

Interior of site 


\section{Appendix B - Abstract Representation of Ward 10 LDZ}

An abstract representation of the three components of the ward 10 local democratic zone, and presented alongside previous model iterations.
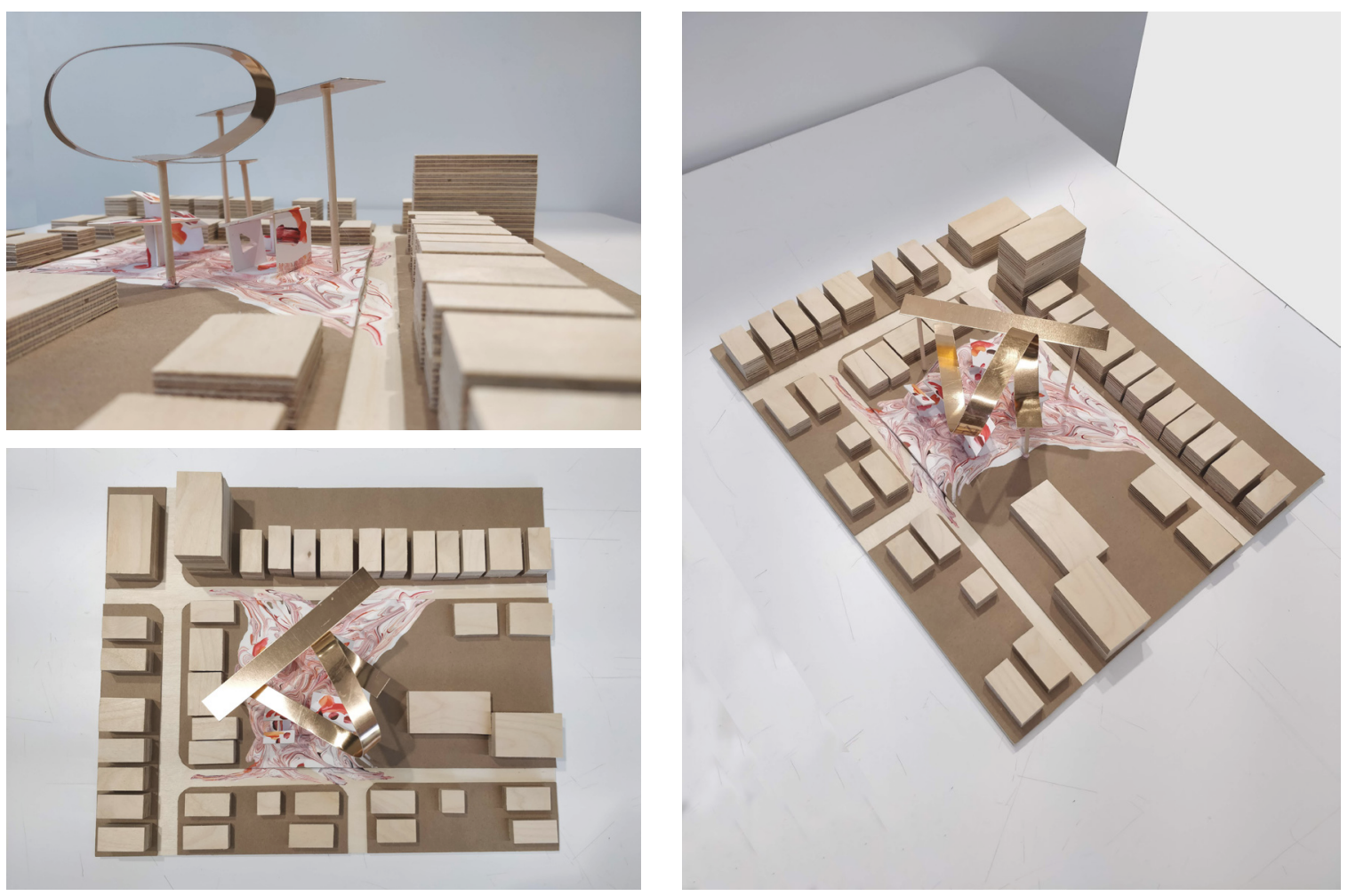

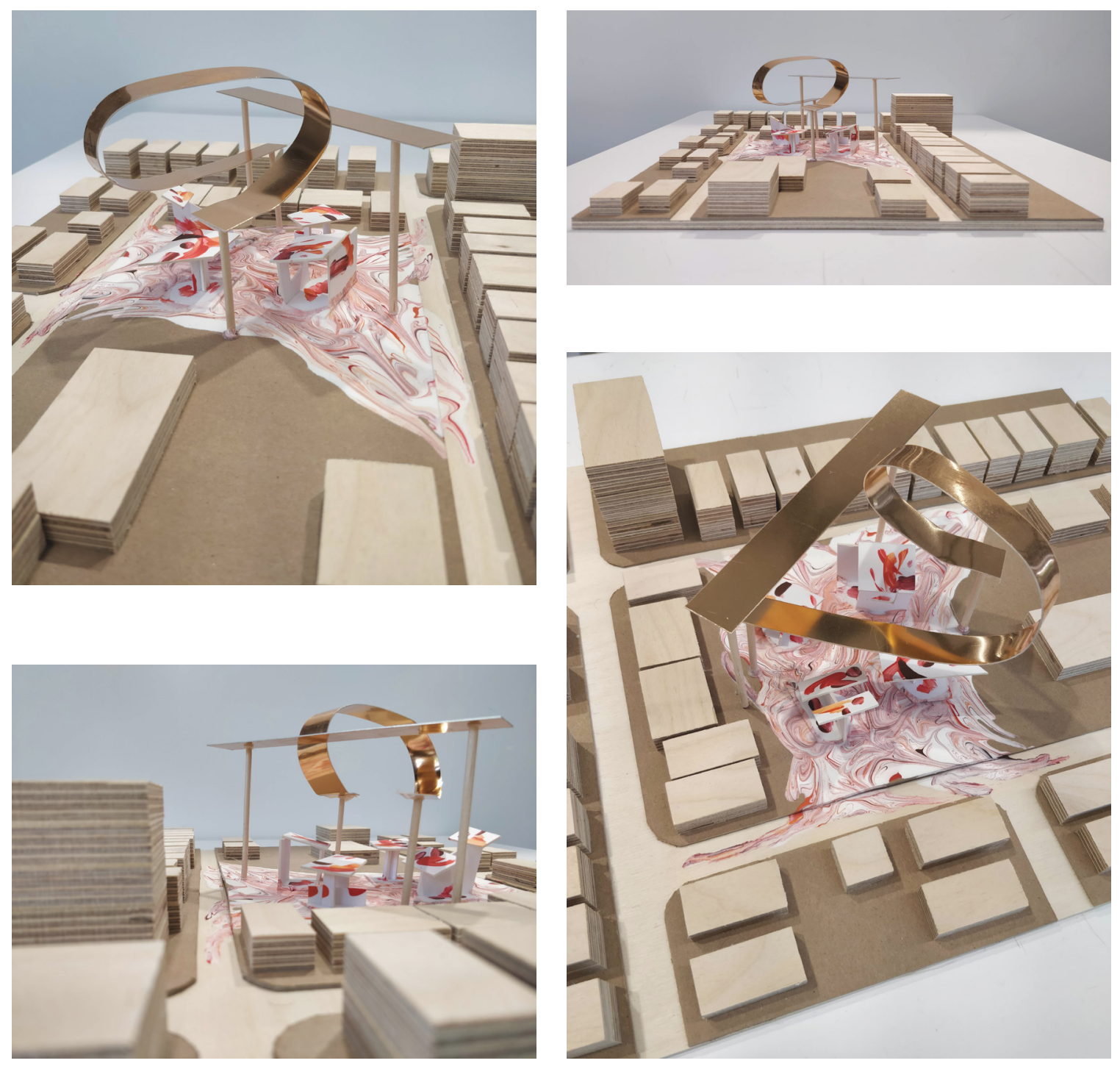


\section{Appendix C - Exploratory Design Drawings}

Drawings completed during the final milestone phase as schematic, investigative exercises.
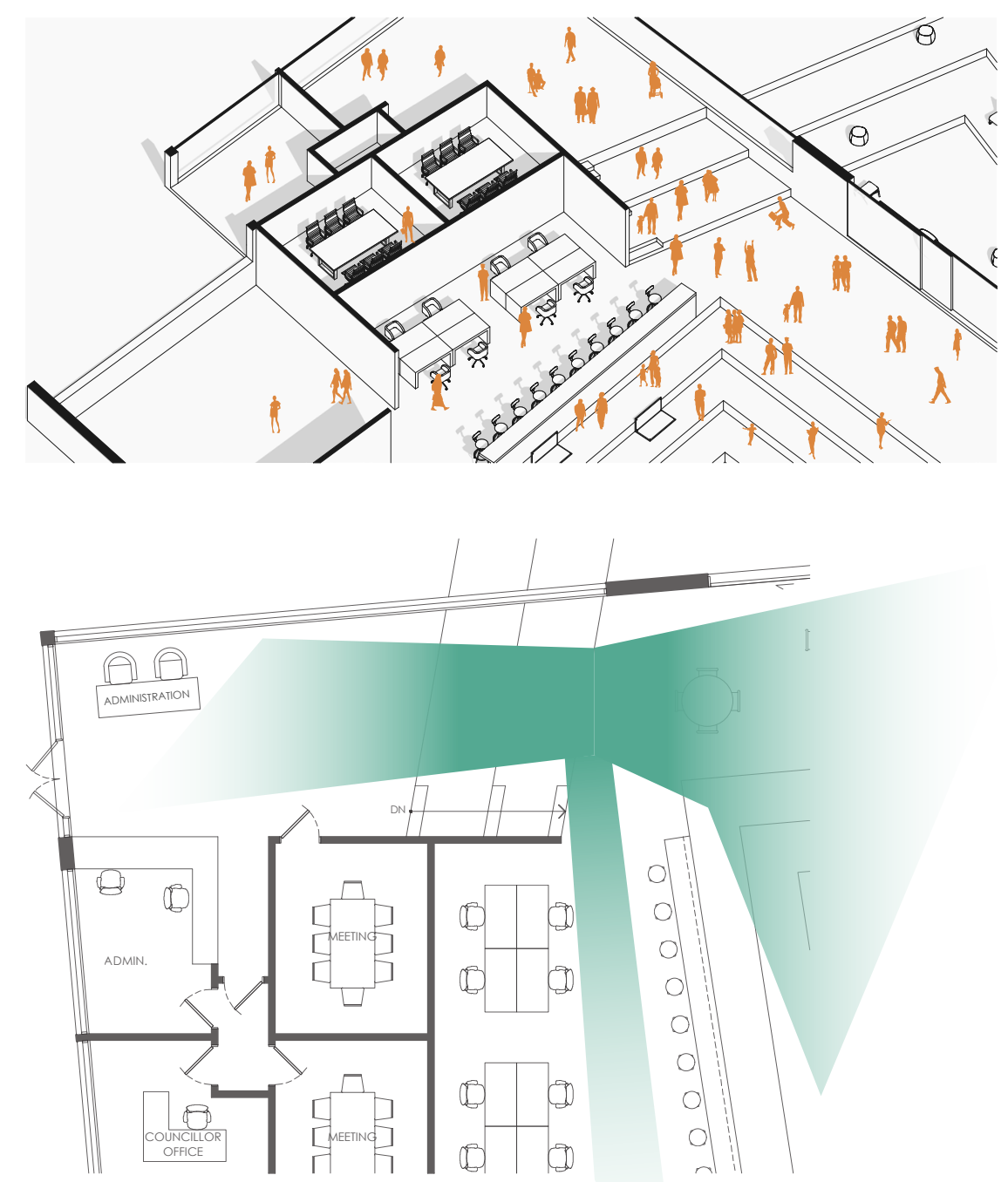

Early studies of circulation 


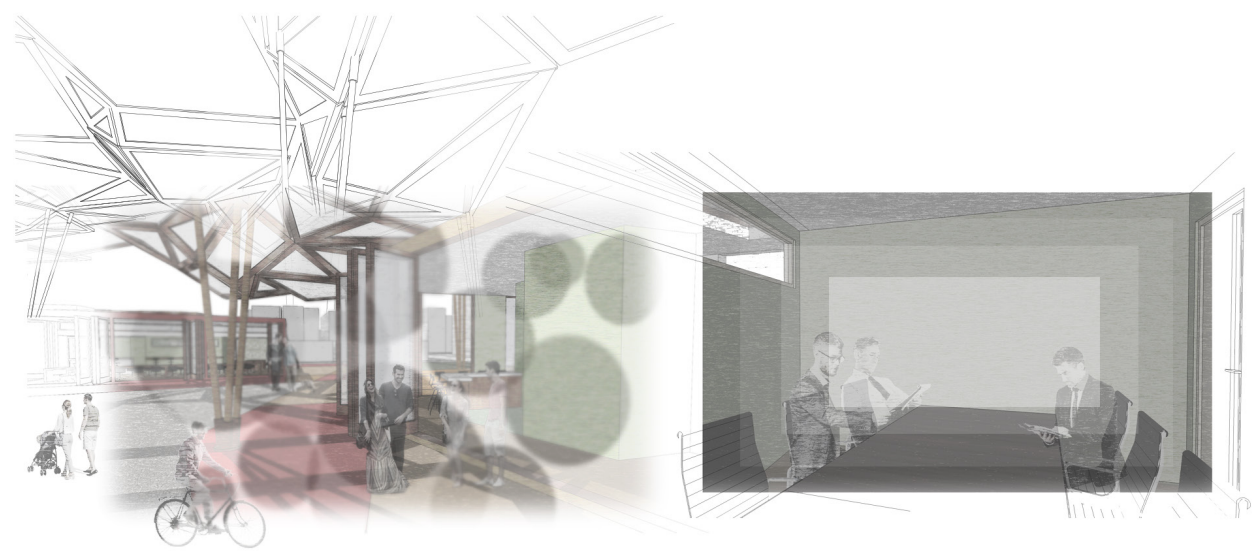

porosity / enclosure

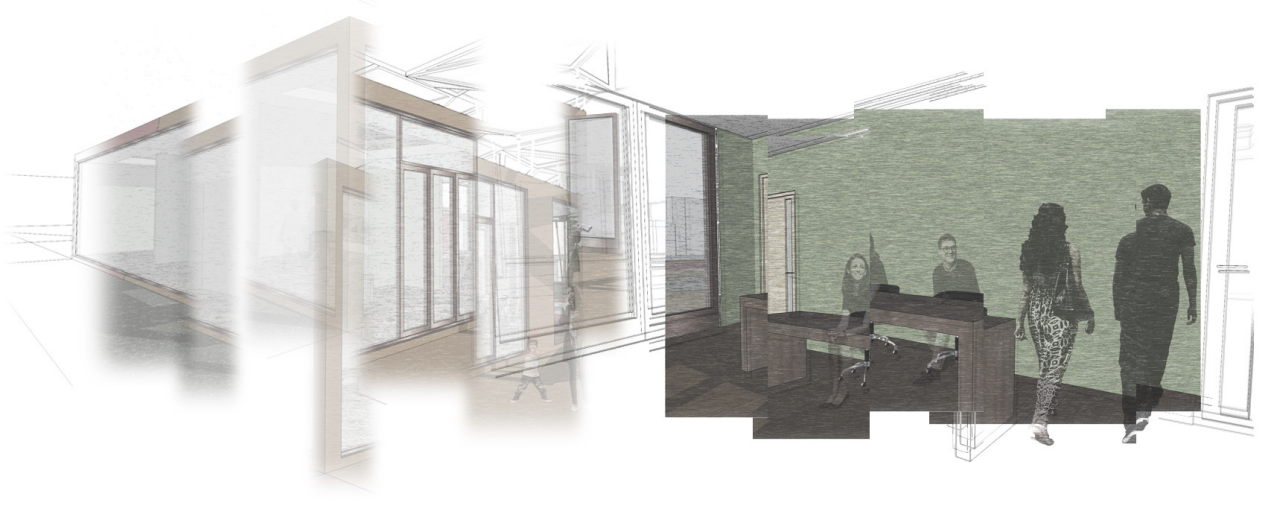

transparency / opacity

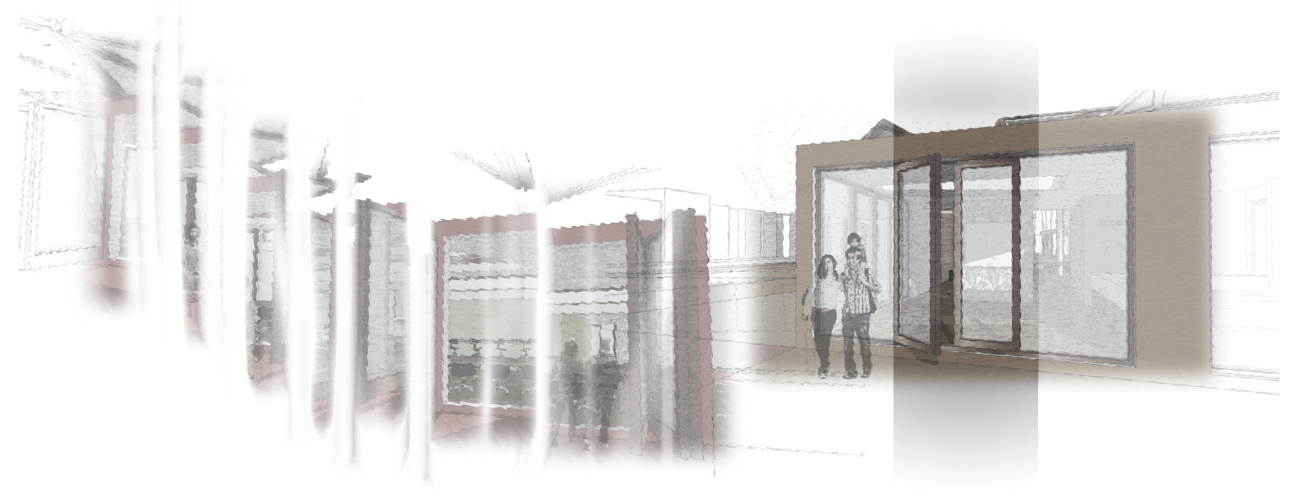

transition / threshold 


\section{Appendix D - Substantial Completion Iteration}

Earlier iterations of the Local Democratic Zone focused on the stitching together of various plan models with sectional moments, focusing on function and atmosphere. The intersected and woven parts formed walkthroughs and situations throughout the site. These previous schematic design exercises have informed the current design, moving even further away from prescriptive adjacencies and spatial components.

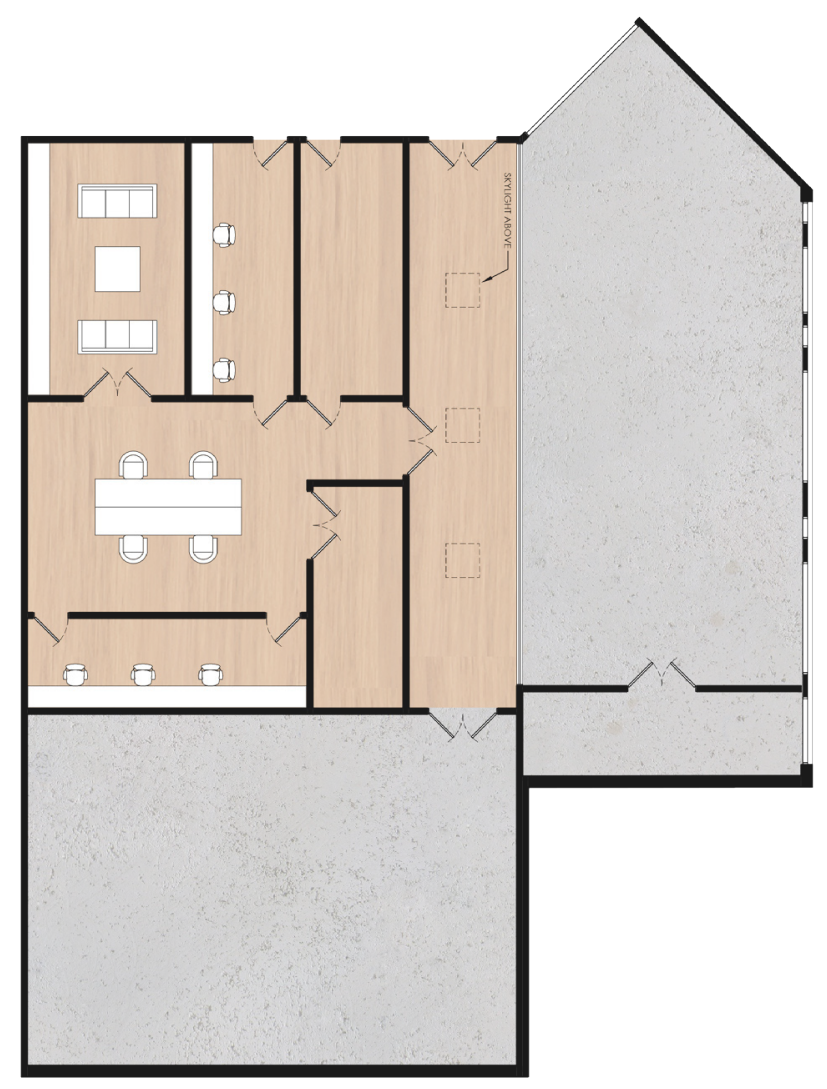

Production Studios 


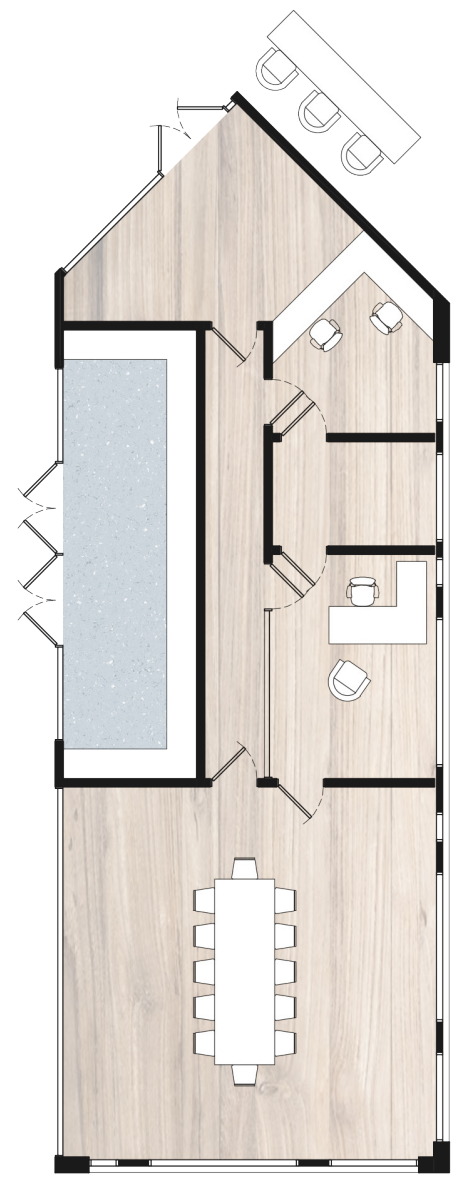

Councillor Office

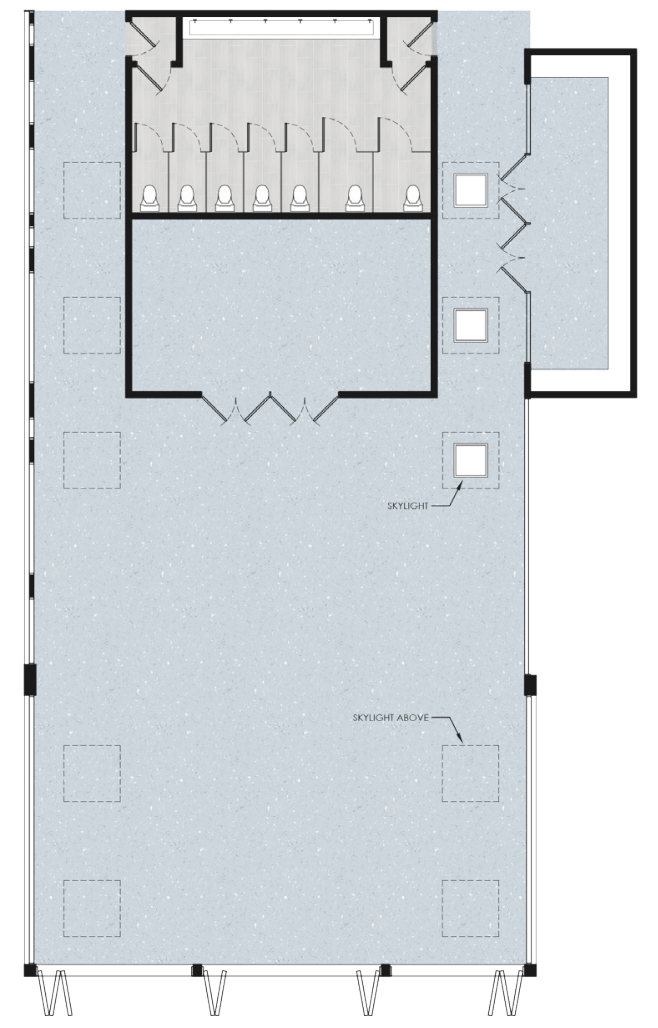

Multi-Purpose Space 


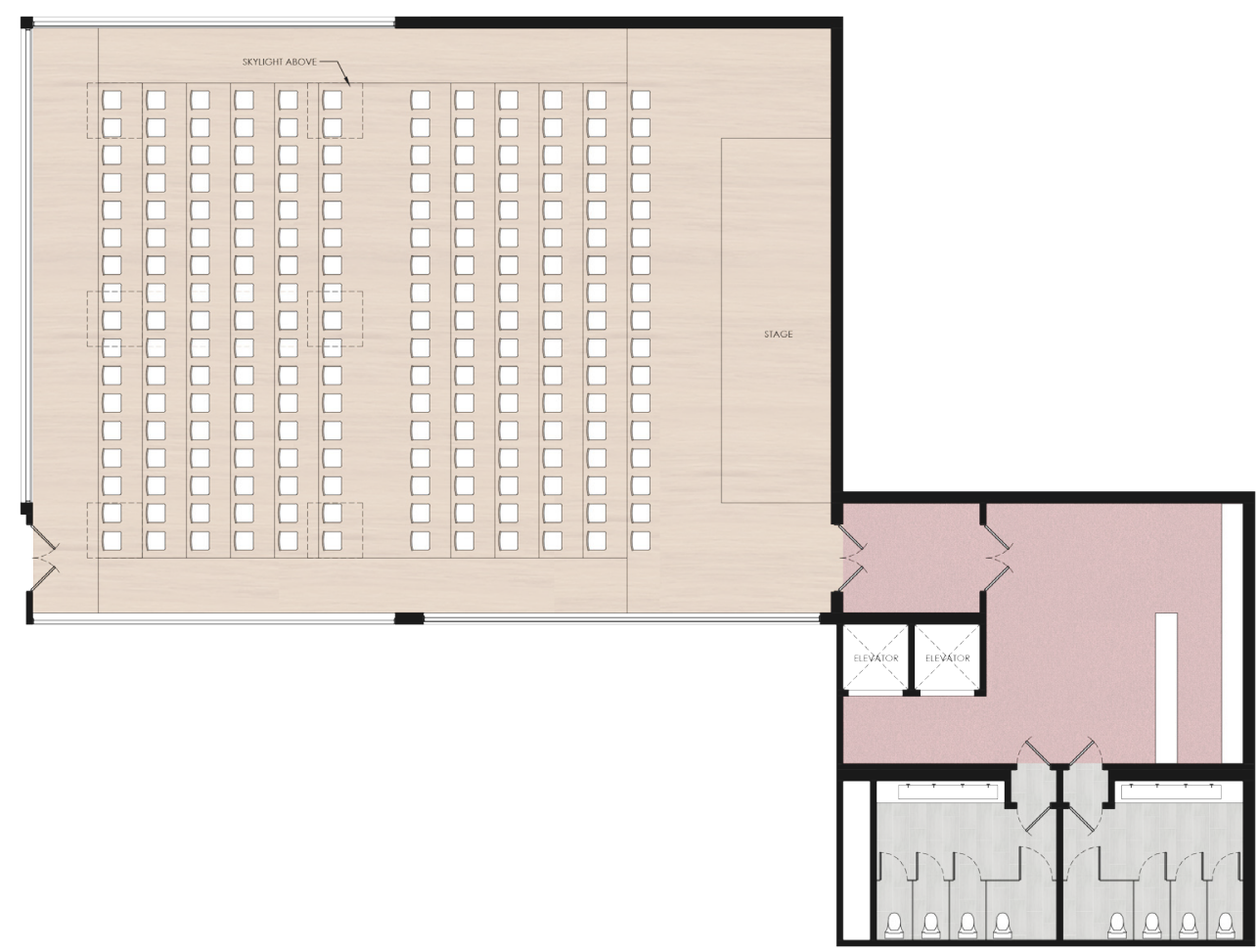

Amphitheatre 

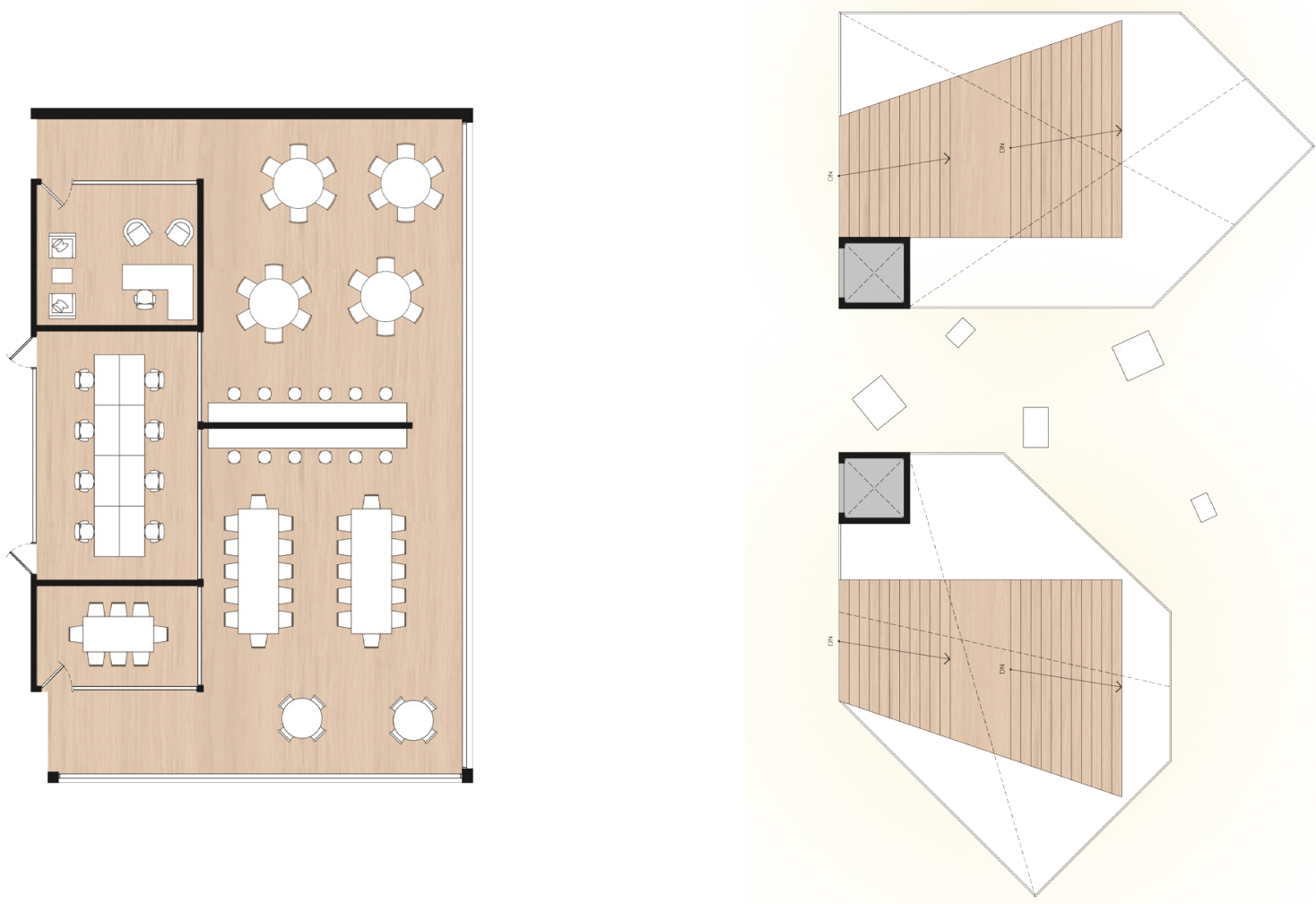

Work Area

Foyer 


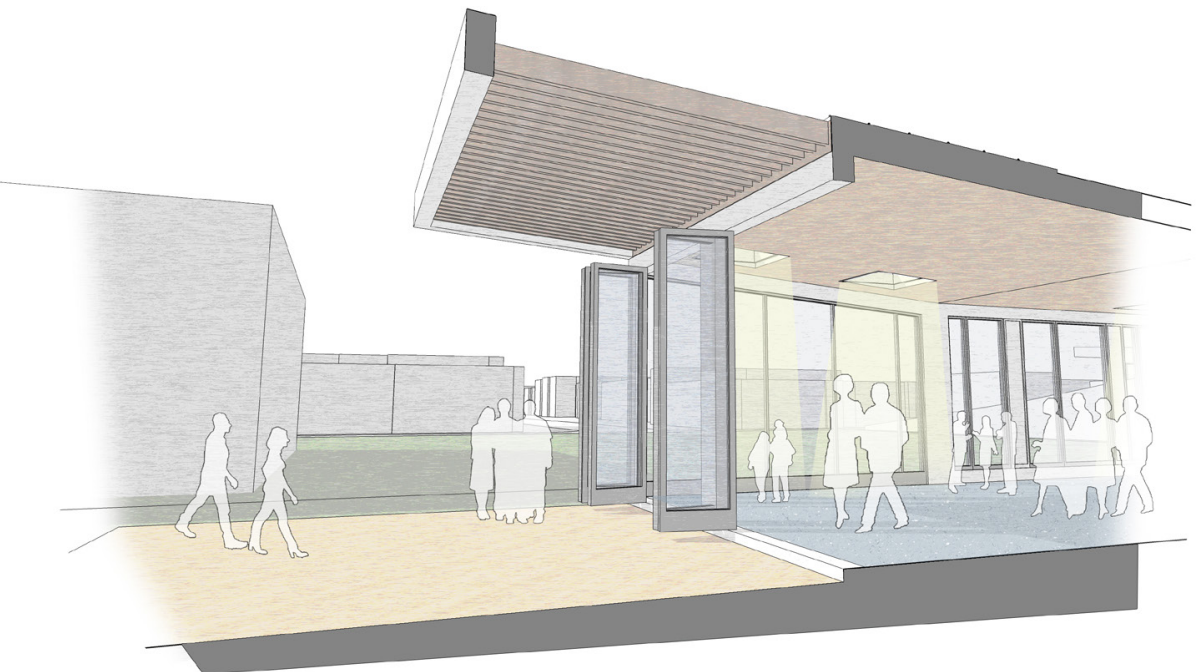

Element: Multi-Purpose Space

Sectional Moment: Connection to Exterior

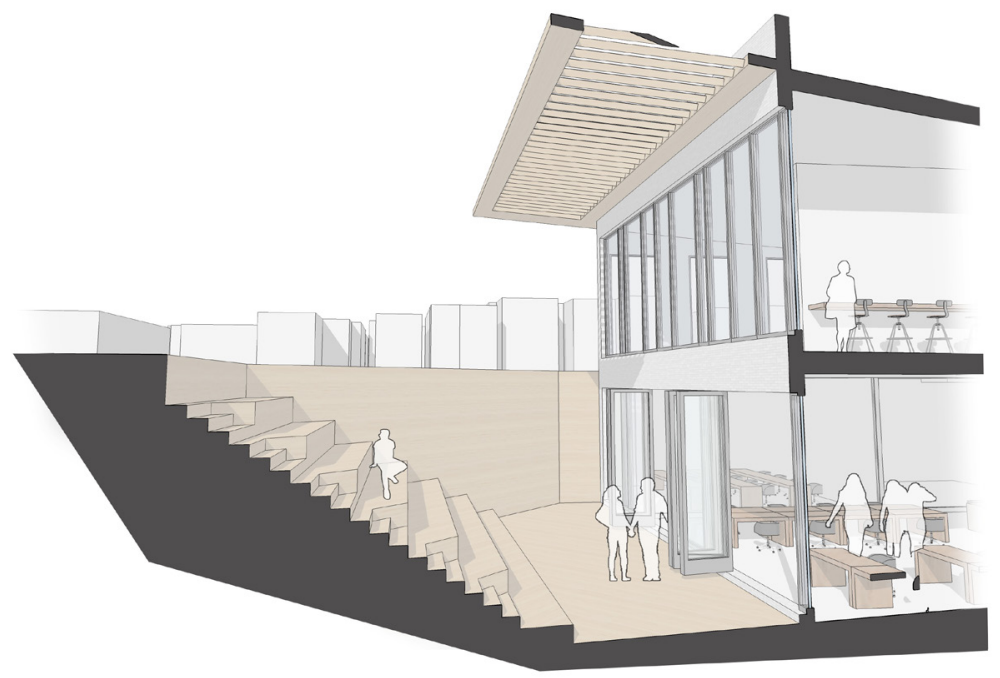

Element: Work Area

Sectional Moment: Connection to Outdoor Terrace 


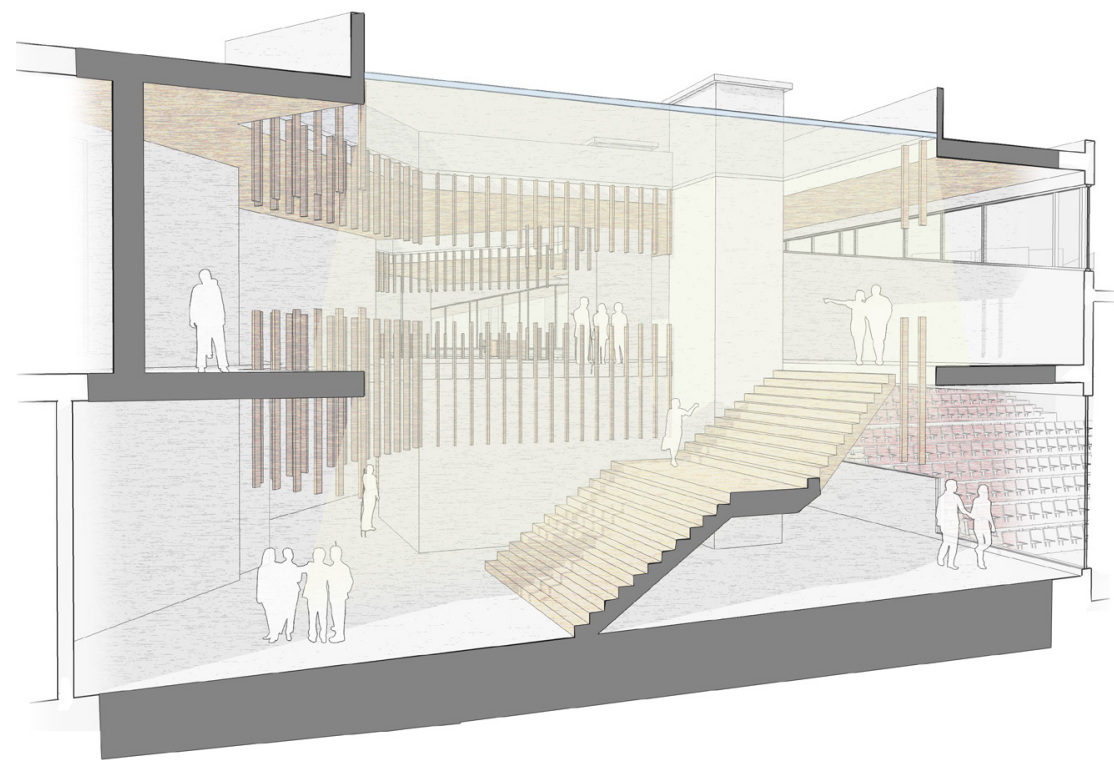

Element: Foyer

Sectional Moment: Vertical Circulation

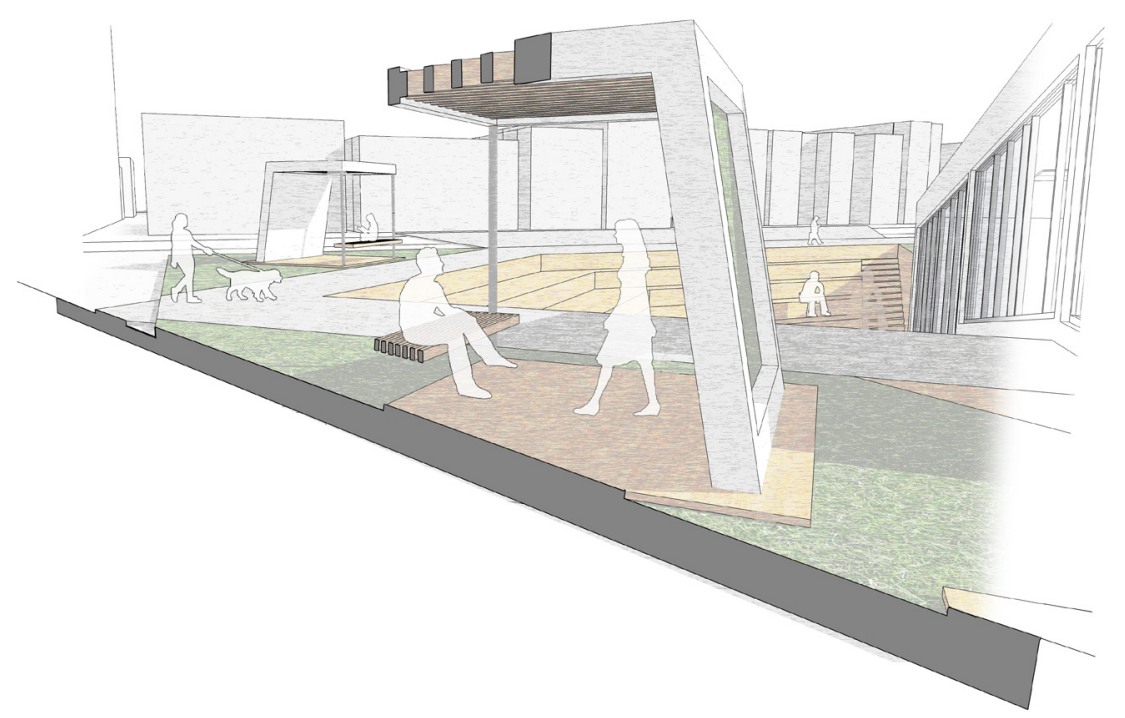

Element: Plaza

Sectional Moment: Street Terrace 


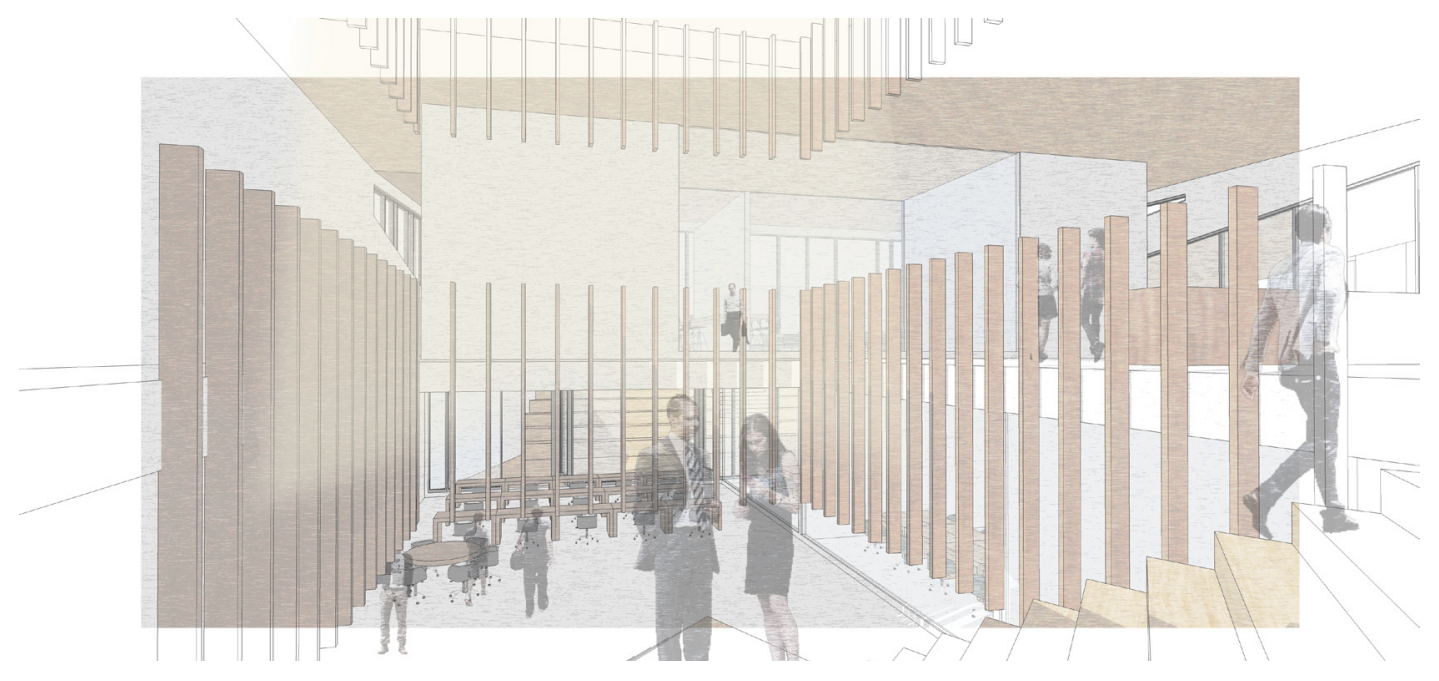

Foyer Interior

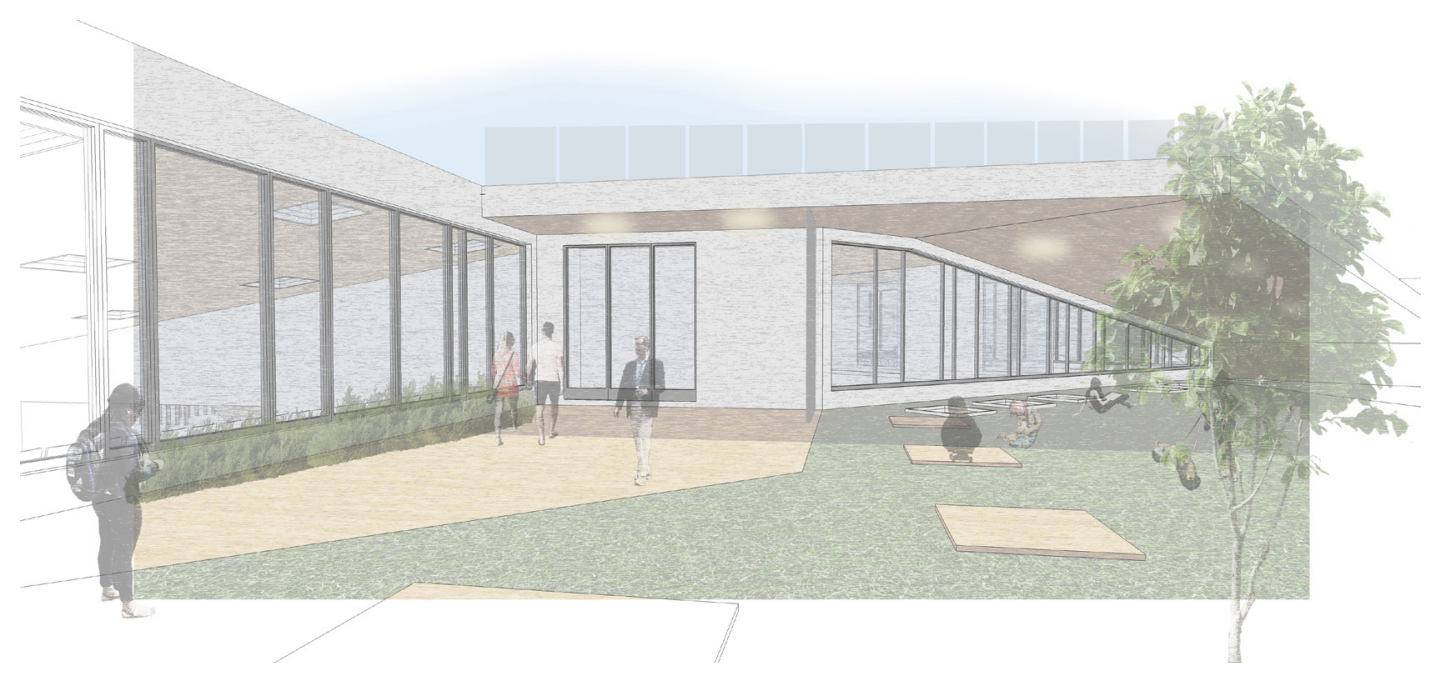

Entrance + Overhang 


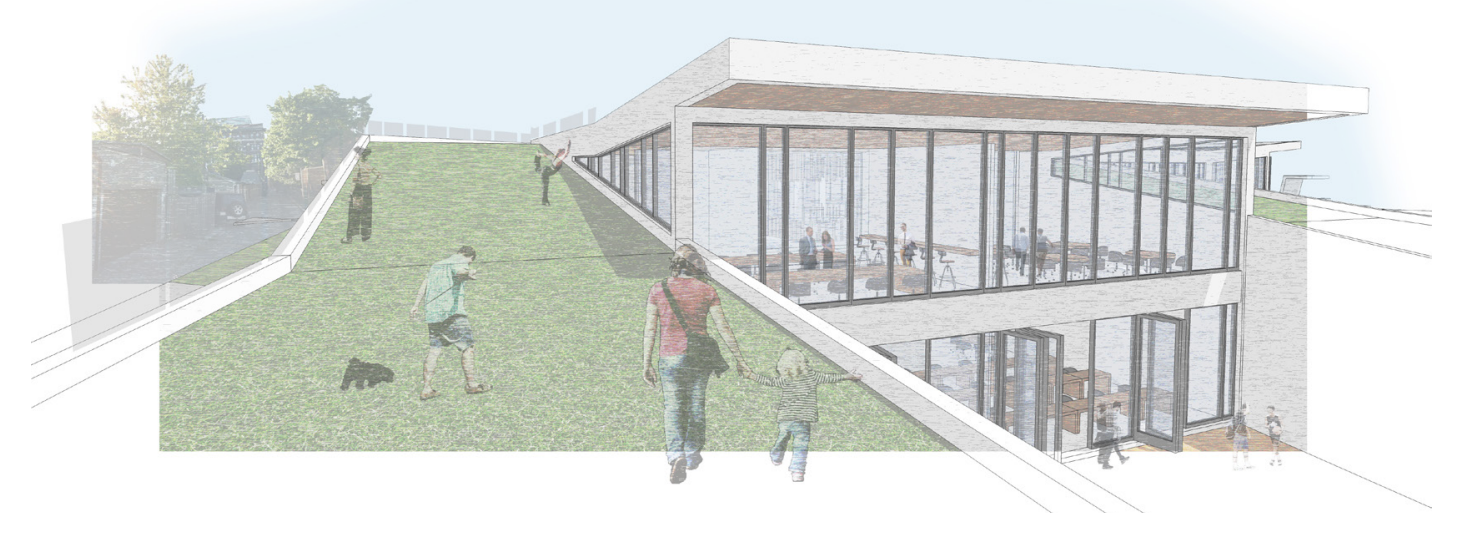

Green Ramp

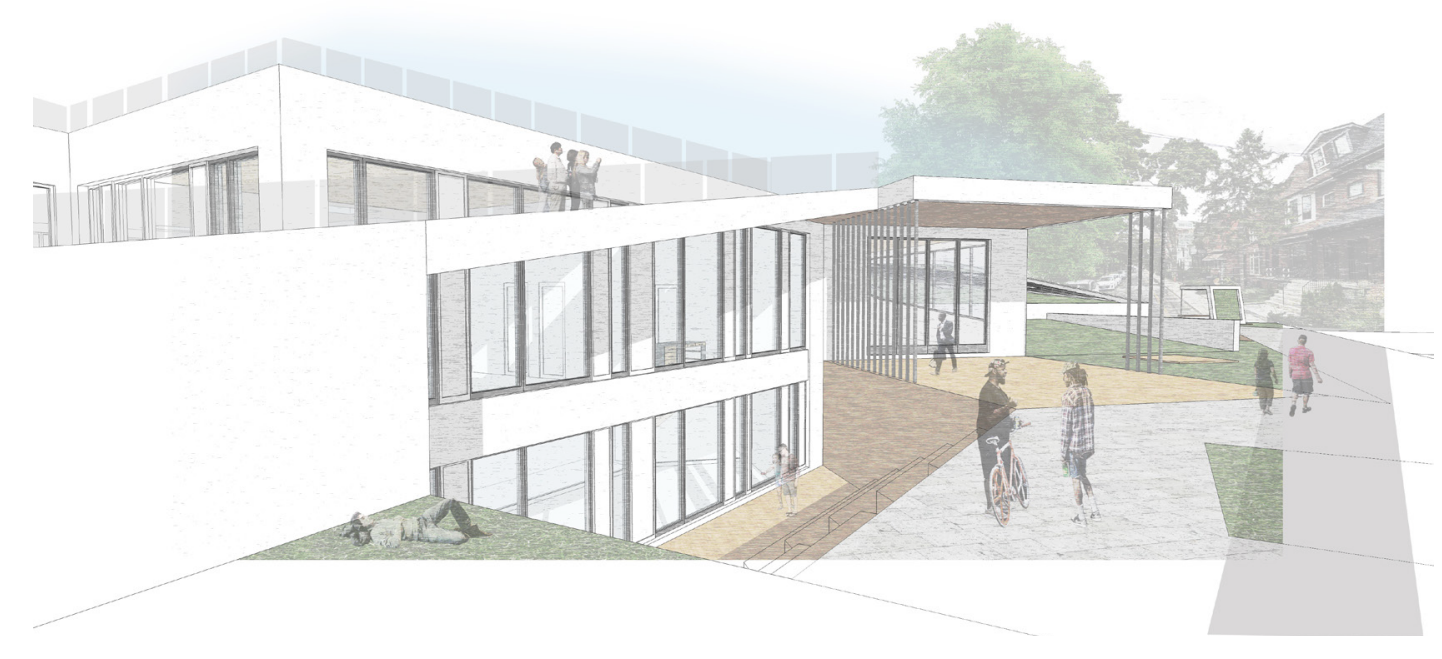

Terracing 
Street - Street Porosity

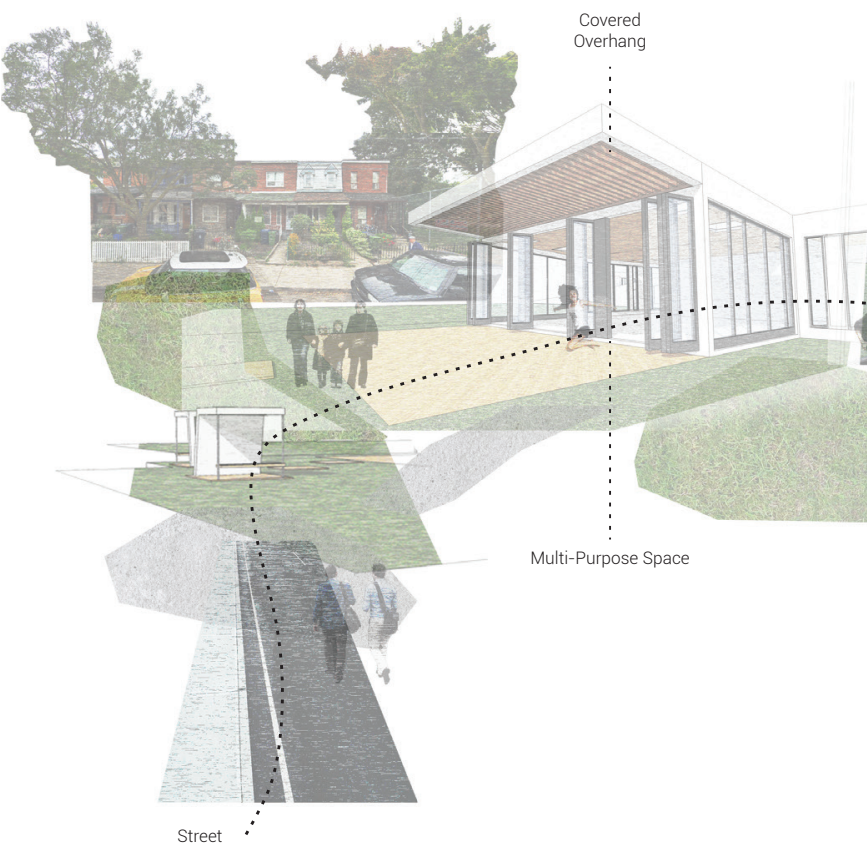

Walkthrough Option 1

Street - Street Porosity

Walkthrough Option 2

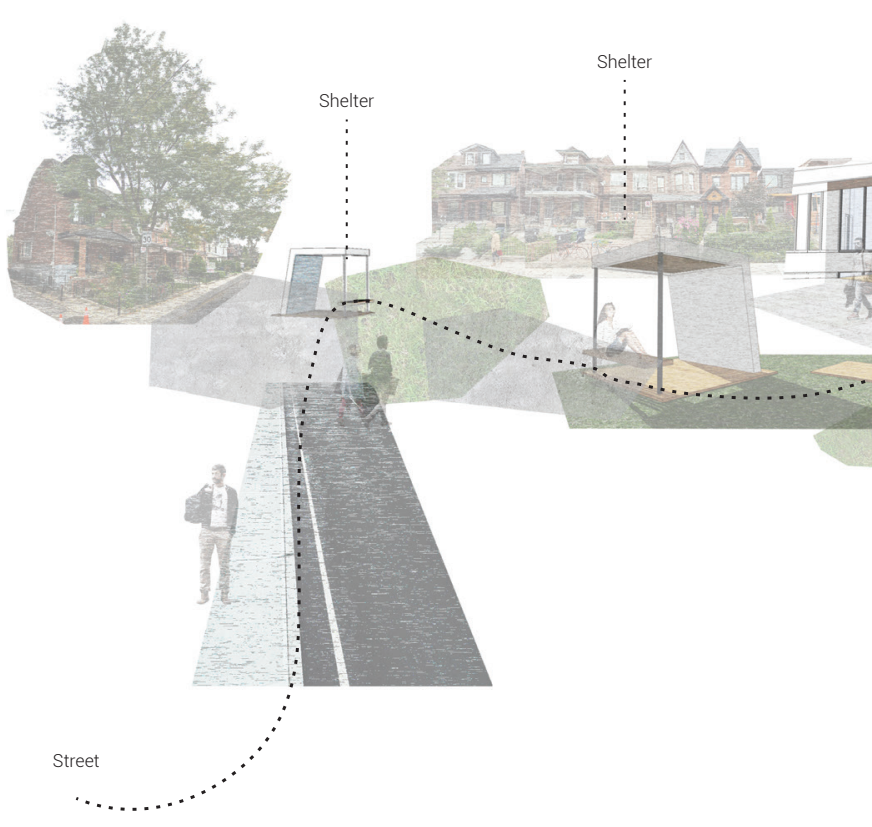




\section{Works Cited}

1. Appadurai, A. \& Holston, J. (1999). Introduction: Cities and citizenship. In J. Holston (Ed.), Cities and citizenship (pp. 1-20). London, UK: Duke University Press.

2. Aureli, P. V. (2011). The possibility of an absolute architecture. Cambridge: MIT Press.

3. Awan, N.; Schneider, T.; and Till, J. (2011). Spatial agency: other ways of doing architecture. New York, N.Y.: Routledge.

4. Balibar, E. (1999). Is European citizenship possible? In J. Holston (Ed.), Cities and citizenship (pp. 195-215). London, UK: Duke University Press.

5. Bender, T. (1999). Intellectuals, cities, and citizenship in the United States: The 1890s and 1990s. In J. Holston (Ed.), Cities and citizenship (pp. 21-41). London, UK: Duke University Press.

6. Casanova Garcia, H. \& Hernandez Mayor, J. (2014). Public space acupuncture: Strategies and interventions for activating city life. New York, N.Y.: Actar Publishers.

7. Castells, M. (1983). The city and the grassroots: A cross-cultural theory of urban social movements. Berkeley, CA: University of California Press.

8. Collins, S. D. (2006). Aristotle and the rediscovery of citizenship. Cambridge, U.K.: Cambridge University Press. Retrieved from https:// ebookcentral-proquest-com.ezproxy.lib.ryerson.ca/lib/ryerson/reader. action?doc $\mid \mathrm{D}=268246$

9. Democratic Audit U.K. (2016). Concentrating minds: How the Greeks designed spaces for the public debate. Retrieved from http://www. democraticaudit.com/2016/11/01/concentrating-minds-how-the-greeksdesigned-spaces-for-public-debate/

10. Department of Neighbourhood Empowerment. (2017). Neighbourhood Councils: Empower LA. Retrieved from http://empowerla.org/councils/

11. Easterling, Keller. (2014). Extrastatecraft: The power of infrastructure space. London: Verso.

12. Fahmy, Mohammed. (2016). The Marriott cell: An epic journey from Cairo's scorpion prison to freedom. Toronto, ON.: Random House Canada.

13. Hertzberger, H. (2015). Architecture and structuralism: The ordering of space. Rotterdam, NL.: NAI010 Publishers.

14. Holston, J. (199). Spaces of insurgent citizenship. In J. Holston (Ed.), Cities and citizenship (pp. 155-176). London, UK: Duke University Press. 
15. Iveson, K. (2007). Publics and the city. Malden, MA: Blackwell Publishing.

16. Moore, R. (2017, July 23). The billion-dollar palaces of Apple, Facebook, and Google. In The Guardian. Retrieved from https://www.theguardian. com/artanddesign/2017/jul/23/inside-billion-dollar-palaces-of-techgiantsfacebook-apple-google-london-california-wealth-power

17. Mulgan, R. (May 1990). Aristotle and the value of political participation. In Political Theory, 18(2), pp. 195-215. Retrieved from https://www.jstor.org/ stable/191341

18. Murray, C. (2012). Coming apart: The state of white America, 1960-2010. New York, New York, USA: Crown Publishing.

19. Parkdale Neighbourhood Land Trust. (n.d.) Retrieved from http://www.pnlt. $\mathrm{ca} /$

20. Provoost, M. (2017). Bottom-up is not enough. In M. Mostafavi (Ed.), Ethics of the urban: The city and the spaces of the political (pp. 81-86). Zurich, Switzerland: Lars Muller Publishers.

21. Scott Brown, D. (1990). Urban concepts. In A. C. Papadakis (Ed.) Architectural Design, 83(60), pp. 21-25. London, U.K.: Academy Editions.

22. Setianto, B. (December 2017). Somewhere in between: Conceptualizing civil society. In International Journal of Not-for-Profit Law, 10(1). Retrieved from https://www.globalpolicy.org/component/content/article/177/31603.html

23. Sidewalk Labs LLC. (2017). Sections of RFP. Retrieved from https:// sidewalktoronto.ca/wp-content/uploads/2018/05/Sidewalk-Labs-VisionSections-of-RFP-Submission.pdf

24. Sidewalk Labs LLC. (2017). Master Innovation and Development Plan. Retrieved from https://quaysideto.ca/sidewalk-labs-proposal-masterinnovation-and-development-plan/

25. Tonkiss, F. (2005). Space, the city and social theory: Social relations and urban forms. Malden, MA: Polity Press.

26. Upton, Dell. (2008). Another city: Urban life and urban spaces in the new American republic. New Haven: Yale University Press.

27. Watts, M. (1999). Islamic modernities? Citizenship, civil society and Islamism in a Nigerian city. In J. Holston (Ed.), Cities and citizenship (pp. 67-102). London, UK: Duke University Press.

28. White, Micah. (2016). The end of protest: A new playbook for revolution. USA: Penguin Random House - Knopf Canada 


\section{Works Considered}

1. (1991). Seaside: Making a town in america. Easterling, Keller; Mohney, David (Eds.) New York: Princeton Architectural Press.

2. Amin, A. (April 2008) Collective culture and urban space. City, 12(1), 5-24. doi: 10.1080/13604810801933495

3. Byass, R. (March 2010). From public garden to corporate plaza: Picadilly Gardens and the new civic landscape. Journal of Landscape Architecture, 5(1), 72-83. doi: 10.1080/18626033.2010.9723432

4. Easterling, Keller. (1999). Organization space: Landscapes, highways, and houses in America. Cambridge: MIT Press.

5. Easterling, Keller. (2005). Enduring innocence: Global architecture and its political masquerades. Cambridge, M.A.: The MIT Press.

6. Glaeser, Edward. (2011). Triumph of the city: How our greatest invention makes us richer, smarter, greener, healthier, and happier. New York: Penguin Group.

7. Gottdiener, M. (1985). The social production of urban space. Austin, TX: University of Texas Press.

8. Harvey, D. (2006). The political economy of public space. In S. Low \& N. Smith (Eds.), The politics of public space (pp. 1-16). New York, NY: Routledge.

9. Hertzberger, H. (2000). Space and the architect: lessons in architecture 2. Rotterdam, NL: NAI010 Publishers.

10. Jacobs, J. (1961). The death and life of great American cities. New York: Random House.

11. Levine, M. A. \& Ross, B. H. (2006). Urban politics: Power in metropolitan America. Belmont, CA: Thomson Wadsworth.

12. Low, S., \& Smith, N. (2006). Introduction: The imperative of public space. In S. Low \& N. Smith (Eds.), The politics of public space (pp. 1-16). New York, NY: Routledge.

13. Montgomery, C. (2013). Happy city: Transforming our lives through urban design. USA: Anchor Canada.

14. Sassen, S. (2017). Beyond differences of race, religion, class: Making urban subjects. In M. Mostafavi (Ed.), Ethics of the urban: The city and the spaces of the political (pp. 35-46). Zurich, Switzerland: Lars Muller Publishers.

15. Sewell, John. (1993). The shape of the city: Toronto struggles with modern planning. Toronto: University of Toronto Press.

16. Swyngedouw, E. (2017). Insurgent urbanity and the political city. In M. Mostafavi (Ed.), Ethics of the urban: The city and the spaces of the political (pp. 9-16). Zurich, Switzerland: Lars Muller Publishers. 
(c) Heather Breeze 2019 